\title{
Untersuchungen zur Bedeutung der sal-ähnlichen Gene bei der Maus
}

\author{
DISSERTATION
}

zur Erlangung des Doktorgrades

der Mathematisch-Naturwissenschaftlichen Fakultäten der Georg-August-Universität zu Göttingen

vorgelegt von

Anja Buck

aus Kiel

Göttingen 2001 
D7

Referent:

Prof. Dr. W. Engel

Korreferentin:

Prof. Dr. S. Hoyer-Fender

Tag der mündlichen Prüfung: 


\section{Inhaltsverzeichnis}

Abkürzungen XI

1 Einleitung 1

1.1 Das Gen spalt bei Drosophila melanogaster . . . . . . . . . . 1

1.2 sal-ähnliche Gene bei Vertebraten . . . . . . . . . . . . . . 2

1.2.1 sal-ähnliche Gene beim Fisch Medaka, bei Xenopus laevis und beim Huhn . . . . . . . . . . . . . . . 3

1.2.2 sal-ähnliche Gene beim Menschen . . . . . . . . . . . 4

1.2 .3 sal-ähnliche Gene bei der Maus . . . . . . . . . . . . 6

1.3 Mutationen im SALL1-Gen verursachen TBS . . . . . . . . . 6

1.4 Ziele der vorliegenden Arbeit $\ldots \ldots \ldots \ldots$. . . . . . 7

2 Material und Methoden $\quad 8$

2.1 Chemikalien . . . . . . . . . . . . . . . . . 8

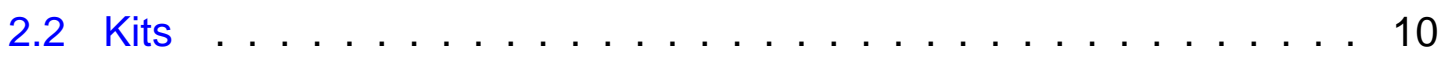

2.3 Gebrauchswaren und Geräte . . . . . . . . . . . . . . . 11

2.3.1 Gebrauchswaren . . . . . . . . . . . . . . . . . 11

2.3 .2 Geräte . . . . . . . . . . . . . . . . . . . . . 12

2.4 Puffer und Lösungen . . . . . . . . . . . . . . . . . . . . . 12

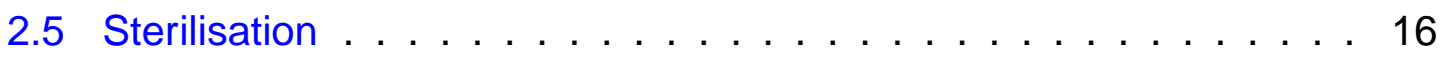

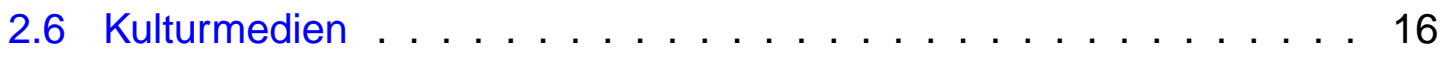

2.6.1 Medien für Bakterien $\ldots \ldots \ldots \ldots$

2.6.2 Medien für die Zellkultur $\ldots \ldots \ldots \ldots$

2.7 Biologisches Material . . . . . . . . . . . . . . . . . . 18

2.7 .1 Bakterienstämme . . . . . . . . . . . . . . 18

2.7 .2 Vektoren . . . . . . . . . . . . . . . . 18

2.7.3 Eukaryotische Zelllinien . . . . . . . . . . . . . . . . . . . 19

2.7 .4 Antikörper . . . . . . . . . . . . . . . . . . 19 
2.7 .5 Oligonukleotide . . . . . . . . . . . . . . . . . . . . 19

2.7 .6 Gensonden . . . . . . . . . . . . . . . . . . . . 20

2.7 .7 DNA-Bibliothek . . . . . . . . . . . . . . 22

2.7 .8 Mausstämme . . . . . . . . . . . . . . . . 22

2.8 Molekulargewichtstandards . . . . . . . . . . . . . . . . 22

2.9 Nukleinsäuretechnische Methoden . . . . . . . . . . . . . . 23

2.9.1 Präparation von Nukleinsäuren . . . . . . . . . . . . . . 23

2.9.1.1 Minipräparation von Plasmid-DNA . . . . . . . . . 23

2.9.1.2 Herstellung von Glycerinkryokulturen . . . . . . . . 23

2.9.1.3 Midi- und Maxipräparation von Plasmid-DNA . . . . . . . 24

2.9.1.4 Endotoxin-freie Maxipräparation von Plasmid-DNA . . . . 24

2.9.1.5 Isolierung genomischer DNA aus Geweben . . . . . . . 24

2.9.1.6 Isolierung von Gesamt-RNA aus Geweben . . . . . . . 24

2.9.2 Bestimmung der Konzentration von Nukleinsäuren . . . . . . 25

2.9.3 Enzymatische Modifikationen von Nukleinsäuren . . . . . . . 25

2.9.3.1 Restriktionsspaltung von Plasmid-DNA . . . . . . . 25

2.9.3.2 Restriktionsspaltung von genomischer DNA . . . . . . 26

2.9.3.3 Dephosphorylierung von Plasmid-DNA . . . . . . . 26

2.9.3.4 Auffüllreaktion . . . . . . . . . . . . . . . 27

2.9.3.5 Radioaktive Markierung von Nukleinsäuren . . . . . . . 27

2.9.4 Isolierung von DNA-Fragmenten aus Agarosegelen . . . . . 27

2.9.5 Klonierung von DNA-Fragmenten . . . . . . . . . . 28

2.9.5.1 Ligation . . . . . . . . . . . . . . . . . 28

2.9.5.2 Herstellung kompetenter E. coli-Zellen . . . . . . . . . 28

2.9.5.3 Transformation . . . . . . . . . . . . . . . . . 29

2.9 .6 Sequenzanalyse . . . . . . . . . . . . . . . . . . . . . . . 29

2.9.7 PCR-Techniken . . . . . . . . . . . . . . . 30

2.9.7.1 PCR an Plasmid-DNA . . . . . . . . . . . . . . 30

2.9.7.2 PCR an genomischer DNA . . . . . . . . . . 31

2.9.7.3 Analytische PCR an genomischer DNA von knock out-

Mäusen . . . . . . . . . . . . . . . . . 31

2.9.8 Agarose-Gelelektrophorese . . . . . . . . . . . . . . . 32

2.9.8.1 Horizontale Gelelektrophorese . . . . . . . . . . . . . 32

2.9.8.2 Vertikale Gelelektrophorese . . . . . . . . . . . . . . 32

2.9.8.3 Denaturierende Gelelektrophorese . . . . . . . . . . . 33

2.9.9 Transfertechniken von Nukleinsäuren . . . . . . . . . . . . 33

2.9.9.1 Southern-Blot . . . . . . . . . . . . . . . . 33 
2.9.9.2 Northern-Blot . . . . . . . . . . . . . . . . . . . . 34

2.9.10 Radioaktive Hybridisierungstechniken . . . . . . . . . . . 34

2.9.10.1 Hybridisierung von Southern- und Northern-Blots . . . . 34

2.9.10.2 Hybridisierung der genomischen Cosmid-Bibliothek 129/Ola . . . . . . . . . . . . . . . . . 35

2.9.11 In situ-Hybridisierungen . . . . . . . . . . . . . . . . . . 35

2.9.11.1 Digoxygenin-Markierung von Nukleinsäuren . . . . . . . 35

2.9.11.2 Präparation von Maus-Embryonen . . . . . . . . . . 36

2.9.11.3 Whole mount-in situ-Hybridisierung . . . . . . . . 36

2.9.11.3.1 Vorbehandlung der Embryonen . . . . . . . . . . 36

2.9.11.3.2 Waschschritte und Antikörper-Inkubation . . . . . 37

2.9.11.3.3 Waschschritte und Farbreaktion . . . . . . . . . 37

2.9.11.3.4 Gelatine-Einbettung . . . . . . . . . . . . . 38

2.9.11.4 Herstellung von Paraffinschnitten . . . . . . . . . . . 38

2.9.11.5 In situ Hybridisierung von Schnittpräparaten . . . . . . 39

2.9.11.5.1 Vorbehandlung und Hybridisierung . . . . . . . . . 39

2.9.11.5.2 Waschschritte und Antikörper-Inkubation . . . . . 39

2.9.11.5.3 Waschschritte und Farbreaktion . . . . . . . . . 40

2.9.11.6 Herstellung von Embryo-Pulver . . . . . . . . . . . 40

2.9.11.7 Fotografische Auswertung . . . . . . . . . . . . . 40

2.9.11.8 Fluoreszenz-in situ-Hybridisierung (FISH) . . . . . . . . 41

2.9.11.8.1 Markierung der Sonde über Nick-Translation . . . . 41

2.9.11.8.2 Vorbehandlung und Hybridisierung . . . . . . . . . 42

2.9.11.8.3 Waschschritte und Antikörper-Inkubation . . . . . 42

2.9.11.8.4 Gegenfärbung der Chromosomen . . . . . . . . . 43

2.10 Proteinchemische Methoden . . . . . . . . . . . . . . . 43

2.10.1 Herstellung der Strep-tag-Fusionsproteine . . . . . . . . 43

2.10.1.1 Klonierung der Plasmide . . . . . . . . . . . . . . . 44

2.10.1.2 Zellwachstum, Genexpression und Präparation des Zellextrakts . . . . . . . . . . . . . 45

2.10.1.3 Aufreinigung des Fusionsproteins . . . . . . . . . . 45

2.10.1.4 Analyse der Expression und der Reinigung . . . . . . 46

2.10 .2 Kernproteinextraktion aus Gewebe . . . . . . . . . . . . 46

2.10 .3 Proteinbestimmung . . . . . . . . . . . . . . . . . 47

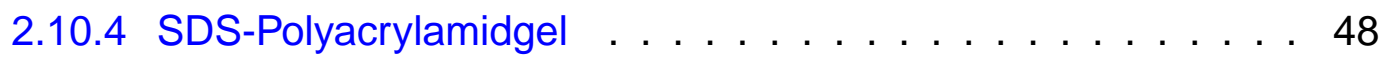

2.10 .5 Western-Blot . . . . . . . . . . . . . . . . . . . . 49

2.10 .6 Färbung von Polyacrylamidgelen . . . . . . . . . . . . . . . 49 
2.10 .7 Reversible Färbung von Western-Blots . . . . . . . . . . 49

2.10 .8 Immunumsetzung von Western-Blots . . . . . . . . . . 50

2.10.9 Aufreinigung monospezifischer Antikörper mittels WesternBlot-Verfahren . . . . . . . . . . . . . . . . 50 50

2.10.10 Aufreinigung monospezifischer Antikörper mittels Affinitäts-

Säulen . . . . . . . . . . . . . . . . . 51

2.10.11 Gewinnung eines polyklonalen Antiserums . . . . . . . . 52

2.11 Zellkultur . . . . . . . . . . . . . . . . . . . 53

2.11 .1 Routinekultur von ES-Zellen . . . . . . . . . . . . . 53

2.11.2 Elektroporation und Selektion von ES-Zellen . . . . . . . . 53

2.11.3 Isolierung und Kryokonservierung von ES-Zellklonen . . . . . 54

2.11.4 DNA-Extraktion aus ES-Zellen . . . . . . . . . . . . . . 54

2.11 .5 Herstellung von Chimären . . . . . . . . . . . . 55

3 Ergebnisse 56

3.1 Isolierung und Charakterisierung des Sall1-Gens der Maus . . . . 56

3.1.1 Isolierung und Charakterisierung zweier genomischer Cosmidklone . . . . . . . . . . . . . . . . . 5 56

3.1.2 Nukleotid- und abgeleitete Aminosäuresequenz von Sall1 . . 58

3.1.3 Identifizierung des Transkriptionsendpunktes . . . . . . . . . 59

3.1.4 Chromosomale Lokalisation von Sall1 . . . . . . . . . . . 63

3.2 Untersuchungen zur Expression des Sall1-Gens der Maus . . . . 63

3.2.1 Expression in adulten Geweben . . . . . . . . . . . . . 63

3.2.2 Expression in neuralen Embryonalgeweben . . . . . . . . 64

3.2.3 Expression in anderen Embryonalgeweben . . . . . . . . . . 65

3.2.4 Expression in den Gliedmaßenknospen . . . . . . . . . . . . 65

3.3 Homologe Rekombination des Sall1-Gens . . . . . . . . . . . . 68

3.3.1 Herstellung eines Sall1-knock out-Konstrukts . . . . . . . . 68

3.3.2 Herstellung von homolog rekombinierten embryonalen Stammzellen . . . . . . . . . . . . . . . . . . 71

3.3.3 Generierung von Sall1-defizienten Mäusen . . . . . . . . . . 71

3.4 Herstellung eines monospezifischen Anti-Sall1-Antikörpers . . . 72

3.4.1 Auswahl von Peptiden zur Immunisierung von Kaninchen . . 72

3.4.2 Herstellung von Sall1- und SALL1-Fusionsproteinen . . . . . 72

3.4.3 Gewinnung der Sall1- und SALL1-Fusionsproteine . . . . . . . 75

3.4.4 Gewinnung von monospezifischen Anti-Sall1-Antikörpern . . 75

3.4.5 Nachweis von Sall1 in Kernproteinextrakten . . . . . . . 76 
3.4.6 Herstellung eines Antiserums gegen Sall1 . . . . . . . . 77

3.5 Untersuchungen zur embryonalen Expression des Sall2-Gens der Maus . . . . . . . . . . . . . . . . 78

3.5.1 Expression in neuralen Embryonalgeweben . . . . . . . . 79

3.5.2 Expression in anderen embryonalen Geweben . . . . . . . 79

3.6 Homologe Rekombination des Sall2-Gens . . . . . . . . . . . . 81

3.6.1 Herstellung eines Sall2-knock out-Konstrukts . . . . . . . . . 81

3.6.1.1 Charakterisierung des Intron 1 und der 3'-Region von Sall2 81

3.6.1.2 Klonierung genomischer Fragmente in den pTKneo-Vektor 81

3.6.2 Herstellung von homolog rekombinierten embryonalen Stammzellen . . . . . . . . . . . . . . . . . . . 85

3.6.3 Generierung von Sall2-defizienten Mäusen . . . . . . . . . . 86

3.7 Analyse Sall2-defizienter Mäuse . . . . . . . . . . . . . . . . 88

3.7.1 Statistische Analyse der Wurfgrößen und Genotypen . . . . 88

3.7.1.1 Der Hintergrund C57BL . . . . . . . . . . . . . . . 88

3.7.1.2 Der Hintergrund 129/SvJ . . . . . . . . . . . . . . . . 89

3.7.2 Deletionskontrolle des Sall2-Gens durch Northern-BlotAnalysen . . . . . . . . . . . . . . . . . . 899

3.7.3 Histologische Analysen an Organen Sall2-defizienter Mäuse . 90

3.7.4 Analyse der Sall1-Expression in Sall2-knock out-Embryonen . 90

3.7.5 Morphologische Analysen an Sall2-knock out-Embryonen . . 92

3.8 Herstellung eines Anti-Sall2/SALL2-Antikörpers . . . . . . . . . 93

3.8.1 Herstellung von Sall2- und SALL2-Fusionsproteinen . . . . . . 94

3.8.2 Gewinnung der Sall2- und SALL2-Fusionsproteine . . . . . . 95

3.8.3 Gewinnung von Antikörpern gegen das murine Sall2- und das humane SALL2-Protein. . . . . . . . . . . . . . . 996

3.8.4 Herstellung eines Antiserums gegen Sall2 . . . . . . . . 97

3.9 Untersuchungen zur Expression des Sall3-Gens der Maus . . . . 98

3.9.1 Generierung einer Sall3-Sonde . . . . . . . . . . . . . 98

3.9.2 Expression des Sall3-Gens in neuralen embryonalen Geweben 99

3.9.3 Expression des Sall3-Gens in anderen embryonalen Geweben 101

3.10 Untersuchungen zur Expression muriner spalt-Gene in sonic hed-

gehog-Mutanten . . . . . . . . . . . . . . . . . . 101

3.10.1 Sall1-Expression in shh-defizienten Embryonen . . . . . . . 101

4 Diskussion 104

4.1 Das Gen Sall1 . . . . . . . . . . . . . . . . . . . . . . . . . . . . 104 
4.1.1 Zur Struktur des Sall1-Gens . . . . . . . . . . . . . . . . 104

4.1.2 Zur Struktur des Sall1-Proteins . . . . . . . . . . . . . . . . 105

4.1.3 Expression des Sall1-Gens . . . . . . . . . . . . . . . . 108

4.1.3.1 Expression des Sall1-Gens in adulten Geweben der Maus 108

4.1.3.2 Expression des Sall1-Gens in embryonalen Neuralgeweben . . . . . . . . . . . . . . . 108

4.1.3.3 Expression des Sall1-Gens in den Gliedmaßenknospen . 110

4.1.3.4 Expression des Sall1-Gens während der Nierenentwicklung . . . . . . . . . . . . . . . . 113

4.1.3.5 Expression des Sall1-Gens im Genitalhöcker . . . . . . . 114

4.1.3.6 Expression des Sall1-Gens in der Augenentwicklung . . . 115

4.1.3.7 Expression des Sall1-Gens in den Branchialbögen . . . . 116

4.1.4 Sall1-Expression in der Maus und das TBS . . . . . . . . . 116

4.1.5 Funktionsanalyse des Sall1-Gens . . . . . . . . . . . 119

4.2 Das Gen Sall2 . . . . . . . . . . . . . . . . . . . . . . . . . . 120

4.2.1 Charakterisierung des Intron 1 und der 3'-UTR von Sall2 . . 120

4.2.2 Expression des Sall2-Gens in adulten Geweben . . . . . . . 121

4.2.3 Expression des Sall2-Gens im embryonalen ZNS . . . . . . 121

4.2.4 Expression des Sall2-Gens in anderen Embryonalgeweben . 122

4.2.5 Funktionsanalyse des Sall2-Gens . . . . . . . . . . . . 123

4.3 Embryonale Expression des Gens Sall3 . . . . . . . . . . . . 126

4.4 Vergleich der drei sal-ähnlichen murinen Gene . . . . . . . . . . 127

4.4.1 Strukturvergleich . . . . . . . . . . . . . . 127

4.4 .2 Expressionsvergleich . . . . . . . . . . . . . . . 128

4.5 sal-ähnliche Vertebratengene lassen sich in Homologiegruppen einteilen . . . . . . . . . . . . . . . . . . . . . . 131

4.5.1 Strukturvergleich . . . . . . . . . . . . . 131

4.5.2 Vergleich der embryonalen Expression . . . . . . . . . 133

4.6 Zur Regulation des murinen sal-ähnlichen Gene durch Sonic hedgehog . . . . . . . . . . . . . . . . . . . 134

4.7 Weiterführende Arbeiten . . . . . . . . . . . . . . . . . 137

5 Zusammenfassung $\quad 139$

$\begin{array}{ll}\text { Literaturverzeichnis } & 141\end{array}$

$\begin{array}{ll}\text { Anhang } & 157\end{array}$ 


\section{Abbildungsverzeichnis}

1.1 Schematischer Vergleich der humanen SAL-Proteine mit dem SALProtein von Drosophila melanogaster . . . . . . . . . . . . . . . . . 5

3.1 Restriktionskarte und genomische Organisation sowie Sequenzierung von Sall1 . . . . . . . . . . . . . . . . . . . . . 5 57

3.2 Genomische Nukleotidsequenz des Sall1-Gens und die abgeleitete Aminosäuresequenz des offenen Leserahmens . . . . . . . . . . . . 62

3.3 Chromosomale Lokalisation des Sall1-Gens . . . . . . . . . . . . . . 63

3.4 Northern-Blot-Analyse des Sall1-Gens in adulten Geweben . . . . . 64

3.5 Expression des Sall1-Gens während der Embryonalentwicklung der Maus . . . . . . . . . . . . . . . . 66 66

3.6 Expression des Sall1-Gens während der Gliedmaßenentwicklung . . 67

3.7 Strategie der homologen Rekombination zur Inaktivierung des Sall1-Gens . . . . . . . . . . . . . . . . . 69 69

3.8 Restriktionsanalyse des Sall1-knock out-Konstrukts . . . . . . . . . 70

3.9 Genotypisierung der ES-Zellklone mittels Southern-Blot . . . . . . . 71

3.10 Homologievergleich zwischen den abgeleiteten Aminosäuresequenzen von Sall1 und SALL1 im Bereich des Peptids S1-I . . . . . 73

3.11 Homologievergleich zwischen den abgeleiteten Aminosäuresequenzen von Sall1 und SALL1 im Bereich des Peptids S1-II . . . . . 73

3.12 Fusionsproteine des Sall1- und SALL1-Gens . . . . . . . . . . . . 74

3.13 Western-Blot-Analyse bakteriell exprimierter Sall1- und SALL1Fusionsproteine . . . . . . . . . . . . . . . . 75

3.14 Test der unterschiedlich aufgereinigten Antikörper auf ihre AntigenSpezifität . . . . . . . . . . . . . . . . . . . . 77

3.15 Nachweis des Sall1-Proteins in Kernproteinextrakten . . . . . . . . . 78

3.16 Expression des Sall2-Gens während der Embryonalentwicklung der Maus ...................... 80 
3.17 Restriktionskarte und genomische Organisation sowie Sequenzierung von Sall2 . . . . . . . . . . . . . . . . . . . . . . . . 82

3.18 Strategie der homologen Rekombination zur Inaktivierung des Sall2-Gens . . . . . . . . . . . . . . . . . . . . . . . 84

3.19 Restriktionsanalyse des Sall2-knock out-Konstrukts . . . . . . . . . 85

3.20 Genotypisierung der ES-Zellklone mittels Southern-Blot . . . . . . . 86

3.21 Genotypisierung der F1-Generation durch PCR . . . . . . . . . . . 87

3.22 Genotypisierung der F2-Generation durch PCR . . . . . . . . . . . . 87

3.23 Northern-Blot-Analyse Sall2-defizienter Mäuse . . . . . . . . . . . . 90

3.24 Histologische Analysen an einer Sall2-/--Maus . . . . . . . . . . . . 91

3.25 Morphologische Analyse Sall2-defizienter Embryonen . . . . . . . . 93

3.26 Fusionsproteine für das murine Sall2- und das humane SALL2-Gens 95

3.27 Western-Blot-Analyse der Fusionsproteine Sall2 und SALL2 . . . . . 96

3.28 Aufreinigung des Fusionsproteins HS2 über immobilisiertes StrepTactin . . . . . . . . . . . . . . . . . . 97

3.29 Test des Antiserums und des Antikörpers gegen das Fusionsprotein HS2 . . . . . . . . . . . . . . . . . . . . . . 98

3.30 Amplifikation der Sall3-Sonde . . . . . . . . . . . . . . . . . . . . . . 99

3.31 Expression des Sall3-Gens während der Embryonalentwicklung der

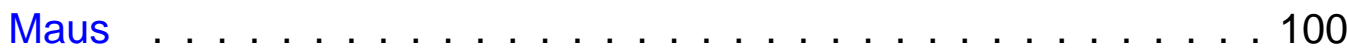

3.32 Expression verschiedener spalt-Gene in dsh-Deletionsmutanten . . 103

4.1 Vergleich der abgeleiteten Aminosäuresequenzen der Gene Sall1 und SALL1 . . . . . . . . . . . . . . . . . . . . . 107

4.2 Die frühe Gehirnentwicklung bei Vertebraten . . . . . . . . . . . . 110

4.3 Die Organisationszentren und Achsen der Gliedmaßenknospen von Vertebraten . . . . . . . . . . . . . . . . . . . 111

4.4 Die Entwicklung der Vertebratenniere . . . . . . . . . . . . . . . . 114

4.5 Die frühe Entwicklung der äußeren Genitalien . . . . . . . . . . . . 115

4.6 Die Entwicklung des Vertebratenauges . . . . . . . . . . . . . . . . . 122

4.7 Vergleich der embryonalen Expressionsmuster von Sall1, Sall2 und Sall3 . . . . . . . . . . . . . . . . . . . . . . . 130

4.8 Phylogenetischer Vergleich aller sal-ähnlicher Vertebratengene . . . 132

A.1 Genomische Nukleotidsequenz des Sall1-Gens . . . . . . . . . . . 162

A.2 Genomische Nukleotidsequenz des Sall2-Gens . . . . . . . . . . . 168 


\section{Abkürzungen}

$\begin{array}{ll}\text { Abb. } & \text { Abbildung } \\ \text { AHT } & \text { Anhydrotetracyclin } \\ \text { ATP } & \text { Adenosintriphosphat } \\ \text { AP } & \text { Alkalische Phosphatase } \\ \text { APS } & \text { Ammoniumperoxidisulfat } \\ \text { BCCP } & \text { biotinyliertes Bakterienprotein } \\ \text { BCIP } & \text { 5-Brom-4-Chlor-3-Indolyl-Phosphat } \\ \text { bp } & \text { Basenpaare } \\ \text { BPB } & \text { Bromphenolblau } \\ \text { BSA } & \text { Rinderserumalbumin } \\ \text { bzw. } & \text { beziehungsweise } \\ { }^{\circ} \text { C } & \text { Grad Celsius } \\ \text { ca. } & \text { circa } \\ \text { cDNA } & \text { komplementäre DNA } \\ \text { Chaps } & \text { 3-[(3-Cholamidopropyl)dimethylammonio]-1-Propansulfonat } \\ \text { Ci } & \text { Curie } \\ \text { cm } & \text { Zentimeter } \\ \text { Cos } & \text { Cosmid } \\ \text { CTP } & \text { Cytidintriphosphat } \\ \text { d- } & \text { desoxy- } \\ \text { dATP } & \text { Desoxyadenosintriphosphat } \\ \text { DB } & \text { Dilution Buffer } \\ \text { dCTP } & \text { Desoxycytidintriphosphat } \\ \text { dd- } & \text { didesoxy- } \\ \text { dest. } & \text { Destilliert } \\ \text { dGTP } & \text { Desoxyguanosintriphosphat } \\ \text { DIG } & \text { Digoxygenin } \\ & \end{array}$




$\begin{array}{ll}\text { DMDC } & \text { Dimethyl-Dicarbonat } \\ \text { DMEM } & \text { Dulbeccos Modified Eagle Medium } \\ \text { DMF } & \text { Dimethylformamid } \\ \text { DMSO } & \text { Dimethylsulfoxid } \\ \text { DNA } & \text { Desoxyribonukleinsäure } \\ \text { DNAse } & \text { Desoxyribonuklease } \\ \text { dNTPs } & \text { Desoxynukleotidtriphosphate } \\ \text { dpc } & \text { days post coitum } \\ \text { DTT } & \text { Dithiothreitol } \\ \text { dTTP } & \text { Desoxythymidintriphosphat } \\ \text { DZF } & \text { Doppelzinkfinger } \\ \text { E. coli } & \text { Escherichia coli } \\ \text { EDTA } & \text { Ethylendiamintetraessigsäure } \\ \text { EDV } & \text { Elektronische Datenverarbeitung } \\ \text { EGTA } & \text { Ethylenglycol-bis(B-Aminoethylether)-Tetraacetat } \\ \text { ERL } & \text { Epitheliale Randleiste } \\ \text { et al. } & \text { et alteres } \\ \text { ES } & \text { Embryonale Stamm- } \\ \text { EtOH } & \text { Ethanol } \\ \text { EZF } & \text { Einzelzinkfinger } \\ \text { Fi } & \text { Fibroblasten } \\ \text { FITC } & \text { Fluorescein-5-isothiocyanat } \\ \text { fkh } & \text { fork head } \\ \text { FKS } & \text { fetales Kälberserum } \\ \text { xg } & \text { Erdbeschleunigung }\left(9.81 \text { m/s }{ }^{2}\right) \\ \text { g } & \text { Gramm } \\ \text { GTP } & \text { Guanosintriphosphat } \\ \text { h } & \text { Stunde } \\ \text { HEF } & \text { human elongation factor } \\ \text { HS2 } & \text { humanes SALL2-Fusionsprotein } \\ \text { HSV } & \text { Herpes simplex-Virus } \\ \text { IPTG } & \text { Isopropyl-B-thiogalaktopyranosid } \\ \text { KAc } & \text { Kaliumacetat } \\ \text { kb } & \text { Kilobasenpaare } \\ \text { L } & \text { Liter } \\ \text { LB } & \text { Luria Bertani } \\ & \end{array}$


LIF Leukämie-Inhibitionsfaktor

M Molarität

m- mili- $(1 \times 10-3)$

m Meter

MAB Maleinsäure-Puffer

$\min \quad$ Minute

$\mu^{-} \quad$ mikro- $(1 \times 10-6)$

MOPS 3-[N-Morpholino]-Propansulfonsäure

mRNA messenger Ribonukleinsäure

MS2 murines Sall2-Fusionsprotein

n- $\quad$ nano- $(1 \times 10-9)$

$\mathrm{NaAc} \quad$ Natriumacetat

NBT Nitrotetrazoliumblau

neo Neomycin-Resistenzgen

n. S. nächste Seite

NTMT Natriumchlorid-Tris-Magnesiumchloridlösung mit Tween-20

OD Optische Dichte

p- pico- (1x10-12)

$P \quad$ Phosphat

p.A. pro analysi

$\mathrm{Pa} \quad$ Pascal

PAGE Polyacrylamid-Gelelektrophorese

PBS Phosphatgepufferte Salzlösung

PBT Phosphatgepufferte Salzsäure mit Tween

pc post coitum

PCR polymerase chain reaction

PFA Paraformaldehyd

Pfu Pyrococcus furiosus

$\mathrm{pH} \quad \mathrm{pH}$-Wert

PVDF Polyvinyliden-Difluorid

PVP Polyvinylpyrrolidon

PZ Progresszone

(B) Registered

RACE rapid amplification of $c D N A$ ends

RE Restriktionsendonukleasen

RNA Ribonukleinsäure 


$\begin{array}{ll}\text { RNase } & \text { Ribonuklease } \\ \text { RT } & \text { Raumtemperatur } \\ \text { RZPD } & \text { Ressourcen-Zentrum-Primärdatenbank } \\ \text { S. } & \text { Seite } \\ \text { s. } & \text { siehe } \\ \text { s.u. } & \text { siehe unten } \\ \text { SDS } & \text { Natriumdodecylsulfat } \\ \text { sec } & \text { Sekunde } \\ \text { SSC } & \text { standard saline citrat(-Puffer) } \\ \text { Taq } & \text { Thermophilus aquaticus } \\ \text { TBE } & \text { Tris-Borat-EDTA(-Puffer) } \\ \text { TBS } & \text { tris buffered saline(-Puffer) } \\ \text { TBS } & \text { Townes-Brocks-Syndrom } \\ \text { TE } & \text { Tris-EDTA(-Puffer) } \\ \text { TK } & \text { Thymidin-Kinase } \\ \text { TM } & \text { Trademark } \\ \text { Tris } & \text { Tris-hydroxymethyl-aminomethan } \\ \text { Tween-20 } & \text { Polyoxyethylensorbitan-Monolaureat } \\ \text { U } & \text { Unit (Einheit der Enzymaktivität) } \\ \text { u. a. } & \text { unter anderem } \\ \text { üN } & \text { über Nacht } \\ \text { Upm } & \text { Umdrehungen pro Minute } \\ \text { UTP } & \text { Uraciltriphosphat } \\ \text { UTR } & \text { untranslatierte Region } \\ \text { UV } & \text { Ultraviolett } \\ \text { V } & \text { Volt } \\ \text { Vol } & \text { Volumen } \\ \text { V/v } & \text { Volumen pro Volumen } \\ \text { WT } & \text { Wildtyp } \\ \text { w/v } & \text { Gewicht pro Volumen } \\ \text { X-Gal } & \text { 5-Brom-4-Chlor-3-Indolyl-B-Galaktosid } \\ \text { z.B. } & \text { zum Beispiel } \\ \text { ZF } & \text { Zinkfinger } \\ \text { ZPA } & \text { Zone polarisierender Aktivität } \\ & \\ \text { TT } & \\ \text { TR } & \end{array}$




\section{Code der Nukleinsäuren}
A Adenin
C Cytosin
G Guanin
$T$ Thymin
U Uracil

\section{Code der Aminosäuren}

$\begin{array}{llllll}\text { A } & \text { (Ala) } & \text { Alanin } & \text { M } & \text { (Met) } & \text { Methionin } \\ \text { C } & \text { (Cys) } & \text { Cystein } & \text { N } & \text { (Asp) } & \text { Asparagin } \\ \text { D } & \text { (Asp) } & \text { Asparaginsäure } & \text { P } & \text { (Pro) } & \text { Prolin } \\ \text { E } & \text { (Glu) } & \text { Glutaminsäure } & \text { Q } & \text { (Glu) } & \text { Glutamin } \\ \text { F } & \text { (Phe) } & \text { Phenylalanin } & \text { R } & \text { (Arg) } & \text { Arginin } \\ \text { G } & (\text { Gly) } & \text { Glycin } & \text { S } & \text { (Ser) } & \text { Serin } \\ \text { H } & \text { (His) } & \text { Histidin } & \text { T } & \text { (Thr) } & \text { Threonin } \\ \text { I } & \text { (lle) } & \text { Isoleucin } & \text { V } & \text { (Val) } & \text { Valin } \\ \text { K } & \text { (Lys) } & \text { Lysin } & \text { W } & \text { (Trp) } & \text { Tryptophan } \\ \text { L } & \text { (Leu) } & \text { Leucin } & \text { Y } & \text { (Tyr) } & \text { Tyrosin }\end{array}$




\section{Einleitung}

\subsection{Das Gen spalt bei Drosophila melanogaster}

Ein großer Teil unseres gegenwärtigen Wissens über genetische Grundlagen der Säugetierembryogenese basiert auf der Klonierung und Charakterisierung von Genen, die aufgrund ihrer Ähnlichkeit zu regulatorischen Entwicklungsgenen bei Drosophila isoliert wurden (Kessel und Gruss, 1990). Eine Untergruppe dieser Regulatorgene bei Drosophila sind die homöotischen Gene, deren Mutation dazu führt, dass ein bestimmter Körperteil an einer Stelle im Embryo entsteht, an der normalerweise ein anderer gebildet wird. Diese Gene kontrollieren folglich die Identität, nicht aber die Anzahl, Polarität oder Größe von Körpersegmenten (Lewin, 1997; Manak und Scott, 1994). Die Großzahl dieser homöotischen Gene von Drosophila befinden sich innerhalb zweier Genkomplexe, dem Antennapedia(ANT-C; Kaufman et al. (1980)) und dem Bithorax- (BX-C; Lewis (1978)) Komplex. Zwei weitere Drosophila-Gene wurden als neuartige homöotische Gene beschrieben, da sie außerhalb der homöotischen Genkomplexe lokalisiert sind. Es handelt sich dabei um die Gene fork head (fkh, Jürgens und Weigel (1988)) und spalt (sal, (Jürgens, 1988)), die die Identität von Kopf- und Schwanz-Regionen des Drosophila-Embryos bestimmen. Diese Gene werden auch als regionsspezifische homöotische Gene bezeichnet. Das $f k h$-Gen kodiert für das sogenannte winged helix- oder fork head-Motiv (Clark et al., 1993; Lai et al., 1990, 1991), das sal-Gen für Zinkfinger-Domänen als DNA-bindende Motive (Miller et al., 1985; Pieler und Theunissen, 1993; Theunissen et al., 1993).

Zinkfinger (ZF) sind ein häufiges Motiv in DNA-bindenden Proteinen. Der Name rührt von der Eigenschaft dieser Proteinmotive her, Zinkionen mittels konservierter Cysteine und Histidine derart in einem Komplex zu binden, dass die zwischen den Cysteinen und Histidinen gelegenen Aminosäuren solcher Motive fingerartig aus dem Protein herausragen (El-Baradi und Pieler, 1991). Das wich- 
tigste ZF-Motiv in Entwicklungsgenen von Drosophila und anderen Spezies ist der $\mathrm{C}_{2} \mathrm{H}_{2}$-ZF. Sind zwei oder mehrere Einheiten von $\mathrm{C}_{2} \mathrm{H}_{2}$-ZFs miteinander verbunden, finden sich zwischen diesen Einheiten regelmäßig sieben konservierte, als HC-link bezeichnete Aminosäuren zwischen dem letzten Histidin des vorangehenden und dem ersten Cystein des folgenden ZF (Schuh et al., 1986).

Die erste Erwähnung fand das Gen sal in einem Artikel von Nüsslein-Volhard et al. (1984), in dem der Genort in der Region 32F/33B auf dem linken Arm von Chromosom 2 beschrieben wurde. Jürgens (1988) charakterisierte das Gen als regionsspezifisches homöotisches Gen, das die Entwicklung von posterioren Kopf- und anterioren Schwanzstrukturen im Drosophila-Embryo determiniert. Die zugehörige Transkriptionseinheit wurde von Kühnlein et al. (1994) beschrieben. Das sal-Transkript von $6.1 \mathrm{~kb}$ setzt sich aus vier Exons zusammen und kodiert für ein Protein von 1355 Aminosäuren. Die Exons des Gens sind durch ein aminoterminales und zwei carboxyterminale Introns getrennt. Das SAL-Protein zeigt eine charakteristische Struktur von drei $\mathrm{C}_{2} \mathrm{H}_{2}$-Doppelzinkfinger (DZF)-Domänen, welche in größeren Abständen über das Protein verteilt sind (s. Abb. 1.1). Zusätzlich findet sich kurz hinter der mittleren DZF-Domäne ein einzelner $\mathrm{C}_{2} \mathrm{H}_{2}$-Zinkfinger (ZF). Die drei DZF-Domänen ähneln sich in ihrer Aminosäuresequenz und weisen jeweils im carboxyterminalen Motiv eine charakteristische Folge von acht Aminosäuren (FTTKGNLK), die sogenannte SAL-Box (Kühnlein et al., 1994), auf.

Neben der Funktion von sal in der frühen Embryogenese konnten dem Gen auch wesentliche Funktionen bei der Entwicklung des larvalen Tracheensystems (Chen et al., 1998; Kühnlein et al., 1994) sowie bei der Morphogenese des adulten Flügels der Fruchtfliege (de Celis et al., 1996; Nellen et al., 1996; Sturtevant et al., 1997) zugeordnet werden. Zudem wird es in den sich entwickelnden sensorischen Organen des Thorax exprimiert (de Celis et al., 1999) und beeinflusst die Entwicklung der im peripheren Nervensystem liegenden neuronalen Vorläuferzellen (Elstob et al., 2001; Rusten et al., 2001). Dabei agiert das sal-Gen downstream des für ein Signalmolekül kodierenden Gens hedgehog (Celis et al., 1996; Sturtevant et al., 1997).

\section{2 sal-ähnliche Gene bei Vertebraten}

Aufgrund der charakteristischen Struktur des sal-Gens aus Drosophila konnten in einer Reihe von Vertebratenspezies sal-ähnliche Gene identifiziert werden. Im Folgenden soll ein kurzer Überblick über das heutige Wissen zur Struktur und Regulation sal-ähnlicher Vertebratengene gegeben werden. 


\subsection{1 sal-ähnliche Gene beim Fisch Medaka, bei Xenopus laevis und beim Huhn}

Aus dem Genom des Fisches Medaka (Oryzias latipes) konnte bislang ein salähnliches Gen isoliert werden (Köster et al., 1997). Das Medaka-sal-Transkript ist ca. $4.7 \mathrm{~kb}$ lang und kodiert wie das Drosophila sal für ein Protein mit drei DZFDomänen. Dem zweiten DZF folgt ein einzelner $\mathrm{C}_{2} \mathrm{H}_{2}-\mathrm{ZF}$, und alle DZF-Domänen enthalten im carboxyterminalen Motiv die SAL-Box. Außerhalb dieser Bereiche finden sich jedoch nur wenige konservierte Regionen. Zusätzlich zu den in Drosophila gefundenen Strukturen ist für das Medaka-SAL-Protein ein einzelner ZF vom $\mathrm{C}_{2} \mathrm{HC}$-Typ am aminoterminalen Ende des Proteins beschrieben. Medaka sal ist ein Zielgen für die Signale von Sonic hedgehog (Köster et al., 1997), ein Mitglied der Hedgehog-Familie in Vertebraten.

Aus dem Krallenfrosch (Xenopus laevis) konnten bereits zwei sal-ähnliche Gene isoliert werden, Xsal-1 (Hollemann et al., 1996) und Xsal-3 (Onuma et al., 1999). Xsal-1 kodiert für ein Protein von 1278 Aminosäuren. Anders als bei Drosophila und Medaka enthält es vier DZF-Domänen, die aber SAL-ähnlich gleichmäßig über das Protein verteilt sind. Nach der zweiten DZF-Domäne folgt ein einzelner $\mathrm{C}_{2} \mathrm{H}_{2}-\mathrm{ZF}$, und wie bei Medaka SAL ist der aminoterminale $\mathrm{C}_{2} \mathrm{HC}-\mathrm{ZF}$ vorhanden. Ein weiterer Unterschied zu sal besteht im Vorkommen alternativer Transkripte, die entweder alle vier, drei oder nur zwei Doppelzinkfinger-Domänen kodieren, wobei das Transkript mit herausgespleißtem DZF Nr. 3 dominiert. Xsal-1 wird bereits früh in der Embryonalentwicklung bevorzugt im prospektiven Neuroektoderm exprimiert, später in spezifischen Regionen des Gehirns, im Rückenmark, im Herzen, im Pronephros, in den Gliedmaßenknospen und in den otischen Vesikeln (Hollemann et al., 1996).

Für Xsal-3 wurden ebenfalls alternative Transkripte mit einer resultierenden Länge von 1061 bzw. 826 Aminosäuren nachgewiesen (Onuma et al., 1999), die für zwei bzw. drei DZF-Domänen kodieren. Ebenso wie bei dem Xsal-1-Protein folgt nach dem zweiten DZF ein einzelner ZF, und am aminoterminalen Ende des Proteins findet sich ein einzelner $\mathrm{C}_{2} \mathrm{HC}-\mathrm{ZF}$. Xsal-3 wird stark in der Neuralfalte und -platte exprimiert, des Weiteren wurden Transkripte im Mandibular- und Hyalbogen, den anterioren und posterioren Branchialbögen, dem pronephrischen Gang und in geringen Mengen auch im otischen Vesikel und der sich entwickelnden Schwanzspitze festgestellt (Onuma et al., 1999).

Aus dem Huhn sind bisher zwei sal-ähnliche Gene identifiziert worden. Das von Farrell und Munsterberg (2000) isolierte Csal1-Gen kodiert für ein Transkript 
von $3924 \mathrm{bp}$. Wie bei den anderen aufgeführten SAL-Vertebratenproteinen sind die typischen DZF-Domänen mit den SAL-Boxen und der aminoterminale $\mathrm{C}_{2} \mathrm{HC}$ ZF konserviert. Die Aminosäuresequenz zeigt eine hohe Homologie zum humanen SALL1-Protein (s.u.) (Farrell und Munsterberg, 2000). In den Gliedmaßenknospen wird Csal1 in der epithelialen Randleiste und im distalen Mesenchym exprimiert, des Weiteren im ZNS. Die Expression des Csal1-Gens in den Gliedmaßenknospen wird unter anderem durch Sonic hedgehog reguliert (Farrell und Munsterberg, 2000).

Für das von Farrell et al. (2001) beschriebene Csal2-Protein treffen ebenfalls die für SAL-ähnliche Vertebratenproteine beschriebenen Charakteristika zu, es enthält die üblichen vier DZF-Domänen, den aminoterminalen $\mathrm{C}_{2} \mathrm{HC}-\mathrm{ZF}$ und die SAL-Boxen. Das Csal2-Protein zeigt eine hohe Homologie zum Xsal-1-, Sall3- und SALL3-Protein (Farrell et al., 2001). Auch Csal2 wird schon in frühen Embryonalstadien exprimiert, hauptsächlich in der Neuralplatte und später im Neuralrohr, in bestimmten Gehirnregionen, in den Gliedmaßenknospen, der Schwanzknospe, dem Mesonephros und dem Genitalhöcker.

\subsection{2 sal-ähnliche Gene beim Menschen}

Drei sal-ähnliche humane Gene konnten bislang aus dem menschlichen Genom isoliert werden, SALL1 (SALL = spalt-like), SALL2 (beide Kohlhase et al. (1996)) und SALL3 (Kohlhase et al., 1999a). Zudem wurde das SALL1-ähnliche Pseudogen SALL1P identifiziert (Kohlhase et al., 1999b).

Das Gen SALL1 (vormals HSAL1) auf Chromosom 16q12.1 kodiert für ein Protein von 1324 Aminosäuren (Kohlhase et al., 1996, 1999c). Wie für fast alle weiteren SAL-ähnliche Vertebratenproteine bereits beschrieben, enthält es vier DZF-Domänen vom SAL-Typ und das aminoterminale $\mathrm{C}_{2} \mathrm{HC}$-ZF-Motiv (s. Abb. 1.1). Das Csal1-Protein ist von den oben beschriebenen SAL-ähnlichen Proteinen in seiner Struktur und Sequenz dem SALL1-Protein am ähnlichsten (Farrell und Munsterberg, 2000). Eine Expression des Gens konnte in der Niere, im Gehirn und in der Leber des adulten Menschen sowie im fetalen Gehirn nachgewiesen werden (Kohlhase et al., 1996).

Das Gen SALL2 (vormals HSAL2) auf Chromosom 14q11.1-12.1 (Kohlhase et al., 1996) kodiert wie das Medaka-sal-Gen für drei DZF-Domänen (s. Abb. 1.1). Nur zwei dieser Domänen zeigen eine deutliche Ähnlichkeit zu SAL, die carboxyterminale Domäne enthält jedoch statt des SAL-ähnlichen DZF mit 49 Aminosäu- 
ren einen Doppelzinkfinger mit 51 Aminosäuren. Zudem findet sich in dieser Domäne keine typische SAL-Box. Die genomische Struktur von SALL2 lässt das für die meisten sal-Gene von Vertebraten beschriebene $3^{\prime}$-Intron vermissen, die typische Proteinstruktur und Aminosäuresequenz-Übereinstimmung mit den SALähnlichen Proteinen weisen SALL2 jedoch eindeutig als Mitglied der sal-Familie aus (Kohlhase et al., 1996). In adulten Geweben des Menschen wird SALL2 hauptsächlich in Gehirn und Herz exprimiert, auch eine Expression im fetalen Gehirn wird beschrieben.

Das putative Protein des Gens SALL3 auf Chromosom 18q23 (Kohlhase et al., 1999a) entspricht in seiner Struktur mit vier DZF-Domänen, einem zusätzlichen $\mathrm{C}_{2} \mathrm{H}_{2}$-ZF-Motiv nach dem zweiten DZF und einem aminoterminalen $\mathrm{C}_{2} \mathrm{HC}$-ZFMotiv dem Bild eines typischen SAL-Vertebratenproteins (s. Abb. 1.1).

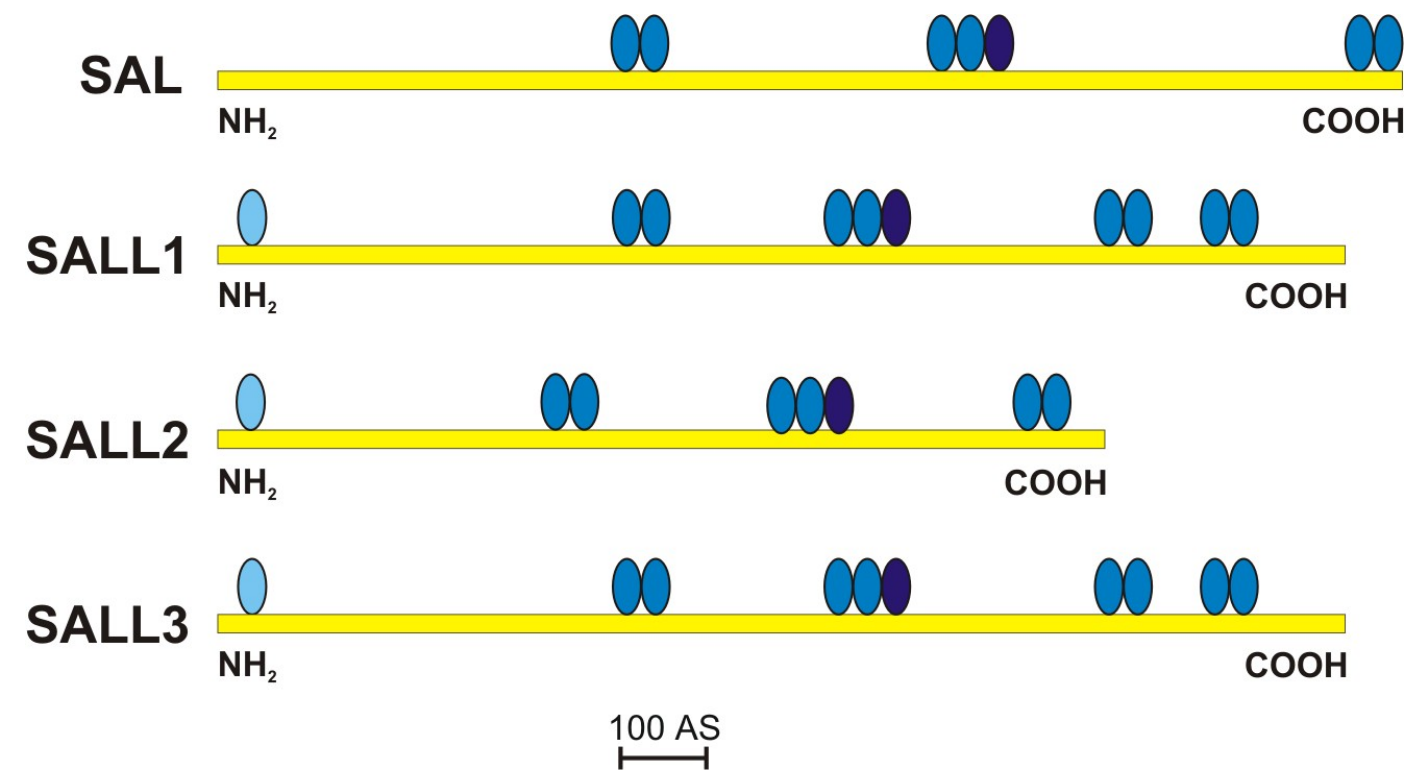

Abbildung 1.1: Schematischer Vergleich der humanen SAL-Proteine mit dem SAL-Protein von Drosophila melanogaster. Die Ovale stellen die Zinkfingermotive innerhalb der Proteine dar. Die Doppelzinkfinger sind blau, der angehängte Zinkfinger dunkelblau und der aminoterminale $\mathrm{C}_{2} \mathrm{HC}$-Zinkfinger hellblau unterlegt.

Die für die vierte DZF-Domäne kodierende Nukleotidsequenz ist durch ein Intron getrennt, ein $5^{\prime}$-Intron ist ebenfalls vorhanden. Das Protein Csal2 zeigt eine hohe Homologie zur Sequenz des humanen SALL3-Proteins (Farrell et al., 2001). Durch alternatives Spleißen entsteht ein Produkt ohne das aminoterminale $\mathrm{C}_{2} \mathrm{HC}$ ZF-Motiv, und der von Spleißstellen umgebene dritte DZF scheint immer aus dem Transkript entfernt zu werden (Kohlhase et al., 1999a). In adulten Geweben des 
Menschen wird SALL3 hauptsächlich im Herzen, schwächer im Gehirn, Pankreas, Niere, Skelettmuskel, Leber und Plazenta exprimiert. Eine Expression des SALL3-Gens im fetalen Gehirn wurde ebenfalls festgestellt.

\subsection{3 sal-ähnliche Gene bei der Maus}

Das erste murine sal-ähnliche Gen, Msal-1, wurde von Ott et al. (1996) publiziert. Nach Rücksprache mit dem Nomenclature committee for human and mouse genomes (Kohlhase, 2000a) werden die murinen Gene nun entsprechend ihrer Homologie zu den humanen Genen nummeriert und benannt. Somit ist die neue Bezeichnung für Msal-1 jetzt Sall3. Das putative Protein enthält vier DZF-Domänen vom SAL-Typ, ein aminoterminales $\mathrm{C}_{2} \mathrm{HC}$-ZF-Motiv und kann alternativ gespleißt werden. Dem kürzeren Transkript fehlt wie bei SALL3 und Xsal-1 der für den dritten DZF kodierende Bereich, und das vollständige Transkript mit allen vier DZF wird nur sehr schwach exprimiert (Ott et al., 1996). Während der Embryogenese wird Sall3 hauptsächlich im sich entwickelnden Neuroektoderm von Gehirn, Innenohr und Rückenmark exprimiert. Weitere Expressionsdomänen sind von der Urogenitalleiste abstammende Gewebe wie Testis, Ovar und Nieren. Eine Expression wurde außerdem in den Kiemenbögen, im Notochord, in den Gliedmaßenknospen und im Herz festgestellt (Ott et al., 1996).

Ein weiteres murines sal-Gen, Sall2 (vormals Msal-2, Kohlhase et al. (2000)), kodiert für ein putatives Protein von 1004 Aminosäuren. Es enthält zwei kurze 5 '-Exons, die alternativ gespleißt werden. Exon 2 kodiert für drei DZF-Domänen, wobei wiederum der zweiten ein einzelner $\mathrm{ZF}$ folgt und am aminoterminalen Ende ein $\mathrm{C}_{2} \mathrm{HC}$-ZF-Motiv vorliegt. Das Sall2-Protein ähnelt in hohem Maße dem humanen SALL2-Protein. Das ca. $5 \mathrm{~kb}$ lange Sall2-Transkript wird in adulten Mäusen in abnehmender Stärke in Gehirn, Niere, Lunge und Ovar exprimiert. Eine Analyse mittels RT-PCR ergab, dass Sall2-Transkripte bereits in 8.5 Tage alten Embryonen vorliegen (Kohlhase et al., 2000).

\subsection{Mutationen im SALL1-Gen verursachen TBS}

Mutationen im SALL1-Gen verursachen das Townes-Brocks-Syndrom (TBS, OMIM Nr. 107480), ein nach seinen Erstbeschreibern Townes und Brocks (1972) benanntes autosomal-dominant vererbtes Fehlbildungssyndrom (Kohlhase et al., 1998; Kohlhase, 2000b). Es ist gekennzeichnet durch Analatresie, Fehlbildun- 
gen der oberen Extremitäten (triphalangealer Daumen, präaxiale Polydaktylie) und Ohrmuscheldysplasien (Kohlhase et al., 1998). Seltener treten Schwerhörigkeit, urogenitale Fehlbildungen, Zehen- und Fußfehlbildungen sowie mentale Retardierung auf (Cameron et al., 1991; Ishikiriyama et al., 1996; O'Callaghan und Young, 1990; Powell und Michaelis, 1999; Wischermann und Holschneider, 1997). Alle bislang in Patienten identifizierten SALL1-Mutationen sind Stopp-Mutationen oder kurze Deletionen bzw. Insertionen, wobei sämtliche Veränderungen zu einem vorzeitigen Translationsabbruch führen (Kohlhase et al., 1998, 1999c; Marlin et al., 1999). Es wird angenommen, dass die beschriebenen Mutationen zu funktionslosen SALL1-Allelen und damit über eine Haploinuffizienz zu TBS führen. Das SALL1-Gen scheint somit eine wichtige Funktion bei der Entwicklung der beim TBS betroffenen Organe einzunehmen.

\subsection{Ziele der vorliegenden Arbeit}

Im Rahmen der vorliegenden Arbeit sollte das bisher unbekannte murine Homolog zu dem humanen SALL1-Gen isoliert und hinsichtlich seiner Expression in der Embryogenese und in adulten Tieren charakterisiert werden. Es sollten monospezifische Antikörper zum Nachweis des Proteins gewonnen werden. Durch die Methode der homologen Rekombination sollten knock out-Mäuse hergestellt werden, die das rekombinierte Allel im heterozygoten und homozygoten Zustand enthalten.

Die bisher vorliegenden Informationen zur Sequenz und Struktur des murinen Sall2-Gens sollten ergänzt und die Expression des Gens während der Embryogenese analysiert werden. Fusionsproteine sollten erzeugt und zur Herstellung eines Antiserums genutzt werden. Zudem sollten mittels homologer Rekombination knock out Mäuse produziert werden, die das homolog rekombinierte Allel in heterozygotem und homozygotem Zustand enthalten. Diese Mäuse sollten phänotypisch charakterisiert werden.

Des Weiteren sollte die embryonale Expression des Gens Sall3 anhand von whole mount-in situ-Hybridisierungen analysiert werden. 


\section{Material und Methoden}

\subsection{Chemikalien}

Alle Chemikalien, die nicht gesondert aufgeführt sind, wurden von der Firma Merck (Darmstadt) in p.A. Qualität bezogen.

$\begin{array}{ll}\text { Adenosintriphosphat } & \text { Biomol, Hamburg } \\ \text { Acrylamid } & \text { Gibco BRL, Eggenstein } \\ \text { Agarose } & \text { Fluka, Neu-Ulm } \\ \text { Albumin Fraktion V } & \text { Roth, Karlsruhe } \\ \text { Alkalische Phosphatase } & \text { Roche Diagnostics, Mannheim } \\ \text { Ammoniumacetat } & \text { Fluka } \\ \text { Ampicillin } & \text { Sigma, Deisenhofen } \\ \text { Ampuwa }{ }_{2} \mathrm{O} & \text { Fresenius, Bad Homburg } \\ \text { Antifading-Lösung Vectashield } & \text { Camon, Heidelberg } \\ \text { Aqua Poly/Mount } & \text { Polysciences, Heidelberg } \\ \text { Avidin-FITC-Lösung } & \text { Serva, Heidelberg } \\ \text { BCIP } & \text { Roth } \\ \text { Bisacrylamid } & \text { Serva } \\ \text { Blocking Reagenz } & \text { Roche Diagnostics } \\ \text { BM Purple AP Substrat } & \text { Roche Diagnostics } \\ \text { Borsäure } & \text { Roth } \\ \text { BPB } & \text { Sigma } \\ \text { BSA (DNase-frei) } & \text { Biomol } \\ \text { Calf Intestinal Alkaline Phosphatase } & \text { Fluka } \\ \text { Chaps } & \text { Sigma } \\ \text { Chloroform } & \text { Roth } \\ \text { Dextransulfat } & \text { Amersham Pharmacia Biotech, Freiburg } \\ \text { DMDC } & \text { Fluka }\end{array}$




\begin{tabular}{|c|c|}
\hline DTT & Biomol \\
\hline DNase I & Roche Diagnostics \\
\hline dNTPs & Roche Diagnostics \\
\hline EDTA & ICN, Eschwege \\
\hline Entwickler G & AGFA-Gevaert AG, Mortsel, Belgien \\
\hline Ethanol & Roth \\
\hline Essigsäure & Roth \\
\hline Ethidiumbromid & Eurobio, Les Ulis Cedex, Frankreich \\
\hline Ficoll 400 & Amersham Pharmacia Biotech \\
\hline Fixierer G 354 & AGFA-Gevaert AG \\
\hline Formaldehyd & Roth \\
\hline Formamid & Roth \\
\hline Gelatine & Sigma \\
\hline Glycerol & Roth \\
\hline Glycin & ICN \\
\hline Heparin & Sigma \\
\hline IPTG & Biomol \\
\hline Kaliumacetat & Sigma \\
\hline Kaliumphosphat & Sigma \\
\hline Kanamycin & Sigma \\
\hline Klenow-DNA-Fragment & Amersham Pharmacia Biotech \\
\hline Lachsspermien-DNA & Sigma \\
\hline Levamisol (Tetramisol) & Sigma \\
\hline Lysozym & Roche Diagnostics \\
\hline$\beta$-Mercaptoethanol & Serva \\
\hline Mineralöl & Sigma \\
\hline MOPS & Sigma \\
\hline Natriumcarbonat & Sigma \\
\hline NBT & Roth \\
\hline NuPAGETM MOPS SDS Running & Invitrogen (Groningen, Niederlande) \\
\hline \multicolumn{2}{|l|}{ Buffer $(20 x)$} \\
\hline NuPAGETM LDS Sample Buffer (4x) & Invitrogen \\
\hline Orange G & Sigma \\
\hline Paraplast & Sigma \\
\hline PFA & Sigma \\
\hline Pfu Turbo ${ }^{\circledR}$ DNA Polymerase & Stratagene, Heidelberg \\
\hline
\end{tabular}




Phenol
Platinum ${ }^{\circledR}$ Taq DNA Polymerase
Ponceau S
Proteinase K
$\left[\alpha^{-32}\right] \mathrm{P}$ dCTP und $\left[\alpha^{-32}\right] \mathrm{P}$ dATP
$(3000 \mathrm{Ci} / \mathrm{mmol})$
Restriktionsenzyme
RNase A
RNase Away
RNA-Längenstandard 0.29-9.5 kb
SDS
Select Peptone
Select Yeast Extract
Simply BlueTM Safestain
T3-RNA-Polymerase
T4-DNA-Ligase
Total RNA Reagent
Tris
tRNA
Tween-20
X-Gal
Xylol

Biomol

Gibco BRL

Serva

Amersham Pharmacia Biotech

Amersham Pharmacia Biotech

Gibco BRL; Biolabs, Schwalbach

Sigma

Roth

Gibco BRL

ICN

Gibco BRL

Gibco BRL

Invitrogen

Roche Diagnostics

Gibco BRL

Biomol

Gibco BRL

Roche Diagnostics

Sigma

Biomol

Roth

\subsection{Kits}

BigDye ${ }^{\circledR}$ Terminator Cycle

Applied Biosystems (Weiterstadt)

Sequencing Ready Reaction Kit

DIG-RNA Labeling Kit

Roche Diagnostics

DYEnamic ET-Terminator-Mix

Endo Free Plasmid Maxi Kit

HexalabelTM DNA Labeling Kit

JETsorb Gel Extraction Kit

JETstar Plasmid MIDI Kit

Megaprime ${ }^{\circledR}$ DNA Labelling Kit

Nick-Translations-Kit

Amersham Pharmacia

Qiagen, Hilden

MBI-Fermentas, St. Leon-Rot

Genomed, Bad Oeynhausen

Genomed

Amersham Pharmacia Biotech

Gibco BRL 
QIAquick Gel Extraction Kit

Qiagen

Recombinant Protein Expression and

IBA, Göttingen

Purification Kit

Rediprime ${ }^{\mathrm{TM}}$ II Random Prime

Amersham Pharmacia Biotech

Labeling System

The QIAexpressionist ${ }^{\mathrm{TM}}$

Qiagen

\subsection{Gebrauchswaren und Geräte}

\subsubsection{Gebrauchswaren}

Gebrauchswaren, die nicht gesondert aufgeführt sind, wurden von den Firmen Krannich und Schütt (Göttingen), Nunc (Wiesbaden), Greiner (Nürtingen) und Sarstedt (Nürnbrecht) bezogen.

Affinitätssäulen HiTrap affinity

columns, NHS-aktiviert

Aufreinigungssäule MicroSpin ${ }^{\mathrm{TM}}$

S-200 HR

Blottingpapier GB 003

Centrisart I

Elektroporationsküvette Gene Pulser

Cuvette, $0.4 \mathrm{~cm}$, gap 50

Filterpapier 0850

Fotoklebstoff Fix-o-Gum

Rubber-Cement

Glas-Scintillationsgefäße, steril

Nitrocellulose-Membran Hybond ${ }^{\mathrm{TM}}-\mathrm{C}$

NuPAGE ${ }^{\circledR}$ BisTris Gele

Nylon-Membran Hybond ${ }^{T M}-\mathrm{N}$

Objektträger Superfrost* Plus

PAGErTM Gold Precast Gels

Peel-A-Way Einbettungsformen

Pipettenspitzen mit Filter

PVDF-Membran Hybond ${ }^{T M}$ - $P$

Röntgenfilme HyperfilmTM MP

Sterilfilter
Amersham Pharmacia Biotech

Amersham Pharmacia Biotech

Schleicher \& Schüll, Dassel

Sartorius, Göttingen

BioRad, München

Schleicher \& Schüll

Marabu, Tamm

Sigma

Amersham Pharmacia Biotech

Invitrogen

Amersham Pharmacia Biotech

Schütt

Biozym

Polysciences

Biozym, Hess. Oldendorf

Amersham Pharmacia Biotech

Amersham Pharmacia Biotech

Sartorius 


\subsubsection{Geräte}

\begin{tabular}{|c|c|}
\hline Automated DNA-Sequencer ABI 377 & Applied Biosystems, Foster City, USA \\
\hline DNA Thermal Cycler 480 & Perkin Elmer, Überlingen \\
\hline Dispergierwerkzeug Ultraturrax T25 & Schütt \\
\hline Elektrophoresesystem SCell & Invitrogen \\
\hline \multicolumn{2}{|l|}{ SureLock ${ }^{\mathrm{TM}}$ Mini-Cell } \\
\hline Fotostereomikroskop SZX12 & Olympus, München \\
\hline Fotomikroskop BX60 & Olympus \\
\hline GeneAmp PCR System 9600 & Perkin Elmer \\
\hline Gene Pulser & BioRad \\
\hline Paraffin-Einbettungsstation & Shandon, Frankfurt a.M. \\
\hline \multicolumn{2}{|l|}{ Histocentre 2} \\
\hline Luminometer Typ LB 953 & Berthold, Bad Wildbad \\
\hline Mikrotiterplatten-Photometer & BioRad \\
\hline \multicolumn{2}{|l|}{ Microplate Reader 450} \\
\hline Mikrotom RM 2035 & Leica, Nussloch \\
\hline Personal Molecular Imager FX & BioRad \\
\hline Phosphoimager-Screen & Kodak, Rochester, New York \\
\hline Semi-Dry-Blot Fast Blot & Biometra, Göttingen \\
\hline Spektrophotometer Ultrospec 3000 pro & Amersham Pharmacia Biotech \\
\hline SpeedVac concentrator SVC $100 \mathrm{H}$ & Schütt \\
\hline Thermomixer 5436 & Eppendorf, Hamburg \\
\hline TurboblotterTM & Schleicher \& Schüll \\
\hline Ultraschallstab Ultraturrax & Branson, Soest, Niederlande \\
\hline UV StratalinkerTM 1800 & Strategene, Heidelberg \\
\hline Vibratom 1000M & Leica \\
\hline Video-Dokumentationssystem & Herolab, Heidelberg \\
\hline X-Ray Automatic Processor Curix 60 & Agfa, Mortsel, Belgien \\
\hline
\end{tabular}

\subsection{Puffer und Lösungen}

Puffer und Lösungen wurden nach Sambrook et al. (1989) hergestellt. Die Chemikalien wurden den Erfordernissen entsprechend in bidestilliertem oder deionisiertem Wasser gelöst und nach Bedarf autoklaviert oder sterilfiltriert. Für die Arbeiten 
mit RNA wurden die Puffer, sofern sie kein Tris oder SDS enthielten, üN mit $0.1 \%$ DMDC inkubiert und anschließend autoklaviert. Tris-Puffer oder SDS-haltige Lösungen wurden in RNase-freien Gefäßen mit DMDC-behandeltem Wasser angesetzt. Puffer von Enzymen und gebrauchsfertigen Kits wurden wie vom Hersteller angegeben genutzt, ihre Zusammensetzung ist hier nicht weiter aufgeführt.

\begin{tabular}{|c|c|}
\hline Acrylamid-Lösung & $38 \%$ Acrylamid \\
\hline & $2 \%$ Bisacrylamid \\
\hline Auftragspuffer 1 & Glycerol (autoklaviert) \\
\hline & $1 \%$ BPB \\
\hline & 0.25 M EDTA, pH 7.4 \\
\hline & Ampuwa $\mathrm{H}_{2} \mathrm{O}$ \\
\hline Auftragspuffer 2 & $15 \%$ Ficoll 400 \\
\hline & 200 mM EDTA, pH 7.4 \\
\hline & $0.1 \%$ Orange $\mathrm{G}$ \\
\hline $\mathrm{BCIP}$ & $5 \% w / v$ \\
\hline & in $100 \%$ DMF \\
\hline Blocking-Lösung I & $5 \%$ BSA \\
\hline & $4 \times$ SSC \\
\hline & $0.1 \%$ Tween \\
\hline & $\mathrm{pH} 7.0$ \\
\hline Blocking-Lösung II & $3 \%$ Blocking-Reagenz \\
\hline & $0.5 \%$ Tween \\
\hline & $0.02 \%$ Natrium-Azid \\
\hline & in $1 \times$ PBS \\
\hline Blotting-Puffer & $25 \mathrm{mM}$ Tris- $\mathrm{HCl}$ \\
\hline & 150 mM Glycin \\
\hline & $10 \%$ Methanol \\
\hline Denaturierungslösung & $0.5 \mathrm{M} \mathrm{NaOH}$ \\
\hline & $1.5 \mathrm{M} \mathrm{NaCl}$ \\
\hline Denhardt's Lösung (50x) & $1 \% \mathrm{BSA}$ \\
\hline & $1 \% \mathrm{PVP}$ \\
\hline & $1 \%$ Ficoll 400 \\
\hline DMDC- $\mathrm{H}_{2} \mathrm{O}$ & $\begin{array}{l}0.5 \% \text { DMDC in Aqua dest. üN auf Magnetrüher } \\
\text { mischen, danach autoklavieren }\end{array}$ \\
\hline dNTP-Lösung & $2 \mathrm{mM}$ dATP \\
\hline & $2 \mathrm{mM}$ dCTP \\
\hline
\end{tabular}


EDTA

E-Puffer (10x)

ES-Lysispuffer

Färbepuffer

Färbelösung

Gewebe-Lysispuffer

Hybridisierungslösung 1

(für Southern- u. Northern-Blot)

Hybridisierungslösung 2

(für Roboter-erzeugte Filter)

Hybridisierungslösung 3

(für in situ-Hybridisierungen)

MAB-Puffer
$2 \mathrm{mM}$ dGTP

$2 \mathrm{mM}$ dTTP

$0.5 \mathrm{M}$, mit $\mathrm{NaOH}$ auf pH 8.0 einstellen

$300 \mathrm{mM} \mathrm{NaH}_{2} \mathrm{PO}_{4}$

$50 \mathrm{mM}$ EDTA

$\mathrm{pH} 7.0$

$100 \mathrm{mM}$ Tris- $\mathrm{HCl} \mathrm{pH} 8.5$

$5 \mathrm{mM}$ EDTA

$0.2 \%$ SDS

$200 \mathrm{mM} \mathrm{NaCl}$

$100 \mu \mathrm{g} / \mathrm{mL}$ Proteinase $\mathrm{K}$

$100 \mathrm{mM} \mathrm{NaCl}$

$5 \mathrm{mM} \mathrm{MgCl} 2$

$100 \mathrm{mM}$ Tris- $\mathrm{HCl} \mathrm{pH} 8.0$

$10 \mu \mathrm{L}$ NBT

$60 \mu \mathrm{L} \mathrm{BCIP}$

in $20 \mathrm{~mL}$ Färbepuffer

$50 \mathrm{mM}$ Tris- $\mathrm{HCl} \mathrm{pH} 8.0$

$100 \mathrm{mM}$ EDTA

$0.5 \%$ SDS

$10 \%$ Dextransulfat

12.5x Denhardt's Lösung

$5 \times$ SSC

$0.1 \%$ SDS

$0.5 \mathrm{M}$ Natriumphosphatpuffer $\mathrm{pH} 7.2$

$7 \%$ SDS

$1 \mathrm{mM}$ EDTA

$50 \%$ Formamid

$5 \mathrm{x} \mathrm{SSC} \mathrm{pH} 4.5$

$50 \mu \mathrm{g} / \mu \mathrm{L}$ Hefe tRNA

$100 \mu \mathrm{g} / \mu \mathrm{L}$ Heparin

$0.1 \%$ Tween 20

(0.1\% Chaps für Hybridisierungen an

Paraffin-Schnitten)

$0.1 \mathrm{M}$ Maleinsäure

$0.15 \mathrm{M} \mathrm{NaCl}$ 
MAB/Block-Puffer

MEMFA

MOPS-Puffer (10x)

Natriumphosphatpuffer

NBT

Neutralisierungslösung

NTMT

PBS-Puffer (10x)

PBT-Puffer

RF1-Lösung

RF2-Lösung
$0.1 \%$ Tween-20

$\mathrm{pH} 7.5$

$2 \%$ Blocking-Reagenz in MAB

$100 \mathrm{mM}$ MOPS

2 mM EGTA

$1 \mathrm{mM} \mathrm{MgSO}_{4}$

1/10 Formaldehyd (37\%)

$0.2 \mathrm{M}$ MOPS

$50 \mathrm{mM} \mathrm{NaAc}$

$0.5 \mathrm{M}$ EDTA

$\mathrm{pH} 7.0$

$684 \mathrm{~mL} \mathrm{Na}_{2} \mathrm{HPO}_{4}(1 \mathrm{M})$

$316 \mathrm{~mL} \mathrm{NaH}{ }_{2} \mathrm{PO}_{4}(1 \mathrm{M})$

$\mathrm{pH} 7.2$

$5 \% \mathrm{w} / \mathrm{v}$

in $70 \% \mathrm{DMF}$

$130 \mathrm{mM} \mathrm{NaCl}$

$7 \mathrm{mM} \mathrm{Na}_{2} \mathrm{HPO}_{4}$

$3 \mathrm{mM} \mathrm{NaH}_{2} \mathrm{PO}_{4}$

$100 \mathrm{mM}$ Tris- $\mathrm{HCl}$ pH 9.5

$50 \mathrm{mM} \mathrm{MgCl}_{2}$

$10 \mathrm{mM} \mathrm{NaCl}$

$0.1 \%$ Tween-20

$2 \mathrm{mM}$ Levamisol

$130 \mathrm{mM} \mathrm{NaCl}$

$7 \mathrm{mM} \mathrm{Na}_{2} \mathrm{HPO}_{4}$

$3 \mathrm{mM} \mathrm{NaH}_{2} \mathrm{PO}_{4}$

$\mathrm{pH} 7.5$

$1 \times$ PBS

$0.1 \%$ Tween 20

$100 \mathrm{mM} \mathrm{RbCl}$

$50 \mathrm{mM} \mathrm{MnCl}_{2}$

$30 \mathrm{mM} \mathrm{KAc}$

$15 \%$ (w/v) Glycerol

$\mathrm{pH} 5.8$

$10 \mathrm{mM}$ MOPS 


\begin{tabular}{|c|c|}
\hline & $10 \mathrm{mM} \mathrm{RbCl}$ \\
\hline & $75 \mathrm{mM} \mathrm{CaCl}_{2}$ \\
\hline & $15 \%(w / v)$ Glycerol \\
\hline Sammelgel-Puffer & $0.25 \mathrm{M}$ Tris-HCl pH 6.8 \\
\hline & $0.2 \%$ SDS \\
\hline SDS & $10 \%$ in $\mathrm{H}_{2} \mathrm{O}$ oder DMDC- $\mathrm{H}_{2} \mathrm{O}$ \\
\hline $\operatorname{SSC}(20 x)$ & $\mathrm{pH} 6.8$ \\
\hline & $0.3 \mathrm{M} \mathrm{Na}_{3}$ Citrat \\
\hline & $\mathrm{pH} 7.0$ und $\mathrm{pH} 4.5$ \\
\hline TBE $(5 x)$ & $0.45 \mathrm{M}$ Tris- $\mathrm{HCl}$ \\
\hline & $0.45 \mathrm{M}$ Borsäure \\
\hline & 10 mM EDTA \\
\hline & $\mathrm{pH} 8.2$ \\
\hline TE-Puffer & $10 \mathrm{mM}$ Tris-HCl pH 8.0 \\
\hline & $1 \mathrm{mM}$ EDTA \\
\hline TE-Puffer (low EDTA) & $10 \mathrm{mM}$ Tris-HCl pH 8.0 \\
\hline & $0.1 \mathrm{M}$ EDTA \\
\hline Trenngel-Puffer & 1.5 M Tris- $\mathrm{HCl} \mathrm{pH} 8.8$ \\
\hline & $0.4 \%$ SDS \\
\hline tRNA & $20 \mathrm{mg} / \mathrm{mL}$ in $\mathrm{DMDC}-\mathrm{H}_{2} \mathrm{O}$ \\
\hline X-Gal-Lösung & $2 \% \mathrm{X}$-Gal in Dimethylformamid \\
\hline
\end{tabular}

\subsection{Sterilisation}

Die Sterilisation von Lösungen erfolgte $20 \mathrm{~min}$ bei $120^{\circ} \mathrm{C}$ und $10^{5} \mathrm{~Pa}$ im Dampfdruckautoklaven (Webco, Bad Schwartau) oder durch Sterilfiltration (Sterilfilter, 0.2-0.45 $\mu \mathrm{m}$ Porengröße). Gebrauchswaren wurden entweder autoklaviert oder für $8-12 \mathrm{~h}$ bei $180^{\circ} \mathrm{C}$ hitzesterilisiert.

\subsection{Kulturmedien}

\subsubsection{Medien für Bakterien}
LB (Luria-Bertani)-Medium
$1 \%$ Select Pepton 


$\begin{array}{ll} & 0.5 \% \text { Select Yeast Extract } \\ & 1 \% \mathrm{NaCl} \\ & \mathrm{pH} 7.2 \\ \text { Zusätze zur Selektion } & \text { Ampicillin }(0.1 \mathrm{mg} / \mathrm{mL}) \\ \text { Zusätze für Oja-Platten } & \text { Kanamycin }(0.05 \mathrm{mg} / \mathrm{mL}) \\ & 100 \mu \mathrm{M} \mathrm{IPTG} \\ & 0.4 \% \text { X-Gal }\end{array}$

Agarplatten enthielten $1.5 \%(w / v)$ Agar

Die Medien wurden mit einfach destilliertem Wasser angesetzt und autoklaviert.

\begin{aligned} & \hline \multicolumn{2}{c}{ Stammlösungen } \\ & \hline $100 \mathrm{mg} / \mathrm{mL}$ Ampicillin in $\mathrm{H}_{2} \mathrm{O} \\ & 25 \mathrm{mg} / \mathrm{mL}$ Kanamycin in $\mathrm{H}_{2} \mathrm{O} \\ & 0.2 \mathrm{~g} / \mathrm{mL}$ IPTG in $\mathrm{H}_{2} \mathrm{O} \\ & 8 \%$ X-Gal in Dimethylformamid \\ & \hline\end{aligned}

Die Lösungen wurden sterilfiltriert und bei $-20^{\circ} \mathrm{C}$ gelagert. Antibiotika, IPTG und X-Gal wurden nach dem Autoklavieren des Mediums zu den abgekühlten Medien (ca. $50^{\circ} \mathrm{C}$ ) hinzugefügt. Platten und Flüssigmedien wurden bei $4^{\circ} \mathrm{C}$ gelagert.

\subsubsection{Medien für die Zellkultur}

Medien und Zusätze zur Anzucht eukaryotischer Zellen wurden als sterile Lösungen bezogen (Pan, Aidenbach; Gibco BRL, Eggenstein).

RI-ES-Zellmedium

EmFi-Fibroblasten-Zellmedium
DMEM (Dulbecco's Modified Eagle Medium)

$0.1 \mathrm{mM}$ nicht essentielle Aminosäuren

$1 \mathrm{mM}$ Natrium-Pyruvat

$1 \mu \mathrm{M} \beta$-Mercaptoethanol

2 mM L-Glutamin

$1000 \mathrm{U} / \mathrm{mL}$ LIF

DMEM

2 mM L-Glutamin

$10 \%$ FKS 
Zur Langzeitlagerung der Zellen in flüssigem Stickstoff wurden folgende Einfriermedien verwendet:

RI-ES-Zellen

$30 \%$ ES-Zellmedium

$50 \%$ FKS

$20 \%$ DMSO

EmFi-Zellen

$30 \%$ EmFi-Zellmedium

$50 \%$ FKS

$20 \%$ DMSO

\subsection{Biologisches Material}

\subsubsection{Bakterienstämme}

Es wurde mit folgenden Escherichia coli K12-Stämmen gearbeitet:

$\mathrm{DH} 5 \alpha$

Hanahan (1985)

XL1-blue

Bullock et al. (1987)

\subsubsection{Vektoren}

Es wurden folgende Vektoren verwendet:

pASK-IBA2

pBluescript ${ }^{\circledR}$ II SK (+/-)

pBluescript ${ }^{\circledR}$ II KS (+/-)

pGEM ${ }^{\circledR}-\mathrm{T}$

pGEM ${ }^{\circledR}-\mathrm{T}$ easy

Lawrist 7

pTKneo

pQE-32
IBA, Göttingen

Stratagene, Heidelberg

Stratagene

Promega, Wisconsin, USA

Promega

RZPD, Berlin

Dr. N. Brose, MPI für Experimentelle Medizin, Göttingen

Qiagen 


\subsubsection{Eukaryotische Zelllinien}

\begin{tabular}{lll}
\hline Zelllinie & isoliert aus & Referenz \\
\hline $\mathrm{RI}$ & Embryonale Stammzellen & Nagy et al. (1993) \\
$\mathrm{EmFi}$ & Embryonale Fibroblasten & Adham et al. (1997)
\end{tabular}

\subsubsection{Antikörper}

Es wurden folgende Antikörper verwendet:

Biotinylierter Ziege-Anti-Avidin-Antikörper, Serva

Anti-Digoxigenin-Alkalische Phosphatase-FAB-Fragmente, Roche

StrepTactin-Alkalische Phophatase-Konjugat, IBA

Polyklonaler Ziege-Anti-Maus-Alkalische Phosphatase-

konjugierter Antikörper, Invitrogen

\subsubsection{Oligonukleotide}

Alle in dieser Arbeit verwendeten Oligonukleotide wurden von der Firma Roth (Karlsruhe) synthetisiert und im lyophilisierten Zustand erworben, mit Ampuwa auf eine Konzentration von $100 \mu \mathrm{M}(100 \mathrm{pmol} / \mu \mathrm{L})$ eingestellt und als Stock bei $-20^{\circ} \mathrm{C}$ gelagert.

\begin{tabular}{|c|c|}
\hline Primer & Sequenz \\
\hline pTK R & $5^{-}$-AAC AGC TAT GAC CAT GAT TAC G-3 ${ }^{-}$ \\
\hline pTKneo F & $5^{-}$-ATT GTC TGA GTA GGT G-3- \\
\hline pTKneo R & $5^{-}$-GCG CGA ATT CGA TGA TCC TGA ACG GC-3- \\
\hline pTKneo R2 & $5^{-}$-CAG AGG TTA CGG CAG TTT GTC-3- \\
\hline MS3 F1 & $5^{-}-\mathrm{GCA}$ GAC AGC GGC AGC GAG A-3- \\
\hline MS3 R2 & $5^{-}$-GCT GAC TGG CTC GGC TTT AG-3- \\
\hline 1B7 F1 & $5^{-}$-GTC TCG GCG AAA GCA ACG-3- \\
\hline $1 \mathrm{~B} 7 \mathrm{R} 1$ & $5^{-}-\mathrm{TTT}$ AAG ACA AGG TTA CTG AG-3- \\
\hline 1B7 R2 & $5^{-}-\mathrm{CAC}$ GCA CAA CAC AGA CTC-3- \\
\hline 1B7 R3 & $5^{-}$-AGC CCA ATC CTT TTA GAG ACA $\mathrm{C}^{-} 3^{-}$ \\
\hline 1B5 R1 & $5^{-}$-CTC CCT GCC CTC AAG TC-3 \\
\hline 1B5 R2 & 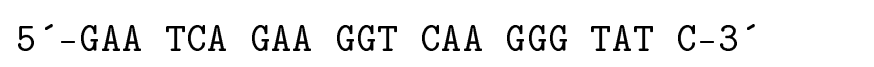 \\
\hline 1B7HB F1 & $5^{-}-\mathrm{TGG}$ ACC TGT GCT GAA CG-3 ${ }^{-}$ \\
\hline 1B7HB F2 & $5^{-}-\mathrm{TCT}$ GTG TAG TTT TGG CTG TCC T-3 \\
\hline
\end{tabular}




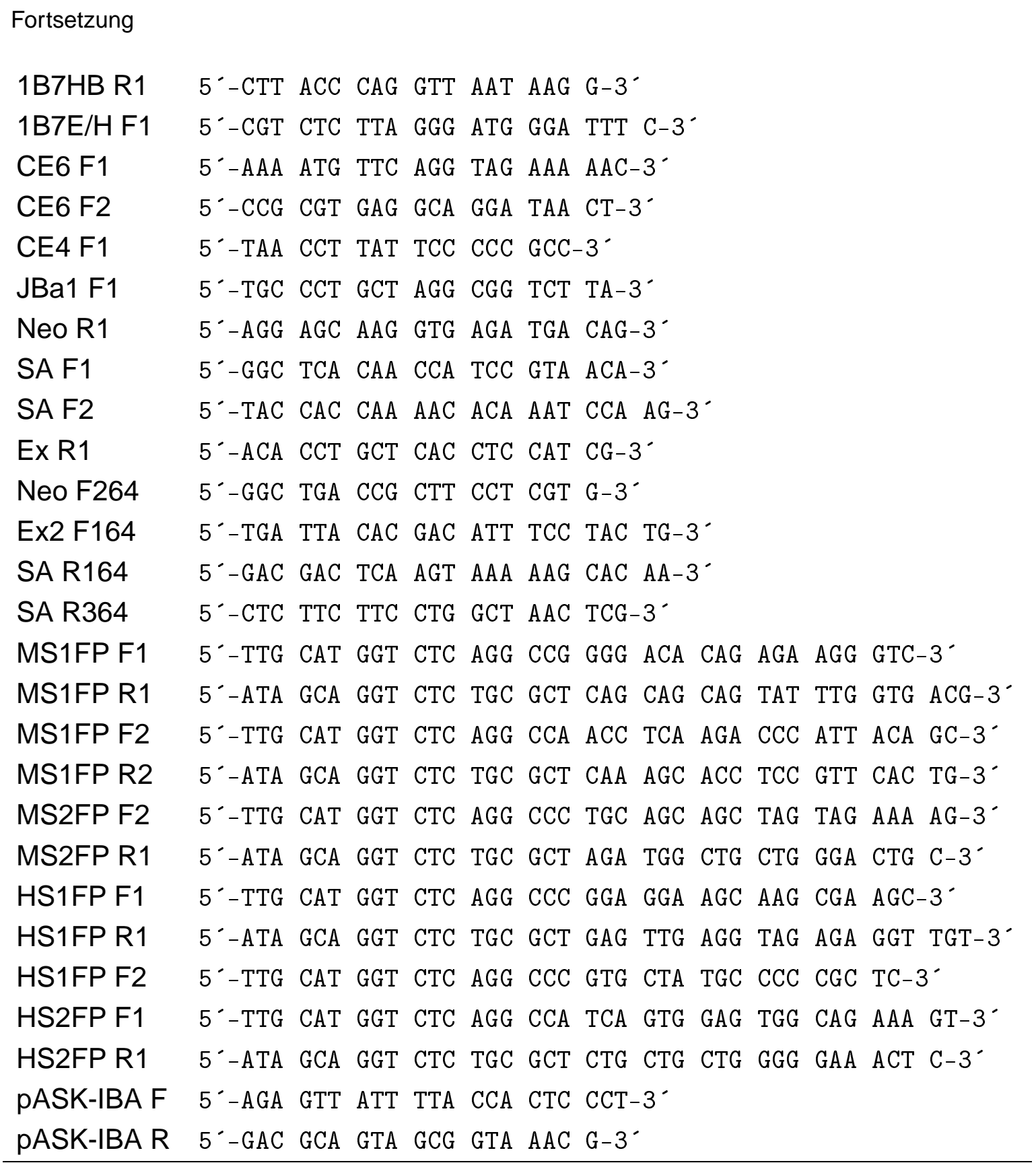

Tabelle 2.1: Verwendete Oligonukleotide

\subsubsection{Gensonden}

Die nachfolgende Tabelle erläutert die Verwendung, Herkunft und Größe sämtlicher in der Arbeit verwendeter Gensonden. Die Positionen der Sall1- und Sall2- 
Fragmente sowie die Startpunkte der Cosmide, soweit bekannt, sind in den Abbildungen 3.1 und 3.17 angegeben.

\begin{tabular}{|c|c|c|}
\hline Sonde & Verwendung & Herkunft \\
\hline 1B1 & $\begin{array}{l}\text { Screening der Cosmidbi- } \\
\text { bliothek } 121\end{array}$ & $\begin{array}{l}600 \text { bp Bam HI-Subklon } \\
\text { aus Cosmid } 7\end{array}$ \\
\hline 1B2 & $\begin{array}{l}\text { Nachweis von Sall2 in } \\
\text { Northern- und Southern- } \\
\text { Blots }\end{array}$ & $\begin{array}{l}1.1 \mathrm{~kb} \text { Bam HI-Subklon aus } \\
\text { Cosmid } 7 \text { (Kohlhase et al., } \\
\text { 2000) }\end{array}$ \\
\hline 1B6 & $\begin{array}{l}\text { Screening der Cosmidbi- } \\
\text { bliothek } 121\end{array}$ & $\begin{array}{l}2.4 \mathrm{~kb} \text { Subklon aus Cosmid } \\
7\end{array}$ \\
\hline CB3E & $\begin{array}{l}\text { Nachweis von Sall } 1 \text { bei in } \\
\text { situ-Hybridisierungen }\end{array}$ & $\begin{array}{l}2 \mathrm{~kb} \text { Bam } \mathrm{HI} / \mathrm{Eco} \text { RI- } \\
\text { Subklon aus Cosmid C }\end{array}$ \\
\hline $1 B 7 \mathrm{E} / \mathrm{H}$ & $\begin{array}{l}\text { Nachweis von homo- } \\
\text { log rekombinierten ES- } \\
\text { Zellklonen für den Sall2- } \\
\text { knock out }\end{array}$ & $\begin{array}{l}1.7 \mathrm{~kb} \text { Eco RI/Hind III- } \\
\text { Subklon aus } 1 \mathrm{~B} 7 \text { von } \\
\text { Cosmid } 7\end{array}$ \\
\hline c-son & $\begin{array}{l}\text { Hybridisierung der murinen } \\
\text { Cosmid-Bibliothek } 121\end{array}$ & $\begin{array}{l}\text { humanes PCR-Fragment } \\
\text { aus Exon } 2 \text { von SALL1 }\end{array}$ \\
\hline CBO & $\begin{array}{l}\text { Nachweis von Sall1 in } \\
\text { Northern-Blots }\end{array}$ & $\begin{array}{l}0.56 \mathrm{~kb} \text { Bam HI-Subklon } \\
\text { aus Cosmid C }\end{array}$ \\
\hline JBa1 X/E4 Bgl II & $\begin{array}{l}\text { Nachweis von homo- } \\
\text { log rekombinierten ES- } \\
\text { Zellklonen für den Sall1- } \\
\text { knock out }\end{array}$ & $\begin{array}{l}240 \text { bp-Subklon aus JBa1 } \\
\text { von Cosmid J }\end{array}$ \\
\hline CE 0.95480 & $\begin{array}{l}\text { Nachweis von Sall1 in } \\
\text { Northern-Blots }\end{array}$ & $\begin{array}{l}480 \text { bp Eco Rl/EcoO109 I- } \\
\text { Fragment aus Cosmid C }\end{array}$ \\
\hline CE 0.95440 & $\begin{array}{l}\text { Nachweis von Sall1 in } \\
\text { Northern-Blots }\end{array}$ & $\begin{array}{l}440 \text { bp Eco Rl/EcoO109 I- } \\
\text { Fragment aus Cosmid C }\end{array}$ \\
\hline Sall3 & $\begin{array}{l}\text { Nachweis von Sall3 bei in } \\
\text { situ-Hybridisierungen }\end{array}$ & $\begin{array}{l}1.7 \mathrm{~kb} \text { MS3 F1/MS3 R2 } \\
\text { PCR-Fragment }\end{array}$ \\
\hline Sall3 B 400 & $\begin{array}{l}\text { Nachweis von Sall3 im } \\
\text { RNAse Protection Assay }\end{array}$ & $\begin{array}{l}320 \mathrm{bp} \text { Bam HI-Fragment } \\
\text { aus pSall3 (Ott, 1995) }\end{array}$ \\
\hline$\beta$-Actin & $\begin{array}{l}\text { Kontrollhybridisierung von } \\
\text { RNA-Blots }\end{array}$ & $\begin{array}{l}1.6 \mathrm{~kb} \text { Not I/Sal I-Fragment } \\
\text { aus humanem RZPD-KIon }\end{array}$ \\
\hline
\end{tabular}


Fortsetzung

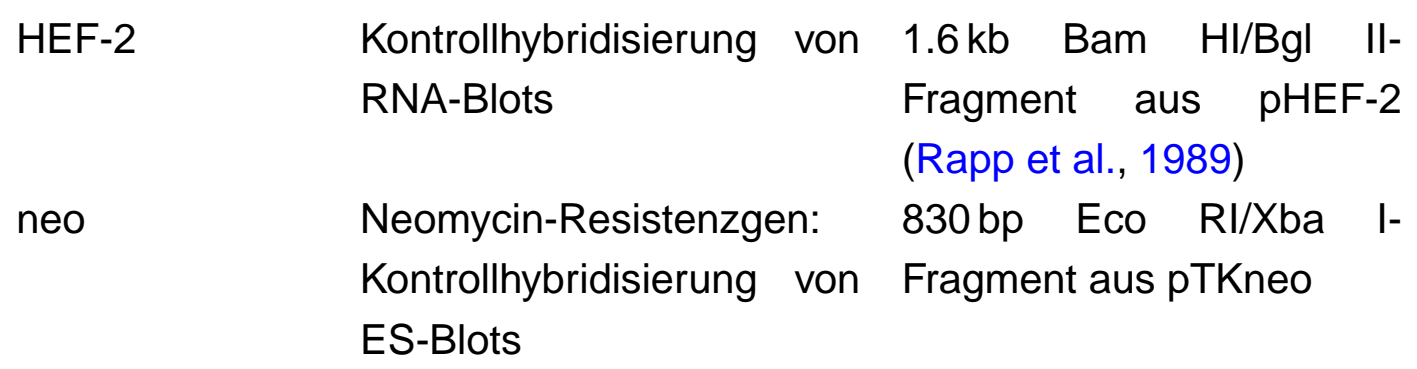

Tabelle 2.2: Gensonden

\subsubsection{DNA-Bibliothek}

Es wurde eine genomische Cosmid-Bibliothek von Mäusen des Stammes 129/Ola verwendet. Die Bibliothek (Nr. 121) wurde von der RZPD (Ressourcen-ZentrumPrimärdatenbank, Berlin) bezogen. Die genomischen Fragmente sind in den Vektor Lawrist 7 kloniert und in E.coli DH5 $\alpha$ transformiert.

\subsubsection{Mausstämme}

Für die Herstellung von Chimären und die Rückkreuzung auf Wildtyp-Stämme wurden die Mausstämme C57BL und 129/SvJ verwendet. Die Embryonen für die whole mount-in situ-Hybridisierung an Wildtyp-Mäusen wurden vom Stamm CD1 präpariert. Die Haltungsbedingungen bestanden aus einem $12 \mathrm{~h}$ Hell-DunkelRhythmus bei $22^{\circ} \mathrm{C}$ und $55 \pm 5 \%$ relativer Luftfeuchtigkeit.

\subsection{Molekulargewichtstandards}

$\begin{array}{ll}\text { DNA-Längenstandard }(1 \mu \mathrm{g} / \mu \mathrm{L}) & 100 \mathrm{bp}-\text { Leiter }(100-1500 \mathrm{bp}) \\ & 1 \mathrm{~kb}-\text { Leiter }(0.12-12.2 \mathrm{~kb}) \\ & 5 \mathrm{~kb}-\text { Leiter }(5-40 \mathrm{~kb}) \\ & \text { (Gibco BRL, Eggenstein) }\end{array}$

Die DNA-Längenstandards wurden nach Herstellerangaben verdünnt und mit Auftragspuffer 1 versetzt. 


$\begin{array}{ll}\text { RNA-Längenstandard }(1 \mu \mathrm{g} / \mu \mathrm{L}) & \text { RNA-Leiter }(0.24-9.5 \mathrm{~kb}) \\ & \text { (Gibco BRL) } \\ \text { SDS-Proteinmarker } & \text { SDS-Page Standard } \\ & \text { 10 kDa Protein-Leiter (10-200) kDa } \\ & \text { (Gibco BRL) } \\ & \text { Gefärbter SDS-Page Standard } \\ & \text { SeeBlue }{ }^{T M} \text { Plus2 (4-500 kDa) } \\ & \text { (Invitrogen, Groningen, Niederlande) }\end{array}$

\subsection{Nukleinsäuretechnische Methoden}

\subsubsection{Präparation von Nukleinsäuren}

\subsubsection{Minipräparation von Plasmid-DNA}

(Sambrook et al., 1989)

Diese Methode diente analytischen Zwecken und wurde nach einer modifizierten Form der alkalischen Lyse (Birnboim und Doly, 1979) durchgeführt. Von einer üN-Kultur wurde durch Behandlung mit den Puffern E1, E2 und E3 DNA isoliert, präzipitiert und in $\mathrm{H}_{2} \mathrm{O}$ aufgenommen. Anschließend wurde eine restriktionsenzymatische Spaltung und bei Bedarf eine Sequenzierung der isolierten Plasmid-DNA durchgeführt.

$\begin{array}{ll}\text { E1 (Resuspensionspuffer) } & 50 \mathrm{mM} \text { Tris-HCl pH8.0 } \\ & 10 \mathrm{mM} \text { EDTA } \\ & 100 \mu \mathrm{g} / \mu \mathrm{L} \text { RNase A } \\ \text { E2 (Lysispuffer) } & 0.2 \mathrm{M} \mathrm{NaOH} \\ & 1 \% \mathrm{SDS} \\ \text { E3 (Neutralisationspuffer) } & 3 \mathrm{M} \mathrm{KAc} \mathrm{pH} 5.5\end{array}$

\subsubsection{Herstellung von Glycerinkryokulturen}

Glycerinkryokulturen wurden aus den LB-üN-Kulturen der PlasmidMinipräparationen (s. 2.9.1.1) durch Zugabe von $300 \mu \mathrm{L}$ sterilem Glycerin zu $700 \mu \mathrm{L}$ der Bakteriensuspension hergestellt. Die Reaktionsgefäße wurden gut durchmischt und bei $-70^{\circ} \mathrm{C}$ gelagert. 


\subsubsection{Midi- und Maxipräparation von Plasmid-DNA}

Größere Mengen Plasmid-DNA wurden über DNA-Affinitätssäulen aus dem Jetstar Plasmid Midi- oder Maxi-Kit nach den Angaben der Hersteller aufgereinigt. Die Bakterien einer üN-Kultur wurden abzentrifugiert und die Plasmid-DNA durch Behandlung mit den Puffern des Kits und Aufreinigung über die mitgelieferte Säule aufgereinigt, präzipitiert und in $\mathrm{H}_{2} \mathrm{O}$ gelöst. Die Konzentration der DNA wurde photometrisch bestimmt.

\subsubsection{Endotoxin-freie Maxipräparation von Plasmid-DNA}

Für die Transfektion von DNA in eukaryotische Zellen wurde das Plasmid mit dem EndoFree Plasmid Maxi-Kit (Qiagen, Hilden) Endotoxin-frei präpariert. Dazu wurden $100 \mathrm{~mL}$ üN-Bakterienkultur abzentrifugiert und mittels alkalischer Lyse aufgeschlossen. Zelltrümmer, Proteine und Salzkomplexe wurden durch Filtration in der QIAfilter Maxi Cartridge abgetrennt, das Lysat über eine äquilibrierte Säule gegeben, die gebundene DNA gewaschen und in ein steriles, Endotoxin-freies Zentrifugenröhrchen aus Glas eluiert. Nach der Präzipitation mit 0.7 Vol Isopropanol wurde das Pellet mit $70 \%$ igem EtOH (hergestellt mit Endotoxin-freiem $\mathrm{H}_{2} \mathrm{O}$ aus dem Kit) gewaschen, luftgetrocknet und in 100-200 $\mu \mathrm{L}$ ebenfalls Endotoxin-freiem TE-Puffer aufgenommen.

\subsubsection{Isolierung genomischer DNA aus Geweben}

(nach Laird et al. (1991))

1-2 $\mathrm{g}$ Gewebe wurden zerkleinert und in $700 \mu \mathrm{L}$ Gewebe-Lysispuffer gemörsert. Für die Genotypisierung von Mäusen wurden 1-2 cm der Schwanzspitze 5 Wochen alter Mäuse mit $700 \mu \mathrm{L}$ Gewebe-Lysispuffer versetzt. Dazu wurden $30 \mu \mathrm{L}$ Proteinase $\mathrm{K}(10 \mu \mathrm{g} / \mu \mathrm{L})$ gegeben und dieser Ansatz üN bei $55^{\circ} \mathrm{C}$ im Thermomixer inkubiert. Nach einer Phenol/Chloroform-Extraktion wurde die DNA mit 1 Vol Isopropanol präzipitiert, mit $70 \%$ igem Ethanol gewaschen, in 100-200 $\mu \mathrm{L} \mathrm{H}_{2} \mathrm{O}$ gelöst und bei $4^{\circ} \mathrm{C}$ gelagert.

\subsubsection{Isolierung von Gesamt-RNA aus Geweben}

Gesamt-RNA für Northern-Blot-Analysen wurde aus unterschiedlichen Geweben der Maus isoliert. Da RNA besonders anfällig gegen Abbau durch RNasen ist, wurden alle Lösungen und das Millipore- $\mathrm{H}_{2} \mathrm{O}$ üN mit $0.1 \%$ DMDC inkubiert und 
autoklaviert und verwendete Glaswaren für $8-12 \mathrm{~h}$ bei $180^{\circ} \mathrm{C}$ erhitzt (s. 2.5). Die Arbeitsschritte wurden nach Möglichkeit auf Eis oder im Kühlraum durchgeführt.

$100 \mathrm{mg}$ frisches Gewebe wurde in ein $15 \mathrm{~mL}$ Falcon-Gefäß mit Total RNA Reagent (Biomol, Hamburg) gegeben. Das Gewebe wurde mit einem Dispergierwerkzeug (Ultraturrax) homogenisiert und die Suspension 5 min auf Eis inkubiert. Nach Zugabe von 0.2 Vol auf $4^{\circ} \mathrm{C}$ vorgekühltem Chloroform wurde der Ansatz vorsichtig invertiert und für weitere $5 \mathrm{~min}$ auf Eis inkubiert. Die Probe wurde anschlieBend mit $4000 \times \mathrm{g}$ bei $4^{\circ} \mathrm{C}$ für 10 min zentrifugiert. Aus dem wässrigen Überstand wurde die RNA mit 1 Vol Isopropanol gefällt, mit $70 \%$ igem Ethanol gewaschen und in DMDC- $\mathrm{H}_{2} \mathrm{O}$ gelöst. Nach der photometrischen Konzentrationsbestimmung und einem Integritätstest im denaturierenden Agarosegel (s. 2.9.8.3) wurde die RNA bei $-70^{\circ} \mathrm{C}$ gelagert.

\subsubsection{Bestimmung der Konzentration von Nukleinsäuren}

Die Konzentrationsbestimmung der Nukleinsäuren erfolgte in einem Spektrophotometer (Amersham Pharmacia Biotech, Freiburg). Es wurden die Extinktionen bei 230, 260, 280 und $320 \mathrm{~nm}$ gemessen und die Differenz $\mathrm{OD}_{260}-\mathrm{OD}_{320}$ sowie die Quotienten $\mathrm{OD}_{260} / \mathrm{OD}_{280}$ und $\mathrm{OD}_{260} / \mathrm{OD}_{320}$ ermittelt. Unter Zugrundelegung einer $\mathrm{OD}_{260}$ von 1 bei einer DNA-Lösung von $50 \mathrm{ng} / \mu \mathrm{L}$ (bzw. $40 \mathrm{ng} / \mu \mathrm{L}$ für RNA) wurden die entsprechenden Konzentrationen errechnet. Die Quotienten $\mathrm{OD}_{260} / \mathrm{OD}_{280}$ und $\mathrm{OD}_{260} / \mathrm{OD}_{320}$ sind ein Maß für die Protein- bzw. Salzkontamination und sollten $>1.8$ bzw. $>2.0$ sein.

\subsubsection{Enzymatische Modifikationen von Nukleinsäuren}

Alle enzymatischen Modifikationen wurden nach den etablierten molekularbiologischen Standardmethoden durchgeführt, wie sie z. B. in Sambrook et al. (1989) bzw. Ausubel et al. (1994) beschrieben sind.

\subsubsection{Restriktionsspaltung von Plasmid-DNA}

Plasmid-DNA wurde durch Restriktionsendonukleasen (RE) verschiedener Hersteller gespalten und weiter verarbeitet. Die Restriktionsansätze enthielten standardmäßig 1/10 Vol des vorgeschriebenen Enzympuffers und maximal 1/10 Vol an Enzym. Es wurden in der Regel 2-10 U RE/ $\mu$ g DNA eingesetzt. Für die simultane restriktionsenzymatische Spaltung mit zwei unterschiedlichen Enzymen wur- 
de, soweit möglich, ein mit beiden Enyzmen kompatibler Puffer eingesetzt, oder die DNA wurde zwischen den beiden Reaktionen präzipitiert, um einen Pufferwechsel zu ermöglichen. Neigten die RE zu unspezifischen Reaktionen, wurde

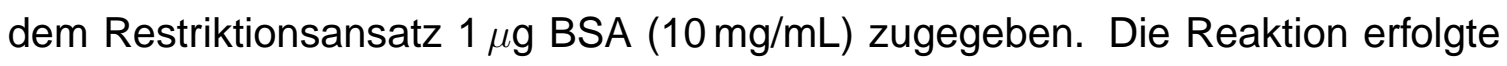
über 1-2 $\mathrm{h}$ im Temperaturoptimum des verwendeten Enzyms. Je nach weiterer Verwendung wurden die Reaktionsansätze auf ein Agarosegel aufgetragen, das Enzym durch Hitze $\left(10 \mathrm{~min}, 70^{\circ} \mathrm{C}\right)$ inaktiviert oder bei Verwendung von hitzeresistenten Restriktionsenzymen diese über eine Phenol/Chloroform-Extraktion und EtOH-Fällung entfernt.

\subsubsection{Restriktionsspaltung von genomischer DNA}

Für Southern-Blots wurden $20 \mu \mathrm{g}$ genomischer DNA in einem $50 \mu \mathrm{L}$ Reaktionsvolumen mit $5 \mu \mathrm{L}$ RE (50 U) für $2 \mathrm{~h}$ restringiert, nachfolgend das Reaktionsvolumen auf $60 \mu \mathrm{L}$ erhöht, weitere $3 \mu \mathrm{L}$ RE zugegeben und üN inkubiert. Die Vollständigkeit der Restriktion wurde auf einem Testgel durch Auftragung von $2 \mu \mathrm{L}$ des Ansatzes überprüft und bei Bedarf durch erneute Zugabe des entsprechenden RE die Reaktion fortgesetzt.

\subsubsection{Dephosphorylierung von Plasmid-DNA}

Bei diesem Verfahren werden Phosphat-Reste am 5'-Ende von DNA-Molekülen, die bei der restriktionsenzymatischen Spaltung (s. 2.9.3.1) entstehen, durch eine Alkalische Phosphatase (AP) entfernt. Dadurch wird die Religation von Vektoren verhindert und somit die Rate der rekombinanten Klone erhöht. Nach Restriktionsspaltung, Präzipitation und Aufnahme der Vektor-DNA in $\mathrm{H}_{2} \mathrm{O}$ wurde ein $30 \mu \mathrm{L}$-Reaktionsansatz mit $1 \mu \mathrm{L} \mathrm{AP}(1 \mathrm{U} / \mu \mathrm{L})$ und $1 / 10$ Vol AP-Puffer hergestellt. Um die optimale $\mathrm{Zn}^{2+}$-Konzentration für das Enzym zu erreichen, wurde soviel Verdünnungs-Puffer (Dilution Buffer, DB) dazu gegeben, dass AP + DB 1/10 des Reaktionsvolumens ergaben, und der Ansatz $1 \mathrm{~h}$ bei $37^{\circ} \mathrm{C}$ dephosphoryliert. Für $3^{\prime}$-überhängende oder glatte Enden wurden $2 \mu \mathrm{L} \mathrm{AP}$ eingesetzt und $1 \mathrm{~h}$ bei $50^{\circ} \mathrm{C}$ inkubiert. Darauffolgend wurde das Enzym für $10 \mathrm{~min}$ bei $70^{\circ} \mathrm{C}$ inaktiviert, die DNA präzipitiert, das Pellet in einer Endkonzentration von $50 \mathrm{ng} / \mu \mathrm{L}$ in $1 \mathrm{x}$ TE-Puffer aufgenommen und bei $-20^{\circ} \mathrm{C}$ gelagert. 


\subsubsection{Auffüllreaktion}

(Costa und Weiner, 1994)

Wurden für Klonierungen DNA-Fragmente mit glatten Enden (blunt ends) benötigt, um so nicht kompatible DNA-Überhänge in blunt end-vorbereitete Vektoren zu ligieren, wurden diese durch eine Reaktion mit der Pfu-Polymerase aufgefüllt. 50500 ng DNA wurden in $20 \mu \mathrm{L}$-Reaktionen mit $2 \mu \mathrm{L}$ Pfu-Puffer, $2 \mu \mathrm{L} 5 \mathrm{mM}$ dNTPs und $2 \cup$ Pfu-Enzym gemischt und $60 \mathrm{~min}$ bei $72^{\circ} \mathrm{C}$ inkubiert. Anschließend wurde die DNA mit Phenol/Chloroform extrahiert und präzipitiert.

\subsubsection{Radioaktive Markierung von Nukleinsäuren}

Für die radioaktive Markierung von DNA-Sonden wurde der Rediprime-Kit zum Einbau von $\left[\alpha^{-32}\right] \mathrm{P}$ dCTP oder der Hexalabel-Kit zum Einbau von $\left[\alpha^{-}{ }^{32}\right] \mathrm{P}$ dATP verwendet. Für die dCTP-Sonden wurden 2.5-25 ng DNA in $45 \mu \mathrm{L}$ TE-Puffer denaturiert, abgekühlt in das Reaktionsgefäß mit dem Rediprime-Pellet gegeben und nach Zugabe von $40 \mu \mathrm{Ci}\left[\alpha^{-32}\right] \mathrm{P} 10 \mathrm{~min}$ bei $37^{\circ} \mathrm{C}$ inkubiert. Der Ansatz wurde auf eine MicroSpin-Aufreinigungssäule aufgetragen und für 1 min bei $3000 x g$ zentrifugiert. Danach konnte die markierte Probe bei $4^{\circ} \mathrm{C}$ bis zur Verwendung gelagert oder sofort für $10 \mathrm{~min}$ bei $95^{\circ} \mathrm{C}$ denaturiert und verwendet werden.

Für dATP-Sonden wurden 100 ng DNA in $10 \mu \mathrm{L}$ Reaktionspuffer und $\mathrm{H}_{2} \mathrm{O}$ denaturiert, abgekühlt und nach Zugabe von dNTP-Mix (ohne dATP), [ $\left.\alpha^{-32}\right] \mathrm{P}$ dATP und Klenow-Fragment nach Angaben des Herstellers für 10 min bei $37^{\circ} \mathrm{C}$ inkubiert. Danach wurden $4 \mu \mathrm{L}$ dNTP-Mix dazugegeben, der Ansatz weitere 5 min bei $37^{\circ} \mathrm{C}$ inkubiert und die markierte Sonde über eine MicroSpin-Säule aufgereinigt.

\subsubsection{Isolierung von DNA-Fragmenten aus Agarosegelen}

Diese Methode wurde eingesetzt, um DNA-Fragmente zur Sequenzierung (s. 2.9.6) sowie für Hybridisierungs- (s. 2.9.3.5) und Klonierungsexperimente (s. 2.9.5) zu isolieren. Hierfür kamen die Fertigsysteme QIAquick Gel Extraction Kit und JETsorb Gel Extraction Kit zum Einsatz.

Die entsprechende DNA-Bande wurde nach gelelektrophoretischer Auftrennung (s. 2.9.8.1) auf einem Transilluminator unter langwelligem UV-Licht ( $366 \mathrm{~nm}$ ) mit einem sterilen Skalpell herausgeschnitten und nach Herstellerangaben isoliert. Sowohl im QIAquick- wie auch im JETsorb-Kit wurde die Agarose anschließend nach Zugabe einer hochmolaren Lösung des chaotropen Salzes Natriumperchlo- 
rat $\left(\mathrm{NaClO}_{4}\right)$ bei $50^{\circ} \mathrm{C}$ irreversibel aufgelöst und die DNA nach dem von Vogelstein und Gillespie (1979) beschriebenen Prinzip in Suspension (Glasmilch) oder in Säulen an Anionenaustauschersilikat gebunden, mehreren Waschschritten mit Hochsalzpuffer und Niedrigsalzpuffer unterzogen und mit Ampuwa- $\mathrm{H}_{2} \mathrm{O}$ oder TEPuffer eluiert. Ein Aliquot der aufgereinigten DNA wurde zur Konzentrationsbestimmung auf ein Agarosegel aufgetragen.

\subsubsection{Klonierung von DNA-Fragmenten}

\subsubsection{Ligation}

Die restriktionsenzymatisch gespaltenen (s. 2.9.3.1), isolierten (s. 2.9.4) und bei Bedarf aufgefüllten DNA-Fragmente (s. 2.9.3.4) konnten direkt in die komplementären Restriktionsschnittstellen des nötigenfalls dephosphorylierten PlasmidVektors (s. 2.9.3.3) ligiert werden. Dafür wurde das Verhältnis der DNA-Enden von Vektor und Fragment auf ca. 1:3 eingestellt und in einer $10 \mu \mathrm{L}$-Reaktion mit $2 \mu \mathrm{L}$ 5x Ligase-Puffer, $1 \mu \mathrm{L} 10 \mathrm{mM}$ ATP und $1 \mathrm{U}$ T4-DNA-Ligase vermischt. Der Ansatz wurde entweder 30 min bei RT oder üN bei $16^{\circ} \mathrm{C}$ inkubiert.

Zur Klonierung von PCR-Produkten wurde das pGEM-T oder das pGEM-T easy Vektorsystem genutzt. Das System enthält linearisierten Vektor mit 3'-TÜberhängen, die kompatibel zu den 3'-A-Überhängen von PCR-Produkten sind, die von den meisten DNA-Polymerasen erzeugt werden (Clark, 1988; Hu, 1993). Zur Ligation in diese Vektoren wurde üN bei $4^{\circ} \mathrm{C}$ inkubiert.

\subsubsection{Herstellung kompetenter E. coli-Zellen}

(nach Dagert und Ehrlich (1979))

$400 \mathrm{~mL}$ LB-Medium (15 $\mu \mathrm{g} / \mathrm{mL}$ Tetracyclin) wurden mit $10 \mathrm{~mL}$ einer üN-Kultur angeimpft und bis zu einer $\mathrm{OD}_{550}=0.5$ vermehrt. Die Kultur wurde auf Eis abgekühlt und nachfolgend bei $5000 \times \mathrm{g}$ für $12 \mathrm{~min}$ bei $4^{\circ} \mathrm{C}$ abzentrifugiert. Das Pellet wurde vorsichtig in $66 \mu \mathrm{L} R$ F1 resuspendiert und 20 min auf Eis inkubiert. Nach erneuter Zentrifugation wurde das Pellet in $16 \mathrm{~mL}$ RF2 aufgenommen und $15 \mathrm{~min}$ auf Eis inkubiert. Die kompetenten Zellen wurden aliquotiert, in flüssigem Stickstoff schockgefroren und bei $-70^{\circ} \mathrm{C}$ gelagert. 


\subsubsection{Transformation}

(Sambrook et al., 1989)

Für die Transformation eines Ligationsansatzes (s. 2.9.5.1) wurden $200 \mu \mathrm{L}$ kompetenter Zellen (s. 2.9.5.2) auf Eis aufgetaut, mit dem Ligationsansatz vermischt und 30 min auf Eis inkubiert. Der Ansatz wurde bei $42^{\circ} \mathrm{C}$ für $90 \mathrm{sec}$ einem Hitzeschock ausgesetzt und nach 2 min Inkubation auf Eis mit $200 \mu$ L LB-Medium versetzt. Die transformierten Bakterien wurden für $45 \mathrm{~min}$ bei $37^{\circ} \mathrm{C}$ unter Schütteln inkubiert, auf Selektionsplatten ausplattiert und üN bei $37^{\circ} \mathrm{C}$ inkubiert.

\subsubsection{Sequenzanalyse}

Die Sequenzierung wurde modifiziert nach dem Kettenabruchverfahren von Sanger et al. (1977) durchgeführt. Die modifizierte Methode beruht auf dem Prinzip der durch den Einbau von fluoreszenzfarbstoffmarkierten ddNTPs (Didesoxynukleosid-5'-triphosphate) statistisch unterbrochenen DNA-Synthese.

Die eingesetzte Menge der zu sequenzierenden Template-DNA wurde nach der Formel ng DNA $=x(b p) / 5$ berechnet. Die DNA wurde mit 10 pmol Sequenzprimer und $\mathrm{H}_{2} \mathrm{O}$ auf ein Vol von $16 \mu \mathrm{L}$ gebracht und mit $4 \mu \mathrm{L}$ BigDye-Mix oder DYEnamic ET-Mix gemischt. Die Ansätze wurden mit Mineralöl überschichtet und mit folgendem PCR-Programm im DNA Thermal Cycler 480 für 25 Zyklen sequenziert:

$$
\begin{array}{rll}
20 \mathrm{sec} & 98^{\circ} \mathrm{C} & \text { Denaturierung } \\
15 \mathrm{sec} & 50^{\circ} \mathrm{C} & \text { Anlagerung } \\
1 \mathrm{~min} & 60^{\circ} \mathrm{C} & \text { Verlängerung }
\end{array}
$$

Die PCR wurde standardmäßig mit vektorspezifischen Primern oder für die direkte Sequenzierung mit den Amplifikationsprimern durchgeführt.

Die Ansätze wurden gefällt und das getrocknete Pellet in Formamid-Ladepuffer (0.5 M EDTA pH 8.0: Formamid im Verhältnis 1:5) 5 min denaturiert. Nach der gelelektrophoretischen Auftrennung im $7 \%$ igen denaturierenden Polyacrylamidgel und der computergesteuerten Analyse in der automatischen Sequenzieranlage wurden die Daten als EDV-Datei gespeichert. Zur Analyse wurden das DNASISProgramm für PC und das MacMollyTetra ${ }^{\circledR}$ Software Paket für Apple Maclntosh Computer verwendet. Vergleiche mit den Sequenzdatenbanken EMBL und GenBank wurden mit Hilfe des BLAST-Programms (Altschul et al., 1998) über die entsprechenden www Server (z. B. NCBI Blast Notebook, http://www.ncbi.nlm.nih/) durchgeführt. 


\subsubsection{PCR-Techniken}

(Saiki et al., 1988)

Mit der Methode der PCR (Polymerase-Kettenreaktion) werden DNATemplates sequenzspezifisch amplifiziert. Dazu wird die DNA zuerst hitzedenaturiert (Denaturierung), darauf binden die Oligonukleotidprimer in einer Anlagerungsreaktion an den komplementären Strang (Anlagerung), und die Polymerase synthetisiert die DNA zwischen den Primern (Verlängerung). Die meist verwendete Platinum ${ }^{\circledR}$ Taq DNA Polymerase (Chien et al., 1976) verfügt über einen hitzelabilen Inhibitor, der während der Denaturierung inaktiviert wird und damit die Durchführung einer hot start PCR möglich macht, wodurch die Entstehung unspezifischer Amplifikate während des ersten Zyklus vermieden wird.

Es wurden zwei verschiedene Termocycler verwendet (s. 2.3.2), wobei entweder 0.2 oder $0.5 \mu \mathrm{L}$-Reaktionsgefäße verwendet und bei dem Thermocycler ohne Deckelheizung die Ansätze mit Mineralöl überschichtet wurden.

\subsubsection{PCR an Plasmid-DNA}

Eine PCR an Plasmid-DNA wurde durchgeführt um Fragmente zu erhalten, die nicht über eine restriktionsenzymatische Spaltung isoliert werden konnten. Dazu wurde folgender Reaktionsansatz hergestellt:

$$
\begin{array}{rl}
\mathrm{x} \mu \mathrm{L} & \text { Plasmid-DNA (30-500 ng) } \\
5 \mu \mathrm{L} & 10 x \text { Taq Polymerase Puffer } \\
1 \mu \mathrm{L} & \text { Primer } 1(10 \mathrm{pmol} / \mu \mathrm{L}) \\
1 \mu \mathrm{L} & \text { Primer } 2(10 \mathrm{pmol} / \mu \mathrm{L}) \\
1.5 \mu \mathrm{L} & \mathrm{MgCl}_{2}(50 \mathrm{mM}) \\
1 \mu \mathrm{L} & \text { dNTP-Lösung }(10 \mathrm{mM}) \\
0.5 \mu \mathrm{L} & \text { Taq Polymerase }(5 \mathrm{U} / \mu \mathrm{L}) \\
\cline { 1 - 1 } \text { ad } 50 \mu \mathrm{L} & \mathrm{H}_{2} \mathrm{O}
\end{array}
$$

Der Reaktionsansatz wurde folgendem Zyklus 15-35x im Thermocycler unterworfen:

$$
\begin{array}{llll}
30-60 \mathrm{sec} & 95 & { }^{\circ} \mathrm{C} & \text { Denaturierung } \\
15-30 \mathrm{sec} & 50-65 & { }^{\circ} \mathrm{C} & \text { Anlagerung } \\
30-90 \mathrm{sec} & 72 & { }^{\circ} \mathrm{C} & \text { Verlängerung }
\end{array}
$$


Vor Beginn des ersten Zyklus wurde die DNA 5 min bei $95^{\circ} \mathrm{C}$ denaturiert. An den letzten Zyklus schloss sich ein weiterer Verlängerungsschritt von 5 min bei $72^{\circ} \mathrm{C}$ an. Nach Abschluss der PCR wurde zur Kontrolle 1/10 des Ansatzes mit Auftragspuffer 2 gemischt, je nach Größe des erwarteten PCR-Produkts auf ein 1-1.5\%iges Agarosegel aufgetragen und elektrophoretisch aufgetrennt.

\subsubsection{PCR an genomischer DNA}

Zur Amplifikation spezifischer Sequenzen genomischer DNA wurde diese wie unter 2.9.1.5 beschrieben extrahiert und mit folgenden Substanzen in einem Reaktionsansatz zusammen gegeben:

$$
\begin{array}{rl}
\mathrm{x} \mu \mathrm{L} & \text { DNA }(300-500 \mathrm{ng}) \\
2 \mu \mathrm{L} & 10 x \text { Taq Polymerase-Puffer } \\
1 \mu \mathrm{L} & \text { Primer } 1(10 \mathrm{pmol} / \mu \mathrm{L}) \\
1 \mu \mathrm{L} & \text { Primer } 2(10 \mathrm{pmol} / \mu \mathrm{L}) \\
0.6 \mu \mathrm{L} & \mathrm{MgCl}_{2}(50 \mathrm{mM}) \\
1 \mu \mathrm{L} & \text { dNTP-Lösung }(10 \mathrm{mM}) \\
0.2 \mu \mathrm{L} & \text { Taq Polymerase }(5 \mathrm{U} / \mu \mathrm{L}) \\
\cline { 1 - 2 } \text { ad } 20 \mu \mathrm{L} & \mathrm{H}_{2} \mathrm{O}
\end{array}
$$

Für jede Primerkombination wurden die $\mathrm{MgCl}_{2}$ - und dNTP-Menge optimiert und optional DMSO zu der Reaktion zugegeben. Die Dauer des Verlängerungsschritts wurde nach der Länge des zu amplifizierenden Fragments gewählt ( $1 \mathrm{~kb} \approx 1 \mathrm{~min}$ ), die Anlagerungstemperatur nach dem Schmelzgrad der jeweiligen Primer. Die PCR begann mit einer initialen Denaturierung für 5 min bei $95^{\circ} \mathrm{C}$, der Zyklus wurde zumeist 35x wiederholt und nach dem letzten Zyklus ein weiterer Verlängerungsschritt für 5 min bei $72^{\circ} \mathrm{C}$ durchgeführt. Nach der Amplifikation wurde der gesamte Reaktionsansatz in einem 1\%igen Agarose-Gel aufgetrennt (s. 2.9.8.1).

\subsubsection{Analytische PCR an genomischer DNA von knock out-Mäusen}

Für die Genotypisierung von knock out-Mäusen wurde ein dritter Primer eingesetzt, so dass ein Wildtyp- und ein mutiertes Allel unterschiedlicher Länge amplifiziert werden konnten. Dazu wurde folgender Reaktionsansatz zusammen gegeben: 


$$
\begin{array}{cl}
\mathrm{x} \mu \mathrm{L} & \text { DNA (300-500 ng) } \\
2 \mu \mathrm{L} & \text { 10x Taq Polymerase-Puffer } \\
1 \mu \mathrm{L} & \text { Primer 1 (10 pmol } / \mu \mathrm{L}) \\
1 \mu \mathrm{L} & \text { Primer 2 (10 pmol } / \mu \mathrm{L}) \\
1 \mu \mathrm{L} & \text { Primer } 3(10 \mathrm{mM}) \\
0.6 \mu \mathrm{L} & \mathrm{MgCl}_{2}(50 \mathrm{mM}) \\
1 \mu \mathrm{L} & \mathrm{dNTP}^{2} \text { Lösung }(10 \mathrm{mM}) \\
0.2 \mu \mathrm{L} & \text { Taq Polymerase }(5 \mathrm{U} / \mu \mathrm{L}) \\
\hline \text { ad } 20 \mu \mathrm{L} & \mathrm{H}_{2} \mathrm{O}
\end{array}
$$

Die DNA wurde über 30 Zyklen nach folgendem Programm amplifiziert:

$$
\begin{array}{lll}
30 \mathrm{sec} & 94^{\circ} \mathrm{C} & \text { Denaturierung } \\
30 \mathrm{sec} & 64^{\circ} \mathrm{C} & \text { Anlagerung } \\
60 \mathrm{sec} & 72^{\circ} \mathrm{C} & \text { Verlängerung }
\end{array}
$$

Vor Beginn des ersten Zyklus erfolgte eine initiale Denaturierung für 5 min bei $94^{\circ} \mathrm{C}$, an den letzten Zyklus schloss sich ein weiterer Verlängerungsschritt von 5 min bei $72^{\circ} \mathrm{C}$ an. Nach der Amplifikation wurde der gesamte Reaktionsansatz in einem 1.5\%igen Agarose-Gel aufgetrennt (s. 2.9.8.1).

\subsubsection{Agarose-Gelelektrophorese}

\subsubsection{Horizontale Gelelektrophorese}

(Sambrook et al., 1989)

Die horizontale Gelelektrophorese wurde hauptsächlich bei Testgelen, Gelen für Restriktionskartierungen und Insertisolierungen eingesetzt. Je nach Größe der zu trennenden Fragmente wurden 0.8-2\%ige Gele in 0.5x TBE-Puffer hergestellt. Die DNA wurde mit Auftragspuffer 2 vermischt, aufgetragen und elektrophoretisch aufgetrennt. Die DNA-Gele wurden fotografisch dokumentiert und die aufgetrennte DNA bei Bedarf auf Nitrozellulose-Membran transferiert (s. 2.9.9.1). Die Größenbestimmung der DNA-Fragmente erfolgte durch den Vergleich mit der DNA-Leiter (s. 2.8).

\subsubsection{Vertikale Gelelektrophorese}

Die vertikale Gelelektrophorese wurde in einigen Versuchen zur Auftrennung der restriktionsenzymatisch gespaltenen genomischen DNA verwendet. Die geringere 
Dicke des Gels gewährleistet eine bessere Übertragung der DNA beim Blotten. Zum Abdichten der Innenkammer wurde ein 1.5\%iges Sockelgel aus Agarose gegossen und nach Aushärtung der Agarose ein $1 \%$ iges Gel darüber geschichtet. Als Lauf- und Gelpuffer wurde 1x E-Puffer benutzt. Die Elektrophorese wurde unter ständigem Umwälzen (Peristaltikpumpe Ismatec Sa, Zürich) des Laufpuffers durchgeführt.

\subsubsection{Denaturierende Gelelektrophorese}

(Hodge, 1994)

Für die Auftrennung von RNA wurden $1 \%$ ige Gele verwendet. Die Gele wurden wie unter 2.9.8.1 und 2.9.8.2 beschrieben in Horizontal- oder Vertikalkammern gegossen, wobei für die horizontale Elektrophorese 1x MOPS-Puffer und für die vertikale 1x E-Puffer verwendet wurde. Zusätzlich enthielten diese Gele $7.4 \%$ Formaldehyd, um die Rückbildung der Sekundärstrukturen der RNA während der Elektrophorese zu verhindern.

Die Proben (20 $\mu \mathrm{g}$ Gesamt-RNA) wurden mit 10x MOPS- oder E-Puffer, Formaldehyd (37\%) und Formamid (40\%) gemischt und 10 min bei $65^{\circ} \mathrm{C}$ denaturiert. Nach dem Abkühlen auf Eis wurden Auftragspuffer 2 und Ethidiumbromid zu der RNA gegeben und der Ansatz auf das Gel aufgetragen. Die Elektrophorese wurde bei $4^{\circ} \mathrm{C}$ und $65 \mathrm{~V}$ für $6-8 \mathrm{~h}$ durchgeführt.

\subsubsection{Transfertechniken von Nukleinsäuren}

\subsubsection{Southern-Blot}

(Southern, 1975)

Mit Hilfe des Southern-Transfers werden DNA-Fragmente im KapillarblottingVerfahren aus Agarosegelen auf Nitrocellulosemembranen oder Nylonmembranen transferiert. Sollten DNA-Fragmente $>10 \mathrm{~kb}$ aus Gelen transferiert werden, wurden die Gele zunächst für $15 \mathrm{~min}$ in $0.25 \mathrm{M} \mathrm{HCl}$ depuriniert, alle Gele wurden 15 min mit Denaturierungslösung und 15 min mit Neutralisierungslösung behandelt. Das Gel wurde luftblasenfrei auf die mit 20x SSC vorbehandelte Membran gelegt, unter der sich ein ebenfalls mit SSC getränktes Blotting-Papier sowie ca. 30 weitere, trockene Blotting-Papiere befanden. Auf das Gel wurden luftblasenfrei zwei weitere getränkte Blotting-Papiere gelegt und mit einem langen BlottingPapier die Verbindung zu zwei Puffertanks an zwei Seiten der Blot-Apparatur her- 
gestellt. Die Größen der jeweiligen Papiere und Membrane wurde so gewählt, dass sie genau die Gelgröße abdeckten.

Der Transfer erfolgte üN, anschließend wurde die Position der Geltaschen auf der Nitrocellulose markiert und die DNA durch eine Behandlung des Filters im UV-Stratalinker oder durch Backen $\left(2 \mathrm{~h}, 80^{\circ} \mathrm{C}\right)$ auf der Membran fixiert. Alternativ wurde für das Blotten genomischer DNA ein Turboblotter ${ }^{\mathrm{TM} M}$ (Schleicher \& Schüll, Dassel) nach den Angaben der Hersteller verwendet.

\subsubsection{Northern-Blot}

Die RNA aus dem denaturierenden RNA-Gel (s. 2.9.8.3) wurde direkt nach der Elektrophorese ohne weitere Vorbehandlung auf einen Nitrocellulosefilter transferiert und nach dem Transfer an die Membran fixiert. RNA-Längenstandard enthaltende Spuren wurden vom Filter abgeschnitten, die RNA 15 min in $5 \%$ Essigsäure auf der Membran fixiert und 10 min in Methylenblau (0.04\% in $0.5 \mathrm{M} \mathrm{NaAc}, \mathrm{pH} 5.2)$ angefärbt. Überschüssige Färbung wurde unter fließendem Wasser entfernt, bis die blaugefärbten RNA-Banden sichtbar wurden, und die Membran anschließend luftgetrocknet.

\subsubsection{Radioaktive Hybridisierungstechniken}

\subsubsection{Hybridisierung von Southern- und Northern-Blots}

(Denhardt, 1966)

Die DNA- bzw. RNA-Filter (s. 2.9.9.1 bzw. 2.9.9.2) wurden zur Absättigung unspezifischer Bindungen mit $15 \mathrm{~mL}$ Hybridisierungslösung 1 und $150 \mu \mathrm{L}$ denaturierter Lachsspermien-DNA ( $10 \mathrm{mg} / \mathrm{mL})$ für mindestens $2 \mathrm{~h}$ bei entsprechender Temperatur, die je nach Homologiegrad zwischen eingesetzter DNA-Sonde und zu hybridisierender DNA oder RNA zwischen $55-68^{\circ} \mathrm{C}$ gewählt wurde, vorhybridisiert. Die radioaktiv markierte DNA-Probe (s. 2.9.3.5) wurde im Thermomixer bei $95^{\circ} \mathrm{C}$ denaturiert, auf Eis gekühlt und der Hybridisierungslösung zugesetzt.

Die Hybridisierung erfolgte üN, anschließend wurde $15 \mathrm{~min}$ bei RT und $15 \mathrm{~min}$ bei Hybridisierungstemperatur mit 2x SSC und $0.1 \%$ SDS und nochmals bei Hybridisierungstemperatur mit $0.2 \times$ SSC und $0.1 \%$ SDS gewaschen. Die Filter wurden in PE-Folie eingeschweißt, in eine Autoradiografiekassette mit Verstärkerfolie eingelegt, ein Röntgenfilm bei $-70^{\circ} \mathrm{C}$ exponiert und nach 1-10 Tagen entwickelt. Alternativ wurde der Blot mit dem Phosphor-Imager-System nach 0.5-5 Tagen ausgewertet. 


\subsubsection{Hybridisierung der genomischen Cosmid-Bibliothek 129/Ola}

Die Hybridisierung der Cosmid-Bibliothek erfolgte nach den von der RZPD empfohlenen Bedingungen. Die 12 Cosmid-Filter wurden im Wasserbad je nach Homologie der Sonde zum gesuchten Klon bei $55-65^{\circ} \mathrm{C} 2 \mathrm{~h}$ in Hybridisierungslösung 2 mit $500 \mu \mathrm{L}$ Lachsspermien-DNA (10 mg/mL) vorhybridisiert. Nach Zugabe der denaturierten Sonde und Hybridisierung üN wurden die Filter 2x 20 min in $40 \mathrm{mM}$ Natriumphosphatpuffer, $0.1 \%$ SDS bei Hybridisierungstemperatur gewaschen, in PE-Folie eingeschweißt, autoradiographiert und die Signale nach Angaben der RZPD ausgewertet. Die berechneten Cosmid-Klone wurden bei der RZPD online bestellt (http://www.rzpd.de).

\subsubsection{In situ-Hybridisierungen}

In situ-Hybridisierungen an Embryonen wurden durchgeführt, um die räumliche und zeitliche Verteilung von Transkripten während der Embryonalentwicklung der Maus zu untersuchen. Zur genaueren Bestimmung der exprimierenden Zellen erfolgte eine Hybridisierung an Embryonen- oder Gewebsschnitten. Die im folgenden beschriebenen Protokolle wurden modifiziert nach Ausubel et al. (1994) durchgeführt und in der Arbeitsgruppe von Dr. A. Kispert im Max-Planck-Institut für Immunbiologie in Freiburg erlernt.

\subsubsection{Digoxygenin-Markierung von Nukleinsäuren}

Die in vitro-Transkripte wurden nach der Anleitung des DIG-RNA Labeling Kits markiert. Die zu markierende Template-DNA wurde über Phenol/ChloroformExtraktion und Ethanolfällung aufgereinigt. Die Reagenzien wurden in folgender Reihenfolge zum Reaktionsansatz pipettiert:

$$
\begin{array}{ll}
5 \mu \mathrm{L} & \text { DMDC- } \mathrm{H}_{2} \mathrm{O} \\
2 \mu \mathrm{L} & 10 x \text { Transkriptionspuffer } \\
2 \mu \mathrm{L} & \text { linearisierte Plasmid-DNA }(500 \mathrm{ng} / \mu \mathrm{L}) \\
2 \mu \mathrm{L} & 10 x \text { DIG NTP Labeling-Mix } \\
1 \mu \mathrm{L} & \text { RNase Inhibitor } \\
1 \mu \mathrm{L} & \text { RNA-Polymerase T3/T7/SP6 } \\
2 \mu \mathrm{L} & 0.2 \mathrm{M} \mathrm{DTT}
\end{array}
$$

Der Ansatz wurde $2 \mathrm{~h}$ bei $37^{\circ} \mathrm{C}$ inkubiert und das DNA-Template durch Inkubation mit $1 \mu \mathrm{L}$ DNAse für 15 min bei $37^{\circ} \mathrm{C}$ aus dem Ansatz entfernt. Die markierte 
RNA wurde durch Zugabe von $100 \mu \mathrm{L}$ DMDC- $\mathrm{H}_{2} \mathrm{O}, 10 \mu \mathrm{L} 4 \mathrm{M} \mathrm{LiCl}$ und $300 \mu \mathrm{L}$ EtOH gefällt, das Pellet getrocknet, mit $70 \%$ Ethanol/DMDC- $\mathrm{H}_{2} \mathrm{O}$ gewaschen und in $55 \mu \mathrm{L} \mathrm{DMDC}-\mathrm{H}_{2} \mathrm{O}$ gelöst. Ein $5 \mu \mathrm{L}$-Aliquot wurde auf ein nicht-denaturierendes TBE-Gel aufgetragen, fotografisch dokumentiert und daraus die einzusetzende Menge der DIG-markierten Sonde abgeschätzt.

\subsubsection{Präparation von Maus-Embryonen}

Weibliche NMRI-Mäuse bzw. Sall2-knock out-Mäuse wurden verpaart und am nächsten Morgen auf einen Vaginalpfropf als äußeres Zeichen für eine erfolgte Verpaarung kontrolliert. Die Embryonen wurden an den gewünschten Tagen post coitum (dpc; 7.5-14.5 Tage pc, für embryonale Gewebe 12.5-18.5 Tage pc) präpariert, 2x in DMDC-PBS gewaschen und üN in $4 \%$ PFA in PBT fixiert. Am nächsten Tag folgten zwei Waschschritte in PBT (je $5 \mathrm{~min}$ ) und eine aufsteigende Methanolreihe in PBT (25\%, 50\%, 75\%, 100\%), um das Gewebe zu entwässern. Nach zweimaliger Inkubation in $100 \%$ Methanol für je 5 min konnten die Embryonen bis zur weiteren Verwendung bei $-20^{\circ} \mathrm{C}$ in $100 \%$ Methanol gelagert werden.

\subsubsection{Whole mount-in situ-Hybridisierung}

Alle Schritte wurden in sterilen $20 \mathrm{~mL}$ Glas-Szintillationsgefäßen mit Schraubdeckel oder 12-Loch Zellkultur-Platten durchgeführt. Die Gefäße wurden auf einem Taumel-Rollenmischer bewegt, die Platten auf einer Laborwippe.

\subsection{Vorbehandlung der Embryonen}

Die Behandlung der Embryonen vor der Hybridisierung mit DIG-markierten RNASonden begann mit der Rehydrierung in einer absteigenden Methanolreihe in PBT (75\%, 50\%, 25\%) für je 5-10 min. Durch 2 Waschschritte in PBT für 10 min wurden die Methanolreste aus den Embryonen entfernt. Das Bleichen erfolgte in $6 \%$ $\mathrm{H}_{2} \mathrm{O}_{2}$ in PBT für $1 \mathrm{~h}$ bei RT, danach wurde erneut in PBT für $3 \times 5$ min gewaschen. Embryonen, die älter als $8.5 \mathrm{dpc}$ waren, wurden mit einer $0.5 \mathrm{~mm}$ Kanüle 1-2x im Kopfbereich punktiert, um eine unspezifische Einlagerung der Sonde in die Hohlräume zu vermeiden (probe trapping). Darauf folgte eine Behandlung mit Proteinase $\mathrm{K}(10 \mu \mathrm{g} / \mathrm{mL})$ bei RT in 12-Loch Zellkultur-Platten, durch die das Gewebe für die Sonde zugänglich gemacht wurde. Die Inkubationsdauer variierte abhängig vom Alter der Embryonen. 


$\begin{array}{lr}7.5 \text { und } 8.5 \text { dpc-Embryonen } & 1 \mathrm{~min} \\ 9.5 \mathrm{dpc}-E m b r y o n e n & 4 \mathrm{~min} \\ 10.5 \mathrm{dpc}-E m b r y o n e n & 6 \mathrm{~min} \\ 11.5 \mathrm{dpc}-E m b r y o n e n & 8 \mathrm{~min} \\ 12.5 \mathrm{dpc}-E m b r y o n e n & 10 \mathrm{~min} \\ 13.5 \mathrm{dpc}-E m b r y o n e n & 12 \mathrm{~min} \\ 14.5 \mathrm{dpc}-E m b r y o n e n & 14 \mathrm{~min}\end{array}$

Die Reaktion wurde durch 2x 10 min Waschen mit $2 \mathrm{mg} / \mathrm{mL}$ Glycin in PBT bei RT abgestoppt und die Embryonen danach $3 \times 5$ min bei RT in PBT gewaschen. Nach einer Postfixierung für 20 min bei RT in $4 \%$ PFA/0.2\% Glutardialdehyd in PBT und nachfolgenden $3 \times 5$ min in PBT wurden die Embryonen in ZellkulturPlatten übertragen und 5 min bei RT mit $1 \mathrm{~mL}$ Hybridisierungslösung 3 inkubiert. Mit frischer Hybridisierungslösung erfolgte darauf eine Vorhybridisierung für $1-2 \mathrm{~h}$ bei $70^{\circ} \mathrm{C}$ im Inkubator, wobei die Zellkultur-Platte in einer Feuchtkammer plaziert wurde. Die Hybridisierung wurde nach erneutem Wechsel der Hybridisierungslösung und Zugabe der DIG-RNA-Sonde üN bei $70^{\circ} \mathrm{C}$ durchgeführt.

\subsection{Waschschritte und Antikörper-Inkubation}

Die Embryonen wurden 3x 30 min in vorgewärmter Waschlösung I bei $70^{\circ} \mathrm{C}$ gewaschen, anschließend wieder in Szintillationsgefäße überführt und $3 x 5$ min bei RT mit TNT gewaschen. Darauf folgte eine Inkubation in den Zellkultur-Platten für $30 \mathrm{~min}$ mit $100 \mu \mathrm{g} / \mathrm{mL}$ RNase in TNT bei $37^{\circ} \mathrm{C}$, um nicht gebundene und damit einzelsträngige RNA abzubauen. Gewaschen wurde anschließend $5 \mathrm{~min}$ bei RT mit TNT/Waschlösung II (1:1), $3 \times 30$ min bei $65^{\circ} \mathrm{C}$ mit Waschlösung II und $3 \times 5$ min bei RT mit MAB. Zur Absättigung unspezifischer Bindungen wurden die Embryonen 2-3h in Zellkultur-Platten bei RT mit 10\% Schafserum in MAB/2\% Blocking Lösung I inkubiert, 1-2 mL Antikörperlösung mit Anti-DIG-Alkalische PhosphataseKonjugat (Roche Diagnostics) zugegeben und üN bei $4^{\circ} \mathrm{C}$ unter leichtem Schütteln inkubiert.

\subsection{Waschschritte und Farbreaktion}

Am nächsten Tag wurden die Embryonen wieder in Schraubdeckelgefäße überführt und zunächst $3 \times 10$ min bei RT mit MAB gewaschen, darauf erfolgte ein stündliches Wechseln der Waschlösung über den Tag und ein Waschschritt mit MAB bei $4^{\circ} \mathrm{C}$ üN. Danach wurde $3 \times 10$ min bei RT mit NTMT gewaschen und 
die Embryonen bei RT in Dunkelheit so lange in BM Purple inkubiert, bis die gewünschte Anfärbung erreicht war; falls nötig, erfolgte die Inkubation üN. Zum Abstoppen der Farbreaktion wurden die Embryonen $3 \times 5$ min bei RT in PBT pH 4.5 gewaschen und nachfolgend $1 \mathrm{~h}$ bei RT bis üN bei $4^{\circ} \mathrm{C}$ in $4 \% \mathrm{PFA} / 0.1 \%$ Glutardialdehyd fixiert. Zur Lagerung verblieben die Embryonen in PBT pH4.5, zur fotografischen Dokumentation wurden sie in $80 \%$ Glycerol/PBT und für die Anfertigung von Schnitten in 70\% Ethanol/isotonische Kochsalzlösung überführt.

\subsection{Gelatine-Einbettung}

Zur Anfertigung von Vibratom-Schnitten wurden die Embryonen zunächst in einen Gelatine-Block in einer Einbettungsform eingebettet. Dazu wurde in $2 \mathrm{~mL}$ der Gelatine-Lösung mit $120 \mu \mathrm{L}$ Glutardialdehyd (25\%) eine Polymerisierungsreaktion gestartet, kurz verrührt und luftblasenfrei in eine Einbettungsform überführt. Je nach Größe wurde ein Embryo nach 30-60 sec auf die polymerisierende Schicht verbracht und mit einer zweiten Gelatineschicht überdeckt. Nach ca. $1 \mathrm{~h}$ waren die Gelatineblöcke vollständig ausgehärtet und konnten im Vibratom auf 20-80 $\mu \mathrm{m}$ geschnitten werden. Zur Lagerung wurde Aqua Poly/Mount aufgetragen, luftblasenfrei ein Deckglas aufgelegt und die Objektträger bei $4^{\circ} \mathrm{C}$ für max. 1 Woche gelagert.

\section{Gelatinelösung}

$2.2 \mathrm{~g}$ Gelatine

$135 \mathrm{~g}$ Rinderserumalbumin

$90 \mathrm{~g}$ Saccharose in $450 \mathrm{~mL}$ PBS bei $65^{\circ} \mathrm{C}$ erhitzen

bis zum Lösen verrühren

fertige Lösung bei $-20^{\circ} \mathrm{C}$ lagern

\subsubsection{Herstellung von Paraffinschnitten}

Das frisch präparierte Material (Organe, Embryonen) wurde in PBS gewaschen, üN bei $4^{\circ} \mathrm{C}$ in PFA fixiert und erneut $2 \times 5$ min in PBS bei RT gewaschen. Durch eine aufsteigende Methanolreihe (s. 2.9.11.2) wurde das Gewebe entwässert und zur vollständigen Entfernung des Alkohols $3 \times 15$ min in Xylol inkubiert. Für die Einbettung wurde eine Paraffin-Einbettungsstation genutzt. Nach Aushärtung des Blocks wurde das Material in einem Mikrotom auf $7 \mu \mathrm{m}$ geschnitten und auf Superfrost-Objektträger überführt. Paraffinblöcke und Schnitte wurden bei $4^{\circ} \mathrm{C}$ gelagert. 


\subsubsection{In situ Hybridisierung von Schnittpräparaten}

\subsection{Vorbehandlung und Hybridisierung}

Die Embryonen- oder Gewebsschnitte wurden zunächst 2x 10 min in Xylol bei RT deparaffiniert, $5 \mathrm{~min}$ in Methanol gewaschen und durch eine absteigende Methanolreihe in DMDC- $\mathrm{H}_{2} \mathrm{O}(75 \%, 50 \%, 25 \%)$ rehydriert. Nach einem Waschschritt in PBS für 5 min wurden die Schnitte durch Inkubation für 20 min in 4\% PFA in PBS postfixiert. Darauf folgten 2x 5 min Waschen mit PBS bei RT und eine Behandlung mit Proteinase $\mathrm{K}(10 \mu \mathrm{g} / \mathrm{mL})$ in $0.1 \mathrm{M}$ Tris $\mathrm{pH} 7.5$ bei $37^{\circ} \mathrm{C}$ für $15 \mathrm{~min}$, um das Gewebe für die Hybridisierung durch die DIG-RNA-Sonde zugänglich zu machen. Diese Reaktion wurde durch $0.2 \%$ Glycin in PBS abgestoppt, in dem die Schnitte $1 \times 10$ min bei RT inkubiert wurden. Nach 2 Waschschritten für 5 min in PBS wurden die Schnitte acetyliert. Dazu wurden die Objektträger in eine Küvette mit $0.25 \%$ Essigsäureanhydrid überführt, unter heftigem Rühren $0.1 \mathrm{M}$ Triethanolamin ( $\mathrm{pH}$ 8.0) zugegeben und $10 \mathrm{~min}$ bei RT inkubiert. Es folgten 2 Waschschritte in PBS und DMDC- $\mathrm{H}_{2} \mathrm{O}$ für je 5 min bei RT, anschließend wurden die Schnitte für $2 \mathrm{~h}$ bei $65^{\circ} \mathrm{C}$ mit je $100 \mu \mathrm{L}$ Hybridisierungslösung 3 vorhybridisiert. Für die Hybridisierung wurde $50 \mu \mathrm{L}$ frische Hybridisierungslösung mit DIG-markierter Sonde (s. 2.9.11.1) dazugegeben und die Schnitte mit einem sterilem Deckglas abgedeckt und mit Fotoklebstoff umrandet, um ein Verdunsten der Lösung zu vermeiden. Die Hybridisierung erfolgte üN bei $65^{\circ} \mathrm{C}$ in einer Feuchtkammer mit DMDC$\mathrm{H}_{2} \mathrm{O}$.

\subsection{Waschschritte und Antikörper-Inkubation}

Der Fotoklebstoff wurde entfernt, die Schnitte $3 \times 30$ min in vorgewärmter Waschlösung I bei $65^{\circ} \mathrm{C}$ inkubiert und $3 \times 5$ min mit TNT bei RT gewaschen. Um den Hintergrund zu reduzieren, folgte eine Behandlung mit $100 \mu \mathrm{L}$ RNase $(100 \mu \mathrm{g} / \mathrm{mL})$ in TNT für $30 \mathrm{~min}$ bei $37^{\circ} \mathrm{C}$ um den Hintergrund zu reduzieren und darauf ein Waschschritt für 5 min mit TNT/Waschlösung II (1:1) bei RT. Die 3 Waschschritte mit Waschlösung II wurden für 30 min bei $65^{\circ} \mathrm{C}$ durchgeführt. Zur Vorhybridisierung wurden die Objektträger in MAB/2\% Blocking-Lösung I mit 10\% Schafserum für 2-3 h bei RT inkubiert, darauf $200 \mu \mathrm{L}$ Antikörper-Lösung zugegeben, die Schnitte mit einem Deckglas abgedeckt und in einer Feuchtkammer bei $4^{\circ} \mathrm{C}$ üN inkubiert. 


\subsection{Waschschritte und Farbreaktion}

Die Schnitte wurden zunächst 3x 10 min bei RT mit MAB, anschließend 3x 10 min mit NTMT bei RT gewaschen. $100 \mu \mathrm{L}$ Färbelösung wurden auf die Objektträger gegeben und unter gelegentlicher Überprüfung unter einem Mikroskop so langeinkubiert, bis die gewünschte Farbintensität erreicht war. Zum Abstoppen der Reaktion wurde $2 \times 10$ min mit PBS bei RT gewaschen, die Fixierung erfolgte für $45 \mathrm{~min}$ bei RT in MEMFA. Die Schnitte wurden 2x 5 min in PBS bei RT gewaschen und zur Lagerung bei $4^{\circ} \mathrm{C}$ mit Aqua Poly/Mount überschichtet.

\subsubsection{Herstellung von Embryo-Pulver}

(Harlow und Lane, 1988)

Das Maus-Embryo-Pulver wurde verwendet, um unspezifische Antikörper, die mit Maus-Antigenen reagieren und den Hintergrund erhöhen können, aus der Antikörper-Lösung zu entfernen. Zur Herstellung wurden ca. 6014.5 dpcEmbryonen aus 5 Mäusen in DMDC-PBS auf Eis mit einem Dispergierwerkzeug homogenisiert und mit $4 \times \mathrm{Vol} 4^{\circ} \mathrm{C}$ kaltem Aceton versetzt. Das Gemisch wurde kräftig geschüttelt und 30 min auf Eis unter gelegentlichem Schütteln inkubiert. Nach Zentrifugation bei $10000 \times \mathrm{g}$ für $10 \mathrm{~min}$ wurde der Überstand verworfen und das pelletierte Präziptitat in kaltem Aceton gelöst. Erneut wurde kräftig geschüttelt, für 10 min auf Eis inkubiert und bei $10000 x \mathrm{~g}$ für 10 min zentrifugiert. Das Pellet wurde auf einem Filterpapier ausgestrichen und während der Trocknungszeit bei RT wiederholt mit einem Spatel gemischt und verstrichen. Das Embryo-Pulver wurde bei $-20^{\circ} \mathrm{C}$ in einem luftdichten Behälter gelagert. Vor Benutzung erfolgte eine Hitzeinaktivierung endogener Alkalischer Phosphatasen durch Inkubation bei $70^{\circ} \mathrm{C}$ für $30 \mathrm{~min}$ in $\mathrm{MAB} / \mathrm{B}$ lock-Puffer.

\subsubsection{Fotografische Auswertung}

Die in situ-gefärbten Embryonen und Schnittpräparate wurden mit einem Fotostereomikroskop und/oder Fotomikroskop mit Hilfe der Analysis ${ }^{\circledR}$-Software und einer digitalen Kamera fotografiert und die Bilder mit den Programmen Corel PhotoPaint und Microsoft PowerPoint bearbeitet. 


\subsubsection{Fluoreszenz-in situ-Hybridisierung (FISH)}

(Koehler et al., 1996)

Die chromosomale Lokalisation des murinen Sall1-Gens erfolgte über mit Hilfe der Fluoreszenz-in situ-Hybridisierung. Die Methode beruht auf der Hybridisierung von Chromosomenpräparaten mit Biotin-markierten einzelsträngigen DNAFragmenten an komplementäre Sequenzen auf den denaturierten Chromosomen. Ein Fluoreszenzfarbstoff-gekoppeltes Antikörpersystem ermöglicht die Detektion des Hybridisierungsergebnisses bei gleichzeitiger Verstärkung des Signals. Die in dieser Arbeit verwendeten Maus-Metaphasenpräparate der WMP-1-Zelllinie (Zörnig et al., 1995) von neugeborenen WMP-Mäusen Chromosomen, die die Robertsonsche Translokation tragen (Said et al., 1986), wurden freundlicher Weise von Dr. C. Dixkens angefertigt und zur Verfügung gestellt.

\subsection{Markierung der Sonde über Nick-Translation}

(Rigby et al., 1977)

Für die Markierung großer genomischer Fragmente mit markierten Desoxyribonukleotiden wird die Methode der Nick-Translation angewandt. Hierbei setzt eine Desoxyribonuklease I (DNase I) Einzelstrangbrüche (nicks) in die doppelsträngige DNA, die durch eine Klenow-Polymerase unter Einbau von im Überschuss zugesetztem Biotin-16-dUTP wieder komplettiert wird. Zeitgleich kommt es durch die DNAse I zur Fragmentierung des DNA-Templates, so dass markierte Fragmente von 200-600 bp Länge entstehen. Diese Länge gewährleistet eine gute Diffusionsfähigkeit durch Chromosomenmatrix zu den Zielsequenzen und eine spezifische Hybridisierung.

Hier wurde als Sonde für die Hybridisierung von Maus-Chromosomenpräparaten murine genomische DNA aus dem Cosmidklon $C$ eingesetzt, die mittels Nick-Translation mit Biotin-16-dUTP in folgendem Reaktionsansatz markiert wurde:

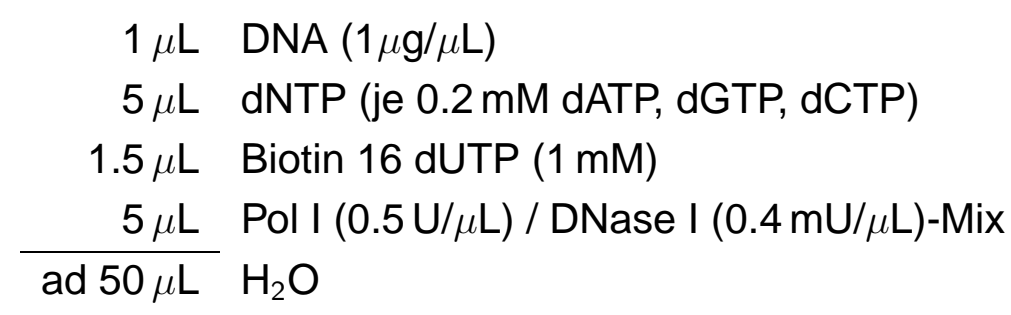

Nach 90 min Inkubation wurde ein Aliquot von $8 \mu \mathrm{L}$ auf ein $1.6 \%$ iges Agarosegel (s. 2.9.8.1) aufgetragen und der Fragmentlängenbereich bestimmt. Bei einer 
mittleren Fragmentlänge von 200-600 bp wurde die Sonde mit $10 \mu \mathrm{g}$ Lachs-DNA (zur Absättigung von unspezifischen Sequenzen, siehe Lichter et al. (1988); Pinkel et al. (1986)) und $4 \mu \mathrm{g}$ Cot1-DNA (zur Absättigung von hochrepetitiven Sequenzen) präzipitiert und das gewaschene Pellet in Mastermix (8\% Dextransulfat in 4x SSC) und Formamid ( $\mathrm{pH} 7.0)$ gelöst. Bei einer deutlich größeren mittleren Fragmentlänge wurde die Inkubationszeit bei $16^{\circ} \mathrm{C}$ verlängert oder erneut $50 \mu \mathrm{L}$ Markierungsansatz ohne DNA zugegeben, weitere 30 min inkubiert und der Fragmentlängentest wiederholt.

\subsection{Vorbehandlung und Hybridisierung}

Die Proben-DNA wurde bei $75^{\circ} \mathrm{C}$ im Heizblock denaturiert, zur Absättigung der hochrepetitiven DNA-Sequenzen bei $37^{\circ} \mathrm{C}$ vorhybridisiert und auf die denaturierten Chromosomenpräparate gegeben. Die Objektträger wurden mit einem Deckglas abgedeckt, mit Fotoklebstoff umrandet und üN bei $37^{\circ} \mathrm{C}$ in einer Feuchtkammer hybridisiert.

\subsection{Waschschritte und Antikörper-Inkubation}

Durch die Bindung von Fluorochrom-gekoppeltem Avidin an Biotin kann die biotinmarkierte Sonde nach der Hybridisierung unter dem Fluoreszenzmikroskop sichtbar gemacht werden. Als Fluorochrom wurde FITC (Fluorescein-5-isothiocyanat) verwendet, dessen Signal über ein Verstärkungssystem verstärkt wird. Dazu wurde das Biotin-Signal im ersten Detektionsschritt mit einer Avidin-FITC-Lösung und im zweiten und dritten Detektionsschritt mit einem biotinylierten anti-Avidin markiert und darauf erneut mit Avidin-FITC verstärkt, wie im Folgenden kurz erläutert.

Die Objektträger wurden 1x in 2xSSC, 3x 10 min in $50 \%$ Formamid/2x SSC und nochmal $3 \times 5 \mathrm{~min}$ in $2 \times \mathrm{SSC}$ gewaschen und für $30 \mathrm{~min}$ bei $37^{\circ} \mathrm{C}$ in BlockingLösung I inkubiert. Die Detektion der gebundenen Sonde erfolgte über eine Antikörper-Reaktion mit FITC-Avidin, das 1:200 in 1\% BSA/4x SSC/0.1\% Tween $(\mathrm{pH} 7.0)$ verdünnt wurde. Die Lösung wurde auf die Objektträger aufgetragen, $30 \mathrm{~min}$ bei $37^{\circ} \mathrm{C}$ in einer Feuchtkammer inkubiert und anschließend $3 \times 5 \mathrm{~min}$ in $4 \times \mathrm{SSC} / 0.1 \%$ Tween bei $45^{\circ} \mathrm{C}$ gewaschen. Die Verstärkung des Signals erfolgte durch einen zweiten Antikörperschritt mit biotinyliertem Anti-Avidin, 1:100 in 1\% $\mathrm{BSA} / 4 \mathrm{x} \mathrm{SSC} / 0.1 \%$ Tween verdünnt. Die Inkubation wurde für $45 \mathrm{~min}$ bei $37^{\circ} \mathrm{C}$ in einer Feuchtkammer durchgeführt, die Waschschritte erfolgten bei $45^{\circ} \mathrm{C} 3 \mathrm{x}$ in 4x SSC/0.1\% Tween. Anschließend wurde der Biotinnachweis mit FITC-Avidin wiederholt. 


\subsection{Gegenfärbung der Chromosomen}

Im Anschluss an den Immunfluoreszenz-Nachweis wurden die Chromosomenpräparate mit Propidiumjodid (PI) und DAPI $(3 \mu \mathrm{g} \mathrm{PI}$ und $70 \mu \mathrm{g}$ DAPI in $70 \mathrm{~mL}$ 4x SSC/0.1\% Tween, Lin et al. (1977)) für 5-10 min bei RT gegengefärbt. Diese Substanzen binden ausschließlich an DNA und bilden stark fluoreszierende Farbkomplexe. Nachfolgend wurden die Objektträger $4 x$ kurz in $\mathrm{H}_{2} \mathrm{O}$ gewaschen, luftgetrocknet und mit einer Antifading-Lösung (Johnson und Nogueira Araujo, 1981) überschichtet. Die Auswertung der Chromosomenpräparate erfolgte mit einem Zeiss Axiophot-Fluoreszenzmikroskop mit Filterradkombination.

\subsection{Proteinchemische Methoden}

\subsubsection{Herstellung der Strep-tag-Fusionsproteine}

Zur Gewinnung spezifischer Antikörper bzw. zur Aufreinigung der bereits vorhandenen Antiseren sollten Fusionsproteine in Bakterien erzeugt werden. Hierzu wurde das Recombinant Protein Expression and Purification Kit von IBA verwendet.

Der pASK-IBA2-Vektor trägt nach dem Polylinker eine Strep-tag II-Sequenz, die bei Expression der klonierten cDNA C-terminal das Strep-tag II-Peptid $\mathrm{NH}_{2}$ WSHPQFEK-COOH an das Protein fusioniert. Dadurch kann das Fusionsprotein in einem Schritt mittels Chromatographie an immobilisiertem StrepTactin von den bakteriellen Proteinen abgetrennt und über das mit der Alkalischen Phosphatase (AP)-konjugierte StrepTactin im Western-Blot detektiert werden.

Die Expressionskassette des pASK-IBA2-Vektors steht unter der Kontrolle des tetA-Resistenzgens, das nach Zugabe von geringen, nicht antibiotisch wirksamen Konzentrationen an Anhydrotetracyclin (AHT) die Expression der klonierten cDNA induziert. In Abwesenheit des Induktors wird der Promotor durch das ebenfalls auf dem Vektor kodierte tet-Repressorgen reprimiert, um einen Wachstumsnachteil der Bakterien durch die Produktion des Fremdproteins zu vermeiden. Da der tetA-Promotor/Operator keinen weiteren zellulären Regulationsmechanismen unterliegt, kann weitestgehend jeder $E$. coli-Bakterienstamm verwendet werden. In der vorliegenden Arbeit wurde der Stamm DH5 $\alpha$ genutzt. 


\subsubsection{Klonierung der Plasmide}

Der Polylinker des pASK-IBA2-Vektors trägt u. a. die Restriktionsschnittstelle Bsa I. Das Enzym produziert bei der Restriktion zwei verschiedene Enden, so dass das Fragment gerichtet in den Vektor kloniert werden kann. Dazu muss die entsprechende cDNA mit zwei Primern, die die Erkennungssequenz für das Enzym enthalten, amplifiziert werden.

Zur Klonierung der verschiedenen cDNA-Fragmente wurden genspezifische Primer mit 5'-angefügten artifiziellen Bsa I-Schnittstellen mit einer Schmelztemperatur von je $64^{\circ} \mathrm{C}$ hergestellt. Um den Einbau von nicht komplementären Nukleotiden in das PCR-Produkt zu vermeiden, wurde die proof reading Pfu turbo-Polymerase von Stratagene verwendet. Folgende Substanzen wurden in ein $200 \mu$ L-Reaktionsgefäß pipettiert:

$$
\begin{array}{rl}
\mathrm{x} \mu \mathrm{L} & \text { Plasmid-DNA }(20-200 \mathrm{pg}) \\
5 \mu \mathrm{L} & 10 \mathrm{x} \text { Pfu-Polymerase-Puffer } \\
2.5 \mu \mathrm{L} & \text { Primer } 1(10 \mathrm{pmol} / \mu \mathrm{L}) \\
2.5 \mu \mathrm{L} & \text { Primer } 2(10 \mathrm{pmol} / \mu \mathrm{L}) \\
2.5 \mu \mathrm{L} & \mathrm{MgCl}_{2}(50 \mathrm{mM}) \\
1 \mu \mathrm{L} & \text { dNTP-Lösung }(10 \mathrm{mM}) \\
1 \mu \mathrm{L} & \text { Pfu-Polymerase }(2.5 \mathrm{U} / \mu \mathrm{L}) \\
\cline { 1 - 2 } 50 \mu \mathrm{L} & \mathrm{H}_{2} \mathrm{O}
\end{array}
$$

Die PCR wurde im GeneAmp-Thermocycler nach folgendem Schema durchgeführt:

$$
\begin{array}{lll}
30 \mathrm{sec} & 94^{\circ} \mathrm{C} & \text { Denaturierung } \\
30 \mathrm{sec} & 64^{\circ} \mathrm{C} & \text { Anlagerung } \\
60 \mathrm{sec} & 72^{\circ} \mathrm{C} & \text { Verlängerung }
\end{array}
$$

Die Ansätze wurden einer initialen Denaturierung bei $95^{\circ} \mathrm{C}$ für 3 min unterworfen, der Zyklus 35x wiederholt und die Ansätze nachfolgend für 5 min bei $72^{\circ} \mathrm{C}$ inkubiert. Nach der Auftrennung in einem Agarosegel (s. 2.9.8.1) wurden die amplifizierten Fragmente isoliert (s. 2.9.4) und mit Bsal restriktionsenzymatisch gespalten. Nach Konzentrationskontrolle auf dem Gel erfolgte die Klonierung in den

vorher mit Bsa I linearisierten pASK-IBA2-Vektor (s. 2.9.5.1) und die Überprüfung der amplifizierten DNA mittels Sequenzanlayse durch vektorspezifische Primer (s. 2.9.6). 


\subsubsection{Zellwachstum, Genexpression und Präparation des Zellextrakts}

Als Wirtsstamm für die Expression wurde der E. coli-Stamm $\mathrm{DH} 5 \alpha$ verwendet. $5 \mathrm{~mL}$ LB-Medium $(100 \mu \mathrm{g} / \mathrm{mL}$ Ampicillin) wurden mit einer frisch ausplattierten Einzelkolonie des transformierten Expressionstammes angeimpft und üN bei $30-37^{\circ} \mathrm{C}$ inkubiert. Am nächsten Morgen wurden 2x $100 \mathrm{~mL}$ LB-Medium (100 $\mathrm{g} / \mathrm{mL}$ Ampicillin) mit je $2.5 \mathrm{~mL}$ der Vorkultur angeimpft und bei $37^{\circ} \mathrm{C}$ bis zum Erreichen einer $\mathrm{OD}_{550}$ von 0.5 inkubiert. In einer der Kulturen wurde darauf die Expression des Fusionsproteins durch Zugabe von $10 \mu \mathrm{L}$ AHT $(2 \mathrm{mg} / \mathrm{mL})$ induziert und beide Ansätze wurden für weitere $3 \mathrm{~h}$ inkubiert. Die Ernte der Zellen erfolgte durch Zentrifugation bei $4^{\circ} \mathrm{C}$ und $4000 \times \mathrm{g}$ für $12 \mathrm{~min}$. Nach vollständigem Entfernen des Mediums wurde das Pellet bei $4^{\circ} \mathrm{C}$ in $1 \mathrm{~mL}$ Puffer W resuspendiert und die Zellen durch Ultraschallbehandlung für 2 min bei $40 \%$ Impulsstärke mit einem Ultraschallstab (Branson) aufgeschlossen. Zur Abtrennung unlöslicher Bestandteile wurde die Suspension bei $4^{\circ} \mathrm{C}$ für $15 \mathrm{~min}$ bei $14000 \mathrm{xg}$ zentrifugiert, der klare Überstand in ein neues Reaktionsgefäß überführt und bis zur weiteren Verwendung bei $-20^{\circ} \mathrm{C}$ gelagert.

Um ähnliche Proteinmengen in der Western-Blot-Analyse einsetzen zu können, erfolgte eine Konzentrationsbestimmung der Proteinextrakte (s. 2.10.3). Die entsprechenden Mengen wurden anschließend wie unter 2.10 .4 beschrieben elektrophoretisch aufgetrennt und mit AP-konjugiertem StrepTactin getestet.

\subsubsection{Aufreinigung des Fusionsproteins}

Für die Immunisierung von Kaninchen bzw. zur Gewinnung von monospezifischen Antikörpern musste das Fusionsprotein von den bakterieneigenen Proteinen abgetrennt werden. Hierzu erfolgte eine Aufreinigung der wie unter 2.10.1.2 beschrieben gewonnenen Rohextrakte über die StrepTactin-Säule. Die Säule wurde zunächst durch Waschen mit Puffer W $(2 \times 2.5 \mathrm{~mL})$ von Resten des Lagerpuffers gereinigt und äquilibriert, anschließend wurde $1 \mathrm{~mL}$ des Bakterienextrakts für $15 \mathrm{~min}$ bei $14000 \mathrm{xg}$ und $4^{\circ} \mathrm{C}$ abzentrifugiert und der Überstand aufgetragen. Nach vollständigem Eindringen in die Matrix wurde diese mit $5 \times 1 \mathrm{~mL}$ Puffer W gewaschen, um nicht an das StrepTactin haftende Bestandteile auszuwaschen. Danach erfolgte die Elution der Fusionsproteine mit $6 \times 0.5 \mathrm{~mL}$ Puffer E, der den spezifischen Kompetitor Desthiobiotin enthält. Das Eluat wurde in $0.5 \mathrm{~mL}$-Fraktionen aufgefangen und die Säule anschließend zur Regenerierung mit $3 \times 5 \mathrm{~mL}$ Puffer $R$ gespült. Die Bestandteile des Puffers verdrängen das Strep-tag-Peptid von der 
StrepTactin-Bindungsstelle und führen zu einer Rotfärbung der Säule, so dass die Regenerationskapazität der Säule optisch zu verfolgen ist. Der Puffer $R$ wurde durch $2 \times 4 \mathrm{~mL}$ Puffer W entfernt und die StrepTactin-Säule konnte bis zur nächsten Aufreinigung in diesem Puffer bei $4^{\circ} \mathrm{C}$ gelagert werden. Für die Analyse durch SDS-PAGE wurden von jeder Fraktion $20 \mu \mathrm{L}$ auf einem SDS-PAGE-Gel aufgetrennt, geblottet und wie unter 2.10.1.4 beschrieben mit AP-konjugiertem StrepTactin umgesetzt.

\subsubsection{Analyse der Expression und der Reinigung}

Zur Überprüfung der Gesamtprotein-Extrakte bzw. der über die StrepTactin-Säule aufgereinigten Eluate erfolgte nach der SDS-PAGE und dem Western Blotting die Detektion des Strep-tags mittels AP-konjugiertem StrepTactin. Dazu wurden die Proben wie unter 2.10.4 gelelektrophoretisch aufgetrennt und auf eine PVDFMembran geblottet (s. 2.10.5). Zur Abschwächung unspezifischer Proteinbindung erfolgte eine Inkubation des Filters in Blocking-Lösung II. Anschließend wurde die Membran $3 x$ für 5 min mit PBT gewaschen. Danach wurde der Filter $1 \mathrm{~h}$ bei RT mit ca. $20 \mathrm{~mL}$ Blocking-Lösung II mit $1: 4000$ verdünntem AP-konjugiertem StrepTactin inkubiert, 3x 1 min mit PBT und 2x 1 min mit PBS gewaschen und die detektierten Banden durch die Farbreaktion der AP mit dem Färbepuffer visualisiert. Erfolgte keine Inkubation mit Biotin, wurde das bakterielle BCCP-Protein von ca. $20 \mathrm{kDa}$ ebenfalls detektiert. Die Farbentwicklung erfolgte in Dunkelheit und wurde bei Erreichen der gewünschten Intensität durch Waschen mit $\mathrm{H}_{2} \mathrm{O}$ abgestoppt.

\subsubsection{Kernproteinextraktion aus Gewebe}

Alle für diesen Versuch verwendeten Lösungen wurden auf $4^{\circ} \mathrm{C}$ gekühlt und die Präparationsschritte im Kühlraum auf Eis durchgeführt.

$300 \mathrm{mg}$ Gewebe wurden in PBS gewaschen, in $5 \mathrm{~mL}$ Kernproteinpuffer A überführt und mit einem Dispergierwerkzeug (Ultraturrax) homogenisiert. Nach Zentrifugation bei $4^{\circ} \mathrm{C}$ für 20 min und $4000 \mathrm{xg}$ wurde das Pellet in $1 \mathrm{~mL}$ Kernproteinpuffer $C$ resuspendiert, 30 min unter Rühren auf Eis inkubiert und anschließend 30 min bei $4^{\circ} \mathrm{C}$ und $15000 \times \mathrm{g}$ abzentrifugiert. Der Überstand wurde in flüssigem Stickstoff schockgefroren und bei $-70^{\circ} \mathrm{C}$ gelagert. 
Kernproteinpuffer $A$

$\begin{array}{rl}10 \mathrm{mM} & \text { HEPES pH7.9 } \\ 1.5 \mathrm{mM} & \mathrm{MgCl}_{2} \\ 10 \mathrm{mM} & \mathrm{KCl} \\ 0.5 \mathrm{mM} & \text { DTT } \\ 0.5 \mathrm{mM} & \text { PMSF } \\ 0.5 \mu \mathrm{g} / \mathrm{mL} & \text { Leupeptin } \\ 0.7 \mu \mathrm{g} / \mathrm{mL} & \text { Pepstatin } \\ 1.0 \mu \mathrm{g} / \mathrm{mL} & \text { Aprotinin }\end{array}$

Kernproteinpuffer C

$20 \mathrm{mM}$ HEPES pH 7.9

$25 \%$ Glycerin

$1.5 \mathrm{mM} \quad \mathrm{MgCl}_{2}$

$0.42 \mathrm{M} \mathrm{NaCl}$

$0.2 \mathrm{mM}$ EDTA

$0.5 \mathrm{mM}$ DTT

$0.5 \mathrm{mM}$ PMSF

$0.5 \mu \mathrm{g} / \mathrm{mL}$ Leupeptin

$0.7 \mu \mathrm{g} / \mathrm{mL}$ Pepstatin

$1.0 \mu \mathrm{g} / \mathrm{mL}$ Aprotinin

\subsubsection{Proteinbestimmung}

Die Konzentrationsbestimmung des löslichen Proteins erfolgte nach Bradford (1976), als Standard wurde BSA eingesetzt. Aliquots des Extrakts wurden unterschiedlich stark mit $\mathrm{H}_{2} \mathrm{O}$ verdünnt, um im linearen Bereich der Eichreihe $(0-10 \mu \mathrm{g})$ zu messen. Dabei wurde jede Verdünnung $2 x$ angesetzt, um aus den gemessenen Werten die Extinktion mitteln zu können. $20 \mu \mathrm{L}$ des verdünnten Extraktes wurden in 94-Loch-Mikrotiterplatten zu $280 \mathrm{~mL}$ Bradfordlösung pipettiert und für 10 min bei RT inkubiert. Der Proteingehalt wurde photometrisch bei $595 \mathrm{~nm}$ in einem Mikrotiterplatten-Photometer bestimmt. 


\subsubsection{SDS-Polyacrylamidgel}

(Laemmli, 1970)

Zur Auftrennung von Proteinextrakten wurden fertige Gele (s. 2.3.1) mit einem Acrylamidgehalt von 10-15\% bzw. Gradientengele von 4-12\% oder selbst hergestellte Gele mit einem Acrylamidgehalt von 10-15\% verwendet. Zum Auftragen wurden die Proben mit 4x Sample Buffer versetzt, $10 \mathrm{~min}$ bei $95^{\circ} \mathrm{C}$ im Thermomixer denaturiert, abgekühlt und kurz abzentrifugiert.

Zur Herstellung von SDS-PAGE-Gelen wurden die in der folgenden Tabelle aufgeführten Lösungen für das Trenngel zusammen pipettiert, kurz gemischt, zwischen zwei gesäuberte und mit Agarose abgedichtete Glasplatten gefüllt und mit Wasser überschichtet. Nach vollständiger Polymerisierung (ca. $1 \mathrm{~h}$ ) wurde das Wasser abgeschüttet, die Lösungen für das Sammelgel zusammen gegeben und auf das Trenngel geschichtet. Der Gelkamm wurde luftblasenfrei eingesetzt. Nachdem das Sammelgel polymerisiert war, wurde das Gel in der Elektrophoresekammer befestigt und mit MOPS-Elektrophoresepuffer überschichtet. Nach Entfernen des Gelkamms wurden die Taschen gut mit Elektrophoresepuffer ausgespült, die Proben aufgetragen und für $4-8 \mathrm{~h}$ bei $100-120 \mathrm{~V}$ und $4^{\circ} \mathrm{C}$ elektrophoretisch aufgetrennt.

Trenngel $(20 \mathrm{~mL})$

\begin{tabular}{lrrr}
\hline Acrylamidkonzentration & $10 \%$ & $12 \%$ & $15 \%$ \\
\hline $\mathrm{H}_{2} \mathrm{O}$ & $10 \mathrm{~mL}$ & $9 \mathrm{~mL}$ & $7.5 \mathrm{~mL}$ \\
Acrylamidlösung (40\%) & $5 \mathrm{~mL}$ & $6 \mathrm{~mL}$ & $7.5 \mathrm{~mL}$ \\
Trenngel-Puffer $(4 \mathrm{x})$ & $5 \mathrm{~mL}$ & $5 \mathrm{~mL}$ & $5 \mathrm{~mL}$ \\
SDS (10\%) & $0.2 \mathrm{~mL}$ & $0.2 \mathrm{~mL}$ & $0.2 \mathrm{~mL}$ \\
APS (10\%) & $0.1 \mathrm{~mL}$ & $0.1 \mathrm{~mL}$ & $0.1 \mathrm{~mL}$ \\
TEMED & $20 \mu \mathrm{L}$ & $20 \mu \mathrm{L}$ & $20 \mu \mathrm{L}$ \\
\hline
\end{tabular}

Sammelgel $(10 \mathrm{~mL})$

\begin{tabular}{lr}
\hline $\mathrm{H}_{2} \mathrm{O}$ & $3.7 \mathrm{~mL}$ \\
Acrylamidlösung $(40 \%)$ & $1.3 \mathrm{~mL}$ \\
Sammelgel-Puffer $(2 \mathrm{x})$ & $5 \mathrm{~mL}$ \\
$10 \%$ APS & $50 \mu \mathrm{L}$ \\
TEMED & $10 \mu \mathrm{L}$ \\
\hline
\end{tabular}


Die fertigen Gele wurden in die entsprechende Elektrophoresekammer eingespannt, die Kammer mit MOPS-Elektrophoresepuffer gefüllt und die Proben bei RT für 45-120 min bei $200 \mathrm{~V}$ aufgetrennt.

\subsubsection{Western-Blot}

Die Proteine wurden standardmäßig nach einer gelelektrophoretischen Auftrennung (s. 2.10.4) auf eine PVDF-Membran transferiert. Hierzu wurden 6 Filterpapiere sowie ein PVDF-Filter in der Größe des Trenngels zurechtgeschnitten. Es wurden 3 Filterpapiere in Blotting-Puffer getränkt und auf die untere Elektrode des Semi-Dry-Blot-Geräts gelegt. Darauf wurde die zuvor für $10 \mathrm{sec}$ in Methanol aktivierte und 5 min in $\mathrm{H}_{2} \mathrm{O}$ und 10 min in Blotting Puffer gewaschene Membran luftblasenfrei aufgelegt. Das Gel wurde von den Gelplatten gelöst, vorsichtig auf die Membran aufgebracht und erneut mit 3 in Blotting Puffer getränkten Filterpapieren überschichtet. Nach dem Aufbringen der Kathodenplatte erfolgte der Proteintransfer für $1 \mathrm{~h}$ bei max. $5 \mathrm{~mA} / \mathrm{cm}^{2}$. Die Membran wurde anschließend mit einem monospezifischen Antikörper bzw. polyklonalen Antiserum gegen das zu detektierende Protein inkubiert. Wurde ein Proteinmarker ohne Bandenfärbung benutzt, erfolgte eine reversible Anfärbung der Membran (s. 2.10.7).

\subsubsection{Färbung von Polyacrylamidgelen}

SDS-Gele wurden standardmäßig mit Simply Blue ${ }^{T M}$ Safestain angefärbt. Nach erfolgter Gelelektrophorese und Blotting wurde das Gel 3x 5 min in $\mathrm{H}_{2} \mathrm{O}$ gewaschen, ca. $1 \mathrm{~h}$ in der Färbelösung geschwenkt und darauf erneut in $\mathrm{H}_{2} \mathrm{O}$ gewaschen, um die Hintergrundfärbung zu reduzieren. Das Gel konnte nun in Plastikfolie eingeschweißt und für einige Wochen gelagert werden.

\subsubsection{Reversible Färbung von Western-Blots}

(Salinovich und Montelaro, 1986)

An eine Membran gebundene Proteine können reversibel mit $0.5 \%$ Ponceau S in $1 \%$ Essigsäure angefärbt werden. Diese Methode wurde angewandt, wenn ein Proteinstandard ohne gefärbte Banden benutzt wurde, um die Qualität des Proteintransfers zu kontrollieren und die Markerproteine zur späteren Bestimmung der Molekulargewichte zu markieren. Die Entfärbung erfolgte durch Waschen in $\mathrm{H}_{2} \mathrm{O}$. 


\subsubsection{Immunumsetzung von Western-Blots}

Vor der Umsetzung mit dem Antiserum wurden freie Bindungsstellen auf der Membran $1 \mathrm{~h}$ bei RT mit Blocking-Lösung II abgesättigt. Danach wurde der Filter 1-2 $\mathrm{h}$ bei RT mit ca. $20 \mathrm{~mL}$ Antiserum (in Blocking-Lösung II verdünnt) inkubiert und anschließend ungebundener Antikörper durch 3 Waschschritte von 5-30 min mit PBT entfernt. Die Inkubation mit dem an eine AP konjugierten Zweitantikörper erfolgte für $1 \mathrm{~h}$ bei RT, nachfolgend wurden wieder ungebundene Antikörper durch $3 \mathrm{x}$ 1-15 min Waschen in PBT entfernt und die Filter auf die Bedingungen des Färbepuffers eingestellt. Die Visualisierung der detektierten Banden erfolgte durch die Farbreaktion der AP mit dem Färbepuffer. Die Farbentwicklung erfolgte in Dunkelheit und wurde bei Erreichen der gewünschten Intensität durch Waschen mit $\mathrm{H}_{2} \mathrm{O}$ abgestoppt.

\subsubsection{Aufreinigung monospezifischer Antikörper mittels Western-Blot-Verfahren}

Die polyklonalen Antiseren gegen Sall1 und Sall2 wurden aufgereinigt, um die spezifisch gegen die Proteine reagierenden Antikörper von den übrigen im Serum enthaltenen Antikörpern abzutrennen. Hierzu wurde ein bakterieller Proteinextrakt mit den jeweiligen StrepTag-Fusionsproteinen nach Aufreinigung über die StrepTactin-Säule mittels PAGE aufgetrennt und auf eine PVDF-Membran transferiert. Nach dem Transfer wurden schmale Randstreifen vom Filter abgetrennt und mit AP-Streptactin-Konjugat inkubiert, um die Höhe der Fusionsproteinbande festzustellen. Diese wurde nach Inkubation mit $200 \mu \mathrm{L}$ des polyklonalen Antiserums ausgeschnitten, $3 \times 10$ min in PBT gewaschen und zur Elution der monospezifischen Antikörper 15 min mit $1 \mathrm{~mL}$ Elutionslösung mit dem Vortexer kräftig geschüttelt. Nach Waschschritten in PBS wurde der Filterstreifen erneut mit dem Antiserum inkubiert.

Die eluierten Antikörper wurden in ein Centrisart-Röhrchen überführt und durch Zentrifugtion bei $4^{\circ} \mathrm{C}$ und $2500 \times \mathrm{g}$ konzentriert, wobei der Elutionspuffer in den inneren Stempel übertritt und der Antikörper durch die Membran im Außenröhrchen zurückgehalten wird. Der Überstand wurde verworfen, die Restflüssigkeit mit PBS auf das Ausgangsvolumen aufgefüllt und erneut zentrifugiert. Dieser Vorgang wurde so oft wiederholt, bis das KSCN vollständig aus der Antikörperlösung entfernt war (3-4x).

Die monospezifische Antikörperlösung wurde mit $0.2 \% \mathrm{NaN}_{3}$ versetzt und bei $4^{\circ} \mathrm{C}$ gelagert. 
Elutionslösung

$\begin{array}{rl}3 \mathrm{M} & \mathrm{KSCN} \\ 0.1 \% & \mathrm{BSA} \\ \text { in } 1 \mathrm{x} & \mathrm{PBS}\end{array}$

\subsubsection{Aufreinigung monospezifischer Antikörper mittels Affinitäts-Säulen}

N-Hydroxysuccinimid-aktivierte SepharoseTM-Säulen (HiTrap affinity columns, Amersham Pharmacia Biotech) können kovalent Liganden mit primären Aminogruppen binden. So konnten die Peptide, die zur Immunisierung von Kaninchen gegen SALL1 eingesetzt wurden, an die Säule gebunden und diese zur Aufreinigung monospezifischer Antikörper verwendet werden.

Das zur Vermeidung der Deaktivierung von NHS-Gruppen bei der Lagerung zugegebene Isopropanol wurde direkt vor der Verwendung mit $3 \times 2 \mathrm{~mL} 1 \mathrm{mM} \mathrm{HCl}$ $\left(4^{\circ} \mathrm{C}\right)$ ausgewaschen. Die Lösung wurde mit Hilfe einer Spritze und eines Adapters auf die Säule appliziert. Um die Matrix nicht irreversibel zu komprimieren, wurde für diesen und alle weiteren Schritte eine Flussrate von maximal $1 \mathrm{~mL} / \mathrm{min}$ eingehalten. $1 \mathrm{~mL}$ der Peptide S1-I und S1-II, die in einer Konzentration von je $10 \mu \mathrm{g} / \mathrm{mL}$ in Bindungspuffer aufgenommen worden waren, wurden auf je eine Säule gegeben und diese nach dem Eindringen der Ligandenlösung $4 \mathrm{~h}$ bei $4^{\circ} \mathrm{C}$ inkubiert. Durch eine Behandlung mit 3x $2 \mathrm{~mL}$ Puffer A, 3x $2 \mathrm{~mL}$ Puffer $B, 3 \times \mathrm{mL}$ Puffer $A$, Inkubation bei RT für $30 \mathrm{~min}, 3 \times 2 \mathrm{~mL}$ Puffer $\mathrm{B}, 3 \times 2 \mathrm{~mL}$ Puffer $A$ und nochmals $3 x$ 2 mL Puffer B1 wurden die überzähligen aktiven Gruppen, die keinen Liganden gebunden hatten, deaktiviert und unspezifisch gebundene Liganden ausgewaschen. Die Lagerung der Säulen erfolgte im Lagerungspuffer. Vor der Verwendung für die Aufreinigung von Antikörpern wurde der Lagerungspuffer mit $3 \mathrm{~mL}$ PBS und $3 \mathrm{~mL}$ Elutionspuffer ausgewaschen. Anschließend wurde die Säule mit $10 \mathrm{~mL} P B S$ äquilibriert und $2 \mathrm{~mL}$ des mit PBS 1:4 verdünnten Antiserums appliziert. Durch eine am unteren Ende der Säule angebrachte Spritze konnte die Serum/PBS-Lösung mehrmals durch die Matrix gepumpt werden. Die Säule wurde mit 7x $1 \mathrm{~mL}$ PBS gewaschen und der an die Peptide gebundene Antikörper mit $2 \mathrm{~mL}$ Elutionspuffer eluiert. Das Eluat wurde wie unter 2.10.9 beschrieben entsalzt. Die Säulen wurden mit 7x $1 \mathrm{~mL}$ PBS reäquilibriert und bis zur weiteren Verwendung in Lagerungspuffer bei $4^{\circ} \mathrm{C}$ aufbewahrt. 


$\begin{array}{ll}\text { Bindungspuffer } & 0.2 \mathrm{M} \mathrm{NaHCO}_{3} \\ & 0.5 \mathrm{M} \mathrm{NaCl} \\ & \text { pH8.3 } \\ \text { Puffer A } & 0.5 \mathrm{M} \mathrm{Ethanolamin} \\ & 0.5 \mathrm{M} \mathrm{NaCl} \\ & \text { pH8.3 } \\ \text { Puffer B } & 0.1 \mathrm{M} \mathrm{NaAc} \\ & 0.5 \mathrm{M} \mathrm{NaCl} \\ & \mathrm{pH} 4.0 \\ \text { Lagerungspuffer } & 0.05 \mathrm{M} \mathrm{Na}_{2} \mathrm{HPO}_{4} \\ & 0.1 \% \mathrm{Natriumazid} \\ & \mathrm{pH} 7.0 \\ \text { Elutionspuffer } & 3 \mathrm{M} \mathrm{MgCl}_{2} \\ & \text { in } 1 \times \mathrm{PBS}^{2}\end{array}$

\subsubsection{Gewinnung eines polyklonalen Antiserums}

Aufgereinigte Fusionsproteine können genutzt werden, um Kaninchen durch Injektion mit dem gewünschten Antigen zur Produktion von spezifischen Antikörpern anzuregen. Zur Präimmunisierung wurden stark überexprimierte, aufgereinigte Strep-tag-Fusionsproteine ausgewählt und 1:1 mit Freund's Complete Adjuvans gemischt. Vor der ersten subkutanen Injektion wurde den Kaninchen Präimmunisierungsserum abgenommen, um nach der Immunisierung eine spezifisch auf das applizierte Antigen erfolgte Antikörperbildung nachweisen zu können. Nach 3 Wochen erfolgte eine Boost-Immunisierung mit dem Fusionsprotein 1:1 mit Freund's Incomplete Adjuvans versetzt. Es wurde erneut Serum abgenommen, um zu prüfen, ob eine Reaktion auf die Erstimmunisierung erfolgt war. 14 Tage nach der zweiten Immunisierung wurde dem Kaninchen durch Herzpunktion das Blut entnommen. Zur Gerinnung der zellulären Bestandteile wurde das Blut für $1 \mathrm{~h}$ bei $37^{\circ} \mathrm{C}$ und nachfolgend üN bei $4^{\circ} \mathrm{C}$ inkubiert. Die agglutinierten Bestandteile wurden durch Zentrifugation (15 min, $10000 \mathrm{x} \mathrm{g}$ ) pelletiert und das aliquotierte Serum bei $-80^{\circ} \mathrm{C}$ gelagert. Die Überprüfung auf eine erfolgte Antikörperbildung erfolgte mittels Immunodetektion (s. 2.10.5, 2.10.8). 


\subsection{Zellkultur}

\subsubsection{Routinekultur von ES-Zellen}

Embryonale Stammzellen (ES-Zellen) wurden zusammen mit Mitomycin C behandelten embryonalen Fibroblasten auf $0.2 \%$ Gelatine beschichteten Kulturschalen ausplattiert. Das Kulturmedium wurde auf Grund der starken Ansäuerung durch die ES-Zellen täglich gewechselt. Eine erneute Passagierung wurde je nach Dichte der Zellen alle 2-3 Tage durchgeführt und die ES-Zellen in Trypsin/EDTA-Puffer 1:3 bis 1:8 geteilt. Vor der erneuten Ausplattierung wurde die Trypsinlösung durch Zentrifugation mit 270xg für $5 \mathrm{~min}$ bei RT entfernt. Bei jeder Passage wurden Stocks der ES-Zellen in flüssigem Stickstoff kryokonserviert (s. 2.11.3).

\subsubsection{Elektroporation und Selektion von ES-Zellen}

(Joyner, 2000)

Durch Elektroporation wird eine biologische Membran durch die Einwirkung kurzer elektrischer Impulse oberhalb der kritischen Feldstärke vorübergehend permeabilisiert, ohne die Membranstruktur zu zerstören. Während der Phase erhöhter Durchlässigkeit kann ein Eindringen linearisierter Plasmid-DNA durch die Membran stattfinden. Die Elektroporation der ES-Zellen wurde nach den Angaben von Joyner (2000) durchgeführt. Dazu wurden $7 \times 10^{6}$ bis $2 \times 10^{7}$ exponentiell wachsende Zellen nach der Trypsinierung in $800 \mu \mathrm{L}$ Elektroporationspuffer und $40 \mu \mathrm{g}$ linearisierte DNA eingesetzt.

Die wie unter 2.9.1.4 beschrieben aufgereinigte Konstrukt-DNA wurde nach der Linearisierung mit dem entsprechenden Restriktionsenzym zunächst mit Phenol/Chloroform extrahiert, präzipitiert und gewaschen. Um eine Kontamination mit Endotoxinen zu vermeiden, fanden dabei sämtliche Schritte, soweit möglich, unter der Sterilbank statt. Das DNA-Pellet wurde luftgetrocknet und in $100 \mu \mathrm{L}$ Elektroporationspuffer aufgenommen. Die ES-Zellen wurden nach der Trypsinisierung in $9 \mathrm{~mL}$ Elektroporationspuffer und nach erneuter Zentrifugation in $700 \mu \mathrm{L}$ Elektroporationspuffer aufgenommen. Die Suspensionen wurden in einer Gene Pulser Küvette vereinigt und mit $240 \mathrm{~V}$ und $55 \mu \mathrm{F}$ bei RT im Gene Pulser elektroporiert. Anschließend wurden die ES-Zellen für $20 \mathrm{~min}$ auf Eis inkubiert und nachfolgend in fünf $60 \mathrm{~mm}$ Kulturschalen auf embryonalen Fibroblasten ausplattiert.

Die Selektion in G418 (Positivselektion) und Gancyclovir (Negativselektion) begann nach 12 bis $16 \mathrm{~h}$. Die Gancyclovir-Selektion wurde nach 5 Tagen beendet, 
während die G418-Selektion bis zur Isolierung resistenter Klone an Tag 8-9 aufrecht erhalten wurde.

\subsubsection{Isolierung und Kryokonservierung von ES-Zellklonen}

Resistente ES-Zellklone wurden lichtmikroskopisch identifiziert und die Kolonien nach einer G418-Selektion über 8-9 Tage isoliert. Dazu wurden die Kulturen 1x in PBS-Puffer gewaschen und mit $10 \mathrm{~mL}$ PBS-Puffer überschichtet. Die Klone wurden mechanisch mit Hilfe einer sterilen Pasteurpipettenspitze von den Fibroblasten getrennt und bei $37^{\circ} \mathrm{C}$ in $1 \times$ Trypsin-EDTA in 96-Loch-Zellkulturplatten dissoziiert. Die Restriktion wurde nach 5 min durch Zugabe von $50 \mu \mathrm{L}$ ES-Zellmedium gestoppt. Die vereinzelten Klone wurden auf 24-Loch-Zellkulturplatten mit Fibroblasten und frischem ES-Zellmedium übertragen und bei $37^{\circ} \mathrm{C}$ kultiviert.

Nach 2-3 Tagen wuchsen die Einzelklone zur Konfluenz und wurden erneut trypsinisiert. Eine Hälfte der Zellen wurde wieder auf Fibroblasten ausplattiert (master plate), während die andere Hälfte der Zellen auf einer Gelatinebehandelten Platte (duplicate plate) inkubiert wurde. Die auf Fibroblasten wachsenden ES-Zellen wurden nach Erreichen der Konfluenz mit $100 \mu \mathrm{L}$ Trypsin/EDTA bei $37^{\circ} \mathrm{C}$ für $5 \mathrm{~min}$ dissoziiert, in $1 \mathrm{~mL}-\mathrm{Kryogefäße}$ (Nunc) überführt und nach Zugabe von $100 \mu \mathrm{L} 2 x$ Gefriermedium gemischt und bei $-80^{\circ} \mathrm{C}$ eingefroren. Die für die DNA-Isolierung vorgesehenen Zellen wurden ebenfalls bis zur Konfluenz kultiviert und anschließend der DNA-Extraktion unterworfen (s. 2.11.4).

\subsubsection{DNA-Extraktion aus ES-Zellen}

Die Platten mit den ES-Zellen (s. 2.11.1) wurden mit PBS gewaschen und mit $500 \mu \mathrm{L}$ ES-Lysispuffer pro ES-Zellklon üN bei $37^{\circ} \mathrm{C}$ inkubiert. Nach erfolgter Zelllyse wurde die DNA mit $500 \mu \mathrm{L}$ Isopropanol gefällt und 15 min bei RT unter leichtem Schütteln inkubiert. Der Überstand wurde danach vorsichtig entfernt. Mit $500 \mu \mathrm{L}$ $70 \%$ igem Ethanol wurde die DNA unter Schütteln für ebenfalls 15 min gewaschen und die DNA in ein Reaktionsgefäß überführt, in dem $90 \mu \mathrm{L}$ TE-Puffer vorgelegt waren. Die DNA wurde bei offenem Deckel bei $60^{\circ} \mathrm{C}$ für 30 min gelöst und dabei noch vorhandene Ethanolrückstände verdampft. Um ein vollständiges Lösen der DNA zu erreichen, wurde das Volumen auf 200-300 $\mu \mathrm{L}$ mit TE-Puffer aufgefüllt und eine üN-Inkubation im Wasserbad bei $55^{\circ} \mathrm{C}$ durchgeführt.

Die genomische DNA konnte nun restriktionsenzymatisch geschnitten (s. 2.9.3.1), über ein ein analytisches Agarosegel aufgetrennt (s. 2.9.8.1) und einem Southern-Transfer (s. 2.9.9.1) unterworfen werden. 


\subsubsection{Herstellung von Chimären}

Die Isolierung von 2.5 Tage alten Mausembryonen, die Injektion von rekombinanten ES-Zellen in die Embryonen und die Reimplantation der injizierten Blastocysten in pseudoschwangere Mäuse wurden von MitarbeiterInnen des Max-PlanckInstituts für Experimentelle Medizin, Göttingen, durchgeführt. Die ES-Zellen wurden aus Tieren des Mausstammes 129/SvJ isoliert, deren Fell eine braune Färbung aufweist (Agouti-Fellmarker). Die bei der Aggregation eingesetzten Blastocysten wurden aus dem C57BL-Stamm isoliert, dessen Mäuse eine schwarze Fellfärbung zeigen. Sind ES-Zellen an der Entwicklung der reimplantierten Embryonen involviert, können die chimären Tiere anhand einer gescheckten Fellfärbung identifiziert werden. Männliche Mäuse mit einem Chimerismus von mindestens $80 \%$ wurden auf die Stämme C57BL und 129/SvJ zurückgekreuzt und die Tiere der F1-Generation im Alter von 5 Wochen mit Hilfe der PCR (s. 2.9.7.3) genotypisiert. 


\section{Ergebnisse}

\subsection{Isolierung und Charakterisierung des Sall1-Gens der Maus}

Bei Beginn der vorliegenden Arbeit waren zwei spalt-homologe Gene der Maus bekannt, Sall2 (Kohlhase et al., 2000) und Msal, später Sall3 genannt (Ott et al., 1996). Da das Gen Msal zum Xenopus-Gen Xsal-1 eine höhere Ähnlichkeit ausweist als zu SALL1, wurde vermutet, dass bei der Maus ein weiteres SALL1homologes sal-ähnliches Gen existiert. Dieses Gen sollte im Rahmen der vorliegenden Arbeit zunächst isoliert werden.

\subsubsection{Isolierung und Charakterisierung zweier genomischer Cosmidklone}

Eine Maus-Cosmid-Bibliothek (s. 2.7.7) wurde mit einer humanen SALL1-Sonde aus Exon 2 (c-son, s. 2.2) nach den von der RZPD empfohlenen Bedingungen (s. 2.9.10.2) mittelstringent hybridisiert. Das $1.5 \mathrm{~kb}$ große Fragment aus Exon 2 wurde mit den Primern TF1 und TR2 (Kohlhase et al., 1998) amplifiziert und enthält unter anderem die für den ersten Doppelzinkfinger kodierende Sequenz. Die Signale wurden ausgewertet und die entsprechenden Klone bestellt. Nach der Rehybridisierung mit der humanen SALL1-Sonde erwiesen sich zwei Klone als positiv (RZPD-ID-Nrs. MPMGc12109685Q3 = Cos C, MPMGc121J23368Q3 = Cos J), die im Folgenden kartiert und partiell sequenziert wurden. Ein Teil der klonierten Fragmente ist in Abb. 3.1 dargestellt. 


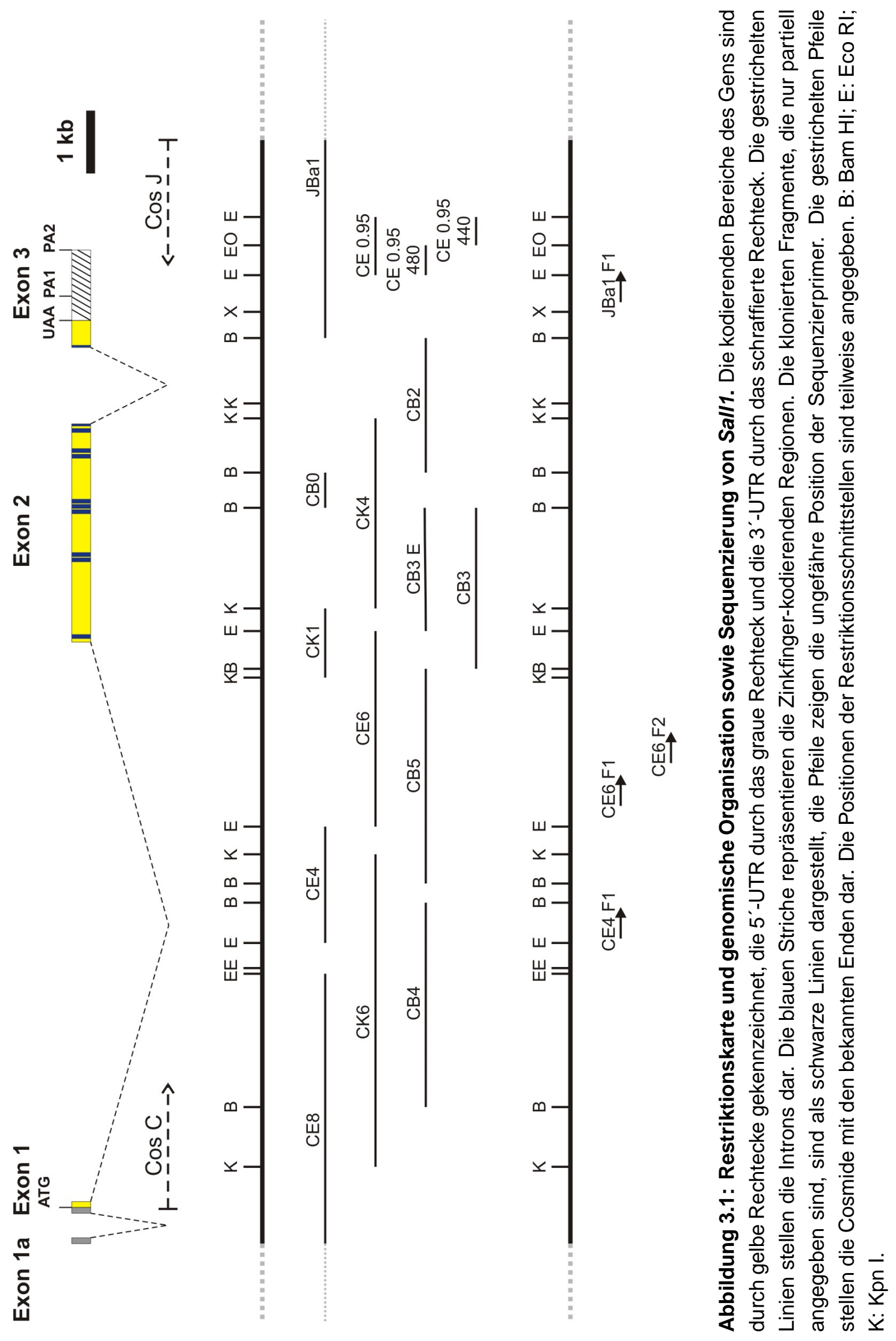




\subsubsection{Nukleotid- und abgeleitete Aminosäuresequenz von Sall1}

Aus Cos C konnte das Kpn I-Fragment CK4 (s. Abb. 3.1) isoliert werden, das mit der humanen SALL1-Sonde c-son hybridisierte. Mit dem 5'- bzw. 3'-Bereich dieses Fragments wurden weitere Hybridisierungen der mit verschiedenen Enzymen restringierten DNA von Cos $C$ durchgeführt und so zunächst eine durchgehende Sequenz von ca. 5000 bp erstellt. Der größte offene Leserahmen dieser Sequenz kodiert im 5'-Bereich für ein vermutliches $\mathrm{C}_{2} \mathrm{HC}$-Einzelzinkfinger (EZF)-Motiv gefolgt von Sequenzen, die für vier $\mathrm{C}_{2} \mathrm{H}_{2}$-Doppelzinkfinger (DZF)-Domänen kodieren (s. Abb. 3.1.3). Die Sequenz, die für die letzte DZF-Domäne kodiert, ist durch eine Insertion von 1129 bp unterbrochen. Der Vergleich mit der humanen Sequenz zeigte eine Konservierung der Spleißstellen am Anfang und Ende der eingefügten Sequenz, was zu der Annahme führte, dass es sich hierbei um Intron 2 handelt. Auch die Spleißstelle 105 bp in 5'-Richtung des $\mathrm{C}_{2} \mathrm{HC}$-Zinkfingers ist konserviert, was vermuten ließ, dass die Position des Intron 1 ebenfalls konserviert ist und somit noch ein weiteres Exon vorliegt. Damit wurde das Exon mit dem Hauptteil an Zinkfinger-kodierenden Regionen Exon 2 genannt und eine Länge von 3464 bp festgestellt, das kleine Exon mit 435 bp wurde Exon 3 genannt.

Um das vermutlich einige $\mathrm{kb}$ in $5^{\prime}$-Richtung lokalisierte Exon $1 \mathrm{zu}$ isolieren, wurde der Cos C-Blot mittelstringent mit einem Exon 1 enthaltenden PCRFragment aus SALL1 hybridisiert und das resultierende CE8-Fragment mit humanen Primern sequenziert. Das so identifizierte Exon 1 des Sall1-Gens der Maus weist 76 bp codierender Sequenz und 17 AS 5'-UTR auf (s. Abb. 3.2). Die Länge des Introns wurde mit 9079 bp bestimmt. Im Rahmen einer anderen Arbeit in dieser Arbeitsgruppe wurde mittels 5'RACE (Rapid Amplification of cDNA Ends) ein weiteres, nicht translatiertes Exon in 5'-Richtung des ATG ermittelt (Exon 1a), das ebenfalls in der humanen Sequenz konserviert ist (Archangelo, 1999). Es ist 151 bp lang und wird von Exon 1 durch ein Intron von 1587 bp (Intron 1a) getrennt.

Neben den EZF- und DZF-Motiven sind in der Aminosäuresequenz eine Prolinreiche (AS 78-94), eine Glutamin-reiche (AS 232-249), eine Alanin-reiche (AS 295-309) und eine Serin-reiche (AS 353-383) Domäne vorhanden (s. Abb. 3.2).

Die gesamte in der vorliegenden Arbeit aus den Cosmidklonen ermittelte genomische Sequenz beträgt $16410 \mathrm{bp}$ und ist im Anhang (s. Abb. A.1) dargestellt. 


\subsubsection{Identifizierung des Transkriptionsendpunktes}

Zur Bestimmung des 3'-Endes der Sall1-Transkriptionseinheit wurden elektronische Datenbanken nach Sall1-EST-Sequenzen durchsucht. Dabei konnte ein muriner EST-Klon (Zugangsnr. Al426947, IMAGE-Klon-Nr. 537158) gefunden werden, der mit dem das Stopp-Kodon enthaltenden Bam HI / Xba I-Fragment CBX überlappt und ein Polyadenylierungssignal (Poly-AS) 383 bp in 3'-Richtung des Stopp-Kodons, gefolgt von einem poly-(A)-Schwanz, aufweist. Des Weiteren wurde ein EST-Klon (Zugangsnummer AU067623) identifiziert, der mit dem ESTKlon 537158 überlappt, im weiteren 3'-Bereich ist jedoch keine weitere Poly-ASKonsensus-Sequenz vorhanden. In Burfeind und Hoyer-Fender (1991) wurde ein Poly-AS mit der Sequenz AATACA beschrieben, und dieses Motiv konnte $728 \mathrm{bp}$ nach dem ersten Poly-AS gefunden werden. Eine 3'RACE sollte klären, ob es möglicherweise noch weitere Transkripte gibt bzw. die Nutzung beider Poly-AS bestätigt werden, die Methode konnte jedoch nicht etabliert werden. Daher wurde mittels Northern-Blot-Analyse mit den Fragmenten CE 0.95480 bzw. CE 0.95440 (s. 2.2), die vor und hinter dem zweiten identifizierten Poly-AS lokalisiert sind, das Vorhandensein der entsprechenden Transkripte überprüft. Dabei ergab sich in dem Hybridisierungsexperiment mit dem Fragment nach dem Poly-AS 1 ein im Vergleich zur Kontrollhybridisierung mit der CBO-Sonde schwächeres Signal, in dem Experiment mit der Sonde nach dem Poly-AS 2 gar kein Signal (Daten nicht gezeigt). Somit ist anzunehmen, dass beide Poly-AS genutzt werden, weiter $3^{\prime}-$ wärts jedoch kein weiteres funktionelles Signal vorliegt. 


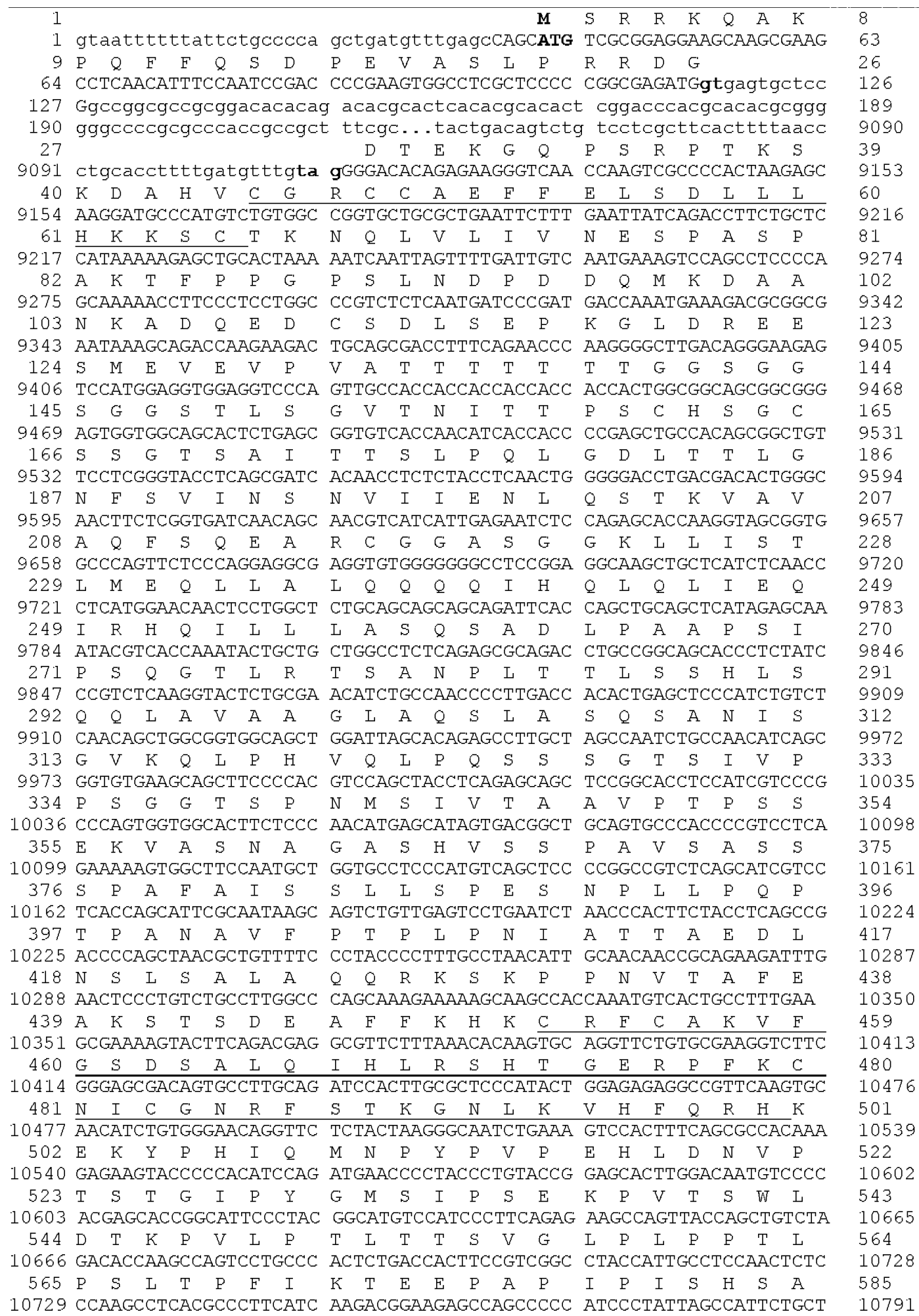


$\begin{array}{lllllllllllllllllllllll}586 & \mathrm{~A} & \mathrm{~S} & \mathrm{P} & \mathrm{O} & \mathrm{G} & \mathrm{S} & \mathrm{V} & \mathrm{K} & \mathrm{S} & \mathrm{D} & \mathrm{S} & \mathrm{G} & \mathrm{A} & \mathrm{P} & \mathrm{D} & \mathrm{L} & \mathrm{A} & \mathrm{T} & \mathrm{R} & \mathrm{N} & \mathrm{P} & 606\end{array}$

10792 GCCAGTCCCCAAGGCTCAGTC AAAAGTGACTCTGGGGCCCCT GATTTGGCCACAAGAAACCCA 10854

$\begin{array}{lllllllllllllllllllllll}607 & S & G & V & P & E & E & V & E & G & S & A & V & P & P & F & G & G & K & G & E & E & \end{array}$

10855 AGCGGCGTCCCCGAGGAAGTG GAAGGGTCTGCTGTGCCACCC TTTGGTGGCAAGGGTGAAGAG 10917

$\begin{array}{lllllllllllllllllllllll}628 & S & N & M & A & S & S & A & V & P & T & A & G & N & S & T & L & N & S & P & V & A & \end{array}$

10918 AGTAACATGGCAAGCTCCGCC GTCCCGACAGCGGGCAACAGT ACTCTGAACTCCCCAGTGGCT 10980

$\begin{array}{llllllllllllllllllllllll}649 & D & G & G & P & G & G & T & T & F & T & N & P & \text { L } & \text { L } & \text { P } & \text { L } & \text { M } & S & E & Q & F & & 669\end{array}$

10981 GACGGTGGTCCAGGAGGGACC ACCTTCACCAACCCTCTGTTG CCCCTCATGTCTGAGCAGTTC 11043

$\begin{array}{lllllllllllllllllllllll}670 & K & A & K & F & P & F & G & G & L & L & D & S & A & Q & A & S & E & T & S & K & L & \end{array}$

11044 AAGGCCAAGTTTCCTTTTGGG GGACTCTTAGATTCTGCCCAG GCCTCAGAGACATCCAAGCTG 11106

$\begin{array}{llllllllllllllllllllllll}691 & \mathrm{O} & \mathrm{Q} & \mathrm{L} & \mathrm{V} & \mathrm{E} & \mathrm{N} & \mathrm{I} & \mathrm{D} & \mathrm{K} & \mathrm{K} & \mathrm{A} & \mathrm{T} & \mathrm{D} & \mathrm{P} & \mathrm{N} & \mathrm{E} & \mathrm{C} & \mathrm{I} & \mathrm{I} & \mathrm{C} & \mathrm{H} & & 711\end{array}$

11107 CAGCAACTGGTAGAAAACATT GACAAGAAGGCCACGGATCCC AATGAGTGTATCATCTGCCAC 11169

$\begin{array}{lllllllllllllllllllllll}712 & \mathrm{R} & \mathrm{V} & \mathrm{L} & \mathrm{S} & \mathrm{C} & \mathrm{Q} & \mathrm{S} & \mathrm{A} & \mathrm{L} & \mathrm{K} & \mathrm{M} & \mathrm{H} & \mathrm{Y} & \mathrm{R} & \mathrm{T} & \mathrm{H} & \mathrm{T} & \mathrm{G} & \mathrm{E} & \mathrm{R} & \mathrm{P} & \\ 732\end{array}$

11170 CGGGTTCTCAGCTGCCAGAGC GCCTTGAAAATGCACTACCGG ACACACACTGGGGAGAGGCCC 11232

$\begin{array}{lllllllllllllllllllllll}733 & \mathrm{~F} & \mathrm{~K} & \mathrm{C} & \mathrm{K} & \mathrm{I} & \mathrm{C} & \mathrm{G} & \mathrm{R} & \mathrm{A} & \mathrm{F} & \mathrm{T} & \mathrm{T} & \mathrm{K} & \mathrm{G} & \mathrm{N} & \mathrm{L} & \mathrm{K} & \mathrm{T} & \mathrm{H} & \mathrm{Y} & \mathrm{S} & 753\end{array}$

11232 TTCAAGTGTAAGATCTGCGGC CGGGCTTTCACCACGAAAGGG AACCTCAAGACCCATTACAGC 11295

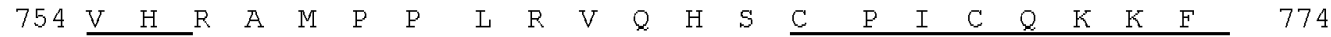

11296 GTCCATCGGGCTATGCCTCCA CTCAGAGTCCAGCATTCCTGC CCCATCTGTCAGAAGAAGTTC 11358

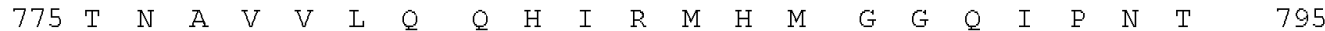

11359 ACAAACGCAGTGGTCCTCCAG CAGCATATTCGTATGCACATG GGAGGCCAGATCCCCAACACC 11421

$\begin{array}{lllllllllllllllllllllll}796 & \mathrm{P} & \mathrm{V} & \mathrm{P} & \mathrm{D} & \mathrm{N} & \mathrm{Y} & \mathrm{P} & \mathrm{E} & \mathrm{S} & \mathrm{M} & \mathrm{E} & \mathrm{S} & \mathrm{D} & \mathrm{T} & \mathrm{G} & \mathrm{S} & \mathrm{F} & \mathrm{D} & \mathrm{E} & \mathrm{K} & \mathrm{N} & 816\end{array}$

11422 CCAGTCCCTGACAACTACCCT GAGTCCATGGAGTCTGACACA GGCTCCTTTGATGAGAAAAAT 11484

$\begin{array}{llllllllllllllllllllllll}817 & \mathrm{~F} & \mathrm{D} & \mathrm{D} & \mathrm{L} & \mathrm{D} & \mathrm{N} & \mathrm{F} & \mathrm{S} & \mathrm{D} & \mathrm{E} & \mathrm{N} & \mathrm{M} & \mathrm{E} & \mathrm{E} & \mathrm{C} & \mathrm{P} & \mathrm{E} & \mathrm{G} & \mathrm{S} & \mathrm{I} & \mathrm{P} & & 837\end{array}$

11485 TTCGACGACTTAGACAACTTC TCAGATGAGAATATGGAAGAG TGTCCTGAGGGCAGCATCCCA 11547

\begin{tabular}{lllllllllllllllllllllll}
838 & $\mathrm{D}$ & $\mathrm{T}$ & $\mathrm{P}$ & $\mathrm{K}$ & $\mathrm{S}$ & $\mathrm{A}$ & $\mathrm{D}$ & $\mathrm{A}$ & $\mathrm{S}$ & $\mathrm{Q}$ & $\mathrm{D}$ & $\mathrm{S}$ & $\mathrm{L}$ & $\mathrm{S}$ & $\mathrm{S}$ & $\mathrm{S}$ & $\mathrm{P}$ & $\mathrm{L}$ & $\mathrm{P}$ & $\mathrm{L}$ & $\mathrm{E}$ & \\
\hline
\end{tabular}

11546 GACACACCCAAGTCAGCGGAC GCTTCCCAAGATAGCCTGTCA TCTTCGCCTCTGCCCCTCGAG 11610

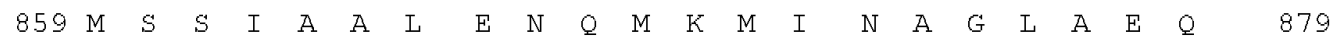

11611 ATGTCGAGCATCGCTGCTCTG GAAAATCAGATGAAGATGATC AATGCTGGCCTGGCGGAGCAG 11673

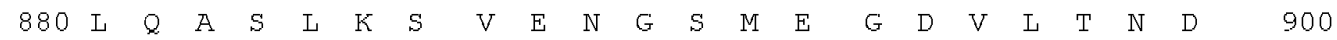

11674 CTGCAGGCCAGCCTGAAGTCT GTGGAGAACGGATCCATGGAA GGGGATGTGCTGACCAACGAC 11736

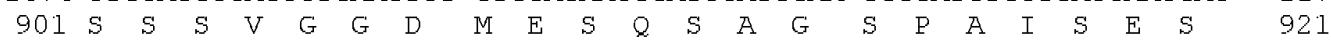

11737 TCTTCCTCAGTGGGTGGCGAC ATGGAGAGCCAGAGTGCAGGC AGCCCAGCCATCTCAGAGTCT 11799

$\begin{array}{lllllllllllllllllllllll}922 & T & S & S & M & Q & A & L & S & P & S & N & S & T & Q & E & F & H & K & S & P & G & 942\end{array}$

11800 ACCTCTTCCATGCAGGCTCTG TCCCCGTCCAACAGCACCCAA GAATTTCACAAGTCACCCGGC 11862

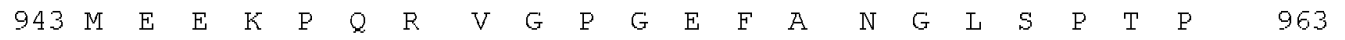

11863 ATGGAGGAAAAGCCACAGCGA GTGGGGCCAGGCGAGTTCGCC AATGGTCTATCTCCCACCCCA 11925

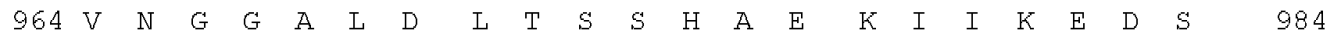

11926 GTGAACGGAGGTGCTTGGAC TTGACTTCTAGTCATGCAGAG AAAATCATCAAAGAAGATTCT 11988

$\begin{array}{llllllllllllllllllllllll}985 & \mathrm{~L} & G & \mathrm{I} & \mathrm{L} & \mathrm{F} & \mathrm{P} & \mathrm{F} & \mathrm{R} & \mathrm{D} & \mathrm{R} & \mathrm{G} & \mathrm{K} & \mathrm{F} & \mathrm{K} & \mathrm{N} & \mathrm{T} & \mathrm{A} & \mathrm{C} & \mathrm{D} & \mathrm{I} & \mathrm{C} & & 1005\end{array}$

11989 CTGGGAATCCTCTTTCCTTTC AGAGACCGGGGTAAATTTAAA AACACTGCTTGCGACATTTGT 12051

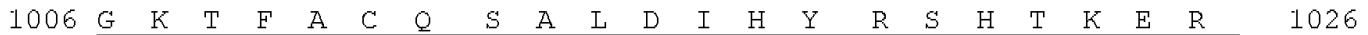

12052 GGCAAGACCTTTGCTTGTCAG AGTGCCTTGGACATTCACTAC AGAAGTCATACCAAAGAGAGA 12114

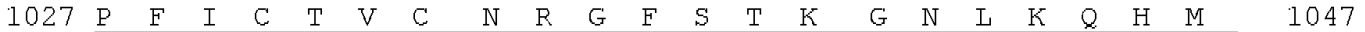

$12115 \overline{C C G T T C A T T T G C A C A G T T T G C}$ AATCGTGGCTTTTCCACAAAG GGTAATTTGAAGCAGCACATG 12177

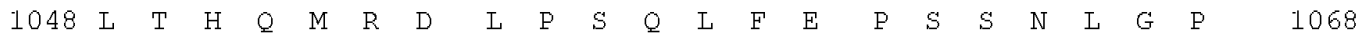

12178 TTGACACATCAGATGCGAGAT CTGCCATCGCAGCTCTTTGAG CCCAGTTCCAACCTCGGCCCC 12240

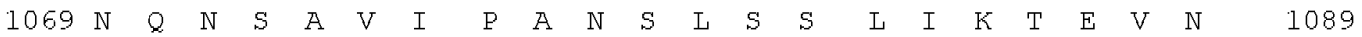

12240 AATCAGAACTCTGCAGTGATT CCCGCCAACTCGCTGTCATCT CTCATCAAAACAGAGGTCAAC 12303

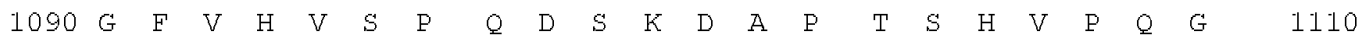

12304 GGCTTTGTACACGTTTCTCCT CAGGACAGTAAGGACGCCCCC ACTAGTCATGTCCCTCAGGGG 12366

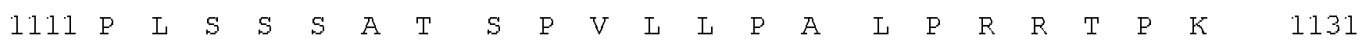

12367 CCTCTGTCGTCCTCTGCGACA TCCCCAGTTCTGCTCCCAGCT CTGCCCCGGAGAACTCCCAAA 12429

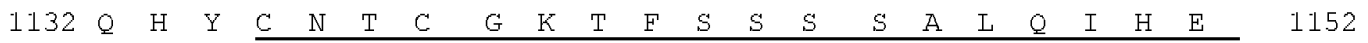

12430 CAGCACTATTGTAACACGTGT GGTAAAACCTTCTCTTCTTCG AGTGCCCTGCAGATCCACGAG 12492

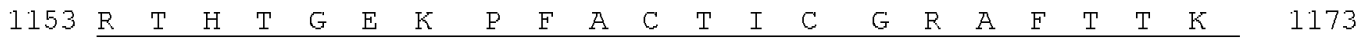

12493 AGAACTCACACTGGAGAGAAG CCCTTTGCTTGCACTATCTGT GGAAGAGCATTCACAACAAAA 12555

1174 G N L K 1177

12556 GGCAATCTGAAGgtaccaat ttattcaaggcgttgggacag ...ttctctctcttcccccaa 13684

$\begin{array}{llllllllllllllllllll}1178 & \text { V } & H & M & G & \text { T } & \text { H } & \text { M } & \text { W } & \text { N } & \text { S } & \text { T } & \text { P } & \text { A } & \text { R } & \text { R } & \text { G } & \text { R } & & 1194\end{array}$

13685 cccacattacagGTCCACATG GGCACCCATATGTGGAACAGC ACCCCTGCACGCCGGGGCCGG 13747 


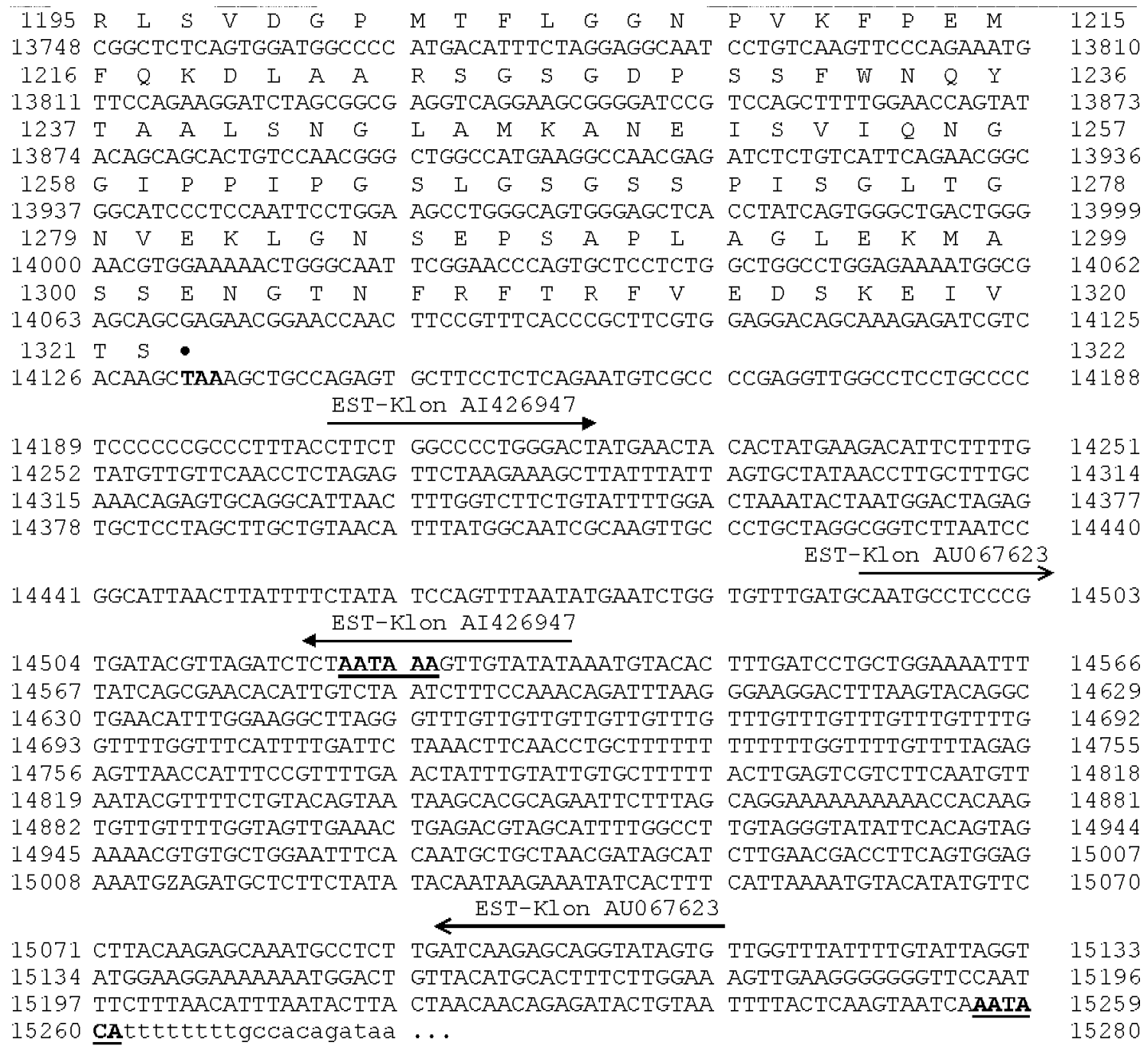

Abbildung 3.2: Genomische Nukleotidsequenz des Sall1-Gens und die abgeleitete Aminosäuresequenz des offenen Leserahmens. Die Sequenz des kodierenden Stranges der cDNA ist in Großbuchstaben angeführt. Die abgeleitete Aminosäuresequenz ist oberhalb der Nukleotidsequenz angeordnet und das Startkodon sowie die Exon/Intron-Übergänge durch Fettdruck hervorgehoben. Intronische Bereiche sind nur partiell angegeben. Die Zinkfingermotive sind unterstrichen, die Poly-AS sind unterstrichen und bezeichnet. Das Stoppkodon nach dem offenen Leserahmen wurde mit $\bullet$ gekennzeichnet. Die Start- und Endpunkte der überlappenden Bereiche zwischen den EST-Klonen und der 3'-UTR sind durch Pfeile gekennzeichnet und die Klon-Nummern angegeben. Die Nummerierungen für die Nukleotid- und Aminosäuresequenz sind auf beiden Seiten angegeben. 


\subsubsection{Chromosomale Lokalisation von Sall1}

Mittels Fluoreszenz-in situ-Hybridisierung (s. 2.9.11.8) wurde die chromosomale Lokalisation des Sall1-Gens durchgeführt. Dazu wurden Metaphasenpräparate der Maus-Zellline WMP-1 (Zörnig et al., 1995) mit einer biotinmarkierten Sonde des Cosmid-Klons CosJ hybridisiert. Die Abbildung 3.3 zeigt die Lokalisierung von Sall1 auf Chromosom 8D der Maus.

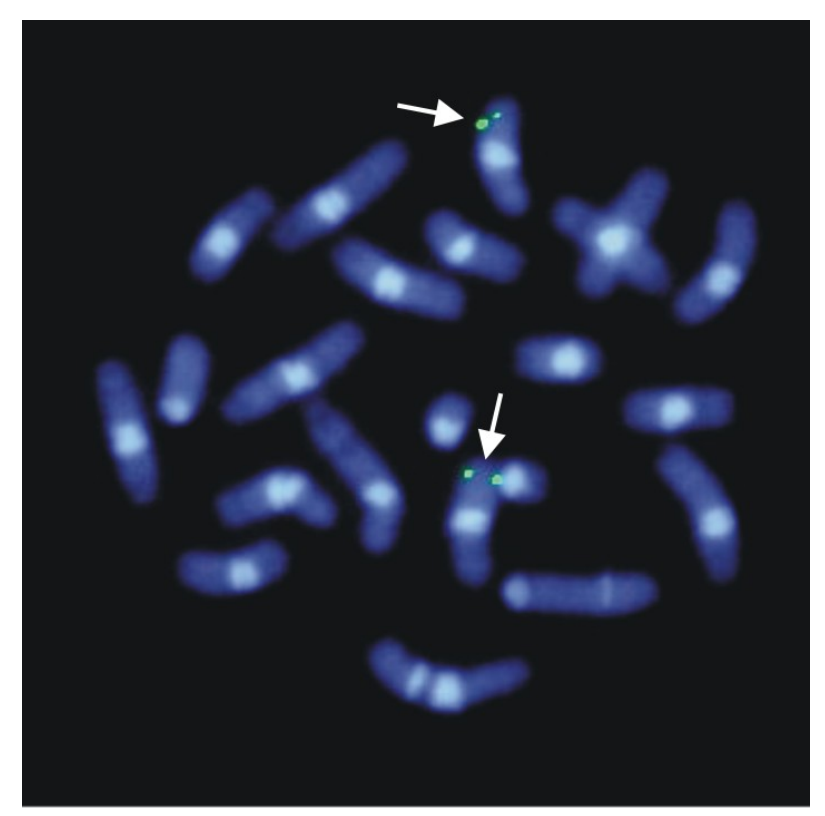

Abbildung 3.3: Chromosomale Lokalisation des Sall1-Gens. Der Cosmidklon Cos J (RZPDKlon-Nr. MPMGc121J23368Q3) wurde als Sonde an murinen Metaphasechromosomen der MausWMP-1-Zelllinie eingesetzt. Die Pfeile deuten auf die spezifischen Hybridisierungssignale auf den Chromosomen $\mathrm{Rb}$ (8.9) an der Position 8D.

\subsection{Untersuchungen zur Expression des Sall1-Gens der Maus}

\subsubsection{Expression in adulten Geweben}

Für die Expressionsanalyse in adulten Geweben wurde von jedem untersuchten Gewebe $20 \mu \mathrm{g}$ Gesamt-RNA für einen Northern-Blot (s. 2.9.9.2) eingesetzt. Die Hybridisierung erfolgte bei $65^{\circ} \mathrm{C}$ mit der Sonde CBO (s. Abb. 3.1). Die stärkste 
Expression war in Niere und Gehirn festzustellen (s. Abb. 3.4), zusätzlich wurden Sall1-Transkripte auch in Leber, Testis und Herz gefunden. In Skelettmuskel und Lunge konnten keine Sall1-Transkripte festgestellt werden. Das Transkript zeigte eine Größe von ca. $5.5 \mathrm{~kb}$. Die Integritätskontrolle und Quantifizierung erfolgte durch eine zweite Hybridisierung mit dem humanen Elongationsfaktor 2 (HEF-2, s. 2.2).

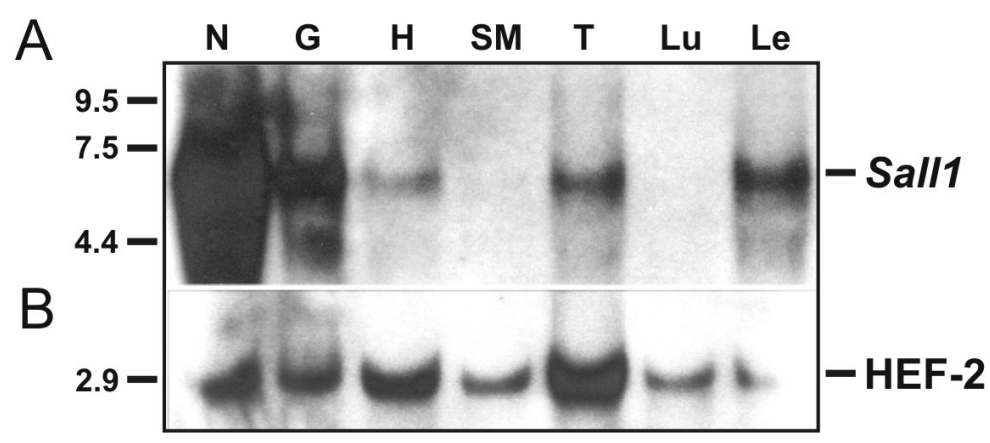

Abbildung 3.4: Northern-Blot-Analyse des Sall1-Gens in adulten Geweben. Je $20 \mu \mathrm{g}$ GesamtRNA wurden für die Northern-Blot-Analyse eingesetzt und mit der Sonde $\mathrm{CB} 0$ bei $65^{\circ} \mathrm{C}$ hybridisiert. Die Abb. A zeigt die Detektion des Sall1-Transkripts in RNA aus Niere, Gehirn, Herz, Testis und Leber, in RNA aus Skelettmuskel und Lunge konnten dagegen keine Transkripte festgestellt werden. Die Transkriptlänge liegt bei ca. $5.5 \mathrm{~kb}$. Die Abb. B zeigt die Nachhybridisierung mit der HEF-2-Sonde. N: Niere; G: Gehirn; H: Herz; SM: Skelettmuskel; T: Testis; Lu: Lunge; Le: Leber.

\subsubsection{Expression in neuralen Embryonalgeweben}

Die Expression des Sall1-Gens in Embryonen wurde mit Hilfe der whole mountin situ-Hybridisierung untersucht. Dazu wurden Embryonen von 7.0-12.5 dpc präpariert sowie Metanephren aus 14.5 bzw. 18.5 dpc Embryonen isoliert. Zur genaueren Analyse wurden einige gefärbte Embryonen in Gelatine eingebettet und mit einem Vibratom auf $20-80 \mu \mathrm{m}$ geschnitten. Von $12.5 \mathrm{dpc}$ Embryonen und den Metanephren wurden $7 \mu \mathrm{m}$ dicke Paraffin-Schnitte angefertigt und für die in situ-Hybridisierung an Schnitten verwendet. Zur Hybridisierung wurde der DIGmarkierte antisense-Strang des Fragments CB3 E (s. Abb. 3.1) eingesetzt.

Ab $7.5 \mathrm{dpc}$ wird eine Sall1-Expression im neuralen Ektoderm in einer breiten anterioren Region im zukünfitigen Kopf detektiert (s. Abb. 3.5.A). Diese Expression bleibt bis $8.5 \mathrm{dpc}$ bestehen, wobei eine zusätzliche Expressionsdomäne in der Neuralgrube zu sehen ist (s. Abb. 3.5.B). An 9.5 dpc sind Transkripte in der 
Mittelhirn-Rautenhirngrenze, der anterioren Region des Mittelhirns und der olfaktorische Plakode zu finden (s. Abb. 3.5.C,D). In späteren Stadien kann ein Signal ebenfalls im Telencephalon und im medialen Nasalprozess sowie den Olfaktorischen Bulbi detektiert werden (s. Abb. 3.5.G,J,L). Sall1-Expression ist auch in dem Gewebe, das die lateralen Ventrikel sowie den dritten und vierten Ventrikel umgibt, festzustellen (s. Abb. 3.5.N). Im Neuralrohr können Signale ab 9.5 dpc bis mindestens $12.5 \mathrm{dpc}$ im Bereich der ependymalen Schicht und der Mantelschicht gefunden werden (s. Abb. 3.5.C,F,G,M).

\subsubsection{Expression in anderen Embryonalgeweben}

Von 8.5 bis mindestens $10.5 \mathrm{dpc}$ wird Sall1-Expression im posterioren Bereich und neuformierten Mesoderm der Embryonen detektiert (s. Abb. 3.5.B,C,G). An 8.5 und $9.5 \mathrm{dpc}$ sind Transkripte im Bereich der Branchialbögen zu finden (s. Abb. 3.5.B,C,E), und an $9.5 \mathrm{dpc}$ in dem Mesenchym, das die Mundhöhle auskleidet (s. Abb. 3.5.E). Des Weiteren sind Signale im Meso- und Metanephros (s. Abb. 3.5.C,F,P,Q) und im Epithel des Genitalhöckers (s. Abb. 3.5.K,N) festzustellen. An 12.5 dpc sind Transkripte im Mesenchym des Oropharynx, genauer in dem Bereich der Gabelung des Oropharynx in Trachea und Oesophagus, vorhanden (s. Abb. 3.5.O). Von 10.5 bis mindestens $12.5 \mathrm{dpc}$ kann Sall1-Expression in der Augenlinse detektiert werden (s. Abb. 3.5.G,H,I,L).

\subsubsection{Expression in den Gliedmaßenknospen}

Sall1-Expression kann in allen untersuchten Embryonalstadien in den GliedmaBenknospen detektiert werden (s. Abb. 3.6). Zu Beginn der Gliedmaßenentwicklung $(10.5 \mathrm{dpc})$ ist eine verstärkte Expression im posterioren Bereich der Handknospe zu beobachten, ab $11.5 \mathrm{dpc}$ werden die Transkripte zusätzlich anterior detektiert (s. Abb. 3.6.A,B,D). Ab $11.5 \mathrm{dpc}$ teilt sich die Expression in eine proximale Domäne im Bereich der Handplatte und eine distale Domäne in der epithelialen Randleiste (ERL) sowie dem darunter befindlichen Mesenchym (s. Abb. 3.6.B,E). Bei der ERL handelt es sich um eine Schicht von Zellen, die im distalen GliedmaBenbereich angesiedelt sind und eine wichtige Rolle bei der Produktion und Steuerung von Signalen zur proximodistalen Entwicklung der Gliedmaßen einnehmen. In der proximalen Region werden Sall1-Signale sowohl in dorsalen und ventralen Geweben als auch einer breiteren posterioren und schmaleren anterioren Region der Handplatte detektiert (s. Abb. 3.6.C,D,G). Ab 13.5 dpc ist eine Abnahme der 

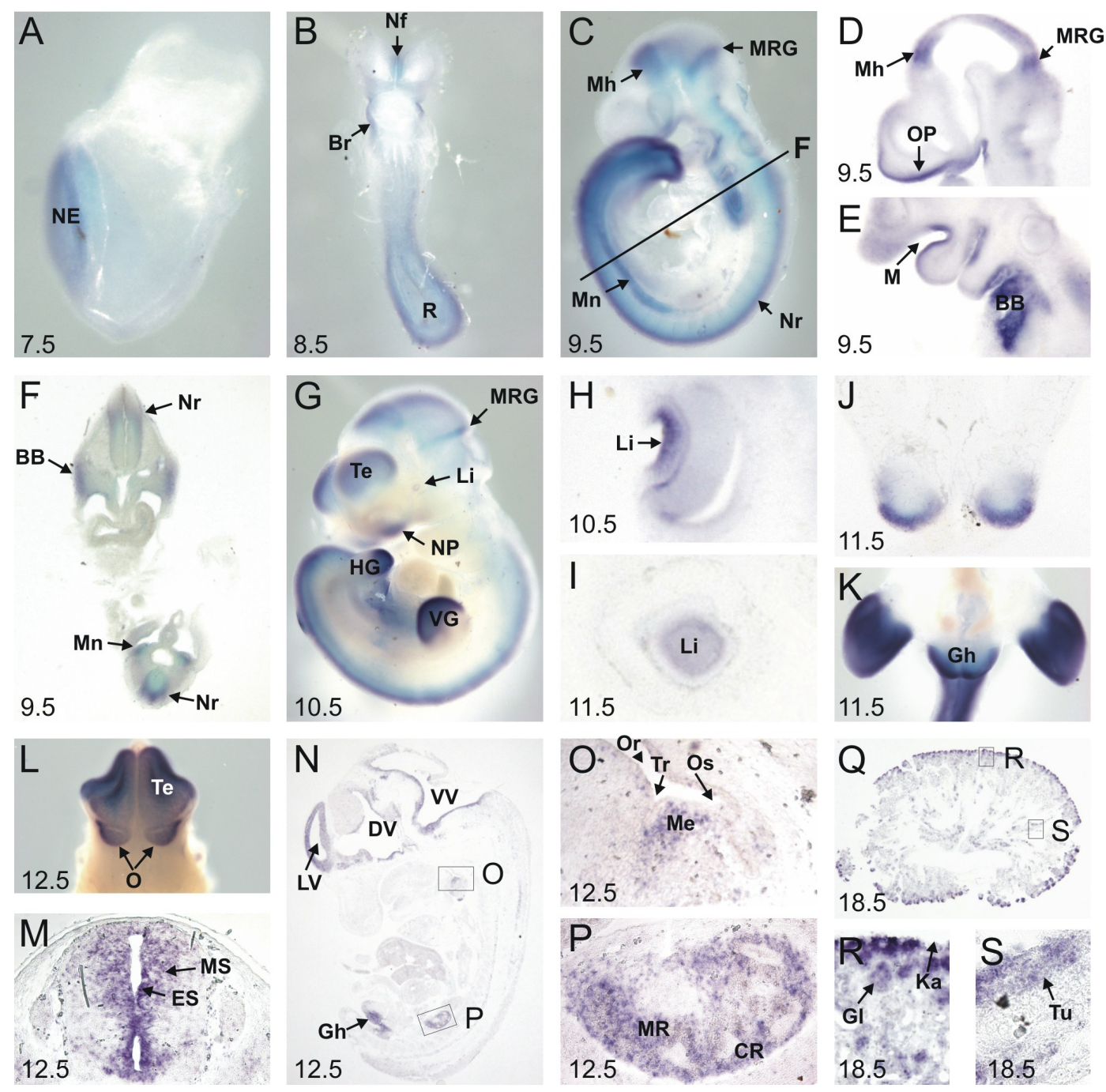

Abbildung 3.5: Expression des Sall1-Gens während der Embryonalentwicklung der Maus. $A, B, C$ und $G$ zeigen whole mount-in situ-Hybridisierungen, $K$ und $L$ Ausschnitte von whole mountgefärbten Embryonen. In $\mathrm{D}, \mathrm{E}, \mathrm{F}, \mathrm{H}, \mathrm{I}$ und $\mathrm{J}$ sind Vibratom-Schnitte von whole mount-in situgefärbten Embryonen gezeigt, in $\mathrm{M}, \mathrm{N}$ und $\mathrm{Q}$ in situ-Hybridisierungen an Mikrotom-Schnitten von in Paraffin eingebetteten Embryonen. Die jeweiligen Altersstadien sind angegeben. BB: Dritter und vierter Branchialbogen; Br: Branchialbögen; CR: cortikale Region; DV: Dritter Ventrikel; ES: ependymale Schicht; Gh: Genitalhöcker; Gl: Glomerulus; HG: Hintere Gliedmaßenknospe; Ka: Kapsel; Li: Linsenvesikel; LV: Lateraler Ventrikel; M: Mundhöhle; Me: Mesenchym; Mh: Mittelhirn; Mn: Mesonephros; MR: medulläre Region; MRG: Mittelhirn-Rautenhirn-Grenze; Ms: Mantelschicht; NE: neurales Ektoderm; Nf: Neuralfurche; NP: Medialer Nasalprozess; Nr: Neuralrohr; O: Bulbus olfaktorius; OP: Olfaktorische Plakode; Or: Oropharynx; Os: Oesophagus; R: Rumpfregion; Te: Telencephalon; Tr: Trachea; Tu: Tubulus; VG: Vordere Gliedmaßenknospe; VV: Vierter Ventrikel. 
Expression in den dorsalen Geweben zu beobachten, jedoch nicht auf der ventralen Seite der Gliedmaßenknospen (s. Abb. 3.6.I,J,L,M). Das Gewebe zwischen den Fingerstrahlen zeigt eine schwache Färbung an $12.5 \mathrm{dpc}$ (s. Abb. 3.6.F). Im distalen Bereich beschränkt sich die Sall1-Transkription zunehmend auf das Mesenchym unter den phalangealen Spitzen, in dem eine Abnahme von $14.5 \mathrm{dpc}$ an beobachtet werden kann (s. Abb. 3.6.H,J,K,L).

A

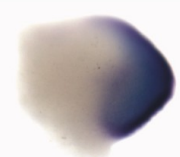

10.5

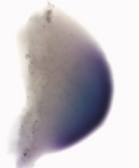

$\mathrm{H}$
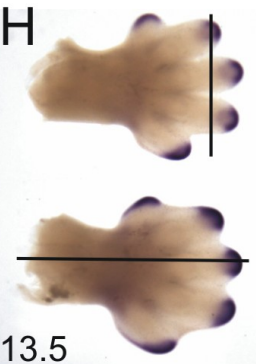

B
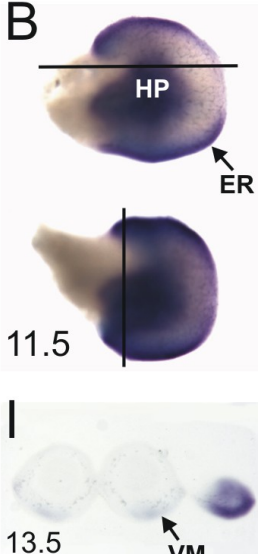

13.5

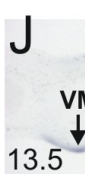

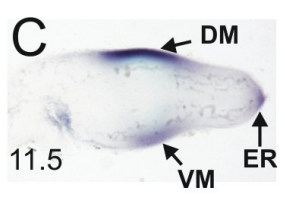

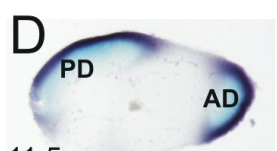

11.5

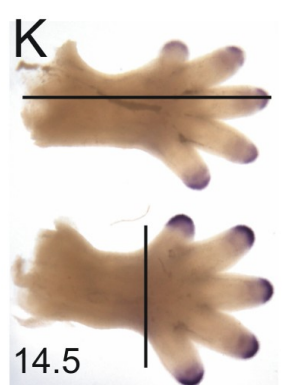

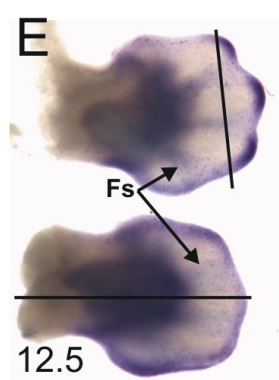
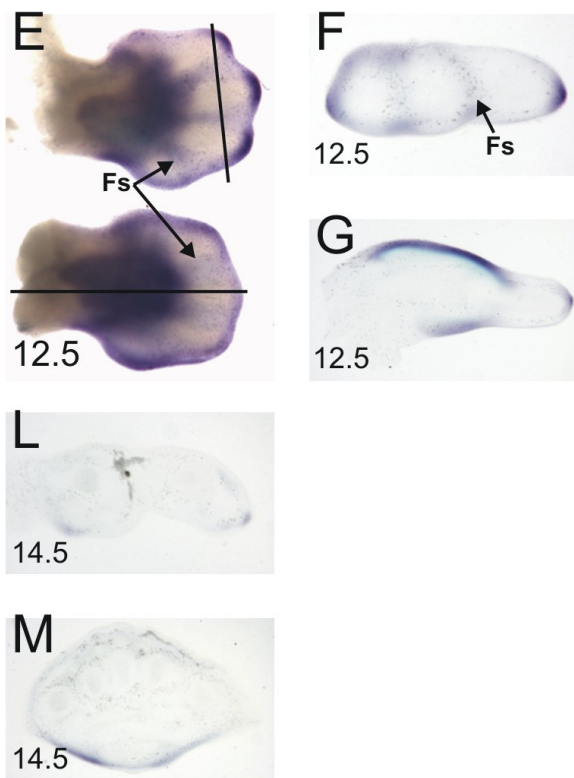

Abbildung 3.6: Expression des Sall1-Gens während der Gliedmaßenentwicklung. In allen Bildern sind die Gliedmaßenknospen mit der dorsalen Seite zum Betrachter abgebildet, die anteriore Seite ist nach oben gerichtet. Die oberen der paarweise angeordneten Gliedmaßen sind jeweils die vorderen, die unteren die hinteren Gliedmaßenknospen. Die Vibratomschnitte wurden aus den whole mount-gefärbten Gliedmaßen zur linken angefertigt, die schwarzen Linien deuten die Schnittebene an. Die sagittalen Schnitte zeigen mit der proximalen Seite nach links, die transversen Schnitte mit der posterioren Seite nach links. ER: Epitheliale Randleiste; DM: dorsales Mesenchym; VM: ventrales Mesenchym; FZ: Bereich zwischen den sich entwickelnden Fingern bzw. Zehen; PD: posteriore Expressionsdomäne; AD: anteriore Expressionsdomäne. Weitere Erläuterungen befinden sich im Text. 


\subsection{Homologe Rekombination des Sall1-Gens}

Um die Funktion eines Gens in vivo zu untersuchen, bietet sich die Erzeugung von knock out-Mäusen an, in denen gezielt ein Gen ausgeschaltet ist. Mit Hilfe eines Targeting-Vektors werden in embryonalen Stammzellen (ES-Zellen) endogene Sequenzen im Allel gegen speziesfremde DNA-Fragmente ausgetauscht, wodurch das Gen inaktiviert wird (Ausubel et al., 1994; Capecchi, 1989). Der Austausch erfolgt durch genomische Fragmente, die die speziesfremde DNA flankieren, deren Gesamtgröße $\geq 7 \mathrm{~kb}$ betragen sollte (Joyner, 2000) und die in richtiger Anordnung und Orientierung in den Vektor kloniert sind.

Der Targeting-Vektor pTKneo (s. 2.7.2), dessen Gesamtgröße 8.3 kb beträgt, basiert auf dem pBluescript-Vektor und enthält somit eine Ampicillin-Resistenz zur Selektion auf geeigneten Agarplatten (s. 2.6.1). Zusätzlich wurde eine Neomycinkassette, die einen Promotor und ein Polyadenylierungssignal der Phosphoglyceratkinase (PGK) besitzt und die Resistenz gegen G418 (s. 2.11.2) bewirkt, in den Vektor integriert. Zur Negativselektion der embryonalen Stammzellen sind zwei Herpes simplex-Virus 1-Thyrosinkinase-Gene (HSV-TK) in 5'-Richtung der Neomycinkassette vorhanden. In 5'- und 3'-Richtung der Neomycinkassette befinden sich Polylinker-Sequenzen, die zur Klonierung von homologen Sequenzen in 5'und 3'-Richtung der zu deletierenden Gen-Sequenz dienen.

\subsubsection{Herstellung eines Sall1-knock out-Konstrukts}

Der knock out des murinen Sall1-Gens sollte durch die vollständige Deletion von Exon 2 und 3 erfolgen, die mit insgesamt 3899 bp nahezu die gesamte kodierende Sequenz mit allen ZF-Domänen beinhalten. Mit dieser Strategie blieb also nur Exon 1, das für keine funktionelle Domäne zu kodieren scheint, erhalten. Für die Herstellung des knock out-Konstrukts war es nötig, mehr Informationen aus dem 3'-Bereich des Gens zu gewinnen. Da kein weiteres Fragment 3' von CE 0.95 aus Cos $C$ gefunden werden konnte (s. Abb. 3.1), wurde angenommen, dass dieser Cosmidklon dort endete. Als das am weitesten 3 '-wärts gelegene Fragment wurde CE 0.95 für die Hybridisierung des zweiten positiven Cosmidklons, Cos J, eingesetzt. Es konnte ein Bam HI-Fragment (JBa1) isoliert werden, das ausreichend Information über den 3'-Bereich von Sall1 enthielt. Zur Klonierung in den pTKneo-Vektor wurde ein $6.2 \mathrm{~kb}$ Xho I/Cla I-Fragment in 5'-Richtung von Exon 2 und ein $1.1 \mathrm{~kb}$ Xba I-Fragment mit $566 \mathrm{bp}$ aus Intron 2, dem gesamten Exon 2 sowie 139 bp aus der 3'-UTR gewählt. 


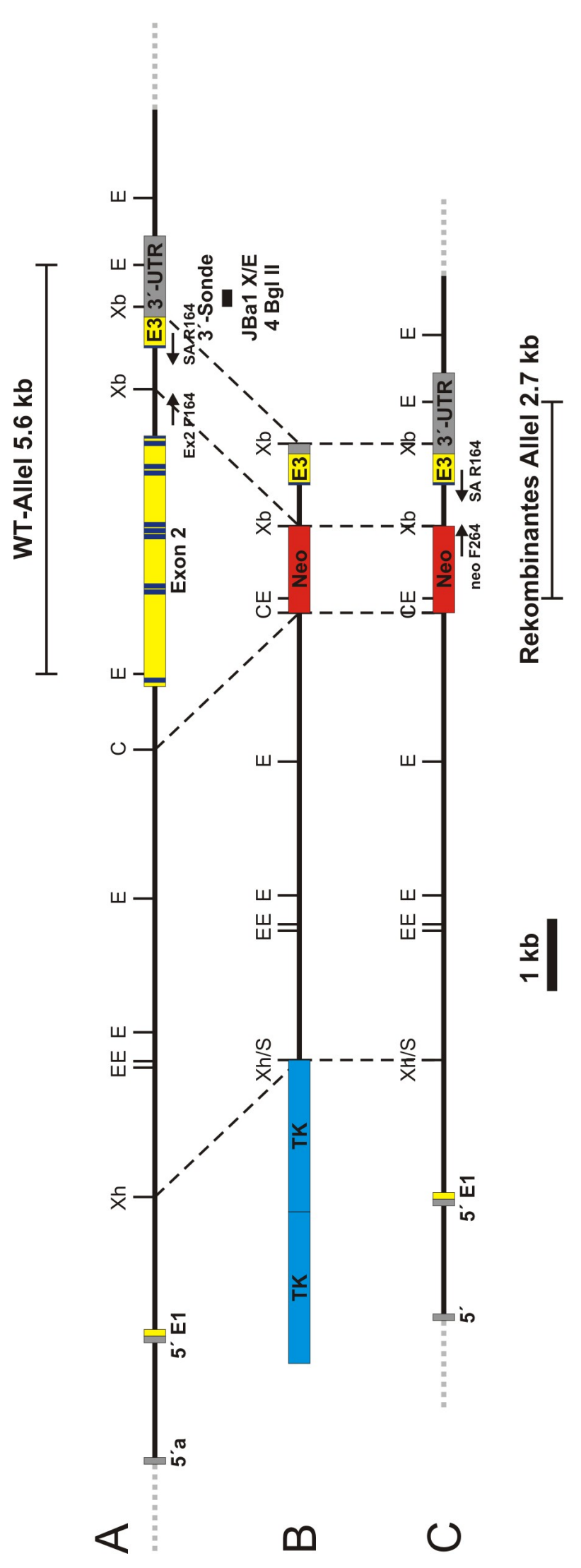

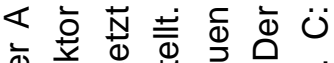
壱 牙 ⿺辶寸

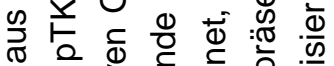
$\sum$ 竞 む)

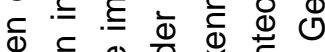

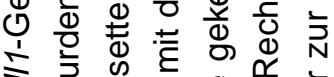
ஸึ

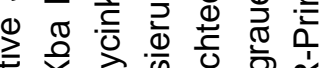
究

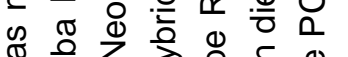

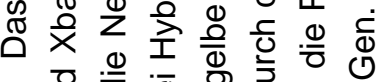
i

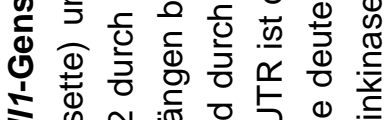
ஸิ \& $\frac{x}{0}$ 竞 ○ है

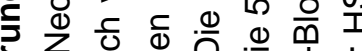
ฮั

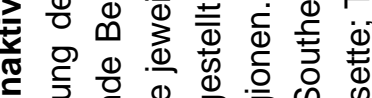

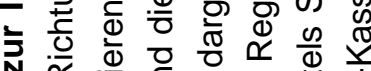
당

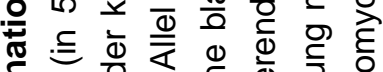

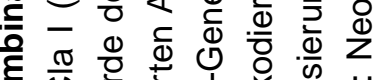

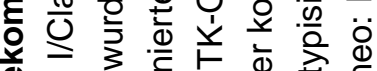

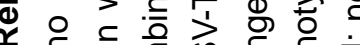
丘 $\frac{1}{\bar{x}}$ के ब

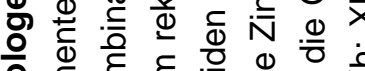

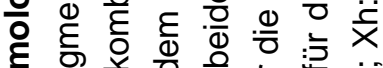

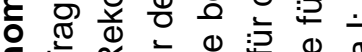

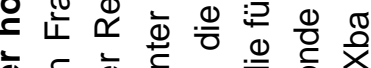

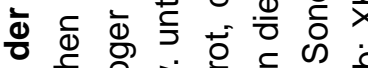

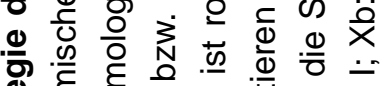

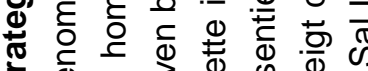
क ब

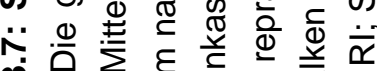

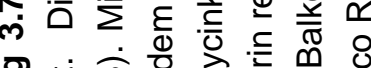

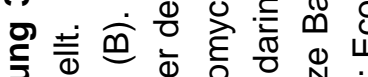

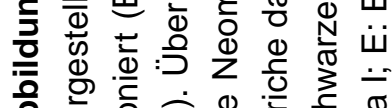

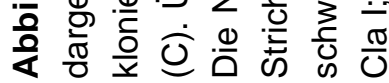


Zunächst wurde das $3^{\prime}$-Fragment in den Vektor ligiert und ein Klon mit richtiger Orientierung des Fragments durch Sequenzierung identifiziert. Das 5'-Fragment konnte danach aufgrund der passenden Schnittstellen gerichtet in die Sal I/Cla I-Schnittstellen des so linearisierten Vektors kloniert werden. Die Gesamtgröße des Sall1-knock out-Konstrukts beträgt $15.2 \mathrm{~kb}$, die Strategie ist in Abb. 3.7 dargestellt. Abb. 3.8 zeigt die Überprüfung des klonierten knock out-Konstrukts mittels restriktionsenzymatischer Spaltung.

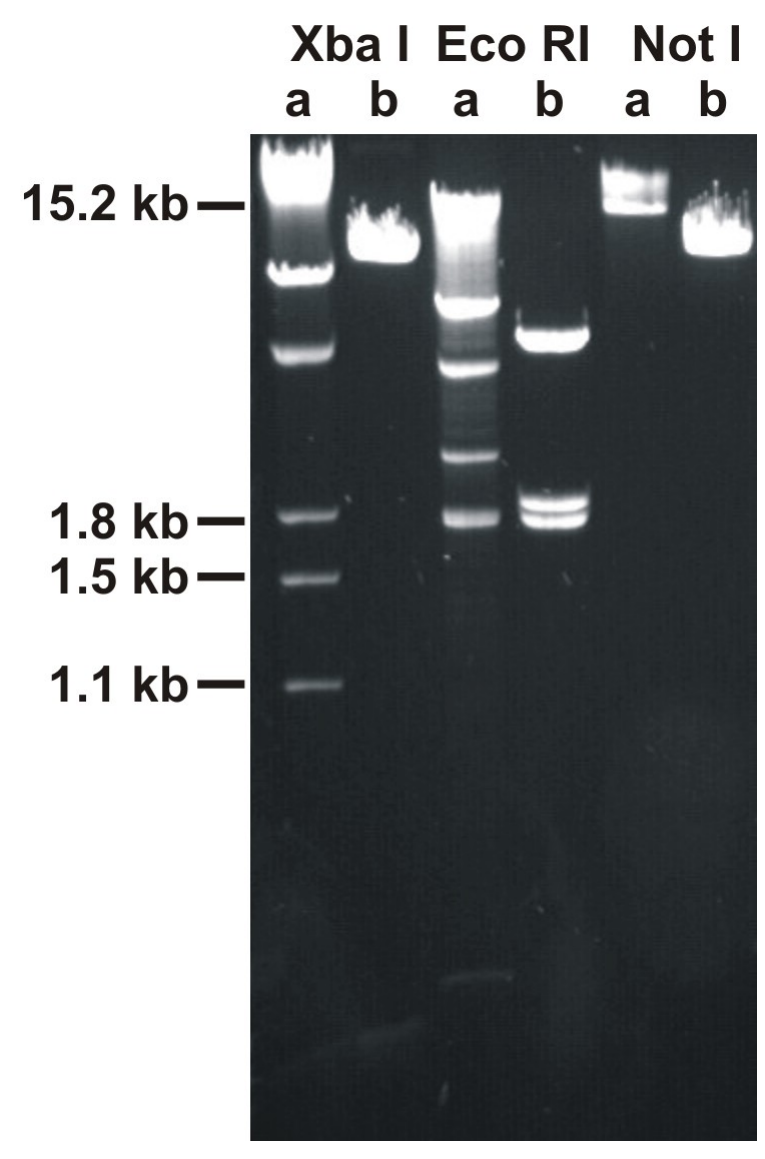

Abbildung 3.8: Restriktionsanalyse des Sall1-knock out-Konstrukts. In den mit a bezeichneten Spuren wurde restriktionsenzymatisch gespaltene Sall1-knock out-Konstrukt-DNA aufgetrennt, in den mit $\mathbf{b}$ bezeichneten Spuren der pTKneo-Vektor ohne Insert. Anhand der Restriktion mit Xba I, das in der Multiple Cloning Site des Vektors restringiert, konnte die Anwesenheit des $3^{\prime}$-Fragments $(1.1 \mathrm{~kb})$ und die richtige Orientierung des $5^{\prime}$-Fragments geprüft werden $(1.5 \mathrm{~kb})$. Mittels Eco RI-Analyse wurde das Vorhandensein beider Gene für die Thymidinkinase im knock out-Konstrukt und pTKneo-Vektor bestätigt (1.8 kb). Die Restriktion mit Not I, das zur Linearisierung des fertigen Konstrukts dienen sollte, zeigt die Anwesenheit nur einer Restriktionsschnittstelle sowie die Gesamtgröße des klonierten knock out-Konstrukts von $15.2 \mathrm{~kb}$. 
Anhand der Restriktion mit Xba I, das in der Multiple Cloning Site des Vektors schneidet, konnte die Anwesenheit des 3'-Fragments (1.1 kb) und die korrekte Orientierung des 5'-Fragments verifiziert werden (1.6 kb). Mittels Eco RI-Analyse wurde das Vorhandensein beider HSV-TKs im knock out- und pTKneo-Vektor bestätigt (1.8 kb). Die Restriktion mit Not I, das zur Linearisierung des fertigen Konstrukts dienen sollte, zeigt die Anwesenheit nur einer Restriktionsschnittstelle.

\subsubsection{Herstellung von homolog rekombinierten embryonalen Stammzellen}

RI-ES-Zellen wurden wie unter 2.11.2 beschrieben elektroporiert und 43 resistente ES-Zellklone isoliert (s. 2.11.3). Die von der duplicate plate isolierte ES-DNA wurde mit Eco RI geschnitten und nach gelelektrophoretischer Auftrennung auf eine Nitrocellulosemembran transferiert. Die Hybridisierung erfolgte mit der externen 240 bp-langen 3'-Sonde JBa1 X/E4 Bgl II sowie der internen NeomycinSonde neo (s. 2.2). Aufgrund des hohen A/T-Gehalts der relativ kurzen 3'-Sonde erfolgte die Markierung mit $\left[\alpha^{-32}\right] P$ dATP (s. 2.9.3.5). Das WT-Allel wurde durch ein Fragment von $5.7 \mathrm{~kb}$, das rekombinierte durch eines von $2.7 \mathrm{~kb}$ repräsentiert (s. Abb. 3.9). Von den 43 getesteten ES-Zellklonen erwiesen sich 27 Klone als positiv. Alle positiven Klone zeigten ein Hybridisierungssignal von $2.8 \mathrm{~kb}$ mit der Neomycin-Sonde (Daten nicht gezeigt).

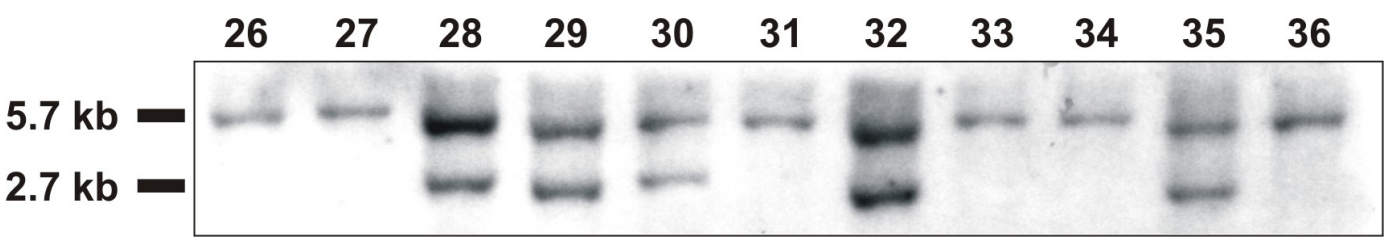

Abbildung 3.9: Genotypisierung der ES-Zellklone mittels Southern-Blot. Die genomische ESZell-DNA wurde mit dem Enzym Eco RI restriktionsenzymatisch gespalten. Die Hybridisierung erfolgte mit der exernen $3^{\prime}$-Sonde JBa1 X/E4 Bgl II, positive Klone zeigen das native Allel durch eine Bande bei $5.7 \mathrm{~kb}$ sowie das mutierte Allel bei $2.7 \mathrm{~kb}$. Die Zelllinien 28, 29, 30, 32 und 35 erwiesen sich als heterozygot für die eingefügte Mutation.

\subsubsection{Generierung von Sall1-defizienten Mäusen}

Die Injektion von rekombinanten ES-Zellen Blastocysten und deren Transfer in pseudoschwangere Mäuse wurde von MitarbeiterInnen des Max-Planck-Instituts 
für Experimentelle Medizin, Göttingen, durchgeführt. 6 männliche Mäuse mit 60$100 \%$ Chimärismus wurden im hauseigenen Tierstall mit Weibchen der Mauslinien C57BL und 129/SvJ verpaart. Die Genotypisierung der Nachkommen konnte im Rahmen der vorliegenden Arbeit nicht mehr durchgeführt werden. Die vorgesehene PCR wurde mit drei verschiedenen Primern etabliert, zwei Primer stammen aus dem nativen Gen und ein Primer aus der inserierten Neokassette (s. Abb. 3.7). Die Primerkombination Ex2 F164 / SA R164 ergibt ein Produkt des nativen Allels von ca. 400 bp, mit dem Vorwärtsprimer neo F264 aus dem Targeting-Vektor und SA R164 entsteht ein Produkt von ca. 750 bp.

\subsection{Herstellung eines monospezifischen Anti-Sall1-Antikörpers}

\subsubsection{Auswahl von Peptiden zur Immunisierung von Kaninchen}

Zur Herstellung eines spezifischen Anti-Sall1-Antikörpers wurden von der Firma Eurogentec aus der von der humanen SALL1-cDNA abgeleiteten Aminosäuresequenz Regionen herausgesucht, die geeignete Epitope darstellen sollten. In diesen Regionen wurden anschließend zwei Peptide (S1-I und S1-II) ausgewählt, die eine relativ hohe Homologie zwischen dem murinen Sall1- und dem humanen SALL1-Protein aufweisen (s. Abb. 3.10, 3.11). Gegen diese Peptide wurden Antiseren in Kaninchen hergestellt, deren Aufreinigung im Folgenden beschrieben wird.

\subsubsection{Herstellung von Sall1- und SALL1-Fusionsproteinen}

Die Aufreinigung der Antiseren sollte über Strep-tag-Fusionsproteine erfolgen, die in den Bereichen des murinen bzw. humanen Proteins liegen, aus denen die Peptide zur Immunisierung eingesetzt wurden (s. Abb. 3.12). Ensprechend wurden für die Herstellung der Konstrukte zur Generierung von Sall1-Fusionsproteinen PCRs mit den Primerpaarungen MS1FP F1 / MS1FP R1 (MS1-I, PCR-Produkt von 696 bp) und MS1FP F2 / MS1FP R2 (MS1-II, PCR-Produkt von 669 bp) etabliert (s. 2.10.1.1). Als Template für die Amplifikation von MS1-I diente der Sall1-Klon CB3, für die Amplifikation von MS1-II der Sall1-Klon CK4. Für die Herstellung 


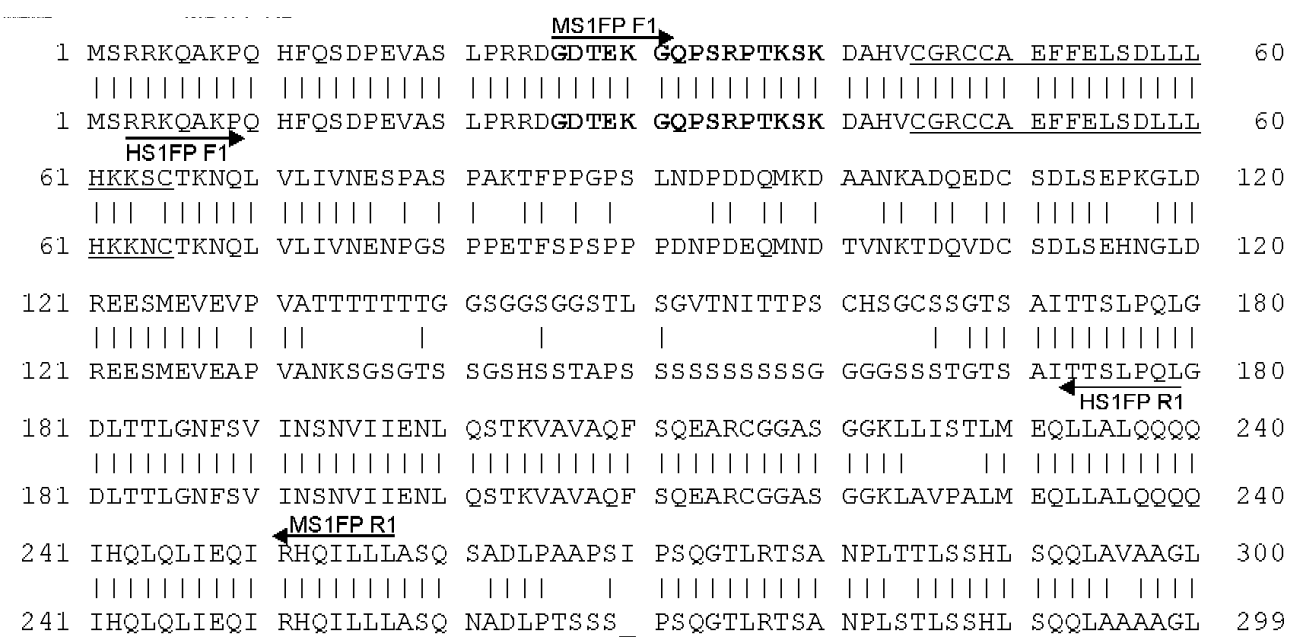

Abbildung 3.10: Homologievergleich zwischen den abgeleiteten Aminosäuresequenzen von Sall1 und SALL1 im Bereich des Peptids S1-I. Die obere Sequenz stellt die aus dem murinen Sall1-Gen abgeleitete Aminosäuresequenz dar, die untere ist die aus dem humanen SALL1Gen abgeleitete Sequenz. Das $\mathrm{C}_{2} \mathrm{HC}$-Zinkfingermotiv ist unterstrichen. Das für die Immunisierung engesetzte Peptid S1-I ist fett gedruckt, die Pfeile symbolisieren die Primer zur Herstellung der murinen und humanen Fusionsproteine.

\begin{tabular}{|c|c|c|c|c|c|c|}
\hline & & & FPF? & & & \\
\hline 719 & ALKMHYRTHT & GERPFKCKIC GRAFTTKGNL & KTHYSVHRAM & PPLRVOHSCP & ICOKKFTNAV & 78 \\
\hline & |||||||||| & |||||||||||||||||||||| & |||||||||| & |||||||||| & |||||||||| & \\
\hline 720 & $\underline{\text { ALKMHYRTHT }}$ & GERFFKCKIC GRAFTTKGNL & KTHYSVHRAM & EPLRVQHSCP & ICOKKFT & \\
\hline 79 & VLQQH I RMHM & GGQI PNTPVP DNYPESMESD & $\begin{array}{r}\text { HS1F } \\
\text { TGSEDEKNFD }\end{array}$ & $\begin{array}{l}\text { PF2 } \\
\text { DLDNFSDENM }\end{array}$ & EECPEGSIPD & 838 \\
\hline & |||||||||| & |||||||||||||||||| $\mid$ & |||||||||| & |||||||||| & |||||||| $\mid$ & \\
\hline 780 & VLQQH I RMHM & GGQI PNTPVP DSYSESMESD & TGSFDEKNFD & DLDNFSDENM & EDCPEGSIPD & \\
\hline 39 & TPKS & SLSSSPLPLE MSSIAALENQ & MKMINAGLAE & $Q L Q A$ & NGSN & \\
\hline & $|1|$ & | | & & I & | | & \\
\hline 40 & TEKSADASQD & SLSSSPLPLE MSSIAALENO & MKMINAGLAE & OLQASLKSVE & NGSIEGDVLT & \\
\hline 99 & NDS & PAI SEST & TQEFH & KSPGMEEKPQ & RVGPG & \\
\hline & 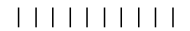 & | 111 & |||||||||| & ||||| | | | | & $1 \quad 1$ & \\
\hline 900 & $\begin{array}{r}\text { NDSSSVGGDM } \\
\text { MS1FP }\end{array}$ & $\begin{array}{l}\text { ESOSAGSPAI SESTSSMQAL } \\
\text { R2 }\end{array}$ & SPSNSTQEFH & KSPSIEEKFQ & RAVPSEFANG & \\
\hline 959 & LSPTPVNGGA & LDLTSSHAEK IIKEDSLGIL & FFFRDRGKFK & NTACDICGKT & FACOSALDIH & 018 \\
\hline & $|1|||||||||$ & $111111111111111111111 \mid$ & ||।||।|||| & $|1| 1||||||$ & 11 & \\
\hline 60 & LSPTPVNGGA & LDLTSSHAEK IIKEDSLGIL & FPFRDRGKFK & NTACDICGKT & FACOSALDIH & \\
\hline
\end{tabular}

Abbildung 3.11: Homologievergleich zwischen den abgeleiteten Aminosäuresequenzen von Sall1 und SALL1 im Bereich des Peptids S1-II. Die obere Sequenz stellt die aus dem murinen Sall1-Gen abgeleitete Aminosäuresequenz dar, die untere ist die aus dem humanen SALL1Gen abgeleitete Sequenz. Die Bereiche, die DZF-Motiven entstammen, sind unterstrichen. Das für die Immunisierung engesetzte Peptid S1-II ist fett gedruckt, die Pfeile symbolisieren die Primer zur Herstellung der murinen und humanen Fusionsproteine. 
der Konstrukte von SALL2-Fusionsproteinen wurden PCRs mit den Primerpaarungen HS1FP F1 / HS1FP R1 (HS1-I, PCR-Produkt von 531 bp) und HS1FP F2 / MS1FP R2 (HS1-II, PCR-Produkt von 624 bp) etabliert (s. 2.10.1.1). Hier dienten als Templates für HS1-I der cDNA-Klon Exon1/2 (Blanck, 2000) und für HS1-II der Klon GT11/6 (Kohlhase, 1996). Die Primer sind in der Tabelle 2.7.5 sowie den Abbildungen 3.10 und 3.11 aufgeführt. Die Positionen der Fragmente innerhalb des Proteins sind in Abbildung 3.12 dargestellt. Die Amplifikate wurden mit Bsa I restriktionsenzymatisch gespalten und in den ebenfalls mit Bsa I linearisierten Vektor IBA2 ligiert. Mehrere aus der Transformation hervorgegangene Kolonien wurden in Selektionsmedium angezogen und mittels Restriktionsanalyse vorselektiert. Einige positive Plasmidklone wurden mittels Sequenzanalyse auf mögliche Punktmutationen und die Klonierung im korrekten Leseraster überprüft. Von den korrekt amplifizierten und klonierten Plasmiden wurden für jedes der herzustellenden Fusionsproteine je zwei für die weiteren Versuche ausgewählt.

\section{$\begin{array}{lll}\text { Exon } 1 & \text { Exon } 2 & \text { Exon } 3\end{array}$}

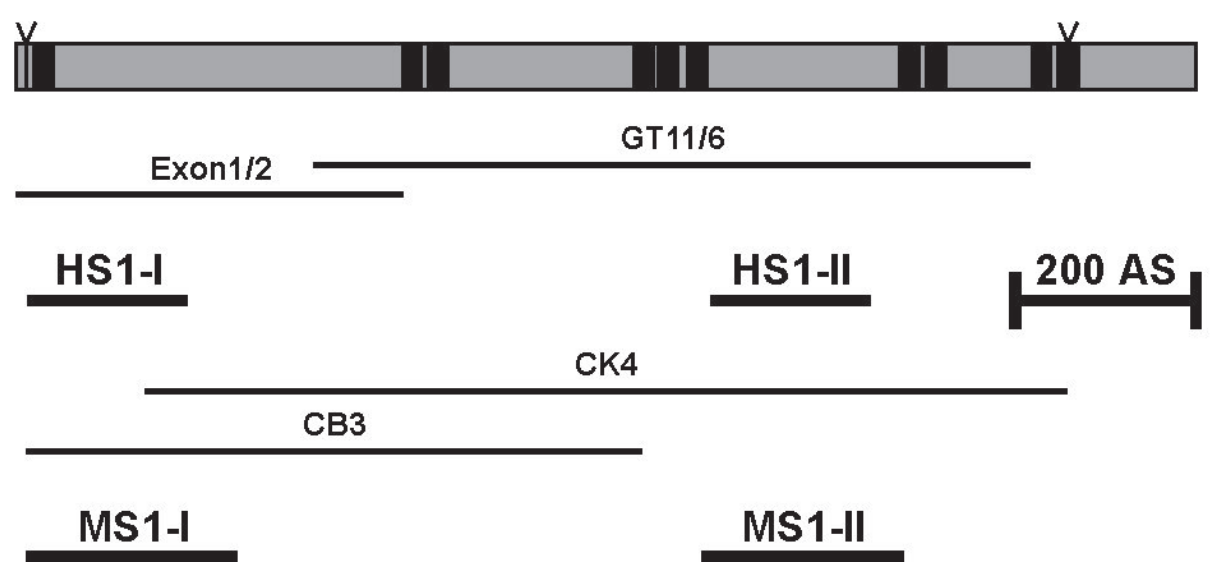

Abbildung 3.12: Fusionsproteine des Sall1- und SALL1-Gens. Die Struktur des Sall1- und des SALL1-Gens sind aufgrund der großen Homologie schematisch in einer Abbildung gezeigt. Die Zinkfingerregionen sind als senkrechte Balken innerhalb der Aminosäuresequenz dargestellt. Die dünnen Striche deuten die für die Amplifikation der FP-Fragmente verwendeten humanen und murinen Klone an, die dicken Striche stehen für die FP-Fragmente. Die Haken repräsentieren die Exon-Intron-Übergänge. 


\subsubsection{Gewinnung der Sall1- und SALL1-Fusionsproteine}

Um die murinen Sall1- bzw. humanen SALL1-Fusionsproteine in E. coli nachzuweisen, erfolgte eine Anzucht der Bakterien wie unter 2.10.1.2 beschrieben. Nach der Anzucht der Bakterien und dem Aufschluss der Proteine wurden diese zur Kontrolle auf einem PAGE-Gel aufgetrennt, auf eine PVDF-Membran übertragen und der Filter mit StrepTactin umgesetzt (s. 2.10.1.4). Dabei konnten Signale bei der erwarteten Größe von ca. $31.5 \mathrm{kDa}$ (MS1-I), $30.5 \mathrm{kDa}$ (MS1-II), $25.5 \mathrm{kDa}$ (HS1-I) und $29.5 \mathrm{kDa}$ (HS1-II) detekiert werden (Abb. 3.13). Davon sind etwa $5 \mathrm{kDa}$ auf das Strep-tag II-Peptid zurückzuführen. Die Extrakte zeigten unterschiedlich viele unspezifische Banden unklarer Herkunft.

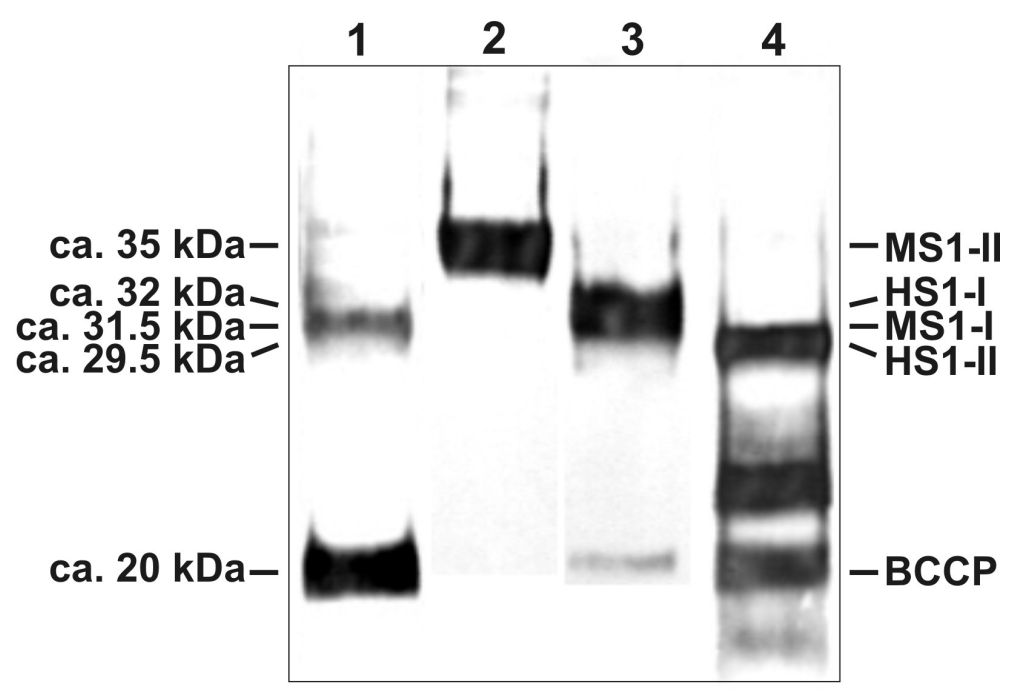

Abbildung 3.13: Western-Blot-Analyse bakteriell exprimierter Sall1- und SALL1Fusionsproteine. Die transformierten Bakterienkulturen wurden nach $3 \mathrm{~h}$ Inkubation mit Anhydrotetracyclin geerntet und der Zellextrakt aufgeschlossen. Nach PAGE und Elektrotransfer wurde die Membran mit AP-konjugiertem StrepTactin umgesetzt und mit NBT/BCIP gefärbt. 1: MS1-I; 2: MS1-II; 3: HS1-I; 4: HS1-II.

\subsubsection{Gewinnung von monospezifischen Anti-Sall1-Antikörpern}

Die zur Aufreinigung der Antiseren verwendeten Fusionsproteine konnten nun eingesetzt werden, um aus den bereits vorhandenen Seren monospezifische Antikörper gegen Sall1 bzw. SALL1 zu isolieren. Hierzu mussten die Rohextrakte 
der geernteten Proteine zunächst über immobilisiertes StrepTactin aufgereinigt werden (s. 2.10.1.3). Je $20 \mu \mathrm{L}$ der Eluate wurden mittels SDS-PAGE analysiert und eine Fraktion mit einer deutlichen Fusionsproteinbande ausgewählt. Das ausgewählte Eluat wurde eingesetzt, um wie in 2.10 .9 beschrieben eine AntikörperAufreinigung durchzuführen. Die Abbildung 3.14.A zeigt die Detektion der MS1-IIFusionsproteinbande mit dem Antikörper, der gegen das Peptid S1-II hergestellt wurde. Bei der Immunumsetzung mit Kernproteinextrakten aus murinem Nierengewebe konnte die native Sall1-Bande jedoch nicht detektiert werden (Daten nicht gezeigt), so dass eine weitere Methode zur Aufreinigung der Seren angewendet wurde. Die von der Firma Eurogentec synthetisierten und mit den Seren gelieferten Peptide wurden wie unter 2.10.10 beschrieben an eine Affinitäts-Säule gebunden und die Seren zur spezifischen Bindung der Antikörper auf die so präparierte Säule gegeben. Die eluierten Antikörper wurden entsalzt und zunächst gegen Western-Blots der Fusionsproteine getestet. Wie in Abb. 3.14.B gezeigt, konnte das Fusionsprotein MS1-I erfolgreich mit dem Antikörper, der gegen das Peptid S1-I hergestellt worden war, detektiert werden. Daher folgten weitere Untersuchungen, um die Qualität des aufgereinigten Antikörpers zu testen.

\subsubsection{Nachweis von Sall1 in Kernproteinextrakten}

Das Sall1-Protein sollte als Transkriptionsfaktor im Zellkern lokalisiert sein. Dies wurde im Rahmen anderer Experimente mit Hilfe von SALL1-Green fluorescent protein-Fusionsproteinen nachgewiesen (Rieger, 2001). An Kernproteinextrakten aus murinem Nierengewebe sollte nun die Präsenz von Sall1 durch eine WesternBlot-Analyse gezeigt werden. Für das Sall1-Protein wurde, abgeleitet von der AS-Sequenz, eine Größe von ca. $158 \mathrm{kDa}$ angenommen. Aus einer Nierengewebe wurden wie unter 2.10 .2 beschrieben Kernproteine extrahiert und mit dem über die Affinitätssäule aufgereinigten anti-Sall1-I Antiserum inkubiert. Da durch den zu Beginn der Aufreinigung durchgeführten Verdünnungsschritt mit dieser Methode keine Anreicherung des Antikörpers erfolgte, wurden die Filter nur mit relativ geringen Verdünnungen inkubiert (s. 3.15). Das Antiserum detektierte eine Bande von ca. $160 \mathrm{kDa}$, die dem angenommenen Molekulargewicht des Sall1-Proteins entspricht. 

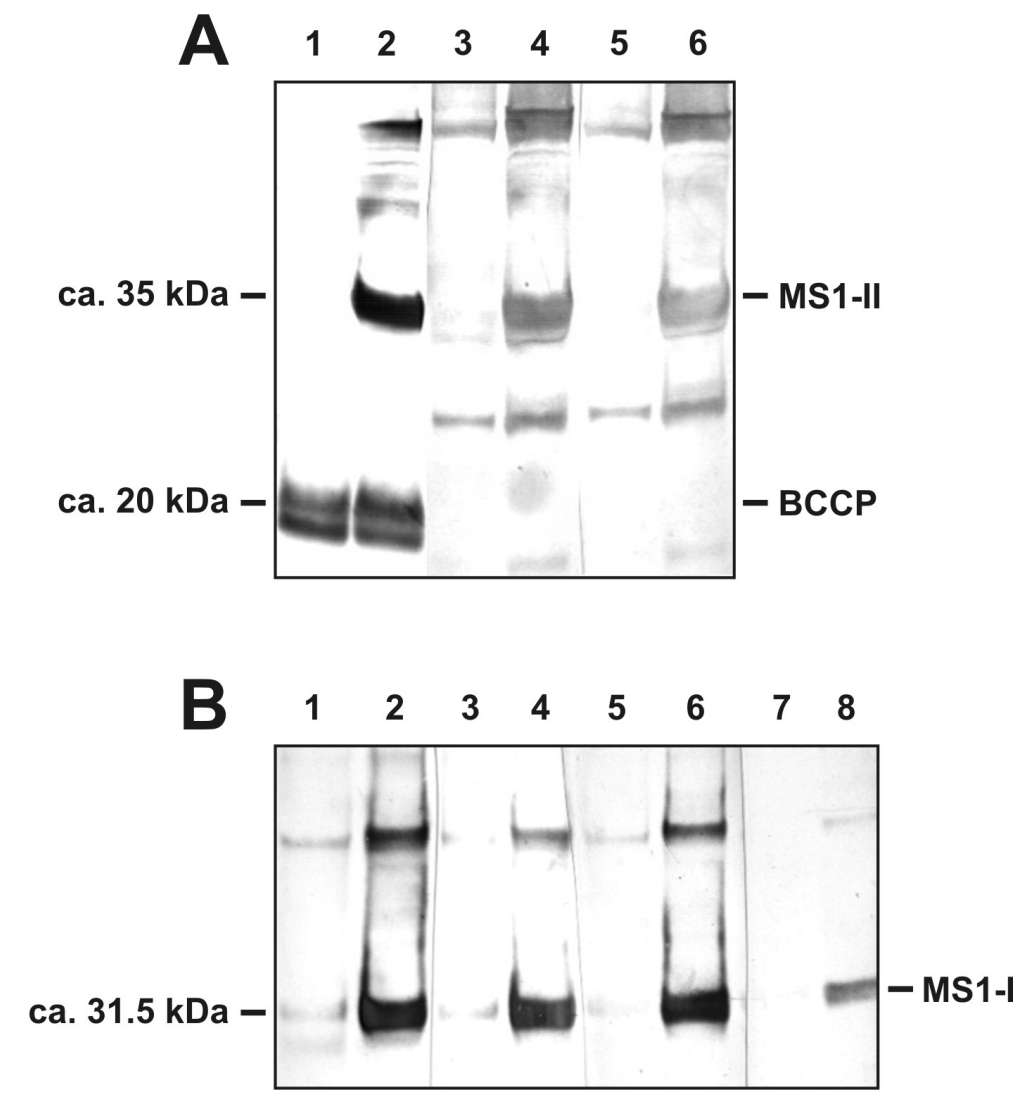

Abbildung 3.14: Test der unterschiedlich aufgereinigten Antikörper auf ihre AntigenSpezifität. Die Abbildung A zeigt die Detektion der Fusionsproteinbande MS1-II bei ca. $35 \mathrm{kDa}$ mit dem über das Western-Blot-Verfahren aufgereinigten Antikörper. Die Spuren $\mathbf{1}$ und $\mathbf{2}$ wurden mit StrepTactin, die Spuren 3 und 4 mit einer 1:500-Verdünnung des Antikörpers und die Spuren 5 und 6 mit einer 1:1000-Verdünnung des Antikörpers umgesetzt. In den mit einer ungeraden Zahl bezeichneten Spuren wurden die jeweiligen Zelllysate, in den Spuren anderen Aliquots einer Elutionsfraktion aufgetragen.

In der Abbildung B ist die Detektion des MS1-I FPs mit dem mittels Affinitätssäule aufgereinigten Antikörper gezeigt. Die Spuren 1 und 2 wurden mit einer 1:50-Verdünnung des Antikörpers umgesetzt, die Spuren 3 und 4 mit einer 1:100-Verdünnung, 5 und 6 mit einer 1:250-Verdünnung des Antikörpers und die Spuren $\mathbf{7}$ und $\mathbf{8}$ mit StrepTactin. In den mit einer ungeraden Zahl bezeichneten Spuren wurden die jeweiligen Zelllysate, in den anderen Spuren Aliquots einer Elutionsfraktion aufgetragen.

\subsubsection{Herstellung eines Antiserums gegen Sall1}

Nach der Aufreinigung des Sall1-I-Antiserums mit einer Affinitätssäule war es zwar gelungen, das Sall1-Protein in Kernproteinextrakten nachzuweisen, jedoch waren die Spezifität und die Stärke des Signals nicht von einer Qualität, die den Einsatz 


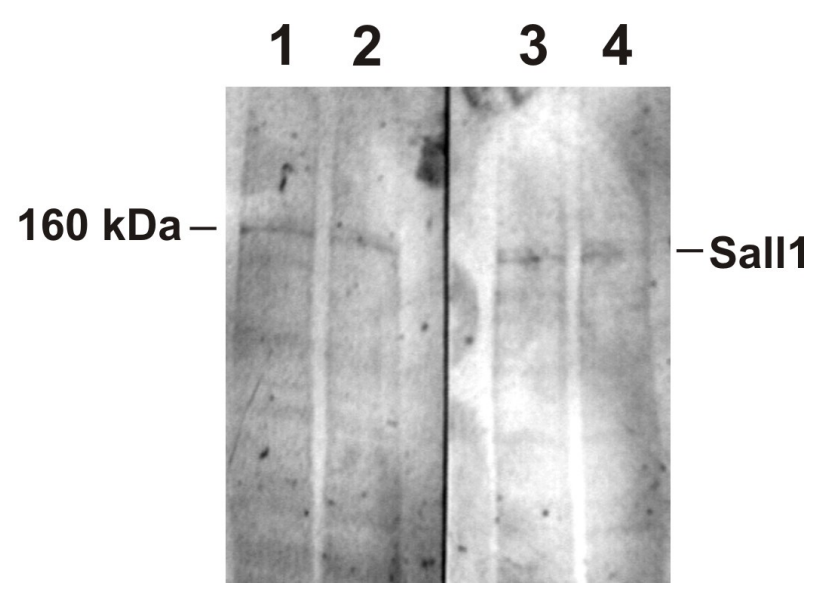

\begin{abstract}
Abbildung 3.15: Nachweis des Sall1-Proteins in Kernproteinextrakten. Aus Nierengewebe der Maus wurden Kernproteine präpariert und einer PAGE und einem Elektrotransfer unterworfen. Der Blot wurde mit dem Anti-Sall1-I Antikörper umgesetzt, mit AP-konjugiertem Anti-Kaninchen Zweitantikörper inkubiert und mit NBT/BCIP gefärbt. Die Spuren 1 und 2 wurden mit einer 1:100Verdünnung des Antikörpers inkubiert, die Spuren 3 und 4 mit einer 1:50-Verdünnung.
\end{abstract}

des Antiserums für in situ-Hybridisierung von Gewebeschnitten erlaubte. Daher sollten mit einer weiteren Methode, bei der nicht gegen Peptide, sondern gegen Proteine immunisiert wird, neue Antikörper gewonnen werden. Für die Herstellung eines Antiserums gegen Sall1 sollte das Fusionsprotein verwendet werden, dass die größte Homologie zwischen der murinen und der humanen Aminosäuresequenz aufweist. Folglich wurde das S1-II-FP für die Immunisierung ausgesucht (vgl. Abb. 3.11). Die Herstellung und Aufreinigung der Strep-tag-Fusionsproteine für Sall1 und SALL1 ließ erkennen, dass das MS1-II-FP stärker als das HS1-II-FP in den Bakterien exprimiert wird (s. 3.13), welches daher für die Injektion von Kaninchen verwendet wurde. Die Analyse des Antiserums konnte im Rahmen dieser Arbeit nicht mehr erfolgen.

\title{
3.5 Untersuchungen zur embryonalen Expression des Sall2-Gens der Maus
}

Aus vorangegangenen Arbeiten war bekannt, dass das Sall2-Gens der Maus hauptsächlich im Gehirn und der Niere exprimiert wird, und eine Analyse mittels RT-PCR hatte ergeben, dass Sall2-Transkripte bereits in Embryonen des Entwicklungsstadiums 8.5 days post coitum (dpc) vorhanden sind (Kohlhase et al., 2000). 
In der vorliegenden Arbeit sollten genauere Untersuchungen über die embryonale Expression von Sall2 durchgeführt werden.

Aus dem 1B2-Subklon von Cosmid 7 (s. Abb. 3.17, S. 82) wurde eine DIGmarkierte antisense-Sonde hergestellt und für die in situ-Hybridisierung verschiedener Embryonalstadien (s. 2.9.11.3) eingesetzt. Verwendet wurden dafür aus CD1-Mäusen präparierte Embryonen der Altersstadien 7.5-12.5 dpc. Einige der gefärbten Embryonen wurden zur besseren Untersuchung der Sall2exprimierenden Gewebe in Gelatine eingebettet und mit einem Vibratom geschnitten (s. 2.9.11.3.4).

\subsubsection{Expression in neuralen Embryonalgeweben}

Die Abbildung 3.16.A zeigt, dass die Expression von Sall2 bereits in den frühesten untersuchten Stadien $(7.5 \mathrm{dpc})$ beginnt. Dabei ist eine starke Anfärbung im neuralen Ektoderm in einer breiten anterioren Region des zukünftigen Kopfes zu finden. Ein identisches Expressionsmuster ist auch im 8.5 dpc-Embryo (s. Abb. 3.16.B) festzustellen. Am Tag $9.5 \mathrm{dpc}$ zeigen das Neuralrohr und große Bereiche des Vorder-, Mittel- und Rautenhirns ein starkes Signal (s. Abb. 3.16.C-E). Diese Expression bleibt auch am Tag $10.5 \mathrm{dpc}$ bestehen (s. Abb. 3.16.G, H). Die Anfärbung des Neuralrohrs lässt ab Tag 11.5 nach, das Telencephalon und der dritte Ventrikel zeigen eine Sall2-Expression bis mindestens $12.5 \mathrm{dpc}$. In den otischen Vesikeln können Sall2-Transkripte an 9.5 dpc detektiert werden.

\subsubsection{Expression in anderen embryonalen Geweben}

Am Tag 7.5 und 8.5 dpc wird Sall2 nahezu ubiquitär im gesamten neuralen Ektoderm und im neuformierten Mesoderm des sich entwickelnden Embryos exprimiert (s. Abb. 3.16.A,B). Kurz darauf schränkt sich die Expression auf spezifische Strukturen ein. Wie an den Vibratom-Sektionen von 9.5 dpc-Embryonen (s. Abb. 3.16.D,E) zu erkennen, ist die Anfärbung bevorzugt im Epithel lokalisiert. An 9.5 und $10.5 \mathrm{dpc}$ ist eine starke Anfärbung des Mesonephros zu erkennen (s. Abb. 3.16.C,D,F). Ab 9.5 können Sall2-Transkripte im optischen Vesikel und an 10.5 in der Linsenplakode detektiert werden (s. Abb. 3.16.C-E,H,J). Ab Tag 11.5 pc begrenzt sich die Expression auf den Bereich des Augenbechers, in dem der Übergang zwischen der äußeren und inneren optischen Schicht lokalisiert ist. 

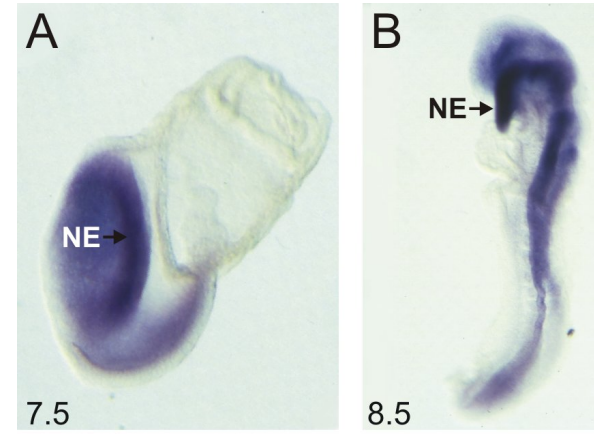

$\mathrm{E}$

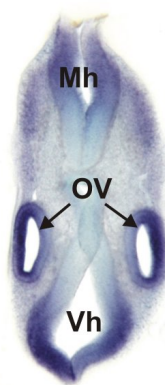

9.5

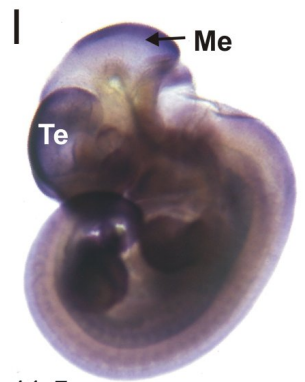

11.5
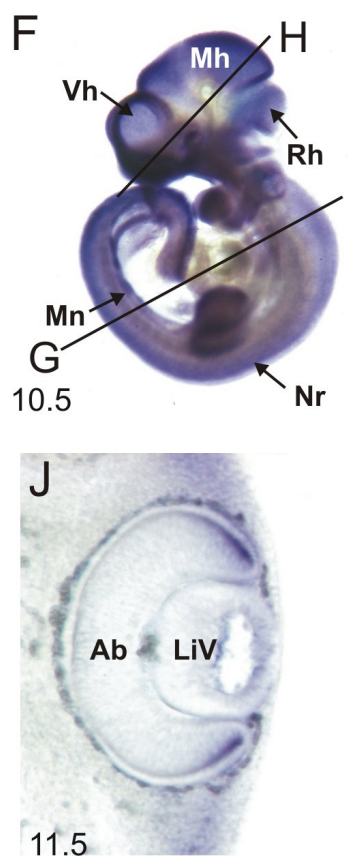
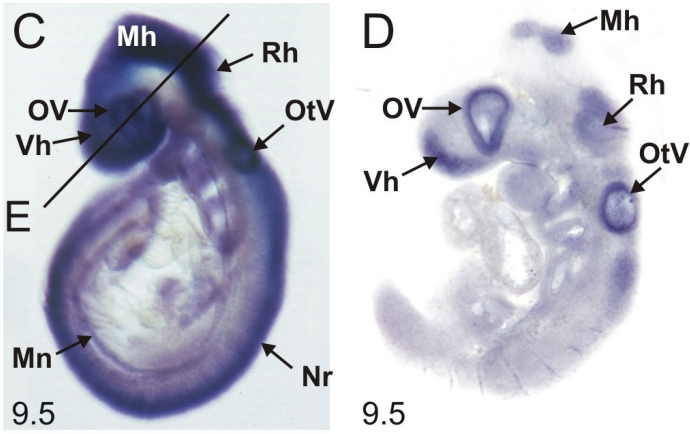

G

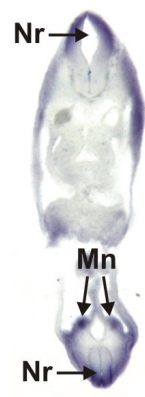

$\mathrm{H}$

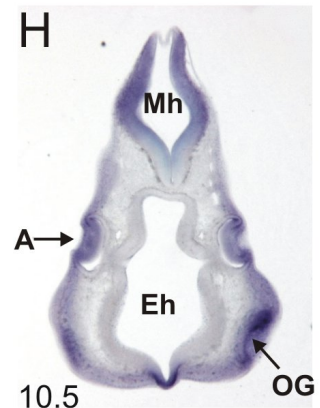

$\mathrm{K}$

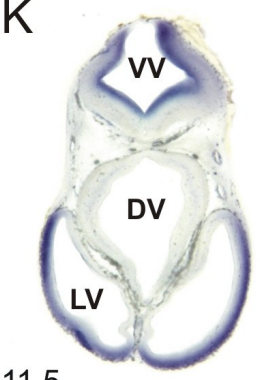

11.5

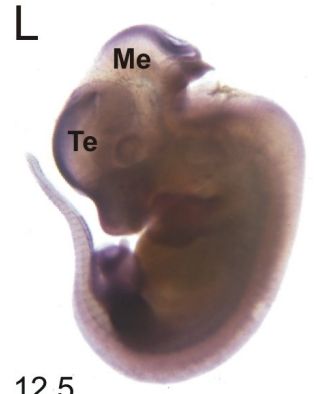

Abbildung 3.16: Expression des Sall2-Gens während der Embryonalentwicklung der Maus. $A, B, C, F, I$ und $L$ zeigen whole mount-in situ-Hybridisierungen, in $D, E, G, H, J$ und $K$ VibratomSchnitte von whole mount-in situ-gefärbten Embryonen. Die jeweiligen Altersstadien sind angegeben. A: Auge; Ab: Augenbecher; DV: Dritter Ventrikel; LV: Lateraler Ventrikel; Me: MesencephaIon; Mh: Mittelhirn; Mn: Mesonephros; NE: neurales Ektoderm; Nr: Neuralrohr; OG: Olfaktorische Grube; OtV: Otischer Vesikel; OV: optischer Vesikel; Rh: Rautenhirn; Te: Telencephalon; Vh: Vorderhirn; VV: Vierter Ventrikel. Die Erklärung befindet sich im Text. 


\subsection{Homologe Rekombination des Sall2-Gens}

\subsubsection{Herstellung eines Sall2-knock out-Konstrukts}

Bei Aufnahme der vorliegenden Arbeit lagen weder Erkenntnisse über die Funktion des murinen Sall2-Gens noch des humanen SALL2-Gens vor. Daher sollten Sall2-knock out-Mäuse erzeugt werden, durch deren Analyse Erkenntnisse über die Funktion des Gens gewonnen werden sollten.

Zur Herstellung eines knock out Targeting-Konstrukts musste zunächst die genomische DNA-Sequenz des Intron 1 und der 3'-untranslatierten Region (3'-UTR) vervollständigt werden, um geeignete Fragmente zur Klonierung in den Targeting Vektor pTKneo zu finden. Dazu wurde das Intron 1, von dem eine grobe Restriktionskarte vorhanden war (Altmann, 1998), auf weitere Schnittstellen untersucht und sequenziert. Zudem wurde aus der genomischen Maus-Cosmid-Bibliothek (s. 2.7.7) der Cosmidklon Cos $\mathrm{N}$ isoliert (s. 2.9.10.2), der zusätzliche Informationen im 3'-Bereich des murinen Sall2-Gens enthält.

\subsubsection{Charakterisierung des Intron 1 und der 3'-Region von Sall2}

Um den Intron 1-Bereich näher zu charakterisieren, wurden aus den vorhandenen Klonen mit Hilfe weiterer Restriktionsspaltungen Subklone hergestellt, durch deren Sequenzierung mit vektor- und sequenzspezifischen Primern (s. 2.7.5) die vollständige Sequenz von Intron 1 erstellt werden konnte (s. Abb. A.2).

Für die weitere Charakterisierung des 3'-Bereichs musste zunächst die genomische Cosmid-Bibliothek 121 der Maus gescreent werden (s. 2.9.10.2), da der für die Isolierung von Sall2 genutzte Cosmidklon 7 in der $3^{\prime}$-UTR endete (Altmann, 1998). Mit den beiden Sonden 1B1 und 1B2 (s. 2.7.6) konnte ein Cosmidklon (Cosmid N) isoliert werden, der weitere Informationen über den 3'-Bereich von Sall2 enthielt. Durch Hybridisierungen und Restriktionsspaltungen wurde ausreichend Information gewonnen, um ein Fragment für das knock out-Konstrukt auszuwählen (s. Abb. 3.17).

\subsubsection{Klonierung genomischer Fragmente in den pTKneo-Vektor}

Der knock out sollte durch die vollständige Deletion von Exon 1a und Exon 2 erfolgen, da mit dieser Strategie annähernd die gesamte kodierende Sequenz und alle Zinkfinger-kodierenden Regionen aus dem rekombinanten Allel entfernt wer- 


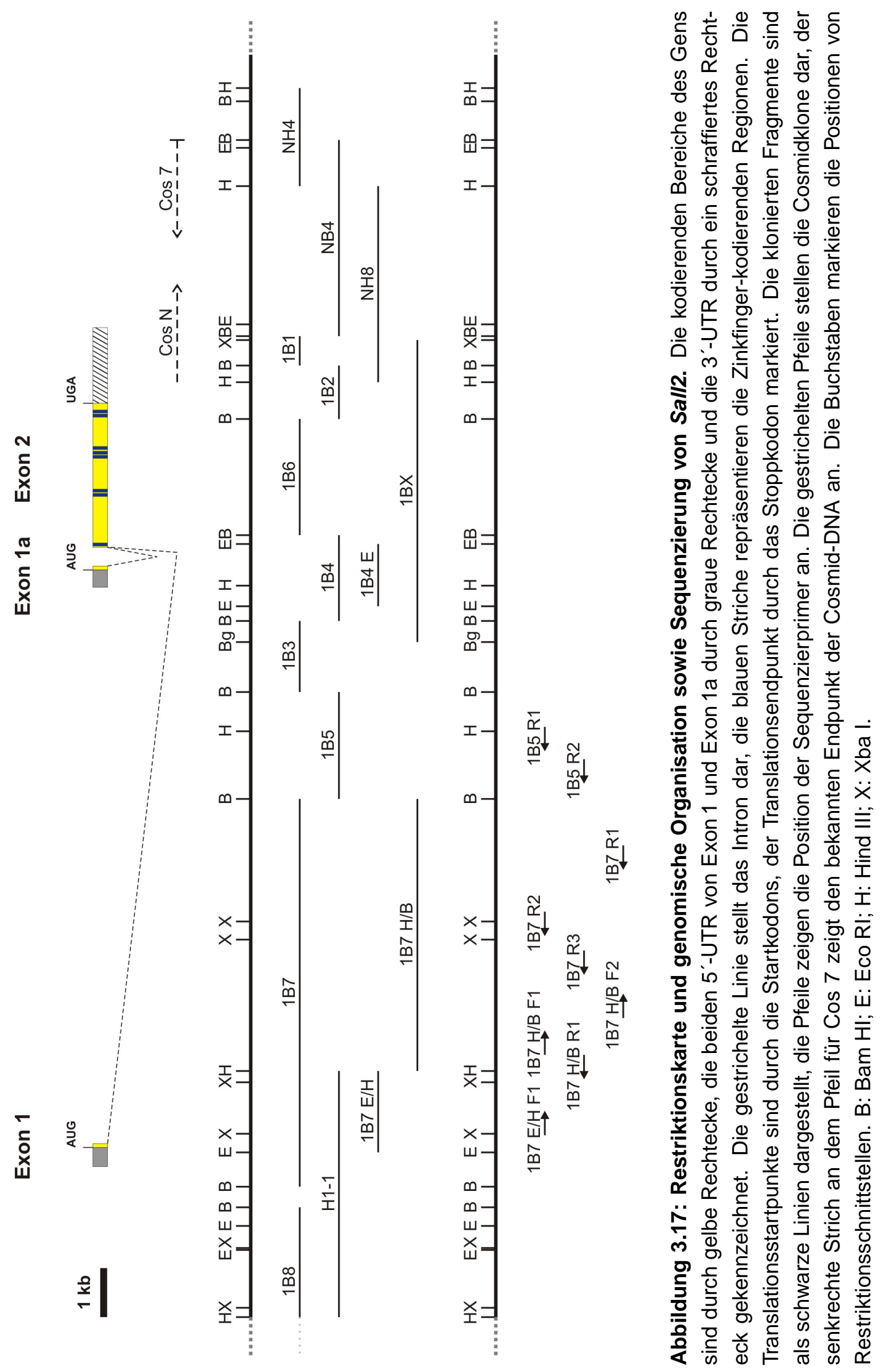


den können. Für die Klonierung des knock out-Konstrukts musste eine Strategie gewählt werden, mit der das bereits in den Vektor ligierte Fragment durch die Klonierung des zweiten Fragments nicht restringiert wird. Aufgrund der wenigen vorhandenen Restriktionsschnittstellen in den beiden Polylinkern erfolgte zunächst eine Klonierung der beiden Fragmente in pBlueskript.

Zunächst sollte ein Fragment aus Intron 1 in den knock out-Vektor kloniert werden. Aus dem Cosmid 7-Subklon 1BX wurde ein $4.3 \mathrm{~kb}$ großes Insert mittels Bgl II gewonnen (s. Abb. 3.18.A), mit der Pfu-Polymerase die Enden des Fragments geglättet (s. 2.9.3.4) und in den zuvor mit Hinc II linearisierten und dephosphorylierten pBlueskript-Vektor ligiert. Aus diesem wurde das Fragment mit den Restriktionsenzymen Xho I und Cla I wieder herausgespalten und gerichtet in den mit Sal I und Cla I geschnittenen pTKneo-Vektor kloniert (s. Abb. 3.18.B). Bei den Restriktionsenzymen Xho I und Sal I handelt es sich um kompatible Enzyme, die überlappende und somit wieder ligierbare Überhänge erzeugen, aber durch die Ligation das Erkennungspalindrom der Ausgangssequenz verlieren. Aus dem 3'Bereich des Gens wurde aus Subklon NB4 ein 3 kb großes Fragment mittels Bam $\mathrm{HI}$ und $\mathrm{Bgl} \mathrm{II}$ isoliert und in die Bam HI-Schnittstelle des zweiten Polylinkers kloniert (Bgl II und Bam HI sind ebenfalls kompatibel; s. Abb. 3.18.A,B). Da diese Klonierung nicht gerichtet erfolgen konnte, wurde durch Restriktionsanalyse und Sequenzierung ein Klon ermittelt, der die richtige Orientierung aufwies. Damit stand ein Sall2-knock out-Konstrukt mit einer Gesamtgröße von 16.2 kb zur Verfügung, das für die homologe Rekombination von murinen embryonalen Stammzellen verwendet werden konnte.

Die Restriktionsanalyse des Konstrukts ist in Abbildung 3.19 dargestellt. Die restriktionsenzymatische Spaltung mit Bam $\mathrm{HI}$ zeigte die richtige Orientierung des 5'-Fragments anhand der $7.3 \mathrm{~kb}$-Bande, bestehend aus beiden TKs, dem pBlueskript-Vektor sowie dem 5'-Bereich des Bgl II/Bgl II-Fragments. Die weiteren Banden entstanden durch das im Bgl II/Bgl II-Fragment vorhandenen Bam HI-Fragment von $2.2 \mathrm{~kb}$ und dem übrigen knock out-Vektor bei $6 \mathrm{~kb}$. Anhand der Kpn I-Restriktion konnte sowohl am leeren pTKneo-Vektor als auch am fertiggestellten knock out-Konstrukt geprüft werden, ob beide TKs im Plasmid vorhanden sind. Dies wurde durch die in beiden Spuren vorkommende $1.8 \mathrm{~kb}$-Bande bestätigt. Das in beiden Restriktionsanalysen vorkommende $0.8 \mathrm{~kb}$-Fragment besteht aus dem 5'-Bereich der an den pBlueskript grenzenden HSV-TK. Die zusätzlichen Fragmente des knock out-Konstrukts sind die $2.8 \mathrm{~kb}$-Bande aus dem 3'Bereich der zweiten TK und dem 5'-Bereich des 5'-liegenden genomischen Fragments sowie 


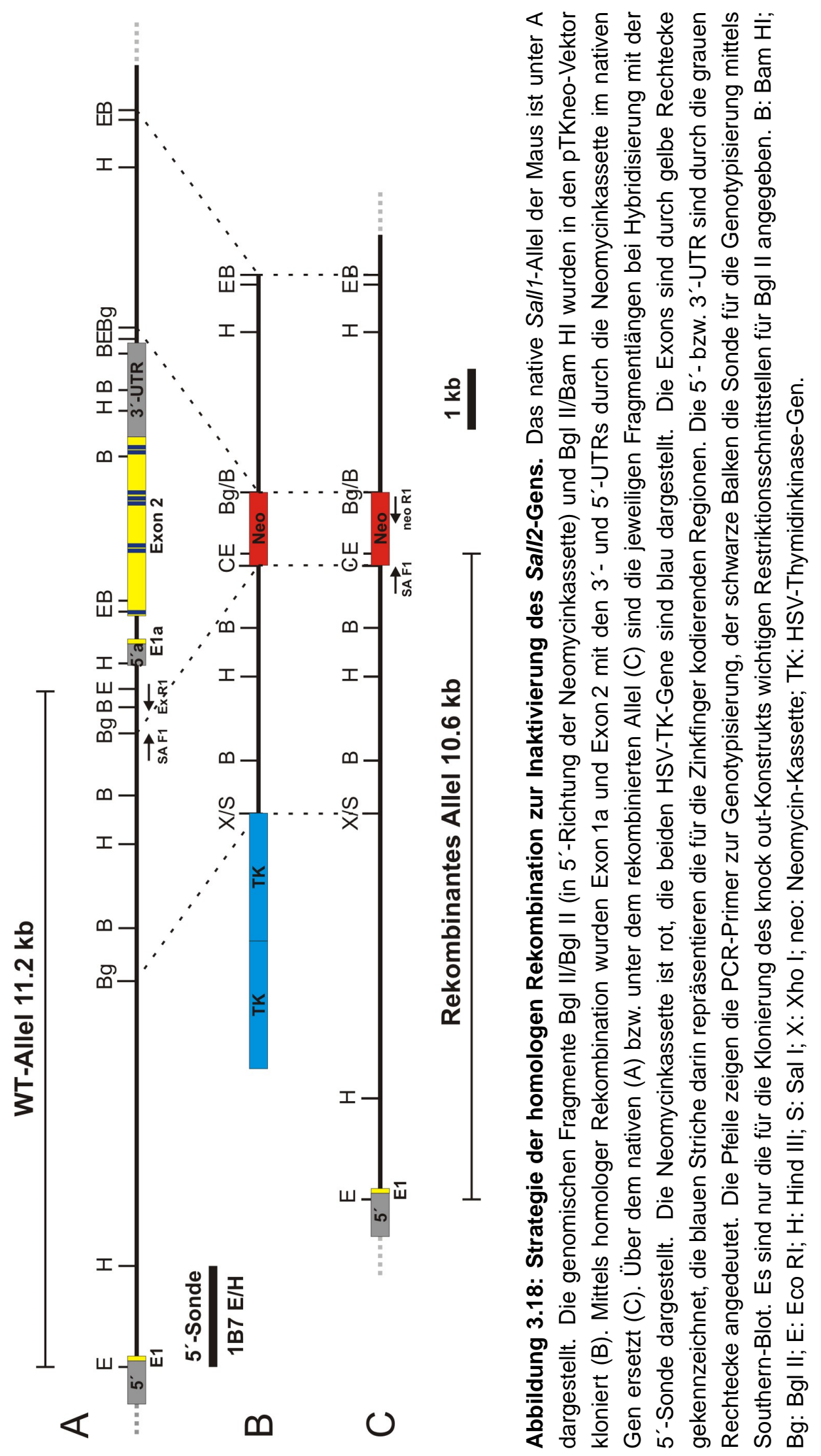


die $10.8 \mathrm{~kb}$-Bande, bestehend aus dem restlichen $5^{\prime}$-Arm, der Neokassette, dem $3^{\prime}$-Arm und dem pBlueskript-Vektor. Anhand der restriktionsenzymatischen Spaltung mit Not I konnte gezeigt werden, dass sich sowohl im pTKneo-Vektor als auch im knock out-Konstrukt nur eine Schnittstelle für das Restriktionsenzym befindet.

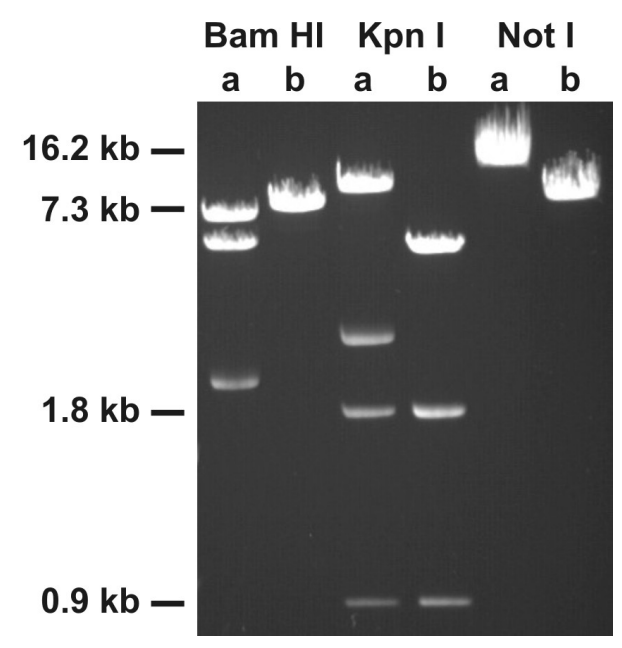

\begin{abstract}
Abbildung 3.19: Restriktionsanalyse des Sall2-knock out-Konstrukts. In den mit a bezeichneten Spuren wurde restriktionsenzymatisch gespaltene Sall2-knock out-Konstrukt-DNA aufgetrennt, in den mit $\mathbf{b}$ bezeichneten wurde der restringierte pTKneo-Vektor ohne Insert aufgetragen. Die Restriktion mit Bam HI zeigt durch das $7.3 \mathrm{~kb}$-Fragment die richtige Orientierung des 5'Fragments an. Die 1.8 und 0.9 kb-Bande der Kpn I-Restriktionsanalyse des knock out-Konstrukts und des pTKneo-Vektors bestätigen die Präsenz beider Gene für die HSV-TKs. Anhand der Not IRestriktionsanalyse konnte gezeigt werden, dass sich sowohl im pTKneo-Vektor als auch im knock out-Konstrukt nur eine Schnittstelle für das Restriktionsenzym befinden. Die Gesamtgröße des vollständig klonierten knock out-Konstrukts beträgt $16.2 \mathrm{~kb}$.
\end{abstract}

\title{
3.6.2 Herstellung von homolog rekombinierten embryonalen Stammzellen
}

RI-ES-Zellen wurden wie unter 2.11.2 beschrieben elektroporiert, selektioniert und 120 resistente ES-Zellklone isoliert (s. 2.11.3). Die von der duplicate plate isolierte ES-Zell-DNA wurde mit Eco RI geschnitten und nach gelelektrophoretischer Auftrennung auf eine Nitrocellulosemembran transferiert und mit der externen $1.7 \mathrm{~kb}$ großen 5'-Sonde 1B7 E/H sowie der internen Neomycin-Sonde neo (s. 2.2) hybridisiert. Das WT-Allel wurde durch eine $11.2 \mathrm{~kb}$ Bande, das rekombinierte Allel durch eine $10.6 \mathrm{~kb}$ Bande repräsentiert. Von den ersten 36 Klonen erwiesen sich bereits 9 als positiv, so dass die restlichen nicht weiter ausgewertet wurden. Ein 
Beispiel für die Genotypisierung der ES-Zellklone ist in Abb. 3.20 dargestellt. Alle positiven Klone zeigen ein Hybridisierungssignal von $4.5 \mathrm{~kb}$ mit der NeomycinSonde (Daten nicht gezeigt).

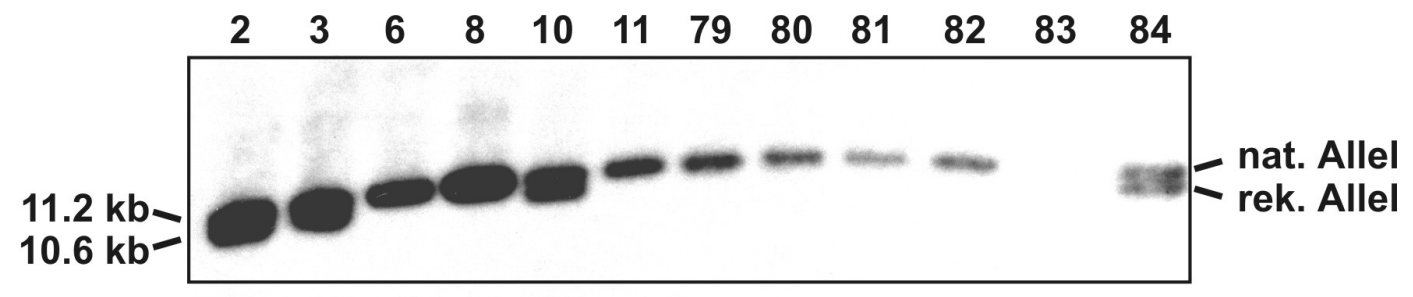

Abbildung 3.20: Genotypisierung der ES-Zellklone mittels Southern-Blot. Die genomische ES-Zell-DNA wurde mit dem Enzym Eco RI restriktionsenzymatisch gespalten. Die Hybridisierung erfolgte mit der externen $5^{\prime}$-Sonde $1 \mathrm{~B} 7 \mathrm{E} / \mathrm{H}$. Die für die homologe Rekombination positiven Klone zeigen das native Allel durch eine Bande bei $11.2 \mathrm{~kb}$ sowie das mutierte bei $10.6 \mathrm{~kb}$. Die ESZellklone 2, 3, 10 und 84 erwiesen sich als heterozygot für das homolog rekombinierte Allel.

\subsubsection{Generierung von Sall2-defizienten Mäusen}

Die Injektion von rekombinanten ES-Zellen in Maus-Blastocysten und deren Transfer in pseudoschwangere Mäuse wurde von Mitarbeiterlnnen des Max-PlanckInstituts für Experimentelle Medizin, Göttingen, durchgeführt. Die Mäuse mit dem stärksten Chimärismus (80-100\%, ca. 10 männliche Tiere) wurden im hauseigenen Tierstall mit Tieren der Mauslinien C57BL und 129/SvJ verpaart und die Nachkommen im Alter von ca. 3-4 Wochen durch Analyse mittels PCR an DNA aus einer Schwanzbiopsie genotypisiert. Dazu wurden drei verschiedene Primer eingesetzt, zwei aus dem nativen Gen und einer aus der inserierten Neomycinkassette (s. Abb. 3.18). Die Primerkombination SA F1 / Ex R1 (s. 2.7.5) ergab ein Produkt des nativen Allels von ca. 400 bp. Mit dem reversen Primer neo R1 aus dem Targeting-Vektor und SA F1 entstand ein Produkt von 620 bp, so dass mittels der amplifizierten Banden eine Genotypisierung zur Identifizierung heterozygoter Mäuse erfolgen konnte. Die Abbildung 3.21 zeigt ein Beispiel für eine Genotypisierung von Nachkommen einer männlichen Chimäre und Weibchen des Stammes C57BL.

Konnten unter den Nachkommen keine heterozygoten Tiere gefunden werden, da sich die rekombinanten ES-Zellen nicht an der Keimbahn beteiligt hatten, wurde die Chimäre aus der Zucht entfernt. Heterozygote Mäuse zeigten in keiner der 


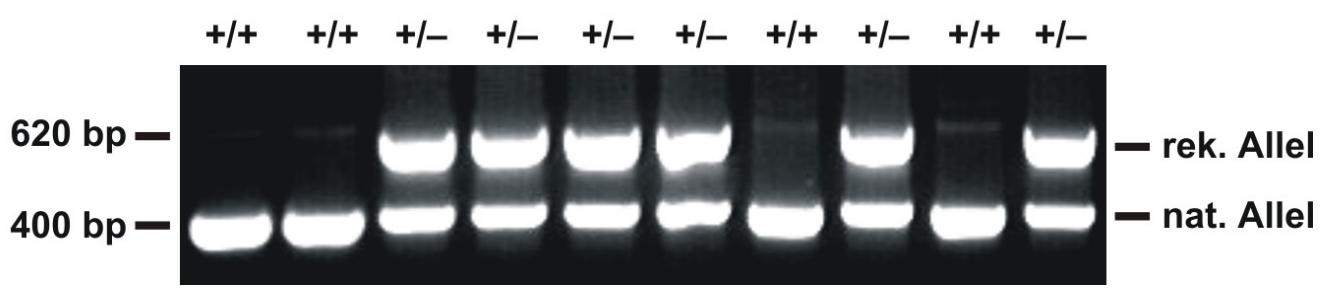

Abbildung 3.21: Genotypisierung der F1-Generation durch PCR. Gezeigt ist eine gelelektrophoretische Auftrennung der Sall2-KO-PCR im 1.5\%igen Agarosegel zur Genotypisierung der Nachkommen aus der Verpaarung einer Chimäre mit weiblichen Mäusen des Mausstammes C57BL. Das vom nativen Gen mit den Primern SA F1 / Ex R1 amplifizierte Fragment zeigt eine Größe von 400 bp, das mutierte Allel, amplifiziert mit den Primern SA F1 / neo R1, liefert ein 620 bp-Fragment.

beiden Mauslinien (C57BL und 129/SvJ) Auffälligkeiten und wurden zur Generierung homozygoter knock out-Mäuse miteinander verpaart. In Abb. 3.22 ist die Genotypisierung von Tieren aus heterozygoten Verpaarungen dargestellt.

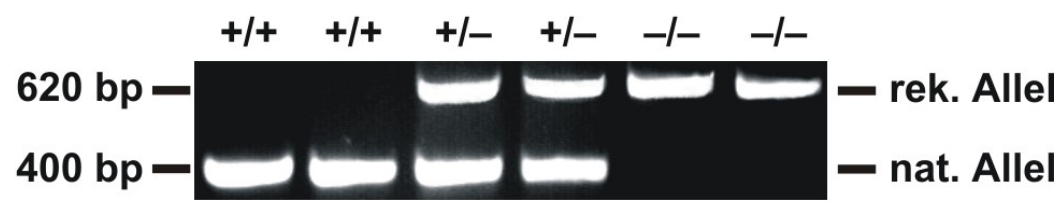

Abbildung 3.22: Genotypisierung der F2-Generation durch PCR. Gezeigt ist eine gelelektrophoretische Auftrennung der Sall2-KO-PCR im 1.5\%igen Agarosegel zur Genotypisierung von F2-Tieren aus Verpaarungen von heterozygoten Mäusen des Mausstammes C57BL. Das vom nativen Gen amplifizierte Fragment zeigt eine Größe von 400 bp, das mutierte Allel liefert ein 620 bpFragment. 


\subsection{Analyse Sall2-defizienter Mäuse}

\subsubsection{Statistische Analyse der Wurfgrößen und Genotypen}

Erste Beobachtungen der Nachkommen aus heterozygoten Verpaarungen zeigten keinen auffälligen Phänotyp in homozygoten F2-Tieren. Um eventuelle Abweichungen von den Mendel-Regeln feststellen zu können, wurde von den beiden Zuchtlinien (C57BL und 129/SvJ) eine Statistik über die Wurfgrößen und den Genotyp der Nachkommen erstellt.

\subsubsection{Der Hintergrund C57BL}

Durch Verpaarungen von 4 transmittierenden männlichen Chimären mit Weibchen des Stammes C57BL wurden in der F1-Generation heterozygote (+/-) und Wildtyp-(+/+) Nachkommen generiert. Dabei betrug die Zahl der heterozygoten Mäuse 30 bei einer Gesamtzahl von 79 in 11 Würfen (durchschnittlichen Anzahl von 7 Nachkommen pro Wurf). Der Anteil homozygoter (-/-) Nachkommen aus Verpaarungen heterozygoter Tiere belief sich bei 12 Würfen mit insgesamt 92 Nachkommen auf 18 Tiere (20\%), was nach den Mendelschen Regeln annähernd dem zu erwartenden statistischen Viertel entspricht. Die durchschnittliche Anzahl der Nachkommen pro Verpaarung betrug 8. Dieses Ergebnis kann als Hinweis darauf gedeutet werden, dass Sall2-/--Mäuse keine embryonalen Entwicklungsstörungen aufweisen und nach der Geburt normal lebensfähig sind. Die Mäuse unterschieden sich äußerlich in keiner Weise von ihren Sall2 ${ }^{+/-}$- und WildtypGeschwistern. Die Nachkommen aus homozygoten Verpaarungen zeigten ebenfalls keine Auffälligkeiten. In Tabelle 3.1 ist die Verteilung der genotypisierten Nachkommen mit C57BL-Hintergrund in den beiden Generationen dargestellt.

\begin{tabular}{ccccccc}
\hline & $\begin{array}{c}\text { Anzahl } \\
\text { Würfe }\end{array}$ & $\begin{array}{c}\text { Anzahl } \\
\text { Nachkom- } \\
\text { men }\end{array}$ & $\begin{array}{c}\text { Mittlere } \\
\text { Wurfgröße }\end{array}$ & $\begin{array}{c}\text { Wildtyp } \\
(+/+)\end{array}$ & $\begin{array}{c}\text { Heterozygot } \\
(+/-)\end{array}$ & $\begin{array}{c}\text { Homozygot } \\
(-/-)\end{array}$ \\
\hline F1 & 11 & 79 & 7.2 & $49(62 \%)$ & $30(38 \%)$ & X \\
F2 & 12 & 92 & 7.7 & $25(27.2 \%)$ & $49(53.3 \%)$ & $18(19.6 \%)$ \\
\hline
\end{tabular}

Tabelle 3.1: Verteilung von Wildtyp-, heterozygoten und homozygoten Sall2-Mäusen auf dem C57BL-Hintergrund. 


\subsubsection{Der Hintergrund 129/SvJ}

Durch die Verpaarung einer transmittierenden männlichen Chimäre mit Weibchen des Stammes 129/SvJ wurden in der F1-Generation bei 3 Würfen mit einer durchschnittlichen Nachkommenzahl von 6 Tieren 13 heterozygote (+/-) und 5 Wildtyp$(+/+)$ Nachkommen generiert. Bei insgesamt 92 Nachkommen von 19 Würfen aus Verpaarungen heterozygoter Tiere betrug der Anteil homozygoter (-/-) Nachkommen 24 Tiere (26.1\%), was nach den Mendelschen Regeln dem zu erwartenden statistischen Viertel entspricht. Die durchschnittliche Anzahl der Nachkommen pro Verpaarung betrug 4.8 Tiere, was etwas unter dem Durchschnitt von 6 Nachkommen beim Stamm 129/SvJ liegt. Die Sall2-/--Mäuse entwickelten sich normal und zeigten keine Aufälligkeiten oder Unterschiede zu ihren Sall2 $2^{+-}$- und WildtypGeschwistern. Die homozygoten Sall2-/--Tiere waren fertil und die Nachkommen ebenfalls unauffällig. In Tabelle 3.2 ist die Verteilung der genotypisierten Nachkommen mit 129/SvJ-Hintergrund in den beiden Generationen dargestellt.

\begin{tabular}{ccccccc}
\hline Anzahl & $\begin{array}{c}\text { Anzahl } \\
\text { Würfe }\end{array}$ & $\begin{array}{c}\text { Mittlere } \\
\text { Nachkom- } \\
\text { men }\end{array}$ & $\begin{array}{c}\text { Wildtyp } \\
(+/+)\end{array}$ & $\begin{array}{c}\text { Heterozygot } \\
(+/-)\end{array}$ & $\begin{array}{c}\text { Homozygot } \\
(-/-)\end{array}$ \\
\hline F1 & 3 & 18 & 6 & $5(27.8 \%)$ & $13(72.2 \%)$ & X \\
F2 & 19 & 92 & 4.8 & $27(29.3 \%)$ & $41(44.6 \%)$ & $24(26.1 \%)$ \\
\hline
\end{tabular}

Tabelle 3.2: Verteilung von Wildtyp-, heterozygoten und homozygoten Sall2-Mäusen auf dem 129/SvJ-Hintergrund.

\subsubsection{Deletionskontrolle des Sall2-Gens durch Northern-Blot-Analysen}

Für die Kontrolle der Deletion des Sall2-Gens in den Mutanten wurden aus adulten Wildtyp-, heterozygoten und homozygoten Mäusen (Hintergrund 129/SvJ) Nieren präpariert und die isolierte RNA mit der 1B2-Sonde hybridisiert.

Die Abbildung 3.23 zeigt, dass wie erwartet in heterozygoten Mäusen die Transkriptmenge verringert ist und homozygote Mäuse keine Sall2-Transkripte exprimieren. Die Quantifizierung der eingesetzten RNA-Menge erfolgte durch eine Rehybridisierung mit einer menschlichen $\beta$-Actin-Sonde (s. 2.2). 


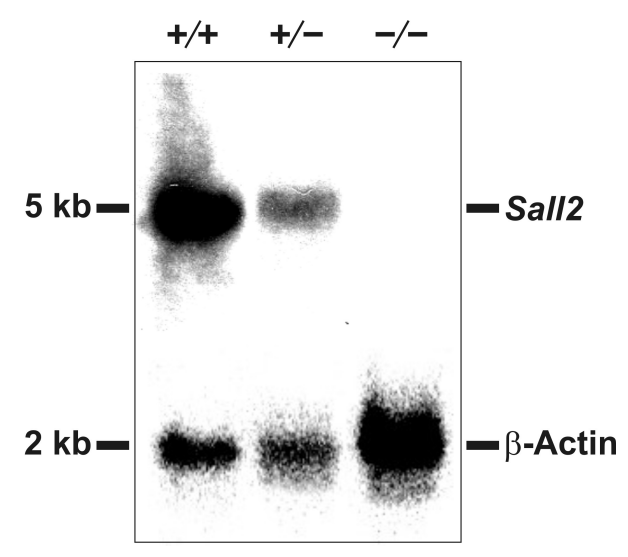

Abbildung 3.23: Northern-Blot-Analyse Sall2-defizienter Mäuse. Die Abbildung zeigt eine Northern-Blot-Analyse mit je $20 \mu \mathrm{g}$ Gesamt-RNA aus Nierengewebe von Wildtyp-Mäusen sowie von heterozygoten und homozygoten Sall2-knock out-Mäusen. Das Sall2-Transkript hybridisierte bei ca. $5 \mathrm{~kb}$, die $\beta$-Actin-Sonde zur Quantifizierung bei ca. $2 \mathrm{~kb}$.

\subsubsection{Histologische Analysen an Organen Sall2-defizienter Mäuse}

Histologische Untersuchungen verschiedener Organe wurden freundlicher Weise von Dr. Schulz-Schaeffer, Abt. Neuropathologie, Universitätsklinikum Göttingen, durchgeführt. Mehrere Organe einer adulten Sall2-knock out-Maus auf dem Hintergrund 129/SvJ wurden in Paraffin eingebettet, geschnitten und mit verschiedenen Methoden angefärbt. Besonderes Augenmerk wurde auf die Gewebe gerichtet, die starke Sall2-Expression in den whole mount-in situ-Hybridisierungen oder in der Northern-Blot-Analyse zeigten. In Abbildung 3.24 ist eine Zusammenstellung von Gewebeaufnahmen dargestellt. Bei den histologischen Untersuchungen ergaben sich keine auffälligen Befunde.

\subsubsection{Analyse der Sall1-Expression in Sall2-knock out-Embryonen}

Eine mögliche Kompensation der Sall2-Defizienz durch das Sall1-Gen sollte anhand von Expressionsanalysen für das Sall1-Gen der knock out-Mäuse überprüft werden. Erfüllt das Sall1-Gen partiell oder vollständig die Aufgabe des in der Maus deletierten Sall2-Gens, ist eine verstärkte oder ektopische Expression zu erwarten. Ist dagegen Sall2 an der Regulation der Sall1-Expression beteiligt, ist eine verminderte Sall1-Expression zu erwarten. Daher wurden whole mount- 

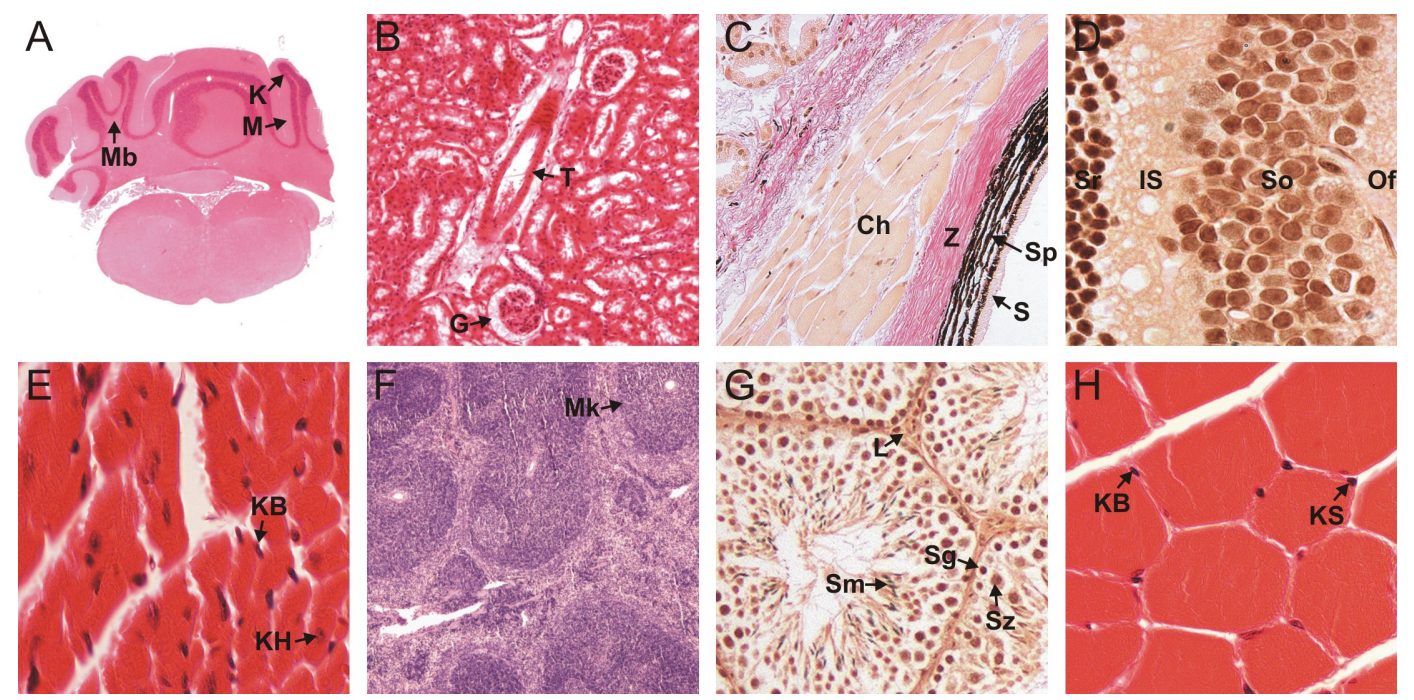

Abbildung 3.24: Histologische Analysen an einer Sall2-/--Maus. Gezeigt sind Aufnahmen von Schnitten, die von verschiedenen Organen einer Sall2-knock out-Maus hergestellt wurden. A, $B, D$ und $H$ wurden mit Hämalaun-Eosin, $C, D$ und $G$ nach der van Gieson-Methode, F mit PAS angefärbt. A: Ausschnitt eines Mediosagittalschnitts durch die Kleinhirnrinde; B: Ausschnitt eines senkrechten Durchschnitts durch die Niere; C, D: Ausschnitte aus einem senkrechten Durchschnitt durch das Auge; E: Querschnitt durch die Herzmuskulatur des linken Ventrikels; F: Ausschnitt eines senkrechten Durchschnitts durch die Milz; G: Ausschnitt eines senkrechten Durchschnitts durch den Testis; H: Ausschnitt eines Querschnitts durch die quergestreifte Muskulatur. Ch: Choroidea; G: Glomerulus; Is: innere plexiforme Schicht der Netzhaut; K: Körnerschicht der Kleinhirnrinde; KB: Kern einer Bindegewebszelle; KH: Kern einer Herzmuskelzelle; KS: Kern einer Skelettmuskelfaser; L: Leydig-Zwischenzelle; M: Molekularschicht der Kleinhirnrinde; Mb: Markblätter; Mk: Milzknötchen mit Zentralarterie; Of: Optikusfaserschicht; S: äußere plexiforme Schicht der Netzhaut; Sg: Spermatogonie; Sm: Spermium; So: Stratum ganglionare n. optici; Sp: Stratum photosensorium; Sr: Stratum ganglionare retinae; Sz: Spermatozyt I; T: Tubulus der Niere; Z: Zone der Innenund Außenglieder der Sehzellen.

in situ-Hybridisierungen an 9.5 bzw. 10.5 dpc-Sall2-/--Embryonen aus Sall2-/-Verpaarungen mit einer DIG-markierten antisense-Sonde des CB3 E-Fragments aus Sall1 (s. Abb. 3.1, S. 57) durchgeführt. Es konnte keine Veränderung in der Expression des Sall1-Gens oder der Lokalisierung der Transkripte festgestellt werden. Die Abbildung 3.25.A zeigt einen 9.5 dpc-Embryo, in dem das typische Sall1-Expressionsmuster mit Transkripten in der Mittelhirn-Rautenhirn-Grenze, in einem anterioren Bereich des Mittelhirns, im Neuralrohr, in der Region des dritten und vierten Branchialbogens, im Mesonephros und einem großen Bereich der Schwanzspitze (vgl. auch Abb. 3.5, S. 80) detekiert wurde. Im Embryonalstadium 10.5 dpc konnte wie bei Wildtyp-Embryonen eine beginnende Expression in 
einer posterioren Domäne der vorderen Gliedmaßenknospen beobachtet werden (s. Abb. 3.25.F).

\subsubsection{Morphologische Analysen an Sall2-knock out-Embryonen}

Im Verlauf der Präparation von Sall2 ${ }^{-/-}$-Embryonen aus Verpaarungen homozygoter Sall2-Deletionsmutanten für whole mount-in situ-Hybridisierungen wurden an mehreren Embryonen verschiedener Altersstadien Fehlbildungen im Kopfbereich festgestellt (s. Abb. 3.25), die bei der Präparation von Wildtyp-Embryonen für whole mount-in situHybridisierungen nicht beobachtet wurden.

Aus 7 Verpaarungen konnten 16 Embryonen präpariert werden, womit die durchschnittliche Anzahl von Nachkommen bei 2.8 lag. 9 dieser Embryonen zeigten eine normale und dem jeweiligen Alter entsprechende Morphologie, 7 wiesen dagegen unterschiedlich starke Störungen bei der Entwicklung verschiedener Gehirnbereiche auf. In den Abbildungen 3.25.B und D ist ein 9.5 dpc-Embryo abgebildet, bei dem festgestellt wurde, dass der rostrale Neuroporus nicht, wie bei normalen Embryonen dieses Entwicklungsstadiums (Abb. 3.25.A, C), geschlossen war, sondern bei dem die Vorderhirnwülste noch auseinander standen. Der Kopf ähnelte dem eines in der Entwicklung noch nicht so weit fortgeschrittenen $8.5 \mathrm{dpc}$-Embryonen. Dieser Defekt konnte bei den Sall2 ${ }^{-/}$-Embryonen nur im Bereich des rostralen Neuroporus, nicht aber im Bereich des caudalen Neuroporus oder des Neuralrohrs beobachtet werden. Die Abbildungen 3.25.F und $\mathrm{H}$ zeigen einen Embryo, bei dem eine gestörte Vorderhirn-Entwicklung beobachtet wurde. Die lateralen Ventrikel waren nicht so ausgebildet wie in einem normal entwickelten 10.5 dpc-Embryo (s. Abb. 3.25.E, G), da der Bereich zwischen den Ventrikeln unvollständig ausgebildet zu sein scheint und die Vorderhirnwülste weit auseinander klaffen. In den Abbildungen 3.25.I und $\mathrm{J}$ sind Aufnahmen eines 10.5 dpc-Embryonen dargestellt, der im Vergleich zu dem Embryo in den Abbildungen 3.25.E und $G$ eine stark reduzierte Mittelhirn-Struktur aufweist, wodurch die Mittelhirn-Rautenhirn-Grenze (MRG) aus dem Kopf hervorzustehen scheint. Auch das Vorderhirn ist in diesem Embryo deformiert, die posteriore Region vor dem Übergang zum Mittelhirn ist stark eingedrückt oder nicht richtig miteinander verwachsen. 

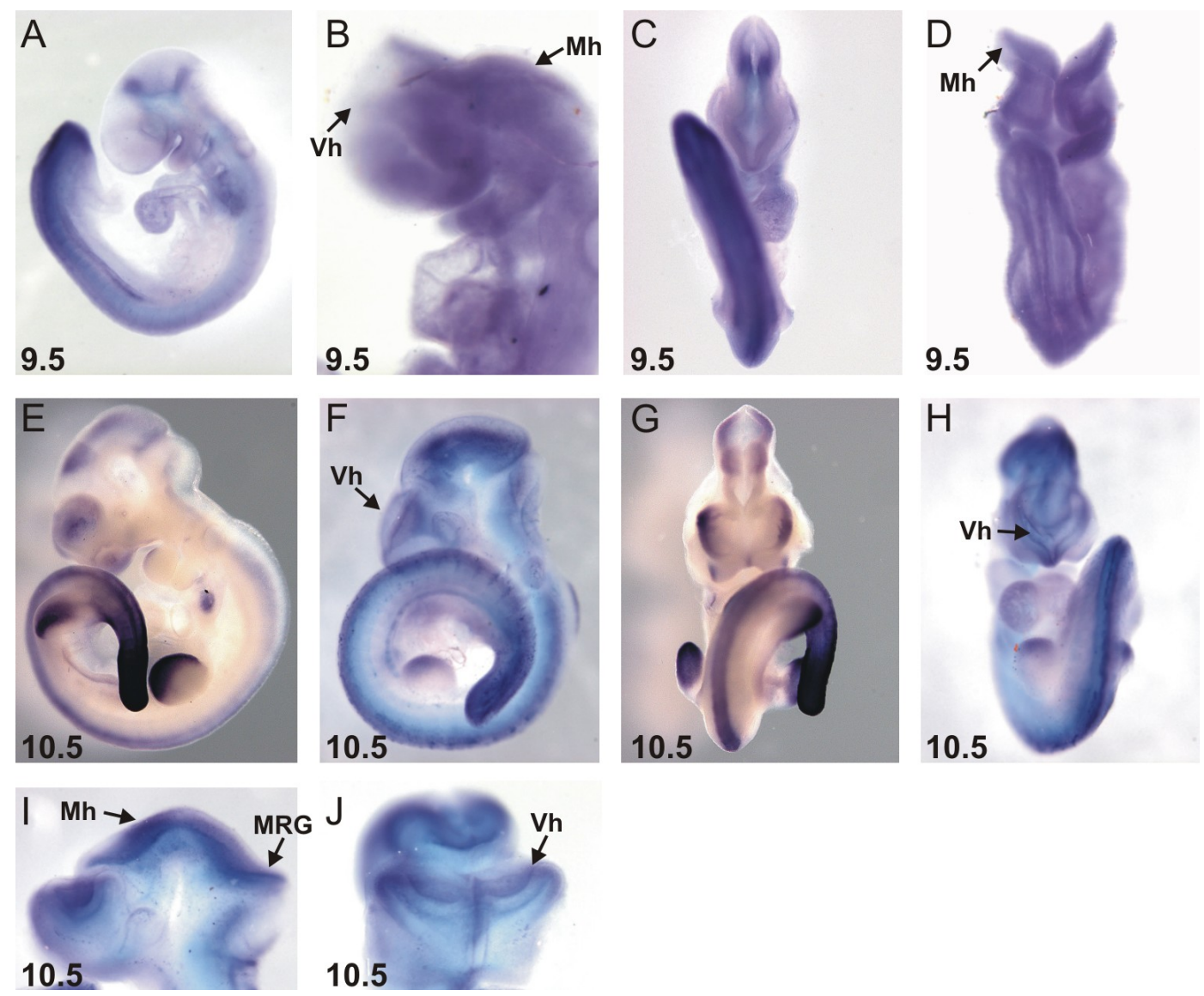

Abbildung 3.25: Morphologische Analyse Sall2-defizienter Embryonen. Gezeigt sind Sall2 ${ }^{-/}$-Embryonen der Stadien 9.5 und $10.5 \mathrm{dpc}$ aus verschiedenen Verpaarungen von Sall2defizienter Mäuse ohne (A, C, E und G) und mit Gehirnfehlbildungen (B, D, F, H, I, J). Bis auf I und $\mathrm{J}$ sind jeweils die entwicklungsgestörten Embryonen zum Vergleich neben gleichaltrigen Vergleichstieren in lateraler bzw. frontaler Ansicht dargestellt. Die Pfeile zeigen auf die deformierten Gehirnregionen. Der Embryo in B und D wurde zur besseren Visualisierung der Morphologie nach der Hybridisierung mit einer sense-Sonde überfärbt, alle anderen Embryonen wurden mit einer DIG-markierten Sall1-Sonde hybridisiert. Mh: Mittelhirn; MRG: Mittelhirn-Rautenhirn-Grenze; Vh: Vorderhirn.

\subsection{Herstellung eines Anti-Sall2/SALL2-Antikörpers}

Um die Expression des Sall2-Proteins in situ und in Western-Blots von Mausgeweben untersuchen zu können, sollte ein monospezifischer Anti-Sall2-Antikörper hergestellt werden. Dies lässt sich durch eine Immunisierung von Kaninchen mit dem gesamten Protein, einem Teil des Proteins oder einer kurzen Peptidsequenz aus dem Protein erreichen. Da die Aminosäuresequenz des murinen Sall2-Proteins 
und des humanen SALL2-Proteins sehr homolog ist ( $86 \%$, Kohlhase et al. (2000)), sollte versucht werden, einen Antikörper der spezifisch beide Proteine detektiert zu gewinnen. Dazu sollte in der vorliegenden Arbeit ein Fusionsprotein (FP) aus einem Bereich des Proteins hergestellt werden, der eine hohe Homologie zu dem humanen Homolog SALL2 aufweist. Um unspezifische Kreuzreaktionen des Antikörpers mit anderen Proteinen zu vermeiden, sollte der Bereich zudem möglichst wenige Homologien zu anderen Proteinen, insbesondere Zinkfingerproteinen, aufweisen. Das FP sollte nachfolgend zur Immunisierung von Kaninchen genutzt werden. Des Weiteren sollte versucht werden, über das hergestellte FP aus einem gegen das humane SALL2-Protein hergestellten Antiserum (Kohlhase, 2000a) Antikörper gegen humane SALL2- bzw. murine Sall2-Proteine zu isolieren. Dazu wurde das Proteinexpressionskit Recombinant Protein Expression and Purification Kit von IBA verwendet (s. 2.10.1).

\subsubsection{Herstellung von Sall2- und SALL2-Fusionsproteinen}

Für die Herstellung des Konstrukts zur Generierung eines murinen Sall2-FPs (MS2) wurde eine PCR mit den Primern MS2FP F2 / MS2FP R1 etabliert (s. 2.10.1.1). Als Template für die PCR, mit der ein Produkt von $495 \mathrm{bp}$ amplifiziert wurde, diente der Sall2-Klon 1B6 (s. Abb. 3.17). Der Forward-Primer MS2FP F2 reicht innerhalb der im Anhang dargestellten Sequenz des murinen Sall2-Gens (s. Abb. A.2) von bp 17394 bis bp 17414, der reverse Primer MS2FP R1 von bp 17870 bis bp 17888 . Das amplifizierte Fragment liegt im Bereich der zweiten Doppelzinkfinger (DZF)-Domäne, der ein weiterer Einzelzinkfinger (EZF) folgt (s. Abb. 3.26). Für das humane SALL2-FP (HS2) wurde mit der Primerkombination HS2FP F1 / HS2FP R2 ein Produkt von 651 bp an dem genomischen Phagenklon H6 (Kohlhase, 1996) amplifiziert. Die Primer liegen innerhalb der humanen Aminosäure (AS)-Sequenz (Kohlhase et al., 2000) im Bereich der AS 535-542 für HS2FP F1 und AS 746-752 für HS2FP R2. Damit deckt HS2 ebenfalls den Bereich des zweiten DZF und des nachfolgenden EZF ab (s. Abb. 3.26).

Beide PCR-Produkte wurden mit Bsa I restriktionsenzymatisch gespalten und in den gleichfalls mit Bsa I linearisierten Vektor IBA2 ligiert. Mehrere aus der Transformation hervorgegangene Kolonien wurden in Selektionsmedium angezogen und mittels Restriktionsanalyse vorselektiert. Einige positive Plasmidklone wurden mittels Sequenzanalyse auf mögliche Punktmutationen und die Klonierung im korrekten Leseraster überprüft. Von den korrekt amplifizierten und klonierten 


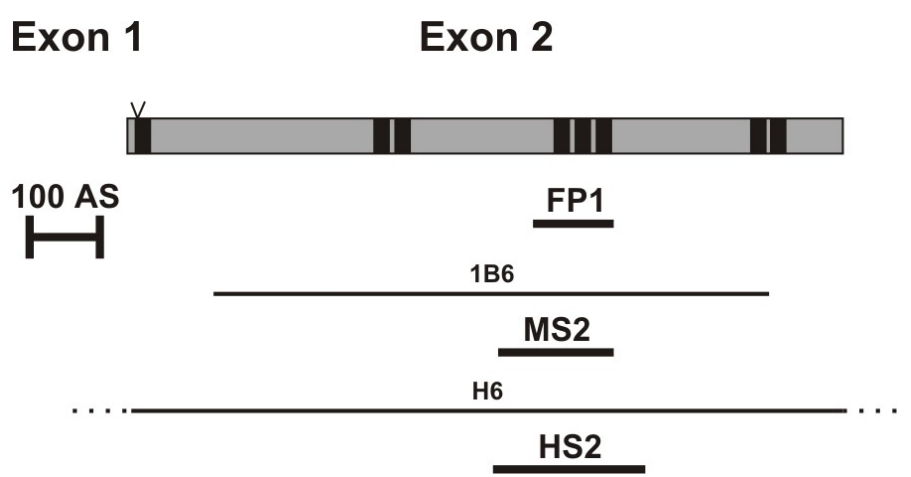

Abbildung 3.26: Fusionsproteine für das murine Sall2- und das humane SALL2-Gens. Die Karte zeigt schematisch die Struktur des murinen Sall2- bzw. des humanen SALL2-Proteins, die aufgrund der großen Homologie durch ein Schema darzustellen sind. Die Zinkfinger sind als senkrechte Balken dargestellt. Das Fusionsprotein FP1 wurde zur Herstellung des bei der Aufnahme dieser Arbeit vorliegenden Antiserums gegen das humane SALL2-Protein eingesetzt. Die FPs sind als dicke Striche dargestellt, die Klone, die als Templates dienten, werden durch die dünnen Striche repräsentiert. Das Häkchen gibt den Übergang von Exon 1 zu Exon 2 an.

Plasmiden wurden je zwei des Sall2- bzw. SALL2-Gens für die weiteren Versuche ausgewählt.

\subsubsection{Gewinnung der Sall2- und SALL2-Fusionsproteine}

Um das MS2- bzw. HS2-FP in E. coli nachzuweisen, erfolgte eine Anzucht wie unter 2.10.1.2 beschrieben. Das tet-Repressorgen verhindert die Expression des klonierten Gens im Zusatz-freien Medium, durch die Zugabe von Anhydrotetracyclin wird die Expression des FPs induziert. Das carboxyterminal fusionierte Streptag II-Peptid ermöglicht die Erkennung durch mit der AP konjugiertem StrepTactin.

Nach der Anzucht der Bakterien und dem Aufschluss der Proteine wurden diese zur Kontrolle auf einem PAGE-Gel aufgetrennt, auf eine PVDF-Membran übertragen und diese mit StrepTactin umgesetzt (s. 2.10.1.4). Dabei konnten Signale der erwarteten Größe von ca. $25 \mathrm{kDa}$ (MS2) und ca. $35 \mathrm{kDa}$ (HS2) detekiert werden (s. Abb. 3.27). Davon sind etwa $5 \mathrm{kDa}$ auf das Strep-tag IIPeptid zurückzuführen. Das HS2-FP lieferte ein stärkeres Signal als das MS2-FP. Die $20 \mathrm{kDa}$-Bande ist auf das bakterielle, kovalent biotinylierte Biotinyl-CarboxylCarrier-Protein (BCCP) zurückzuführen, das ohne Avidin-Behandlung zusätzlich detektiert wird (Schmidt und Skerra, 1993). Unter Anzuchtbedingungen von $30^{\circ} \mathrm{C}$, unter denen auch die hier gezeigten Fusionsprotein-exprimierenden Bakterien ver- 
mehrt wurden, stellte sich in diesen Experimenten das Bakterienprotein als Doppelbande dar.

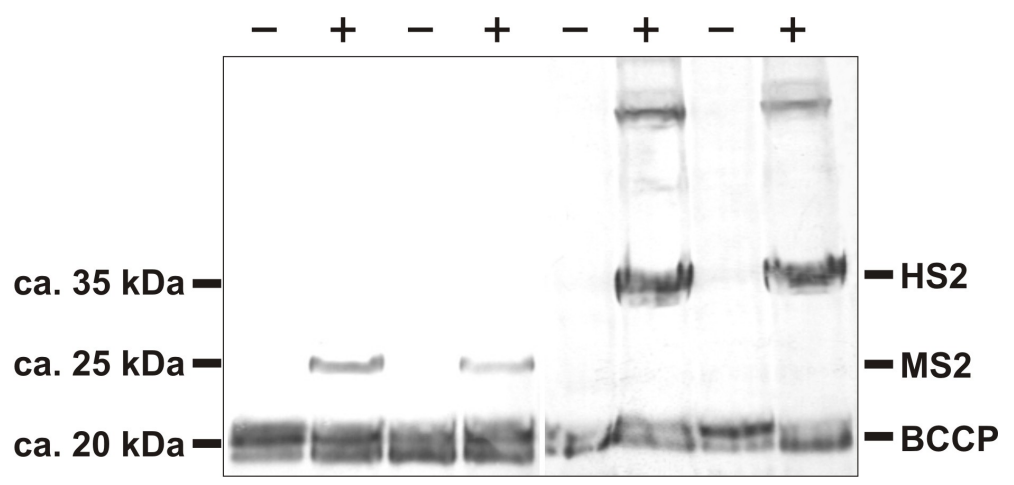

Abbildung 3.27: Western-Blot-Analyse der Fusionsproteine Sall2 und SALL2. Gezeigt ist ein mit NBT/BCIP-gefärbter Westernblot der Fusionsproteine MS2 und HS2 nach PAGE und Elektrotransfer. In den ersten vier Spuren wurden Zelllysate von Sall2-transformierten Bakterien, in den nächsten vier Spuren Lysate von SALL2-transformierten Bakterien aufgetrennt, wobei die mit + bezeichneten $3 \mathrm{~h}$ mit dem Induktor Anhydrotetracyclin inkubiert wurden und die mit - bezeichneten Parallelansätze ohne Induktion als Kontrolle dienten. HS2: humanes SALL2-Fusionsprotein; MS2: murines Sall2-Fusionsprotein; BCCP: biotinyliertes Bakterienprotein.

\subsubsection{Gewinnung von Antikörpern gegen das murine Sall2- und das humane SALL2-Protein.}

Die FPs konnten nun eingesetzt werden, um aus dem bereits vorhandenen antiSALL2-Serum Antikörper zu isolieren, die sowohl das murine Sall2- als auch das humane SALL2-Protein binden. Das Serum war durch Immunisierung eines Kaninchens mit einem SALL2-FP gewonnen worden (Kohlhase, 2000a). Es enthält ein 115 AS großes Fragment des SALL2-Proteins, welches den zweiten Doppelzinkfinger sowie den nachfolgenden Einzelzinkfinger einschließt (s. Abb. 3.26). Da das HS2-FP ein wesentlich stärkeres Signal aufwies als das MS2-FP und die Homologie zwischen den verwendeten murinen und humanen Aminosäuresequenz im überlappenden Bereich bei $97 \%$ liegt (Kohlhase et al., 2000), sollte HS2 für die weiteren Versuche verwendet werden und die so erhaltenen monospezifischen Antikörper auch zur Detektion des murinen Proteins eingesetzt werden.

Die Rohextrakte der geernteten Proteine wurden zunächst über immobilisiertes StrepTactin aufgereinigt (s. 2.10.1.3). Je $20 \mu \mathrm{L}$ der Eluate wurden mittels SDSPAGE analysiert und eine Fraktion mit einer deutlichen Fusionsproteinbande ge- 
wählt (s. Abb. 3.28). Das ausgewählte Eluat wurde eingesetzt, um wie in 2.10.9 beschrieben eine Antikörper-Aufreinigung mittels Western-Blot-Verfahren durchzuführen. Zur Überprüfung der gewonnenen Antikörper wurde eine Immunodetektion gegen das HS2-FP mit verschiedenen Verdünnungen des Antiserums und des Antikörpers durchgeführt. Wie in Abbildung 3.29 gezeigt, konnte mit dieser Methode kein wirkungsvoller monospezifischer Antikörper aufgereinigt werden.

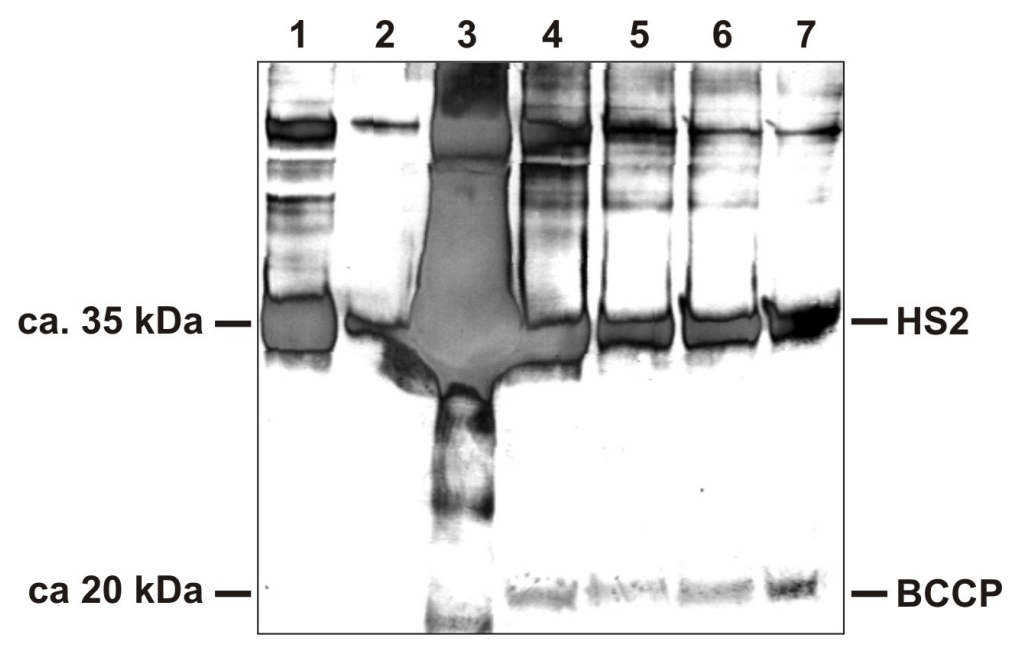

\begin{abstract}
Abbildung 3.28: Aufreinigung des Fusionsproteins HS2 über immobilisiertes StrepTactin. Die Western-Blot-Analyse zeigt die Anreicherung des Fusionsproteins HS2 in den Elutionsfraktionen nach der StrepTactin-Aufreinigung über die Säule. In Spur 1 wurde das Zelllysat, in den Spuren 2-7 je $20 \mu \mathrm{L}$ der Elutionsfraktionen aufgetragen. Der Filter wurde mit AP-konjugiertem StrepTactin umgesetzt und mit NBT/BCIP gefärbt. HS2: humanes SALL2-Fusionsprotein; BCCP: biotinyliertes Bakterienprotein.
\end{abstract}

\title{
3.8.4 Herstellung eines Antiserums gegen Sall2
}

Die Versuche zur Herstellung von Sall2- bzw. SALL2-Fusionsproteinen ergaben eine deutlich stärkere Expression des humanen HS2-FPs gegenüber dem murinen MS2-FP (s. Abb. 3.27). Die geringe Menge des erhaltenen MS2-FPs ließ eine erfolgreiche Immunisierung bezweifeln. Da die Homologie der verwendeten murinen und humanen Aminosäuresequenz für HS2 bzw. MS2 im überlappenden Bereich bei $97 \%$ liegt (Kohlhase et al., 2000), wurde die Immunisierung von zwei Kaninchen nur mit dem HS2-FP durchgeführt. Dabei wurde angenommen, dass das erhaltene Antiserum aufgrund der hohen Homologie sowohl mit dem humanen SALL2- als auch mit dem murinen Sall2-Protein reagieren würde. Die Analyse 
des Antiserums konnte nicht mehr im Rahmen dieser Arbeit erfolgen.

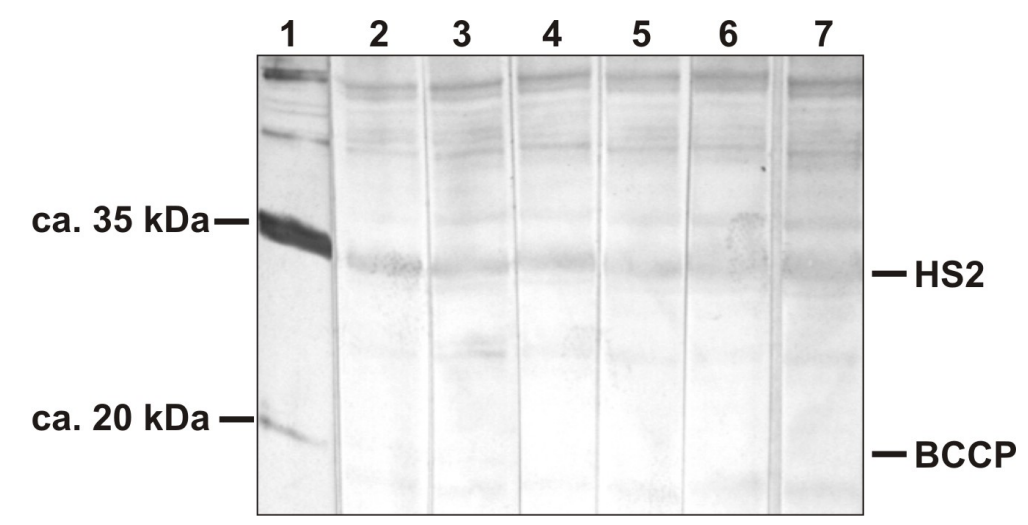

Abbildung 3.29: Test des Antiserums und des Antikörpers gegen das Fusionsprotein HS2. Gezeigt ist ein mit NBT/BCIP-gefärbter Westernblot des Fusionsprotein HS2 nach PAGE und Elektrotransfer. Der mit 1 bezeichnete Membranstreifen wurde zur Kontrolle mit AP-konjugiertem Streptactin umgesetzt. Für die mit 2, 3 und $\mathbf{4}$ bezeichneten Filterstreifen diente das Antiserum als Erstantikörper in den Verdünnungen (von rechts nach links) 1:100, 1:500 und 1:1000. Der Zweitantikörper war mit alkalischer Phosphatase konjugiert. Die drei letzten Spuren auf dem Filter waren mit dem aufgereingten Antikörper in den Verdünnungen 1:100 (5), 1: 500 (6) und 1:1000 (7) inkubiert worden. HS2: humanes SALL2-Fusionsprotein; BCCP: biotinyliertes Bakterienprotein.

\subsection{Untersuchungen zur Expression des Sall3-Gens der Maus}

Aus der Publikation von Ott et al. (1996) ist bekannt, dass das murine Sall3-Gen (vormals Msal) im embryonalen Gehirn, im Neuralrohr und in den aus dem Mesoderm entstehenden Strukturen exprimiert wird. Um die Expression von Sall1 und Sall3 miteinander vergleichen bzw. gegeneinander abgrenzen zu können, sollten whole mount-in situ-Hybridisierungen mit einer DIG-markierten Sall3-Sonde an 7.5-12.5 dpc Embryonen durchgeführt werden.

\subsubsection{Generierung einer Sall3-Sonde}

Ott et al. (1996) haben die Nukleotidsequenz sowie die daraus abgeleitete Aminosäuresequenz des Sall3-Gens beschrieben. Mit Hilfe dieser Daten wurden die Sequenzen für zwei Primer, MS3 F1 und MS3 R2 (s. 2.7.5), abgeleitet, mit deren 
Hilfe ein $1.7 \mathrm{~kb}$ großes Sall3-Fragment an genomischer DNA amplifiziert werden konnte (2.9.7.2; s. Abb. 3.30). Dieses als Sonde eingesetzte Fragment (Sall3) beinhaltet die für den $\mathrm{C}_{2} \mathrm{HC}$-Zinkfinger und die ersten Doppelzinkfingerkomäne kodierende Sequenz am 5'-Ende von Exon 2 des Sall3-Gens. Das PCR-Produkt wurde in den Vektor pGEM-T kloniert und zur Herstellung einer DIG-markierten antisense-Sonde verwendet.

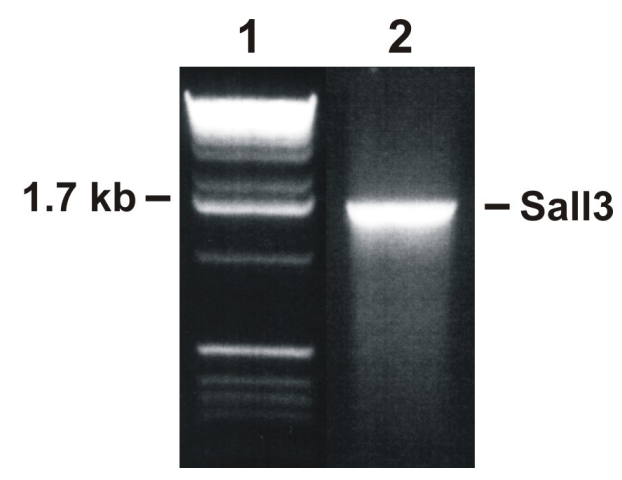

Abbildung 3.30: Amplifikation der Sall3-Sonde. Eine PCR mit den Primern MS3 F1 und MS3 R2 wurde an muriner genomischer DNA durchgeführt. Es konnte ein $1.7 \mathrm{~kb}$-Fragment (Sall3) amplifiziert werden, das für whole mount-in situ-Hybridisierungen eingesetzt werden sollte.

\subsubsection{Expression des Sall3-Gens in neuralen embryonalen Geweben}

Abbildung 3.31.A zeigt eine Expression von Sall3 bereits in den frühesten untersuchten Stadien (7.5 und $8.5 \mathrm{dpc}$ ) im gesamten neuralen Ektoderm (s. Abb. 3.31.B). An $9.5 \mathrm{dpc}$ zeigen das Neuralrohr im dorsalen Bereich und die MittelRautenhirn-Grenze ein starkes Signal (s. Abb. 3.31.C,E,F). Weitere Expressiondomänen im Kopf sind ein anteriorer Bereich des Mittelhirns nahe der Grenze zum Vorderhirn und der ventrale Bereich dieser beiden Vesikel. Diese Expression kann in gleicher Form auch an 10.5 dpc detektiert werden (s. Abb. 3.31.G,H). Die Anfärbung des Neuralrohrs und der Mittel-Rautenhirn-Grenze lässt ab Tag 11.5 pc nach, die des anterioren Mittelhirn-Bereichs ab $12.5 \mathrm{dpc}$. Der $11.5 \mathrm{dpc}-$ Embryo weist eine zusätzliche Sall3-Expressionsdomäne im medianen Telencephalon auf (s. Abb. 3.31.l). 

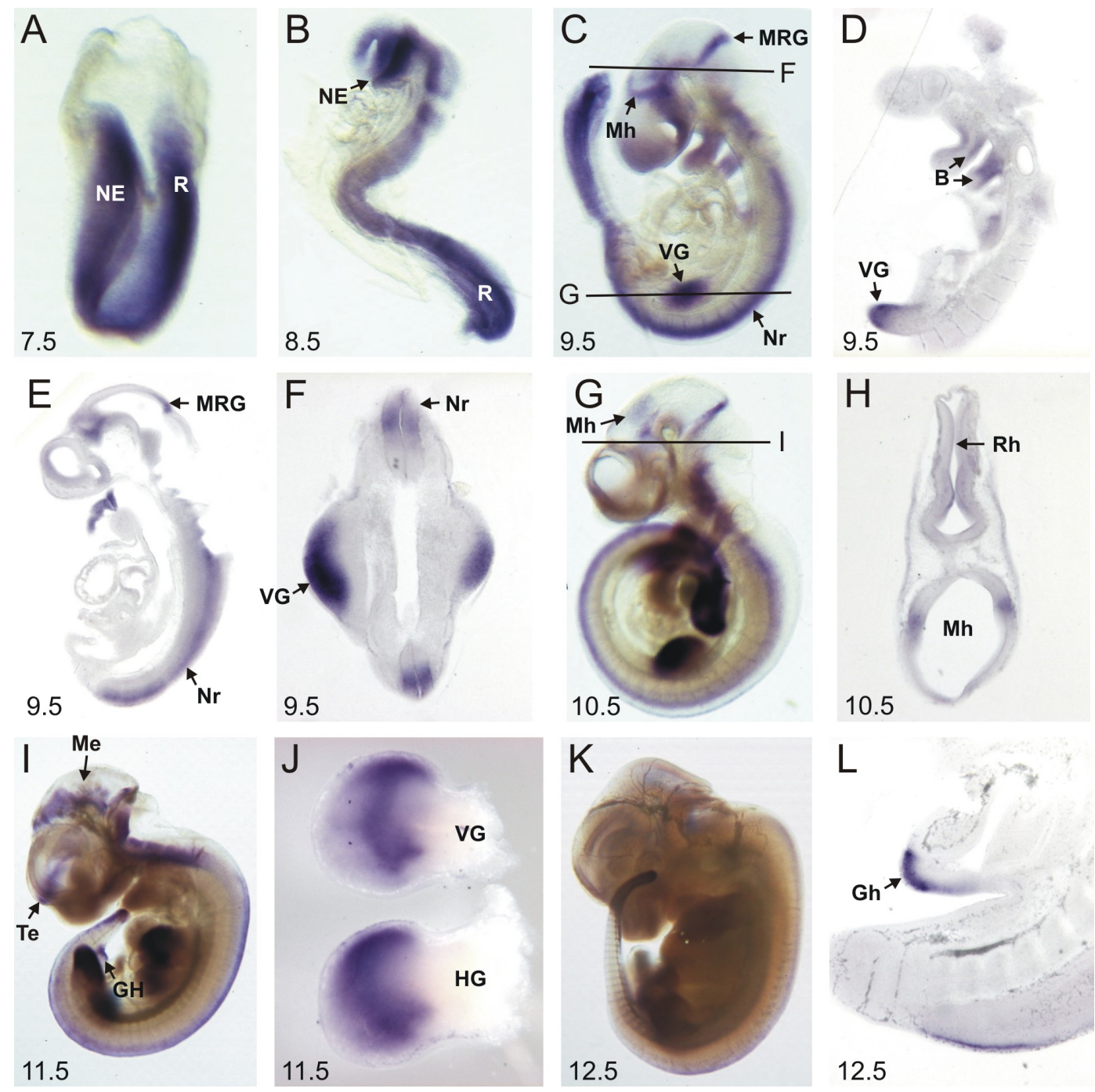

Abbildung 3.31: Expression des Sall3-Gens während der Embryonalentwicklung der Maus. $A, B, C, G$, I und $K$ zeigen whole mount-in situ-Hybridisierungen, in D, E, F, H und L sind VibratomSchnitte von whole mount-in situ-gefärbten Embryonen abgebildet. Von den Gliedmaßenknospen in J, die von einem whole mount-gefärbten Embryo abgetrennt wurden, ist die vordere Gliedmaßenknospe oben abgebildet und die hintere Gliedmaßenknospe unten gezeigt. Die Gliedmaßen sind orienteriert mit der dorsalen Seite zum Betrachter und der anterioren Seite nach oben. Die jeweiligen Altersstadien sind angegeben. B: dritter und vierter Branchialbogen; Gh: Gentialhöcker; HG: hintere Gliedmaßenknospe; Me: Mesencephalon; Mh: Mittelhirn; MRH: Mittelhirn-RautenhirnGrenze; NE: neurales Ektoderm; Nr: Neuralrohr; R: Rumpfregion; Rh: Rautenhirn; Te: Telencephalon; VG: vordere Gliedmaßenknospe. 


\subsubsection{Expression des Sall3-Gens in anderen embryonalen Geweben}

Von $7.5 \mathrm{dpc}$ bis mindestens $10.5 \mathrm{dpc}$ der Embryonalentwicklung wird Sall3 im posterioren Bereich und neu formierten Mesoderm der Embryonen exprimiert (s. Abb. 3.31.A,B,C,G). In 9.5 dpc-Embryonen sind Transkripte im Bereich des ersten und zweiten Branchialbogens zu finden (s. Abb. 3.31.C,D). Eine Expression in den Gliedmaßenknospen findet sich von $9.5 \mathrm{dpc}$ bis mindestens $11.5 \mathrm{dpc}$, wobei die Transkripte zunächst posterior lokalisiert sind (s. Abb. 3.31.C,D,F,G) und nachfolgend in einer breiten mittleren Domäne der sich entwickelnden Gliedmaßen zu finden sind (s. Abb. 3.31.I,J). Der Bereich grenzt anterior direkt an die ERL. An 11.5 und 12.5 dpc-Embryonen sind Signale im distalen Epithel des Genitalhöckers festzustellen.

\subsection{Untersuchungen zur Expression muriner spalt-Gene in sonic hedgehog-Mutanten}

Homozygote sonic hedgehog (shh)-defiziente Embryonen von 9.5-11.5 dpc wurden freundlicher Weise von Prof. Dr. S. Mundlos, Berlin, zur Verfügung gestellt. Durch whole mount-in situ-Hybridisierungen der Mutanten, die durch gezielte Genunterbrechung mittels homologer Rekombination shh-defizient sind (Chiang et al., 1996), sollte überprüft werden, ob die murinen spalt-Gene Sall1, Sall2 und Sall3 downstream-targets von shh sind. Dazu wurden die Deletionsmutanten mit DIGmarkierten antisense-Sonden für die jeweiligen Gene hybridisiert und die Signale mit dem Wildtyp-Hybridisierungsmuster verglichen. shh-Deletionsmutanten sind embryonal letal, zeigen einen stark gedrungenen Rumpf, einen extrem verlängerten Vorderhirnbereich, eine reduzierte Mittelhirnentwicklung und kaum proximodistales Wachstum der Gliedmaßenknospen (Chiang et al., 1996). In Abb. 3.32 sind jeweils die shh-defizienten Embryonen und Wildtyp-Embryonen des desselben Embryonalstadiums zum Vergleich nebeneinander gestellt.

\subsubsection{Sall1-Expression in shh-defizienten Embryonen}

Drei verschiedene Altersstadien der shh-Deletionsmutanten wurden mit einer DIGmarkierten Sall1-Sonde hybridisiert. Zunächst soll die Expression in den sich entwickelnden Neuronalgeweben verglichen werden. Die Expression im anterioren 
Bereich des Mittelhirns stellt sich in den shh ${ }^{-/-}$-Embryonen wesentlich schwächer und diffuser dar als in den Wildtyp (WT)-Embryonen, die an 9.5 und 10.5 dpc eine distinkte Domäne im anterioren Mittelhirnbereich aufweisen (s. Abb. 3.32.A-D). In den $9.5 \mathrm{dpc}$-shh ${ }^{-1-}$-Embryonen kann im Vergleich mit den WT-Embryonen ein schwächeres Signal in der Mittelhirn-Rautenhirn-Grenze (MRG) beobachtet werden, und an $10.5 \mathrm{dpc}$ sind keine Sall1-Transkripte in der MRG mehr festzustellen. In den Vergleichsembryonen wird im Telencephalon ab 10.5 dpc eine Expression detektiert, in den shh-Deletionsmutanten können Transkripte im Telencephalon erst ab $11.5 \mathrm{dpc}$ beobachtet werden (s. Abb. 3.32.C-F). Im Neuralrohr scheint die Expression der im WT-Embryo sehr ähnlich zu sein, das Signal stellt sich jedoch etwas diffuser dar. Die Expression in den olfaktorischen Plakoden bzw. Bulbi lässt sich schwer vergleichen, da die Kopfstrukturen insbesondere durch die Zyklopie und den verlängerten Vorderhirnbereich stark verändert sind. Die Expression in den vorderen und hinteren Gliedmaßenknospen zeigt den gleichen zeitlichen Verlauf wie die in den WT-Embryonen, die Transkripte in den shh ${ }^{-1}$-Embryonen können jedoch nur im distalen Bereich der Gliedmaßenknospen gefunden werden (s. Abb. 3.32.C,E). Im Gegensatz zu den Vergleichsembryonen ist keine verbreiterte posteriore Expressionsdomäne zu sehen. In den übrigen Sall1-exprimierenden Strukturen, wie die Branchialbögen, dem Mesonephros und der Schwanzspitze, lässt in allen untersuchten Stadien der Embryonalentwicklung ein identische Expressionsmuster von Wildtyp- und $s h^{-/-}$-Embryonen feststellen.

In den shh-Deletionsmutanten kann ein den Wildtyp-Embryonen ähnliches Sall2-Expressionsmuster detekiert werden (s. Abb. 3.32.G,H). Transkripte wurden in allen Gehirnbereichen festgestellt, wobei die Expression im Mittelhirn und Telencephalon jedoch etwas geringer erscheint als im Vergleichsembryo. Zudem kann im anterioren Bereich des Telencephalons, der charakteristisch ist für $s h h^{-/-}$-Embryonen, eine Expression beobachtet werden, für die keine entsprechende Expressionsdomäne im WT-Embryo vorhanden ist. In der Deletionsmutante ist eine großflächige, diffuse Expression von Sall2 im Bereich des Neuralrohrs zu sehen, die keine Entsprechung im Vergleichsembryo hat. Sowohl die shh ${ }^{-1-}$ Embryonen als auch die Vergleichsembryonen zeigen eine schwache Expression in den Gliedmaßenknospen.

In den shh-defizienten Embryonen, die mit der Sall3-Sonde hybridisierten wurden, zeigen sich Abweichungen im Kopfbereich von dem im WT-Embryo festgestellten Hybridisierungsmuster (s. Abb. 3.32.I,J). Die Expressiondomäne im Telencephalon scheint im Vergleich zu dem Wildtyp-Embryo stark verkleinert und 
wesentlich schwächer zu sein. Dies trifft auch für die anteriore Expressionsdomäne im Mittelhirn zu. In der MRG ist kein Sall3-Transkript zu finden. Im Neuralrohr kann ein zur Expression im Verlgeichsembryo sehr ähnliches Expressionsmuster festgestellt werden. Das Signal in den Gliedmaßenknospen des $s h^{-/-}$-Embryo ist sehr schwach und eher distal lokalisiert, somit unterscheidet es sich sehr von dem Signal im Vergleichsembryo, in dem eine breite Domäne im medianen Bereich der Gliedmaßenknospen vorhanden ist.
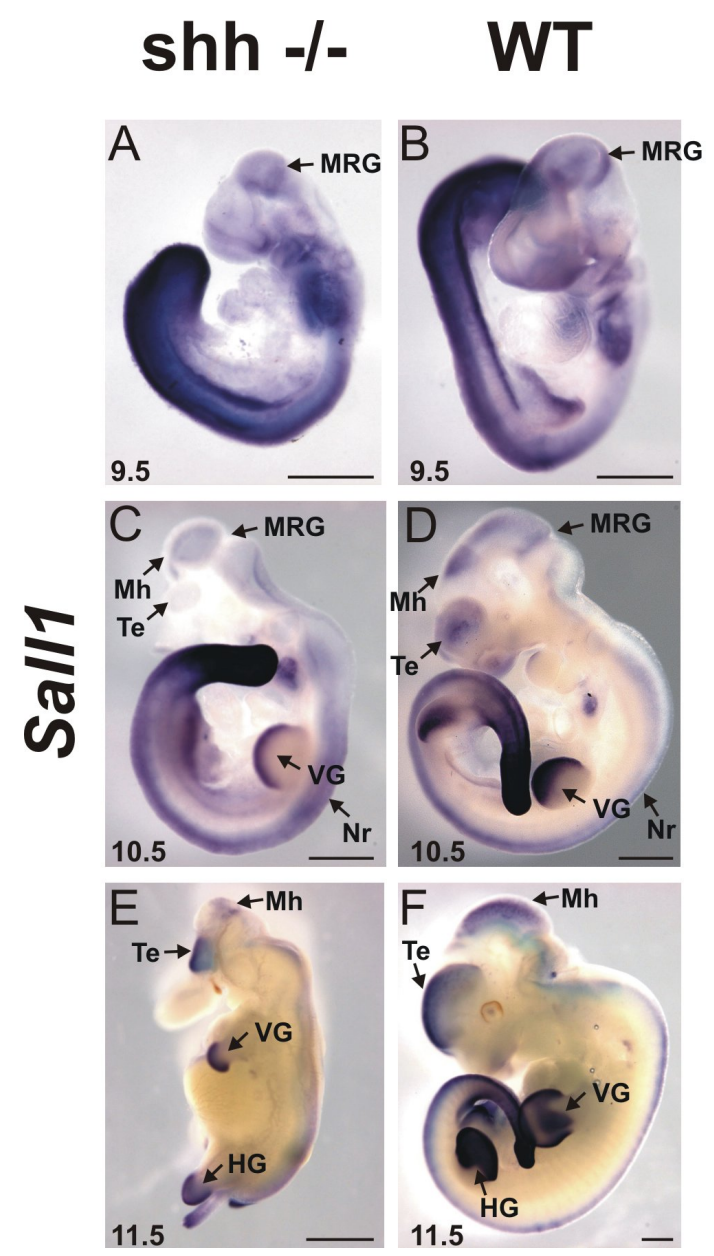

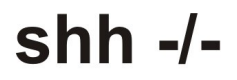

WT
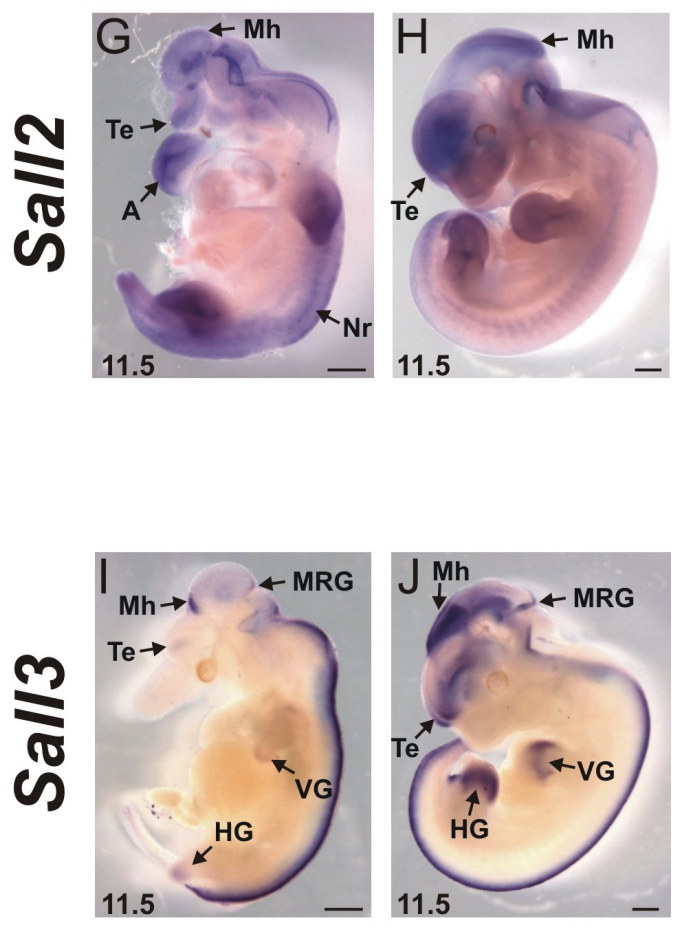

Abbildung 3.32: Expression verschiedener spalt-Gene in dsh-Deletionsmutanten. Die Abbildung zeigt whole mount-in situ-Hybridisierungen verschiedener Embryonalstadien von shhdefizienten Mäusen. Die jeweiligen Altersstadien sind angegeben. In der ersten und dritten Reihe $(\mathrm{A}, \mathrm{C}, \mathrm{E}, \mathrm{G}, \mathrm{I})$ sind die dsh-Mutanten abgebildet, in der zweiten und vierten Reihe die VergleichsEmbryonen (B,D,F,H,J). Die schwarzen Balken entsprechen $0.5 \mathrm{~mm}$. A: Anteriore Domäne im Telencephalon; HG: hintere Gliedmaßenknospe; Mh: Mittelhirn; MRG: Mittelhirn-Rautenhirn-Grenze; Nr: Neuralrohr; Te: Telencephalon; VG: vordere Gliedmaßenknospe. 


\section{Diskussion}

In den letzten Jahren wurden insgesamt zehn spalt (sal)-homologe Gene aus Vertebratenspezies isoliert und charakterisiert (Farrell und Munsterberg, 2000; Farrell et al., 2001; Hollemann et al., 1996; Köster et al., 1997; Kohlhase et al., 1996, 1999a, 2000; Onuma et al., 1999; Ott et al., 1996). Die vorliegende Arbeit beschreibt die Isolierung und Charakterisierung eines dritten sal-homologen Gens der Maus, die Herstellung von zwei knock out-Mauslinien und Studien zur Expression der drei nunmehr bekannten murinen sal-Gene Sall1, Sall2 und Sall3.

\subsection{Das Gen Sall1}

\subsubsection{Zur Struktur des Sall1-Gens}

Aus zwei durch mittelstringente Hybridisierung mit einer humanen SALL1-Sonde isolierten Cosmidklonen wurde eine genomische Sequenz von 16410 bp ermittelt (s. Abb. A.1). Die genomische Größe dieses Gens ohne regulatorische Regionen beträgt ca. $15.2 \mathrm{~kb}$. Der offene Leserahmen umfasst $3975 \mathrm{bp}$ und kodiert für ein putatives Protein von 1325 Aminosäuren. Die kodierende Sequenz wird von zwei Introns unterbrochen, wobei Intron $173 \mathrm{bp}$ nach dem Startkodon beginnt und eine Länge von 9079 bp umfasst. Das Intron 2 beginnt 3464 bp nach der splice-Akzeptorstelle von Intron 2 und umfasst $1129 \mathrm{bp}$. Die Exon/IntronÜbergänge entsprechen den Konsensussequenzen eukaryotischer Gene (Breathnach und Chambon, 1981). Bei der Suche nach dem $3^{\prime}$-Ende des Transkripts (s. 3.1.3) wurden zwei Polyadenylierungssignale (Poly-AS) gefunden, von denen eines die Konsensus-Sequenz AATAAA (Lewin, 1997), das zweite die abgewandelte Sequenz AATACA (Burfeind und Hoyer-Fender, 1991) zeigt. Durch die Identifizierung zweier entsprechender EST-Klone und Nachweis der jeweiligen Transkripte mittels Northern-Blot-Analyse (s. 3.1.3) kann gefolgert werden, dass beide Poly- 
AS genutzt werden.

Mittels FISH wurde das isolierte Gen auf Chromosom 8D der Maus lokalisiert. Bei dieser Region handelt es sich um einen zum humanen SALL1-Lokus auf Chromosom 16q12 (Kohlhase et al., 1996) synthänen Bereich. Aufgrund der hohen Homologie des isolierten Gens, der chromosomalen Lokalisation sowie der im folgenden Kapitel erläuterten Strukturdaten des abgeleiteten Proteins wurde angenommen, dass das isolierte Gen das gesuchte SALL1-homologe Mausgen darstellt, welches im Folgenden Sall1 genannt wurde.

\subsubsection{Zur Struktur des Sall1-Proteins}

Das Sall1-Protein entspricht in seiner Struktur dem eines sal-ähnlichen Vertebratengens. Im offenen Leserahmen finden sich mehrere für Zinkfinger kodierende Regionen. Im 5'-Bereich von Exon 2 konnte eine für einen $\mathrm{C}_{2} \mathrm{HC}$-Einzelzinkfinger (EZF) kodierende Sequenz identifiziert werden, weiter $3^{\prime}$-wärts finden sich in diesem Exon vier für $\mathrm{C}_{2} \mathrm{H}_{2}$-Doppelzinkfinger (DFZ) kodierende Bereiche, wobei sich an den zweiten ein weiterer EZF anschließt und der vierte DZF von Intron 2 unterbrochen wird. Der Vergleich mit dem humanen SALL1-Gen ergab auf der Ebene der Aminosäuresequenz eine Homologie von $90 \%$ (s. Abb. 4.1).

Bei genauerer Betrachtung der strukturellen Eigenschaften des Sall1-Proteins im Vergleich zu SALL1 zeigt sich eine partielle Konservierung von mit bestimmten Aminosäuren angereicherten Regionen (s. 3.1.2). Nur teilweise konserviert ist eine Prolin-reiche Region im 5'-Bereich der AS-Sequenz (s. Tab. 4.1), sie enthält in der Maus zwei dieser Aminosäuren weniger als die entsprechende Region im Menschen. Prolin-reiche Regionen können als Aktivatoren oder als Repressordomänen wirken, abhängig davon, ob sie Threoninreste oder Histidine enthalten (Han und Manley, 1993). Demnach könnte diese Domäne eine Aktivatorfunktion übernehmen. Glutamin- und Serin-reiche Regionen können als TranskriptionsAktivatoren fungieren (Courey und Tjian, 1988; Gashler et al., 1993). Im SALL1Protein befindet sich eine Serin-reiche Region (Kohlhase, 1996), die nicht zwischen Maus und Mensch konserviert ist (s. Tab. 4.1). Ist diese Domäne im humanen Protein funktionell, wäre anzunehmen, dass die putativen Transkriptionsfaktoren Sall1 und SALL1 unterschiedliche Effekte auf ihre Zielgene ausüben können. Eine zweite Serin-reiche Region in SALL1 ist dagegen auch im murinen Protein vorhanden (s. Tab. 4.1), so dass ein regulativer Einfluss auf die Transkription der Zielgene durch diese Region vermutet werden kann. Die Glutamin-reiche Region 
1 MSRRKQAKPQ HFQSDPEVAS LPRRDGDTEK GQPSRPTKSK DAHVCGRCCA EFFELSDLLL |||||||||| |||||||||| |||||||||| |||||||||| |||||||||| ||||||||||

1 MSRRKQAKPQ HFQSDPEVAS LPRRDGDTEK GQPSRPTKSK DAHVCGRCCA EFFELSDLLL

61 HKKSCTKNQL VLIVNESPAS PAKTEPPGPS LNDPDDQMKD AANKADQEDC SDLSEPKGLD ||||||||||||||||||||||||||||||||||||||

61 HKKNCTKNOL VLIVNENPGS PPETFSPSPP PDNPDEOMND TVNKTDQVDC SDLSEHNGLD

121 REESMEVEVP VATTTTTTTG GSGGSGGSTL SGVTNITTPS CHSGCSSGTS AITTSLPQLG ||||||||||$|\quad| \quad|\quad|||||||||||||||$

121 REESMEVEAP VANKSGSGTS SGSHSSTAPS SSSSSSSSSG GGGSSSTGTS AITTSLPQLG

181 DLTTLGNFSV INSNVIIENL QSTKVAVAQF SQEARCGGAS GGKLLISTLM EQLLALQQQQ |||||||||||||||||||||||||||||||||||||||||||| || ||||||||||

181 DLTTLGNFSV INSNVIIENL QSTKVAVAQF SQEARCGGAS GGKLAVPALM EQLLALQQQQ

241 IHQLQLIEQI RHQILLLASO SADLPAAPSI PSQGTLRTSA NPLTTLSSHL SQQLAVAAGL ||||||||||||||||||||||||$\quad \mid$ |||||||||| ||| |||||| ||||| ||||

241 IHQLQLIEQI RHOILLLASO NADLPTSSS PSOGTLRTSA NPLSTLSSHL SOQLAAAAGL

301 AQSLASQSAN ISGVKQLPHV QLPQSSSGTS IVPPSGGTSP NMSIVTAAVP TPSSEKVASN ||||||||||||||||$\quad|||||||| \quad|\quad| \quad|||||||||||||||||| \mid$

300 AQSLASQSAS ISGVKOLPPI OLPQSSSGNT IIPSNSGSSP NMNILAAAVT TPSSEKVASS

361 AGASHVSSPA VSASSSPAFA ISSLLSPESN PLLPQPTPAN AVFPTPLPNI ATTAEDLNSL ||||||| || || ||||||| ||||||| || ||||| || ||| ||||| |||||||||

360 AGASHVSNPA VSSSSSPAFA ISSLLSPASN PLLPQQASAN SVFPSPLPNI GTTAEDLNSL

421 SALAQQRKSK PPNVTAFEAK STSDEAFFKH KCRFCAKVFG SDSALOIHLR SHTGERPFKC |||||||||| |||||||||| |||||||||| |||||||||| |||||||||| |||||||||| 420 SALAQQRKSK PPNVTAFEAK STSDEAFFKH KCRFCAKVFG SDSALQIHLR SHTGERPFKC 481 NICGNRESTK GNLKVHFORH KEKYPHIQMN PYPVPEHLDN VPTSTGIPYG MSIPSEKPVT |||||||||||||||||||||||||||||||||||||||||||||||||||||||||| 480 NICGNRFSTK GNLKVHFORH KEKYPHIOMN PYPVPEHLDN IPTSTGIPYG MSIPPEKPVT

541 SWLDTKPVLP TLTTSVGLPL PPTLPSLTPF IKTEEPAPIP ISHSAASPOG SVKSDSGAPD ||||||||||||||||||||||||||||||||||||||||||||||||||||||

540 SWLDTKPVLP TLTTSVGLPL PPSLPSLIPF IKTEEPAPIP ISHSATSPPG SVKSDSGGPE 601 LATRNPSGVP EEVEGSAVPP FGGKGEESNM ASSAVPTAGN STLNSPVADG GPGG TTFT

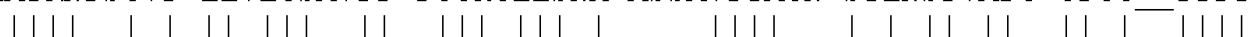
600 SATRNLGGLP EEAEGSTLPP SGGKSEESGM VTNSVPTASS SVLSSPAADC GPAGSATTFT 659 NPLLPLMSEQ FKAKFPFGGL LDSAQASETS KLQQLVENID KKATDPNECI ICHRVLSCOS |||||||||| |||||||||| |||||||||| |||||||||| |||||||||| |||||||||| 660 NPLLPLMSEQ FKAKFPFGGL LDSAQASETS KLQQLVENID KKATDPNECI ICHRVLSCOS

719 ALKMHYRTHT GERPFKCKIC GRAFTTKGNL KTHYSVHRAM PPLRVQHSCP ICOKKFTNAV ||||||||||||||||||||||||||||||||||||||||||||||||||||||||||||||||

720 ALKMHYRTHT GERPFKCKIC GRAFTTKGNL KTHYSVHRAM PPLRVOHSCP ICOKKFTNAV

779 VLOOHIRMHM GGQIPNTPVP DNYPESMESD TGSFDEKNFD DLDNFSDENM EECPEGSIPD |||||||||||||||||||||||||||||||||||||||||||||||||||||||| $\mid$

780 VLOOHIRMHM GGQIPNTPVP DSYSESMESD TGSFDEKNFD DLDNFSDENM EDCPEGSIPD

839 TPKSADASQD SLSSSPLPLE MSSIAALENQ MKMINAGLAE QLQASLKSVE NGSMEGDVLT | | | | | | | | | | | | | | | | | | | | | | | | | | | | | | | | | | | | | | | | | | | | | | | | | | | | | | | 840 TPKSADASQD SLSSSPLPLE MSSIAALENQ MKMINAGLAE QLQASLKSVE NGSIEGDVLT 899 NDSSSVGGDM ESOSAGSPAI SESTSSMOAL SPSNSTOEFH KSPGMEEKPO RVGPGEFANG |||||||||||||||||||||||||||||||||||||||||||||||||||||||| 900 NDSSSVGGDM ESOSAGSPAI SESTSSMOAL SPSNSTOEFH KSPSIEEKPO RAVPSEEANG

959 LSPTPVNGGA LDLTSSHAEK IIKEDSLGIL FPFRDRGKFK NTACDICGKT FACOSALDIH |||||||||| |||||||||| |||||||||| |||||||||| |||||||||| ||||||||||

960 LSPTPVNGGA LDLTSSHAEK IIKEDSLGIL FPFRDRGKFK NTACDICGKT FACOSALDIH 1019

1019 YRSHTKERPF ICTVCNRGES TKGNLKQHML THOMRDLPSQ LFEPSSNLGP NQNSAVIPAN 1078 ||||||||||||||||||||||||||||||||||||||||||||||||||||||||||||

1020 YRSHTKERPF ICTVCNRGES TKGNLKOHML THOMRDLPSQ LFEPSSNLGP NONSAVIPAN 1079

1079 SLSSLIKTEV NGFVHVSPQD SKDAPTSHVP QGPLSSSATS PVLLPALPRR TPKQHYCNTC 1138 |||||||||||||||||||||||||||| $\mid$ ||||||||| |||||||||| ||||||||||

1080 SLSSLIKTEV NGFVHVSPOD SKDTPTSHVP SGPLSSSATS PVLLPALPRR TPKOHYCNTC 1139 


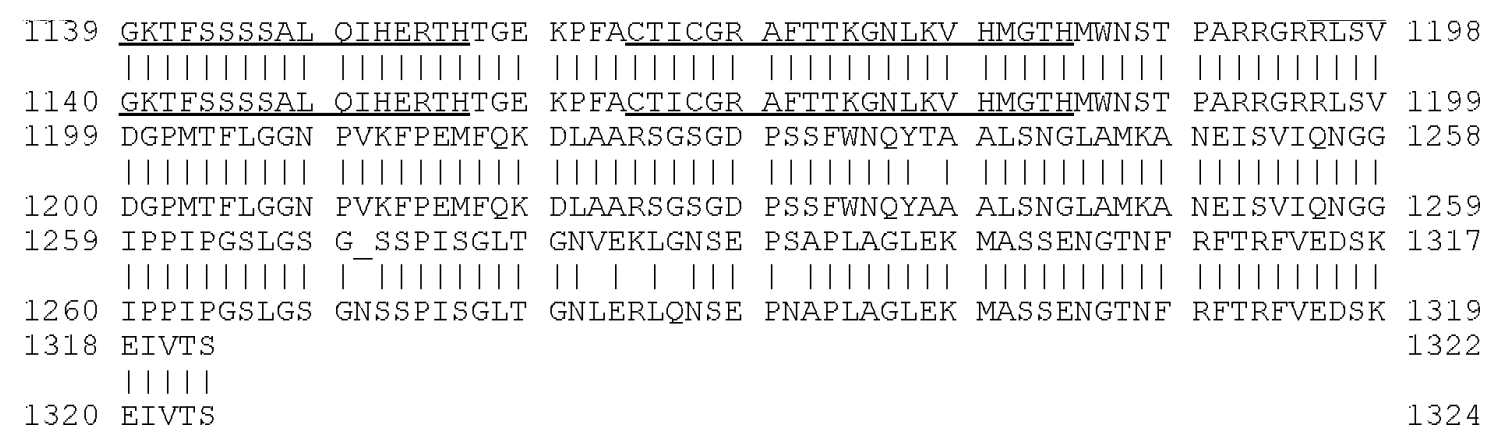

Abbildung 4.1: Vergleich der abgeleiteten Aminosäuresequenzen der Gene Sall1 und SALL1. Die obere Sequenz stellt die aus dem murinen Sall1-Gen abgeleitete Aminosäuresequenz dar, die untere ist die aus dem humanen SALL1-Gen abgeleitete Sequenz. Die Zinkfingermotive sind unterstrichen.

ist, wie in allen sal-Genen (Farrell et al., 2001; Kohlhase, 1996), vollständig konserviert und ist daher mit großer Wahrscheinlichkeit von Bedeutung als Transkriptionsaktivator. Von den Drosophila Gap-Genen krüppel, even-skipped und knirps ist bekannt, dass Alanin-reiche Regionen in ihren Genprodukten als TrankriptionsRepressor-Domänen wirken können (Gerwin et al., 1994; Han und Manley, 1993; Licht et al., 1990). Die hier identifizierte Alanin-reiche Region (s. Tab. 4.1) ist ebenfalls zwischen Maus und Mensch konserviert.

\begin{tabular}{lcccc}
\hline & \multicolumn{2}{c}{ Maus } & \multicolumn{2}{c}{ Mensch } \\
Aminosäure & Position & Anzahl & Position & Anzahl \\
\hline Prolin & $78-94$ & 6 & $78-94$ & 8 \\
Serin & $142-167$ & 4 & $135-166$ & 20 \\
Glutamin & $232-249$ & 8 & $232-249$ & 8 \\
Alanin & $295-309$ & 6 & $294-308$ & 7 \\
Serin & $353-383$ & 11 & $352-382$ & 13 \\
\hline
\end{tabular}

Tabelle 4.1: Vergleich möglicher funktioneller Domänen der abgeleiteten Aminosäuresequenzen des murinen Sall1- und des humanen SALL1-Gens. In der linken Spalte sind die auf eine Konservierung hin untersuchten Aminosäuren angegeben. In den weiteren Spalten finden sich die Positionen der Aminosäuren in der murinen bzw. humanen Sequenz sowie die Anzahl der in den betreffenen Bereichen vorkommenden Aminosäuren.

Die strukturellen Eigenschaften des murinen Sall1-Proteins würden dem putativen Transkriptionsfaktor also sowohl aktivierende als auch reprimierende Eigenschaften ermöglichen. Eventuell ist dies von den Umgebungsfaktoren und dem 
Zielgen selbst abhängig. In weiteren Versuchen dieser Arbeitsgruppe konnte gezeigt werden, dass das humane SALL1-Protein an einem eukaryotischen Promotor eine reprimierende Wirkung entfaltet (Rieger, 2001).

\subsubsection{Expression des Sall1-Gens}

\subsubsection{Expression des Sall1-Gens in adulten Geweben der Maus}

Die Expression des Sall1-Gens wurde zunächst mittels Northern-Blot-Analyse mit RNA aus adulten Geweben der Maus (s. 3.2.1) untersucht. Dabei zeigte sich eine Expression in abnehmender Stärke in Gehirn, Niere, Leber, Herz und Testis. Dies steht größtenteils im Einklang mit den für das humane SALL1-Gen festgestellten Expressionsdomänen (Kohlhase et al., 1996). Für das humane Gen wurde die stärkste Expression im Nierengewebe, die zweitstärkste für das Gehirn beschrieben. Es konnte keine Expression im Herzgewebe gefunden werden. Die Untersuchungen bezüglich der Expression beim Menschen wurden an kommerziell erwerblichen Northern-Blots durchgeführt, für die Poly- ${ }^{+}-$RNA verwendet wird und eine automatisierte Auftragung gleicher RNA-Mengen erfolgt. Die Rehybridisierung des in dieser Arbeit verwendeten Northern-Blots mit muriner Gesamt-RNA weist auf unterschiedlich hohe eingesetzte RNA-Mengen hin, wobei die Konzentration der RNA aus Herzgewebe und Testis im Vergleich zu den anderen Geweben erhöht ist. Dies könnte ein Hinweis darauf sein, dass die SALL1-Transkriptmenge der Herzgewebe-RNA im Northern-Blot mit humaner Poly- $A^{+}-$RNA unterhalb der Detektionsgröße lag. Möglich ist auch, dass sich die Expression der Gene durch Veränderungen in den Regulationsmechanismen leicht verschoben hat.

Die weitere Analyse der Sall1-Expression erfolgte mit in situ-Hybridisierungen an ganzen Embryonen (whole mounts) und an Paraffinschnitten von Geweben und Embryonen.

\subsubsection{Expression des Sall1-Gens in embryonalen Neuralgeweben}

Es zeigte sich in allen untersuchten Stadien der sich entwickelnden Mausembryonen eine ausgeprägte Expression im Zentralen Nervensystem (ZNS, s. 3.2.2). Die Entwicklung des Nervensystems beginnt mit der Formierung des Neuralrohrs aus dem Ektoderm. Dieser Prozess kann in vier Stadien unterteilt werden, die zeitlich und räumlich überlappen. Zunächst wird die Neuralplatte formiert, nachfolgend 
wird sie geformt. Im dritten Stadium erfolgt die Formierung der Neuralfurche durch das Hochwölben der Neuralplatte, abschließend fusionieren die seitlichen Ränder der Neuralfurche und bilden das Neuralrohr (Schoenwolf, 1991). Die Epidermis und das Neuralrohr sind durch die Neuralleiste verbunden (Gilbert, 1997).

Bereits im Stadium der Neuralplattenformierung lässt sich eine Sall1Expression im gesamten neuralen Ektoderm feststellen. An $8.5 \mathrm{dpc}$ finden sich Sall1-Transkripte in der Neuralfurche des noch offenen rostralen Neuroporus, so dass eine Bedeutung von Sall1 in der dorso-ventralen Organisation möglich scheint. Dafür spricht auch, dass in $9.5 \mathrm{dpc}$-Embryonen Sall1-Transkripte nur im dorsalen Bereich des Neuralrohrs zu finden sind. An Tag 12.5 der Embryonalentwicklung wird Sall1 sowohl in dorsalen als auch in ventralen Bereichen des Neuralrohrs exprimiert. Die Transkripte sind dabei auf die ventrikuläre Zone begrenzt. In der ventrikulären Zone reifen die neuronalen Vorläuferzellen heran. Mit ihrer letzten Teilung migriert ein Teil der Zellen in die subventrikuläre Zone, wo sie letzte Differenzierungsteilungen durchlaufen, um schließlich zu Neuronen in lateralen Regionen heranzureifen (Scotting und Rex, 1996). Die Entwicklung der Neuronen hängt von der präzisen Positionierung der Vorläufer innerhalb des ZNS ab und involviert lokale Umgebungsfaktoren (Scotting und Rex, 1996). Folglich könnte das Sall1-Gen an der neuronalen Differenzierung beteiligt sein.

Für eine wichtige Rolle des Gens bei der Entwicklung des ZNS spricht auch die Expression in der Mittel-Rautenhirn-Grenze (MRG, auch Isthmus genannt). Diese Struktur entsteht im Übergang vom Mes- zum Rhombencephalon durch im Vergleich zu den angrenzenden Gehirnbereichen langsameres Wachstum, so dass eine Verengung zwischen Mes- und Rhombencephalon entsteht. Von der MRG ausgehend entwickeln sich das Mittelhirn und das Cerebellum (Wassef und Joyner, 1997). Die Entwicklung und/oder Aktivität der MRG hängt von der spezifischen Expression sezernierter Proteine (Wnt1, Fgf8) und von Transkriptionsfaktoren (Otx2, Gbx2, En1, En2, Pax2, Pax5) ab (Simeone, 2000; Wassef und Joyner, 1997). Die Expression von Sall1 in der MRG lässt also eine Funktion im Zusammenspiel mit einem oder mehrerer dieser Gene in der Entwicklung oder Aktivität der MRG vermuten, da Transkripte direkt mit der ersten Ausbildung der MRG (9.5 dpc) detektiert werden können.

Eine weitere Expressionsdomäne des Sall1-Gens umfasst einen Bereich im anterioren Mittelhirn. In diesem Bereich wird später das Diencephalon ausgebildet (s. Abb. 4.2), in dem ebenfalls Sall1-Transkripte lokalisiert sind. Zudem wird Sall1 in der aus dem Vorderhirn entwickelten Struktur des Telencephalons expri- 
miert. Also spielt das Sall1-Protein vermutlich nicht nur eine Rolle in der frühen Differenzierung des ZNS, sondern könnte auch an der Spezialisierung von Zellen für sich später bildende Strukturen beteiligt sein.

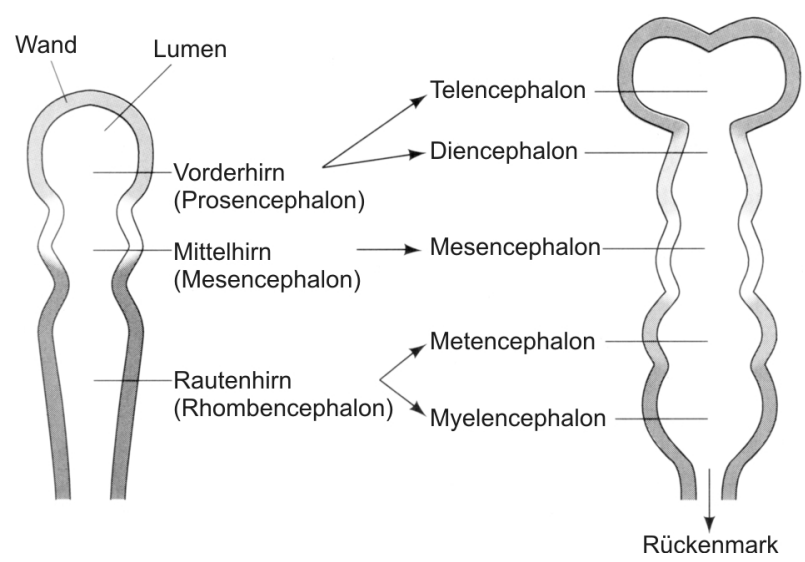

Abbildung 4.2: Die frühe Gehirnentwicklung bei Vertebraten. Links sind die drei primären Gehirnvesikel schematisch dargestellt, rechts die Unterteilung der Strukturen in der voranschreitenden Entwicklung. (Nach Gilbert (1997))

Im anterioren Bereich des Telencephalons entwickelt sich der Bulbus olfactorius (primäres olfaktorisches Areal) als doppelt angelegte ovale Ausstülpung, in denen das Sall1-Gen stark exprimiert wird. Die sehr differenzierte Anlage der Schaltzellen im Bulbus olfactorius benötigt ein komplexes Zusammenspiel der beteiligten Gene, welches die sensorischen Rezeptorzellen der olfaktorischen (Geruchsinn) und der vomeronasalen Epithelien (Pheromonsinn) sowie die zugehörigen Nerven entstehen lässt (Buck, 2000; Demski, 1993; Farbman, 1994). Die Expression von Sall1 bis über den Tag 14.5 pc hinaus macht eine Beteiligung des Gens an den geschilderten Prozessen wahrscheinlich. In diesem Zusammenhang könnte es interessant sein, TBS-Patienten in Bezug auf ihren Geruchsinn zu untersuchen, da dieser bisher bei der Anamnese nicht beachtet wurde (Powell und Michaelis, 1999).

\subsubsection{Expression des Sall1-Gens in den Gliedmaßenknospen}

Eine starke und spezifische Expression des Sall1-Gens zeigt sich auch in den Gliedmaßenknospen (s. 3.2.4). Die Entwicklung der Gliedmaßen muss in drei Richtungen koordiniert werden. Dabei bestimmt die proximo-distale Achse das Längenwachstum, die anterior-posteriore Achse determiniert die Unterscheidung 
von Daumen und kleinem Finger bzw. großem und kleinem Zeh, und entlang der dorso-ventralen Achse werden Hand- und Fußrücken bzw. Hand- und Fußfläche ausgebildet (s. Abb. 4.3). Diese Prozesse werden durch komplexe Interaktionen von Signalmolekülen und Transkriptionsfaktoren gesteuert (Chen und Johnson, 1999; Johnson und Tabin, 1997; Schwabe et al., 1998; Tickle, 1995, 1996). Bei einer Störung dieses Systems z. B. durch Mutationen in bestimmten Genen können eine Reihe von kongenitalen Fehlbildungen auftreten (Cohn und Bright, 1999), wie es auch bei TBS der Fall ist.
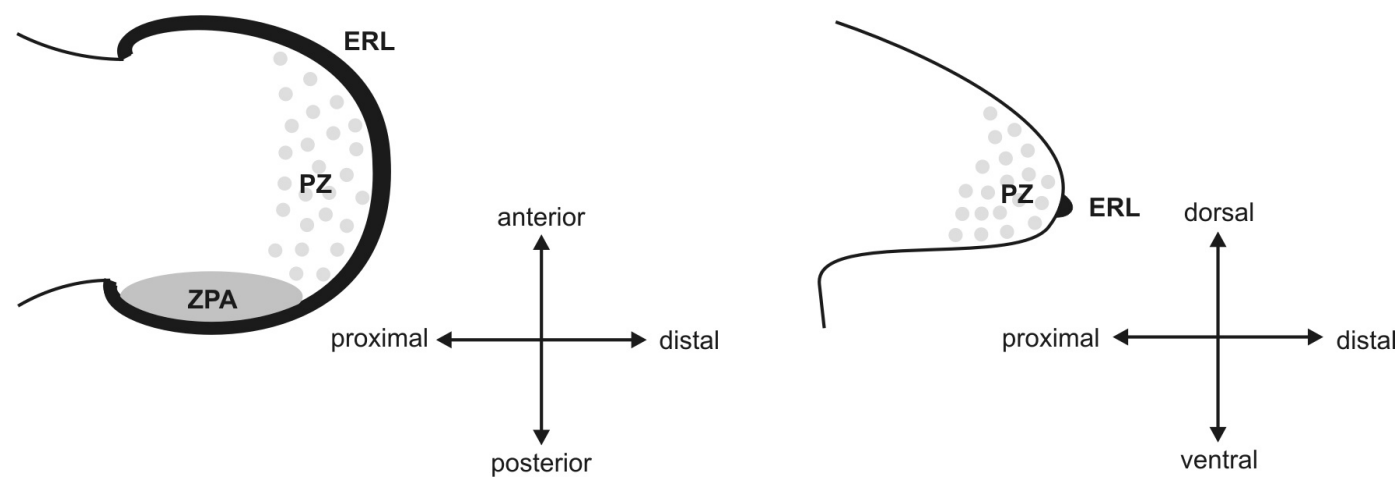

Abbildung 4.3: Die Organisationszentren und Achsen der Gliedmaßenknospen von Vertebraten. ERL: Epidermale Randleiste; PZ: Progress-Zone; ZPA: Zone polarisierender Aktivität.

In welchem der oben genannten Prozesse zur Steuerung der GliedmaßenEntwicklung könnte das Sall1-Gen involviert sein? Die Expressionsstudien deuten auf eine Beteiligung an zumindest zwei der drei genannten Prozesse hin. Zunächst zum proximo-distalen Wachstum: Sall1 wird in der epithelialen Randleiste (ERL, s. Abb. 4.3) exprimiert. Diese entsteht aus ektodermalen Zellen an der Grenze zwischen der dorsalen und ventralen Oberfläche des Embryos, induziert durch das Mesoderm. Die ERL verläuft entlang des distalen Randes der Gliedmaßenknospen und stellt eines der wichtigsten Zentren für ihre Entwicklung dar (Johnson und Tabin, 1997; Schwabe et al., 1998). Ihre Rolle beinhaltet (1) die Aufrecherhaltung des unter ihr liegenden Mesoderms in der Proliferationsphase, die das proximo-distale Wachstum ermöglicht, (2) die Aufrechterhaltung der Expression von Molekülen, die die anterior-posteriore Achse generieren, und (3) die Interaktion mit den Proteinen, die die anterior-posteriore und dorsal-ventrale Achse spezifizieren, so dass jede Zelle Instruktionen über ihre Differenzierung erhält. Die Aktivität der ERL wird hauptsächlich durch Fibroblasten-Wachstumsfaktoren (Fgfs; Niswander et al. (1993, 1994)) gesteuert. Das Längenwachstum der Glied- 
maßenknospen erfolgt durch die Proliferation der Mesenchymzellen unterhalb der ERL, der sogenannten Progress-Zone (PZ). Das Modell der PZ erklärt die Bestimmung der proximo-distalen Identität durch die Verweildauer der Zellen in dieser Zone. Je später eine Zelle sie verlässt, desto distaler ist ihre Identität (Summerbell et al., 1973).

Sall1 wird zunächst in der ERL und einem mit der PZ überlappenden Bereich des darunterliegenden Mesenchyms exprimiert. Zumindest in der ERL und weiteren distalen Mesenchymzellen bleibt die Expression lange erhalten. Selbst nach der fast vollständigen Anlage der Gliedmaßen in eine Struktur mit fünf voneinander getrennten Fingern bzw. Zehen und den Hand- und Fußplatten exprimieren die Zellen in den Spitzen der Finger bzw. Zehen noch stark das Sall1-Gen. Dies macht eine Beteiligung des Gens bei der proximo-distalen Entwicklung der Gliedmaßen sehr wahrscheinlich, die so geartet sein könnte, dass das Sall1-Protein die Differenzierung der Zellen im distalen Bereich in der frühen Gliedmaßen-Entwicklung verhindert. Die nachfolgende Herabregulierung von Sall1, dessen distale Expressionsdomäne sich verkleinert und schwächer wird, könnte dann im distalen Bereich die Formierung der entsprechenden Strukturen erlauben.

Eine weitere wichtige Rolle in der Gliedmaßenentwicklung ist die Spezifizierung der anterior-posterioren Achse. Hier übernimmt die sogenannte Zone polarisierender Aktivität (ZPA, s. Abb. 4.3) die Organisiation. Dabei handelt es sich um eine kleine Gruppe mesodermaler Zellen nahe der posterioren Verbindung zwischen Gliedmaßenknospe und Körperwand (Saunders und Gasseling, 1968; Summerbell, 1979; Tickle et al., 1975), deren Lokalisation von mehreren Faktoren kontrolliert wird (Masuya et al., 1997). Die Identität der gebildeten Finger bzw. Zehen wird durch den Grad der Entfernung zur ZPA bestimmt (Tickle et al., 1975). Die Zone ist identisch mit der Expressionsdomäne von sonic hedgehog (shh), dessen sezerniertes Signalmolekül allein ausreicht, um die anterior-posteriore Achse in den Gliedmaßen festzulegen (Riddle et al., 1993). Die Expressionsdomäne von Sall1 überlappt in den frühen Stadien der Gliedmaßenentwicklung mit der ZPA. Demnach könnte Sall1 als mögliches Zielgen von Shh posterior induziert werden, allerdings wahrscheinlich nur in der frühen anterior-posterioren Organisation eine Bedeutung haben.

Die dorso-ventrale Determinierung der Gliedmaßen wird u. a. durch das Gen Wnt7a, das im dorsalen Ektoderm exprimiert wird (Dealy et al., 1993), und weiteren Faktoren festgelegt (Chen und Johnson, 1999). Ab 11.5 dpc zeigt Sall1 eine ausgeprägte Expression im Bereich der Hand- bzw. Fußplatte, wobei die Domä- 
nen der dorsalen und ventralen Seite sehr unterschiedlich ausgeprägt sind. Die dorsale Expressionsdomäne ist wesentlich größer, bildet sich aber sehr schnell zurück, wohingegen die ventrale, kleinere Domäne noch bis mindestens $14.5 \mathrm{dpc}$ bestehen bleibt. Dies lässt vermuten, dass dem Sall1-Gen unterschiedliche Bedeutungen in der jeweiligen Region zukommen, und da die Expressionszentren eher epidermal angesiedelt sind, könnten diese z. B. in der Ausbildung der sehr unterschiedlichen Hautstruktur von Ober- und Unterseite liegen. Eine Funktion bei der Determinierung von Ober- bzw. Unterseite der Gliedmaßen hat Sall1 dagegen vermutlich nicht, da schon zu Beginn der Knospung sowohl ventral als auch dorsal Transkripte vorhanden sind.

Die Gliedmaßenknospen werden während der Embryonalentwicklung zunächst paddelförmig ausgebildet, ab ca. $12.5 \mathrm{dpc}$ beginnen dann Einbuchtungen im distalen Bereich die Finger- bzw. Zehenstrahlen voneinander zu trennen (Dolle et al., 1989, 1990; Mendelsohn et al., 1991, 1992), und ab 15.0 dpc ist die Separation der individuellen Finger bzw. Zehen der Maus vollständig. Dieser Vorgang geschieht durch den programmierten Zelltod in Zonen zwischen den Finger- und Zehenknorpeln (Alles und Sulik, 1989; Saunders und Fallon, 1966). Eine schwache Expression von Sall1 ist zu Beginn der apoptotischen Vorgänge an 12.5 dpc festzustellen. Somit könne das Gen bei der Festlegung der dem programmierten Zelltod zugedachten Bereiche eine Rolle spielen.

\subsubsection{Expression des Sall1-Gens während der Nierenentwicklung}

Fehlgebildete Nieren finden sich bei ca. 100 genetischen Syndromen (Piscione und Rosenblum, 1999), so auch beim TBS (Newman et al., 1997). Sall1 wird sowohl in der adulten Niere wie auch in früheren Stadien der Nierenentwicklung exprimiert. Die Entwicklung der Säugerniere durchläuft drei Hauptphasen reziproker induktiver Interaktionen zwischen verschiedenen Geweben aus dem intermediolateralen Mesoderm (Burrow, 2000; Lipschutz, 1998; Vainio und Muller, 1997). In der Maus entsteht an Tag 8.0 der Embryonalentwicklung im intermediären Mesoderm ventral der anterioren Somiten der Pronephros (s. Abb. 4.4), der in Säugern nicht funktionell ist. In diesen frühen Entwicklungsprozess scheint Sall1 nicht involviert zu sein, da es nicht in diesem Gewebe exprimiert wird. Die pronephrischen Gänge initiieren die Bildung neuer Nierengänge im angrenzenden Mesenchym und degenerieren. Die neuen Gänge stellen den Mesonephros dar, welcher Sall1-Expression zeigt. In der Maus übernimmt auch der Mesonephros keine Ausscheidungsfunktionen (Kaufman, 1992). In kaudaler Richtung wird durch kom- 
plexe Interaktionen zwischen epithelialen und mesenchymalen Komponenten des intermediären Mesoderms der Metanephros gebildet, in dem das Sall1-Gen in den sich entwickeInden Glomeruli und Tubuli exprimiert wird. Das Sall1-Protein könnte daher ein Faktor für die Differenzierung der Tubuli und Glomeruli sein.

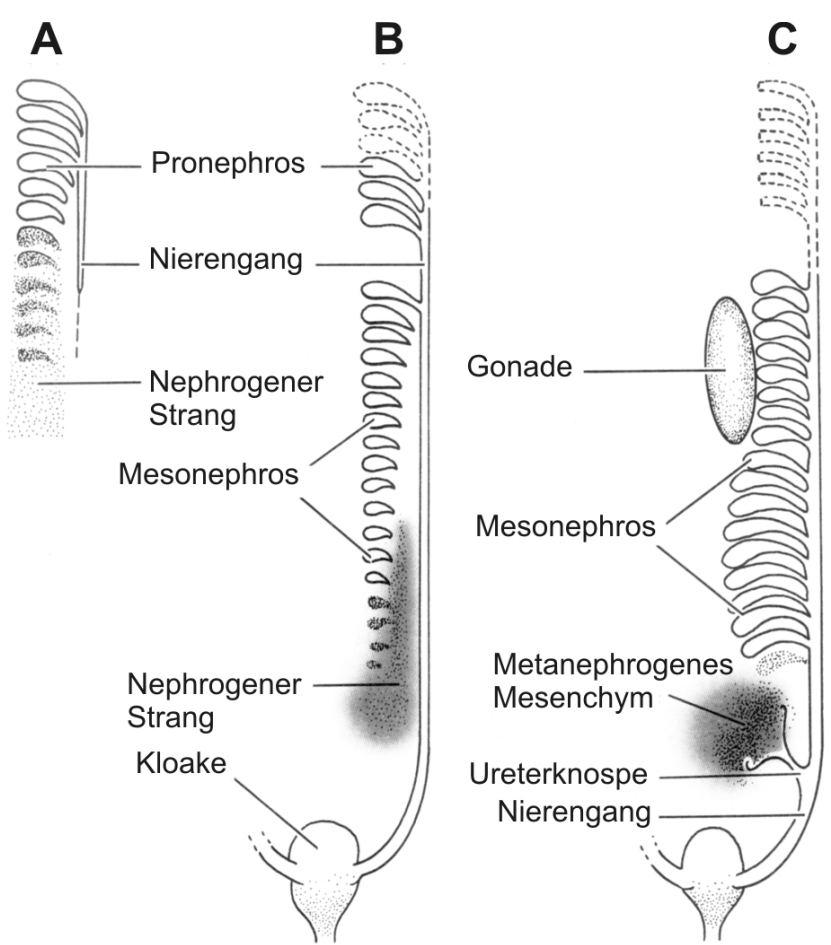

Abbildung 4.4: Die Entwicklung der Vertebratenniere.Das Schema zeigt die generellen Abläufe während der Nierenentwicklung von Vertebraten. A: Während seiner caudalen Migration induziert der Nierengang die Bildung weiterer Tubuli. B: Die mesonephrischen Tubuli bilden sich während die pronephrischen Tubuli degenerieren. C: Die endgültige Säugetierniere, der Metanephros, wird durch die Ureterknospe induziert. (Nach Gilbert (1997))

\subsubsection{Expression des Sall1-Gens im Genitalhöcker}

Eine Sall1-Expression findet sich ab $11.5 \mathrm{dpc}$ auch im Genitalhöcker und dem Bereich der Kloakenmembran mit den angrenzenden Geschlechtsfalten. Der Genitalhöcker ist am kranialen Ende der Kloakenmembran lokalisiert und verlängert sich im Verlauf der Embryonalentwicklung (s. Abb. 4.5). Danach beginnt die Differenzierung in männliche oder weibliche äußere Genitalien (Moore, 1996).

Die molekularen Mechanismen der Formierung des Genitalhöckers sind nur wenig erforscht, es exisitieren jedoch Vermutungen, dass die Entwicklung des Ge- 

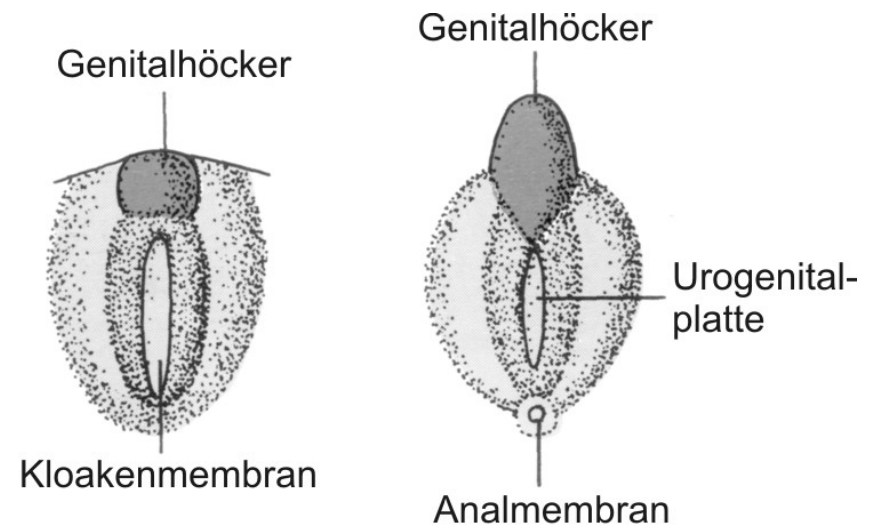

Geschlechtsfalten

Geschlechtswülste

Abbildung 4.5: Die frühe Entwicklung der äußeren Genitalien. Das Schema zeigt die frühen Stadien, die bei beiden Geschlechtern gleich sind. (Nach Moore (1996))

nitalhöckers Ähnlichkeiten zur Entwicklung der Gliedmaßenknospen aufweist (Dolle et al., 1991; Yamaguchi et al., 1999). Bisher konnten weder ERL-ähnliche Strukturen noch Kandidaten-Moleküle für ERL-Funktionen identifiziert werden (Dolle et al., 1991; Murakami, 1986), jedoch wird den (Fgf)-Genen eine zentrale Rolle bei der Entwicklung des Genitalhöckers zugedacht (Haraguchi et al., 2000). Im distalen Plattenepithel exprimiert, steuern sie vermutlich die mesenchymale Genexpression und das Wachstum des Genitalhöckers und erfüllen damit die Funktion eines Signalzentrums für die Entwicklung. Sall1 zeigt eine größere Expressionsdomäne, die sich von der Spitze des Genitalhöckers nach caudal bis über die Kloakenmembran erstreckt. Damit könnte das Gen eine Rolle bei der Differenzierung der Zellen und/oder beim proximo-distalen Wachstum der Struktur einnehmen. Des Weiteren wäre eine Funktion bei der Anlage der Kloakenmembran und der morphologischen Veränderungen der Geschlechtsfalten möglich.

\subsubsection{Expression des Sall1-Gens in der Augenentwicklung}

Sall1 wird ebenfalls im sich entwickelnden Auge der Maus exprimiert. Die Formierung des Vertebratenauges involviert die koordinierte Morphogenese verschiedener embryonaler Gewebe, darunter das Oberflächenektoderm, das aus der Neuralfalte entstandene Kopfmesenchym und das anteriore Neuralrohr (Grainger, 
1992; Graw, 1996; Jean et al., 1998). Das optische Vesikel kontaktiert das darüberliegende Ektoderm, dessen Zellen sich daraufhin aus Linsenplakoden-Zellen in Zellen des optischen Vesikels differenzieren (s. Abb. 4.6). Das Linsenvesikel invaginiert und das optische Vesikel wird zur neuralen bzw. pigmentierten Retina. Nachfolgend induziert das Linsenvesikel das darüberliegende Ektoderm zur Differenzierung in die Cornea (Gilbert, 1997). Eine Sall1-Expression findet im Linsenvesikel statt, so dass Sall1 bei der Invagination des Vesikels oder bei der Cornea-Induktion benötigt werden könnte.

\subsubsection{Expression des Sall1-Gens in den Branchialbögen}

Sall1-Transkripte sind auch in den Branchialbögen (Schlundbögen, Kiemenbögen) zu finden. In der frühen Entwicklung der Branchialbögen wird Sall1 im ersten und zweiten Branchialbogen, auch Mandibular- und Hyalbogen genannt, exprimiert. Am Tag 9.5 der Embryonalentwicklung sind die Sall1-Transkripte in epithelialen Bereichen lokalisiert. Aus dem ersten Branchialbogen entstehen u. a. der Maxillarfortsatz und der Mandibularfortsatz, die beide wichtig für die Entwicklung des Gesichts sind. Von dem ersten und zweiten Branchialbogen werden zudem verschiedene Muskeln und Arterien gebildet (Hinrichsen, 1990; Moore, 1996). An $9.5 \mathrm{dpc}$ wird Sall $1 \mathrm{im}$ Bereich des dritten und vierten Kiemenbogens sowie in den beiden nicht auf der Oberfläche sichtbaren fünften und sechsten Branchialbögen exprimiert. Die Knorpel des vierten und sechsten Branchialbogens sind die Ursprünge des späteren Schildknorpels. Aus den Knorpeln des ersten Branchialbogens bilden sich zwei Gehörknöchelchen, Malleus und Incus. In den dorsalen Abschnitten des Mandibular- und Hyalbogens bilden sich die Auricularhöcker. Diese und tiefere Gewebsabschnitte bilden das Gewebe der späteren Ohrmuschel (Hinrichsen, 1990).

Teile dieser Daten wurden in Buck et al. (2001) publiziert. Parallel wurde von Ott et al. (2001) eine Arbeit publiziert, in der die Autoren ebenfalls Expressionsdaten zu Sall1 beschreiben. Das Gen wurde unter dem nicht mit der offiziellen Nomenklatur übereinstimmenden Namen Msal-3 publiziert.

\subsubsection{Sall1-Expression in der Maus und das TBS}

Die große Homologie zwischen dem murinen Sall1-Gen und dem humanen SALL1-Gen (90\%, s. Abb. 4.1) lässt auch eine funktionelle Konservierung zwischen diesen beiden Genen vermuten. Die Expression in adulten Geweben ent- 
spricht sich zudem größtenteils. Dies lässt vermuten, dass auch die embryonale Expression vergleichbar ist, und die Maus somit einen geeigneten Modellorganismus zur Erforschung der molekularen Grundlagen des TBS darstellt. Die große Übereinstimmung der bei TBS-Patienten betroffenen Organe mit den in diesen Untersuchungen festgestellten Expressionsorten des Sall1-Gens der Maus erhärtet diese Vermutung noch.

Eine Aufstellung der beim TBS mehr oder weniger häufig betroffenen Organe und eine mögliche Entsprechung in Expressionsdomänen des murinen Sall1Gens findet sich in Tabelle 4.2. Dieser Vergleich zeigt, dass in vielen der beim TBS betroffenen Organe das Sall1-Gen während der Embryonalentwicklung der Maus exprimiert wird. Nimmt man eine ähnliche Expression des SALL1-Gens während der Embryonalentwicklung des Menschen an, finden sich viele Ansatzpunkte zur Klärung der beim TBS auftretenden Fehlbildungen.

\begin{tabular}{ll}
\hline Fehlbildung bei TBS & Embryonale Expression von Sall1 \\
\hline Anorektale und Urogeni- & Kloakenbereich und \\
tale Fehlbildungen & Genitalhöcker \\
Daumenanomalien & Gliedmaßenknospen \\
Nierenfehlbildungen & Meso- und Metanephros \\
Schwerhörigkeit & Branchialbögen \\
Geistige Behinderung & Zentrales Nervensystem \\
Iriskolobom und Katarakt & Linsenvesikel \\
Äußeres Ohr & Keine Entsprechung \\
Keine Entsprechung & Bulbus olfactorius
\end{tabular}

Tabelle 4.2: Vergleich der betroffenen Organe beim TBS und der Expressionsdomänen des murinen Sall1-Gens.

Der Phänotyp der triphalangealen Daumen könnte dadurch entstehen, dass das zu Beginn der Gliedmaßen-Entwicklung vornehmlich posterior exprimierte Sall1-Gen durch eine verminderte Transkript-Dosis bei Heterozygotie einem Faktor für posteriore Determinierung nicht mehr genug entgegenwirken kann. So könnte durch die ausbleibende Begrenzung eines Signals auf den posterioren Bereich durch Sall1 der anteriore Bereich Signale zur Ausbildung einer posterioren Struktur erhalten. Riddle et al. (1993) zeigten, dass das Shh-Molekül in der Zone polarisierender Aktivität (ZPA, s. Abb. 4.3) für die anterior-posteriore Determinie- 
rung von Gliedmaßen ausreicht. Als mögliches Zielgen des Shh-Signals in dieser Region könnte Sall1 einer der signalvermittelnden Faktoren sein. Das Fehlen des Sall1-Transkripts könnte folglich eine gestörte anterior-posteriore Determinierung hervorrufen. Zusätzlich könnte es durch die verminderte Transkriptmenge zu einer eingeschränkten Regulation im proximo-distalen Wachstum kommen, die in den beobachteten triphalangealen Daumen resultieren könnte.

Eine reduzierte SALL1-Expression in den Branchialbögen könnte die Ausbildung der Gehörknöchelchen einschränken und zu konduktiven Komponenten der beschriebenen Schwerhörigkeit führen. Es konnte zwar keine konkrete Expressionsdomäne im Bereich der Aurikularhöcker festgestellt werden, die an der Ausbildung des äußeren Ohrs teilhaben, jedoch sind auch tiefer liegende Gewebsbereiche an der Ausbildung beteiligt (Moore, 1996), die hier eventuell nicht detektiert werden konnten. Teilweise wurde bei TBS-Patienten auch von Iriskolobomen (Rossmiller und Pasic, 1994) und Katarakten (Kohlhase, 2000a) berichtet. Die Expression des Sall1-Gens im Auge während der Embryonalentwicklung der Maus lässt vermuten, dass diese Fehlbildungen durch die reduzierte SALL1Transkriptmenge verursacht werden.

Unter der Annahme, dass wie bei der Maus das SALL1-Gen auch im Genitalhöcker und im weiter caudal liegenden Epithel im Bereich der Kloakenmembran exprimiert wird, ist vorstellbar, dass durch ein vermindertes SALL1-Signal die Entwicklungsvorgänge nicht mehr ausreichend koordiniert ablaufen. Ein fehlgesteuertes Wachstum des Sinus urogenitalis könnte eine Verschiebung des Darmausgangs hervorrufen, eine ausbleibende Auflösung der Analmembran eine Analatresie. Die Fehlbildungen der Niere bzw. die einseitig fehlenden Nieren lassen vermuten, dass das Sall1-Gen sowohl bei der Induktion des Metanephros durch die Ureterknospe als auch in der Organisation des Nierenmesenchyms, in dem die nephrogenen Tubuli und Glomeruli gebildet werden, eine Rolle spielt. Die starke Expression in zahlreichen Regionen des ZNS macht vorstellbar, dass bei einer Verminderung der Gendosis Störungen der neuronalen Entwicklung auftreten, welche zu der bei etwa $10 \%$ der TBS-Patienten festgestellten mentalen Retardierung (Kohlhase, 2000a) führen könnten. Eine Störung des Geruchsinns wurde bei TBS-Patienten bisher nicht untersucht, dies könnte jedoch im Hinblick auf die prominente Expression von Sall1 im Bulbus olfactorius interessant sein. 


\subsubsection{Funktionsanalyse des Sall1-Gens}

Die Erzeugung von Funktionsverlustmutanten durch das gene targeting bietet die Möglichkeit, anhand des Phänotyps der gendefizienten Mäuse genauere Kenntnisse über Wirkungsort und -weise des entsprechenden Gens zu gewinnen (Strachan und Read, 1996). Mittels Deletion des Sall1-Gens in einer knock out-Maus sollte ein Modellorganismus für das Townes-Brocks-Syndrom (TBS, s. 1.3) geschaffen werden, um weitere Erkenntnisse über die Pathogenese des Syndroms und die Funktion und Regulation des Gens Sall1 bzw. des humanen Homologs SALL1 zu gewinnen. Die Mäuse sollten anschließend im Hinblick auf ihre Embryonalentwicklung und postnatale Entwicklung mit besonderer Beachtung der Strukturen, die beim TBS fehlgebildet sind, analysiert werden. Zudem können für die Deletion heterozygote oder homozygote Embryonen mit Sonden verschiedener Gene, die ebenfalls in den betroffenen Strukturen exprimiert werden und eventuell in den Sall1-Regulationsweg involviert sind, untersucht werden.

Zur Erzeugung einer Sall1-defizienten Maus wurden das gesamte Exon 2, ein Teil von Exon 3 sowie das dazwischenliegende Intron mit Hilfe eines knock outKonstrukts durch homologe Rekombination in embryonalen Stammzellen deletiert (s. 3.7). Die Stammzellen wurden zur Generierung von Chimären in 2.5 Tage alte Mausembryonen injiziert und die erhaltenen Chimären mit Mäusen der Stämme C57BL und 129/SvJ verpaart. Die Analyse der F1-Generation konnte aus zeitlichen Gründen im Rahmen der vorliegenden Arbeit nicht mehr erfolgen.

Mit der gewählten Strategie sollte das Sall1-Gen vollständig inaktiviert, also eine Nullmutante erzeugt werden. Beim TBS liegt der Mutations-hot spot im SALL1Gen vor dem ersten DZF (Kohlhase, 2000b). Die meisten Mutationen führen durch Insertion oder Deletion einer oder mehrerer Basen zu einem frameshift und durch das verschobene Leseraster zu einem frühzeitigen Translationsabbruch, wobei Transkripte, die ein vorzeitiges Stoppkodon in ihrem Leseraster enthalten, präferenziell abgebaut werden (Hentze und Kulozik, 1999). Es kann jedoch nicht ausgeschlossen werden, dass das verkürzte Protein noch einen Einfluss unbekannter Art ausübt. Daher könnte die vollständige Deletion des Sall1-Gens eine andere Situation herstellen als es bei den TBS-Patienten der Fall ist. Als Beispiel soll hier kurz ein Mausmodell für das Renal-Coloboma-Syndrom herangezogen werden, das zu Veränderungen am Nervus opticus und Störungen der Nierenfunktion führt. Es ist auf Mutationen im Pax2-Gen zurückzuführen. Das aus den bekannten Mutationen resultierende Protein ist vermutlich, wie das SALL1-Protein beim TBS, nicht funktionell, da inm mit der paired- und der Homeodomäne alle funktionellen Domänen fehlen. In der Pax2-knock out-Maus kommt es zu einem ausgepräg- 
ten Phänotyp mit schweren Abnormalitäten im Meso- und Metanephros, die zu einem Fehlen des Genitaltrakts und der metanephrischen Niere führen (Torres et al., 1995). Favor et al. (1996) analysierten eine Maus mit einer zum Menschen identischen Mutation (Sanyanusin et al., 1995). Die Maus-Mutante zeigt neben anderen Fehlbildungen zwar eine schwere Störung der Nierenanlagen, aber nicht den selben Phänotyp wie die knock out-Mäuse. Ein zweiter Schritt bei der Analyse des Sall1-Gens könnte also sein, in Mäuse ein knock in-Konstrukt einzubringen, in welchem das Sall1-Gen eine TBS-typische Mutation trägt. Dies wäre insbesondere dann interessant, wenn die knock out-Mäuse einen vom TBS abweichenden Phänotyp zeigen.

\subsection{Das Gen Sall2}

Sall2 ist ein weiteres spalt-ähnliches Gen der Maus. Wie in Kohlhase et al. (2000) gezeigt, handelt es sich um das murine Homolog zu dem humanen Gen SALL2. Es besteht aus drei Exons, wobei die beiden Exons, die im 5'-Bereich des Zinkfinger-kodierenden Exons liegen, alternativ gespleißt werden. Auf genomischer Ebene umfasst das Gen 17140 bp vom Exon 1 bis zum Polyadenylierungssignal, wobei der Transkriptionsstartpunkt im 5'-Bereich nicht identifiziert wurde (Kohlhase et al., 2000). Die 3'-UTR umfasst $1545 \mathrm{bp}$. Die abgeleitete Aminosäuresequenz weist die typischerweise über einen großen Bereich verteilten Zinkfingerdomänen auf: im 5'-Bereich von Exon 2 befindet sich der in allen bisher isolierten sal-ähnlichen Vertebratengenen vorhandene, jedoch nicht im sal-Gen selbst vorliegende $\mathrm{C}_{2} \mathrm{HC}$-Einzelzinkfinger (EZF), darauf folgen drei $\mathrm{C}_{2} \mathrm{H}_{2}$ Doppelzinkfinger (DZF), wobei der zweite von einem weiteren EZF charakteristischer Struktur gefolgt ist. Der carboxyterminale DZF enthält ungewöhnlicher Weise 51 statt der üblichen 49 Aminosäuren. Nur das humane SALL2-Gen weist dieselbe Struktur auf (Kohlhase et al., 1996).

\subsubsection{Charakterisierung des Intron 1 und der $3^{\prime}$-UTR von Sall2}

Mit Hilfe von Subklonierungen und Sequenzierungen eines bereits vorliegenden murinen Cosmidklons konnte das ca. $9 \mathrm{~kb}$ lange Intron 1 vollständig sequenziert werden. Durch die Isolierung eines weiteren das Sall2-Gen enthaltenden Cosmidklons konnte zudem der 3'-Bereich weiter kartiert werden. Die genomische Sequenz von 20332 bp ohne die regulatorischen Regionen ist im Anhang dargestellt. 


\subsubsection{Expression des Sall2-Gens in adulten Geweben}

Die Northern-Blot-Analyse an adulten Mausgeweben zeigte eine Expression des Sall2-Gens in abnehmender Stärke in Gehirn, Niere, Lunge, Ovar und Milz. Damit entspricht das Expressionsmuster größtenteils dem des humanen SALL2-Gens, wobei für letzteres Transkripte im Herzgewebe detektiert wurden (Kohlhase et al., 1996), jedoch nicht für Sall2 (Kohlhase et al., 2000). Eine RT-PCR zeigte die frühe Expression beider alternativer Transkripte (ab 8.5 dpc für Exon 1a, ab 9.5 dpc für Exon 1). Die genaue Analyse der embryonalen Expression von Sall2 wurde in dieser Arbeit durchgeführt.

\subsubsection{Expression des Sall2-Gens im embryonalen ZNS}

Das Sall2-Gen der Maus wird stark im ZNS exprimiert (s. Abb. 3.16). Die frühe (spätestens am $7.5 \mathrm{dpc}$ ) und auf das gesamte neurale Ektoderm ausgedehnte Expression lässt vermuten, dass Sall2 bei der Differenzierung der verschiedenen ZNS-Bereiche vom neuralen Ektoderm zum Gehirn, Neuralrohr und weiteren Strukturen eine Rolle spielt. Während der Entwicklung der drei zuerst im Kopfbereich gebildeten Gehirnarealen (Prosencephalon oder Vorderhirn, Mesencephalon oder Mittelhirn, Rhombencephalon oder Rautenhirn, s. Abb. 4.2) wird das Gen im gesamten dorsalen Bereich dieser Strukturen exprimiert. Auch die Expression im dorsalen Bereich des Neuralrohrs ist sehr prominent. Im gesamten ZNS finden sich Sall2-Transkripte bis zum ältesten untersuchten Embryonalstadium von 12.5 dpc. Daher lässt sich eine Beteiligung von Sall2 an der Ausbildung des ZNS bei der Maus vermuten. Im adulten Gehirn der Maus ist eine hohe Transkriptmenge vorhanden (Kohlhase et al., 2000), so dass eine Bedeutung von Sall2 für die Funktion der Zellen wahrscheinlich ist. Auch das humane SALL2-Gen wird im Gehirn exprimiert und im fetalen menschlichen Gehirn konnten Transkripte in Neuronen gezeigt werden (Kohlhase et al., 1996). Beide Gene scheinen also auch an der Funktion bestimmter Zellen im adulten Zustand beteiligt zu sein, wobei bislang unklar ist, welche Zellen Sall2 bzw. SALL2 exprimieren.

Zudem wird Sall2 in den otischen Vesikeln exprimiert. Diese entstehen durch die Invagination der otischen Plakode, die wiederum eine Region von Oberflächenund neuralem Ektoderm auf dem lateralen Rhombencephalon darstellt (Baker und Bronner-Fraser, 2001; Hinrichsen, 1990). Elongationen und Verwindungen lassen dann die sechs separaten Organe des inneren Säugetierohrs entstehen. Die Regulation dieses Prozesses wird durch komplizierte Interaktionen einer Vielzahl 
von Faktoren gewährleistet (Fekete, 1996, 1999; Fritzsch et al., 1997; Torres und Giraldez, 1998). Die starke Expression von Sall2 im sehr frühen Stadium der Innenohrentwicklung lässt eine Rolle dieses Gens bei den Entstehungsprozessen vermuten.

\subsubsection{Expression des Sall2-Gens in anderen Embryonalgeweben}

Eine weitere Sall2-exprimierende Struktur stellt der Mesonephros dar. Er ist bei der Maus nicht funktionell, von inm geht jedoch die Induktion des Metanephros aus, der zur adulten Niere weiter differenziert (s. Abb. 4.4). Auch in der adulten Niere sind Transkripte vorhanden (Kohlhase et al., 2000), des Weiteren wird in der adulten humanen Niere das SALL2-Gen exprimiert (Kohlhase et al., 1996). Es lässt sich somit eine Beteiligung dieser Gene bei der Differenzierung und der späteren Funktion der Niere annehmen.

Das Sall2-Gen wird lateral im optischen Vesikel exprimiert, zudem ist eine Expression im Linsenvesikel während der Einfaltung zur Linse (s. Abb. 4.6) zu beobachten. Durch den Kontakt des optischen Vesikels zum Ektoderm wird die Bildung des Linsenvesikels aus der Linsenplakode induziert. An diesem Prozess könnte das Sall2-Protein möglicherweise beteiligt sein, indem es bei der Vermittlung der Signale oder der folgenden Reaktion der Gewebe beteiligt ist.
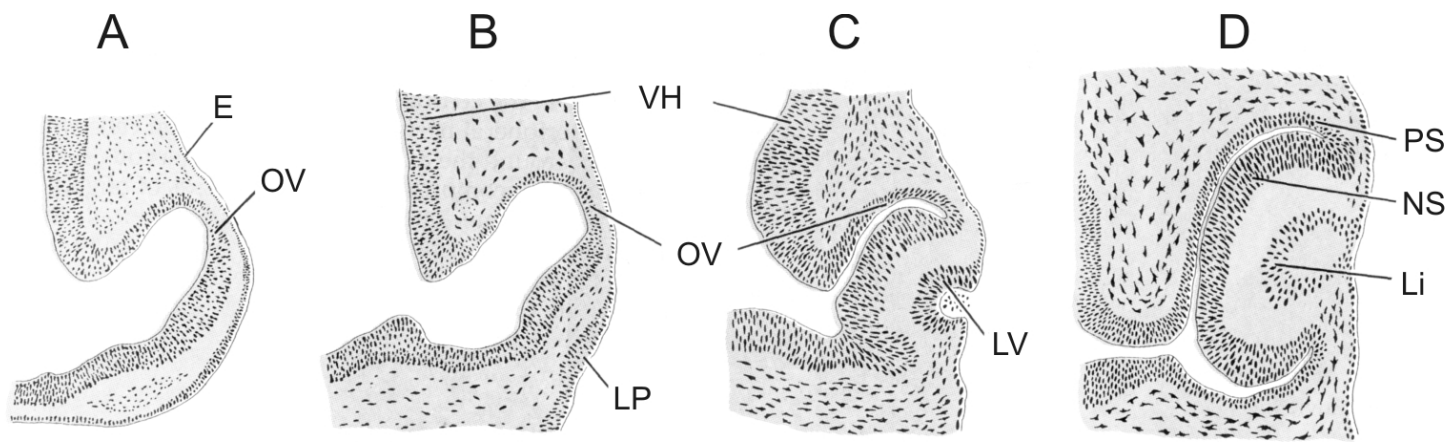

Abbildung 4.6: Die Entwicklung des Vertebratenauges. A: Das optische Vesikel invaginiert und kontaktiert das darüber liegende Ektoderm. B,C: Das Ektoderm differenziert zu Linsenzellen und bildet das Linsenvesikel. Aus dem eingefalteten optischen Vesikel bildet sich die pigmentierte und die neurale Schicht. E: Ektoderm; Li: Linse; LP: Linsenplakode; LV: Linsenvesikel; NS: Neuralschicht; OV: Optisches Vesikel; PS: Pigmentschicht; VH: Vorderhirn. (Nach Gilbert (1997)) 


\subsubsection{Funktionsanalyse des Sall2-Gens}

Bislang ist keine durch SALL2-Mutationen verursachte Erkrankung bekannt. Aufgrund der starken Konservierung des Gens und der Identifizierung von SALL1 als TBS-verursachendes Gen scheint es jedoch möglich, dass auch SALL2 eine ähnlich große Bedeutung in der menschlichen Entwicklung einnimmt. Zur Erzeugung Sall2-defizienter Mäuse wurden Exon 1a und Exon 2 mit Hilfe eines knock outKonstrukts durch homologe Rekombination in embryonalen Stammzellen deletiert (s. 3.7). Die Stammzellen wurden zur Generierung von Chimären in Blastocysten injiziert und die erhaltenen Chimären mit Mäusen der Stämme C57BL und 129/SvJ verpaart. Heterozygote Sall2 ${ }^{+/-}$-Mäuse der F1-Generation wurden untereinander verpaart und brachten homozygote Sall2 ${ }^{-/}$-Mäuse hervor.

Außer im Genotyp unterschieden sich diese Tiere nicht von den heterozygoten und den Wildtyp-Mäusen, ihre Nachkommenzahl war jedoch unterdurchschnittlich (s. 3.7.5). Bei der Präparation von Embryonen aus Verpaarungen homozygoter Mäuse auf dem Hintergrund 129/SvJ zeigten sich bei einem Teil der Embryonen schwere Deformationen im Kopfbereich (s. Abb. 3.25), die ein ähnliches Bild zeigen wie es für die Anencephalie beim Menschen beschrieben wird (Norman et al., 1995). Da alle geborenen Mäuse völlig normal waren, muss davon ausgegangen werden, dass diese Fehlbildungen zum pränatalen Absterben führen oder betroffene Tiere aufgrund ihrer geringeren Vitaliät im Vergleich zu den normalen Tieren von der Mutter durch Kannibalismus aus dem Wurf entfernt werden. Da das Sall2-Gen während der Embryonalentwicklung stark im Kopfbereich exprimiert wird, könnte es sich um einen aus der Deletion des Gens resultierenden Phänotyp handeln.

Fehlbildungen des Neuralrohrs, zu denen die Spina bifida, die Enzephalozele und die Anencephalie gerechnet werden, betreffen eines von 1000 Neugeborenen (Jorde et al., 1995). Die Anencephalie führt in den meisten Fällen kurz nach der Geburt zum Tod (Norman et al., 1995). Der Phänotyp präsentiert sich zumeist in dem Fehlen des Schädeldaches, einer fehlenden oder nach hinten gewölbten Stirn, hervorstehenden Augen, congenitalen Herzfehlbildungen und verlängerten Armen (Norman et al., 1995). Fälle von Anencephalie wurden in Fällen von Trisomie 18 (Nisani et al., 1981), Trisomie 20 (Zumel et al., 1989), partieller Deletion von Chromosom 13 (Rudelli, 1987) und einer Duplikation von Chromosom 2 (Singer et al., 1987) beschrieben. Es konnte bisher kein konsistentes Muster einer chromosomalen Anomalie im Zusammenhang mit Anencephalie beschrieben werden. Es existieren also keine Daten zu einer Kopplung mit 14q, dem Lokus 
des humanen SALL2-Gens.

Die Schließung des Neuralrohrs involviert ein komplexes Zusammenspiel von extrinsischen und intrinsischen Faktoren (Copp et al., 1990; Schoenwolf und Smith, 1990; Smith und Schoenwolf, 1991; van Straaten et al., 1993). In Säugetieren wird die Schließung des Neuralrohrs an verschiedenen Stellen entlang der anterior-posterioren Achse initiiert, wobei die nicht erfolgte Schließung einer dieser Stellen zu bestimmten Neuralrohrdefekten führt (Van Allen et al., 1993). Einige Gene wie Pax3 (Gruss und Walther, 1992; Strachan und Read, 1994) und shh (Chiang et al., 1996; Roessler et al., 1996) sind als notwendig für die Formierung des Neuralrohrs der Maus beschrieben worden. Da eine Rolle von Sall2 bei diesen Prozessen aufgrund des Expressionsmusters möglich ist, könnte durch die fehlende Gendosis ein entsprechender Entwicklungsdefekt auftreten.

Die Deformation betrifft immer nur einen Teil des Wurfs. Dies ist nicht verwunderlich, da Neuralrohrdefekte beim Menschen polygen und multifaktoriell bedingt sind (Gelehrter et al., 1998). Zum einen werden diese Fehlbildungen also durch mehrere verschiedene Gene verursacht, die einzeln betrachtet nur geringe oder keine Auswirkungen auf den Phänotyp haben, zum anderen von multiplen Umgebungsfaktoren, die in Wechselwirkung mit vielen Genen den Phänotyp beeinflussen. Es könnte also unter den Nachkommen eines Wurfes eine unterschiedliche genetische Prädisposition zur Ausbildung der Deformation vorliegen. Zudem könnte der Phänotyp durch unterschiedliche Umgebungsfaktoren entstehen oder von innen verstärkt werden. Diese könnten während der Embryonalentwicklung der Maus z. B. dadurch gegeben sein, dass die Plazenten der einzelnen Nachkommen unterschiedlich gut durchblutet werden.

Durch die Polygenie ließe sich auch erklären, weshalb die analysierten adulten Mäuse keinen Phänotyp zeigen, obwohl durch einen Northern-Blot gezeigt werden konnte, dass in den heterozygoten Nachkommen eine verringerte Transkriptmenge vorliegt und die für die Deletion homozygoten Mäuse keine Sall2-Transkripte mehr aufweisen. Der Verlust oder die Mutation eines Gens, welches an der Steuerung eines so wichtigen Prozesses wie die Schließung des Neuralrohrs beteiligt ist, könnte durch weitere Gene kompensiert werden. In den Sall2-/--Mäusen könnten also andere Entwicklungsgene die fehlende Sall2-Aktivität ersetzen. Eine Erklärung hierfür wäre, dass durch Genduplikationen ohne Funktionsverluste im Verlauf der Evolution eine Art Absicherung entstanden ist, um die Sensibilität der Organismen Mutationen gegenüber zu senken. Das Auftreten dieser Entwicklungsstörungen als Resultat der Spontanmutation eines anderen Gens ist fast aus- 
zuschließen, da bei einem rezessiven Erbgang der Anteil betroffener Embryonen bei $25 \%$ liegen sollte. Dies ist hier nicht gegeben.

Um zu prüfen, ob die Funktion des Gens durch ein anderes Gen der Familie muriner sal-ähnlicher Gene übernommen wird und dieses entprechend verstärkt oder ektopisch exprimiert wird, wurden whole mount-in situ-Hybridisierungen mit einer Sall1-Sonde an Sall2-/--Embryonen durchgeführt. Sowohl in den adulten Tieren wie auch während der Embryonalentwicklung entpricht die Expression jedoch dem Muster in Wildtyp-Tieren.

Die partielle Überlappung der Sall2- und Sall1-Expressionsdomänen allein könnte eventuell schon ausreichen, um die Ausprägung eines Phänotyps in den Sall2-/--Mäusen zu unterdrücken. Dies vermuteten auch Chu et al. (2000) bei der knock out-Mauslinie für das FHL2 (SLIM2)-Gen, das spezifisch im Cardiovaskularsystem exprimiert wird. Es wurde jedoch weder ein Phänotyp noch eine verstärkte Expression FHL2-homologer Gene, deren Expressionsmuster teilweise überlappen, festgestellt (Chu et al., 2000).

Das Auftreten dieses Defekts konnte bisher nur auf dem 129/SvJ-Hintergrund festgestellt werden. Da auf dem C57BL-Hintergrund eine normale Anzahl von Nachkommen zu beobachten ist, ist anzunehmen, dass die Embryonalentwicklung dort normal verläuft. Auf dem Hintergrund 129/SvJ scheint also eher eine genetische Veranlagung zur Anencephalie vorzuliegen als auf dem Hintergrund C57BL. Dies ist noch eingehend durch die weitere Präparation von Embryonen und die Auswertung der durchschnittlichen Nachkommenzahl zu untermauern. Es wurde bereits mehrfach von einem Einfluss des genetischen Hintergrunds auf den Phänotyp einer Deletion oder Mutation bei der Maus berichtet (Bonyadi et al., 1997; LeCouter et al., 1998; Liu et al., 1993). Die Ursache hierfür liegt in der unterschiedlichen Kompetenz des genetischen Hintergrunds zum Ausgleich bestimmter Genverluste.

Es muss auch in Betracht gezogen werden, dass das Sall2-Gen für die entwicklungsbiologischen Prozesse der Strukturen, in denen es spezifisch exprimiert wird, keine wesentliche Rolle spielt. Dies wäre entgegen aller Erwartungen, betrachtet man den hohen Grad der Konservierung dieses Gens im Verlauf der Evolution sowie das spezifische Expressionsmuster und die hohen Transkriptmengen. Es wurden jedoch bereits verschiedene erfolglose knock out-Versuche geschildert, bei denen ähnlich gute Hinweise auf eine wichtige Funktion des entsprechenden Gens vorlagen (Finkenzeller et al., 2000; Harroch et al., 2000; Rojo et al., 2000). Eventuell ist auch bei der Duplikation der Gene bei der Entstehung dieser Familie 
ein Gen entstanden, das keine essentielle Funktion erfültt, aber zur Optimierung einer Funktion dient, die unter natürlichen Bedingungen wichtig ist.

\subsection{Embryonale Expression des Gens Sall3}

Ott et al. (1996) publizierten eine Arbeit mit Daten zur Expression des Sall3Gens, beschränkten sich dort jedoch hauptsächlich auf das ZNS. Für den Vergleich mit den anderen murinen sal-ähnlichen Genen Sall1 und Sall2 wurden daher whole mount-in situ-Hybridisierungen zur Betrachtung weiterer Sall3Expressionsdomänen durchgeführt.

Das murine Sall3-Gen wird stark im ZNS in allen untersuchten Embryonalstadien exprimiert (s. Abb. 3.31). Im frühesten analysierten Stadium (7.5 dpc) ist das Transkript im gesamten neuralen Ektoderm sehr prominent. Zudem wird das Gen am Tag 9.5 und 10.5 der Embryonalentwicklung in der MRG exprimiert, die ein wichtiges Organisationszentrum in der Gehirnentwicklung darstellt. Weitere Expressionsdomänen sind im anterioren Mittelhirn und im ventralen Bereich von Mittel- und Vorderhirn lokalisiert. Die Expression des Gens begrenzt sich im Verlauf der frühen Embryonalentwicklung vom gesamten neuralen Ektoderm auf distinkte Bereiche des ZNS, so dass Sall3 eine Bedeutung bei der Differenzierung zu bestimmten neuronalen Strukturen tragen könnte. Im Neuralrohr, das mindestens am Tag 12.5 der Embryonalenwicklung deutliche Sall3-Expression zeigt, könnte dem Gen eine Bedeutung bei der Differenzierung der Neuroblasten und/oder Glioblasten zukommen.

Zu Beginn des Knospungsprozesses der Gliedmaßen wird das Gen Sall3 im posterioren Bereich, überlappend mit der Zone polarisierender Aktivität (ZPA, s. Abb. 4.3), exprimiert. Dem Sall3-Gen könnte daher eine Bedeutung in der frühen anterior-posterioren Determinierung zukommen. Anschließend ist die Expression in einer relativ regelmäßig verlaufenden Zone im Bereich der Hand- bzw. Fußplatte von anterior nach posterior lokalisiert. In dieser Phase könnte das Gen Funktionen beim proximo-distalen Wachstum erfüllen. Dafür spricht die partiell mit der PZ überlappende Expressionsdomäne. Das Sall3-Gen könnte also an zwei wichtigen Prozessen der Gliedmaßenentsicklung beteiligt sein. Dies trifft jedoch nur für den Beginn des Wachstums der Gliedmaßen zu, da ab 12.5 dpc keine Transkripte mehr in den Gliedmaßenknospen gefunden werden können.

Neben den Gliedmaßenknospen wird Sall3 in einer weiteren aus dem Mesoderm entstandenen Struktur exprimiert, den Branchialbögen. Von $9.5 \mathrm{dpc}$ bis 10.5 
dpc sind Transkripte im Hyal- und Mandibularbogen zu finden, aus denen wichtige Bestandteile der Gesichtsmuskulatur und des Kopfskeletts gebildet werden. Eine weitere Struktur, in der das Sall3-Gen exprimiert wird, ist der Genitalhöcker (s. Abb. 4.5). Die Lokalisierung der Expressionsdomäne im distalen Bereich lassen eine Bedeutung im proximo-distalen Wachstum vermuten.

Parallel zu Durchführung der hier dargestellten Expressionsstudien wurde eine Beschreibung des Sall3-Expressionsmusters anhand von whole mount-in situ-Hybridisierungen von Ott et al. (2001) publiziert, wobei die Autoren wie bei der Erstbeschreibung des Gens (Ott et al., 1996) hauptsächlich das ZNS betrachten. Es konnte in der vorliegenden Arbeit im Gegensatz zu den von Ott et al. (1996) publizierten Daten keine Expression im Auge oder im Mesonephros nachgewiesen werden. Die Autoren berichten jedoch von einer schwachen Expression in diesen Strukturen. Eventuell ist die Transkriptmenge des Sall3-Gens so gering, dass die Expression nur mit der von Ott et al. (1996) angewandten Methode der radioaktiven Hybridisierung von Paraffinschnitten nachgewiesen werden kann.

\subsection{Vergleich der drei sal-ähnlichen murinen Gene}

\subsubsection{Strukturvergleich}

Die in der vorliegenden Arbeit behandelten Gene aus der Maus (s. 3.1, Kohlhase et al. (2000); Ott et al. (1996)) weisen alle Charakteristika für ein sal-ähnliches Vertebratengen auf ( $\geq 3$ weit auseinander liegende DZF-Motive in der abgeleiteten Aminosäuresequenz, interne Sequenzähnlichkeiten zwischen diesen Motiven, ein EZF am aminoterminalen Ende, ein am zweiten DZF angehängter EZF). Ihre Ähnlichkeit untereinander ist jedoch größtenteils auf die Homologien in diesen konservierten Bereichen beschränkt. Die hier angegebenen Daten wurden durch einen Vergleich mit Hilfe des Programms Complign der Software MacMolly ${ }^{\circledR} \mathrm{Te}$ tra (Soft Gene, Berlin) ermittelt. Dabei wurden jeweils die gesamten abgeleiteten AS-Sequenzen betrachtet, nicht jedoch einzelne konservierte Domänen. Daher ergeben die Vergleiche relativ geringe Homologiewerte (s. Tab. 4.3). Die relativ geringe Homologie von Sall2 zu Sall1 und Sall3 lässt sich zum einen durch die Struktur des Sall2-Proteins erklären, das eine DZF-Domäne weniger aufweist und wesentlich kürzer ist als die anderen beiden Proteine, zum anderen sind auch die DZF weniger homolog als zwischen Sall1 und Sall3. 


\begin{tabular}{cc}
\hline AS-Sequenzen & Homologie \\
\hline Sall1 / Sall2 & $14 \%$ \\
Sall1 / Sall3 & $26 \%$ \\
Sall2 / Sall3 & $14 \%$ \\
\hline
\end{tabular}

Tabelle 4.3: Homologievergleich der murinen sal-ähnlichen Gene. Deutlich wird die größere Homologie zwischen Sall1 und Sall3, die Sall2-Sequenz weist im Vergleich eine weniger hohe Konservierung auf.

\subsubsection{Expressionsvergleich}

Die verschiedenen sal-ähnlichen Gene der Vertebraten sind wahrscheinlich durch Duplikationsvorgänge entstanden, wie es für viele Gene von weiteren Genfamilien bekannt ist (Greer et al., 2000; Mansouri et al., 1996). Die Gene einer Familie können trotz hoher Homologie in der Sequenz sehr unterschiedliche Funktionen erfüllen, wenn sie verschiedenen Regulationsmechanismen unterliegen. Eine funktionelle Äquivalenz verschiedener Gene einer Gruppe konnte z. B. für Hoxa3 und Hoxd3 gezeigt werden, die identische biologische Funktionen erfüllen können und deren unterschiedliche Rollen in der Entwicklung das Resultat quantitativer Modulationen in der Genexpression sind (Greer et al., 2000). Das Gen Otx1 kann die meisten Funktionen des Otx2-Gens in der Maus-Embryogenese ersetzten (Suda et al., 1999). Pax2 und Pax5 haben ebenfalls seit ihrer Duplikation zu Beginn der Vertebratenevolution gleiche biochemische Funktionen beibehalten (Bouchard et al., 2000). Zwischen En-1 und En-2 entsteht der funktionelle Unterschied nur durch ihr divergierendes Expressionsmuster (Hanks et al., 1995).

Um Hinweise auf Ähnlichkeiten oder Unterschiede in ihren Funktionen zu erhalten, wurden die Expressionsmuster der in der vorliegenden Arbeit untersuchten sal-ähnlichen Gene der Maus verglichen. Dabei zeigte sich eine größere Ähnlichkeit im Expressionsmuster zwischen Sall1 und Sall3. Alle drei Gene zeigen eine prominente Expression im ZNS. Mit Beginn der Entstehung des neuralen Ektoderms können alle drei Transkripte dort nachgewiesen werden. Dabei zeigen Sall2 und Sall3 eine ausgedehntere Expression, die sich später als bei Sall1 auf bestimmte Strukturen begrenzt. Alle drei Gene werden sowohl in unterschiedlichen wie auch überlappenden Bereichen der Gehirnvesikel zu Beginn der Kopfentwicklung exprimiert. Sall2 wird im Gegensatz zu den anderen beiden Genen nicht in der MRG exprimiert, die ein wichtiges Organisationszentrum der Gehirn- 
entwicklung darstellt. Die Expression von Sall2 im otischen Vesikel ist dagegen sehr ausgeprägt, Sall1 und Sall3 werden dort nicht oder nur schwach exprimiert. Sall1 wird als einziges der drei Gene in den Bulbi olfactorii exprimiert. Sehr prominent und bis in spätere Stadien hinein detektierbar ist bei allen drei Genen die Expression im Neuralrohr. Dabei wird zunächst nur Sall2 im dorsalen Bereich exprimiert. Die Transkripte von Sall1 und Sall2 sind zunächst in einer medianen Region angesiedelt und erst später verlagert sich ihre Expression nach dorsal.

Sall2 zeigt die stärkste Expression im optischen Vesikel, also in der frühen Phase der Augenentwicklung. Die Sall1-Expression in der Augenanlage tritt erst später im Linsenvesikel auf, Sall3 wird gar nicht im Auge exprimiert. Das Sall2-Gen zeigt eine Expression in den Gliedmaßenanlagen, es findet sich dort jedoch keine bestimmte Expressionsdomäne. Sall1 und Sall3 dagegen werden zu Beginn der Gliedmaßenentwicklung in sehr spezifischen Regionen exprimiert und überlappen zu Anfang beide mit der ZPA. Die Expression von Sall1 gliedert sich nachfolgend in einen distalen Bereich, der die ERL mit einschließt, und eine proximale Domäne im Bereich der Hand- bzw. Fußplatte. Sall3 wird nur in einer proximalen Domäne exprimiert und ist an $12.5 \mathrm{dpc}$ nur noch sehr schwach zu detektieren. Die Expression des Sall1-Gens ist bis mindestens 14.5 dpc noch stark in den Finger- bzw. Zehenspitzen vorhanden.

Alle drei Gene werden in verschiedenen und überlappenden Bereichen der Branchialbögen exprimiert. In der Urogenitalleiste werden Sall1 und Sall2 stark in den mesonephrogenen Tubuli exprimiert. Das Epithel des Genitalhöckers koexprimiert Sall1 und Sall3.

Die drei sal-ähnlichen Gene der Maus werden einerseits in vielen gemeinsamen Strukturen exprimiert, unterscheiden sich andererseits jedoch in der genauen Lokalisierung oder dem Zeitpunkt der Expression. Diese unterschiedliche Regulation könnte dadurch entstehen, dass bei den vermutlich aufgetretenen Genduplikationen im Verlauf der Evolution zunächst die Promotorbereiche mit dupliziert wurden, nachfolgend aber unterschiedlich mutierten. Ob die verschiedenen salähnlichen Gene der Maus eine funktionelle Äquivalenz beibehalten haben, ließe sich durch knock in-Mäuse untersuchen, in denen ein Gen durch ein anderes ersetzt wird. Dies ist z. B. für En-1 und En-2 beschrieben (Hanks et al., 1995). 
Sall1

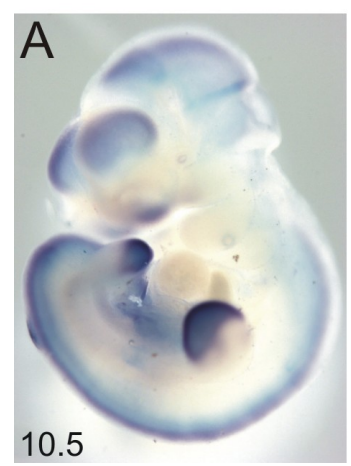

D

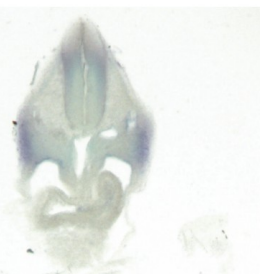

10.5

G

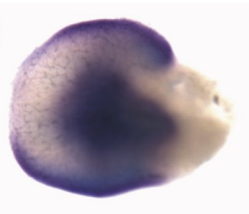

11.5

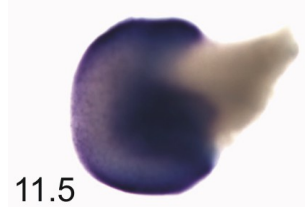

Sall3

B

10.5

E

10.5

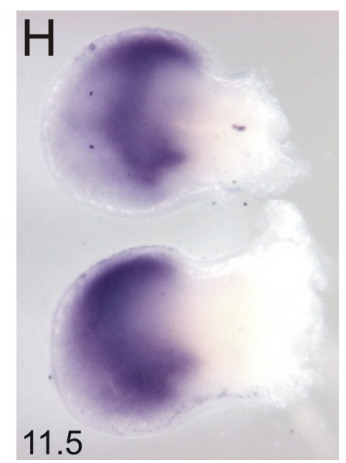

11.5
Sall2

C

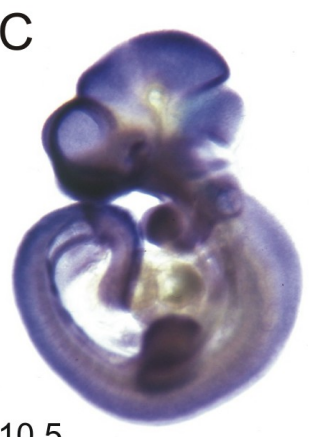

10.5

F

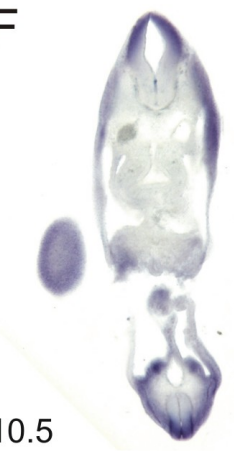

Abbildung 4.7: Vergleich der embryonalen Expressionsmuster von Sall1, Sall2 und Sall3. Gezeigt sind Embryonen der embryonalen Entwicklungsstadien 10.5 und 11.5 dpc, die mit DIGmarkierten Sonden für Sall1, Sall2 oder Sall3 hybridisiert wurden. Aufgrund der größeren Ähnlichkeit zwischen der Expression der Gene Sall1 und Sall3 sind diese nebeneinander gestellt. A, D und $\mathrm{G}$ zeigen Embryonen, die mit der Sonde gegen Sall1 hybridisiert wurden. B, E und H zeigen Hybridisierungen mit der Sonde gegen Sall3. Die Embryonen in C und F wurden mit der Sonde gegen Sall2 hybridisiert. 


\section{5 sal-ähnliche Vertebratengene lassen sich in Homologiegruppen einteilen}

Zwei der drei isolierten murinen sal-ähnlichen Gene konnten aufgrund ihrer Homologie zu einem humanen sal-ähnlichen Gen isoliert werden (Buck et al., 2000; Kohlhase et al., 2000). Zwischen diesen beiden Spezies scheint also ein hoher Konservierungsgrad von sal-ähnlichen Genen vorzuliegen. Fast alle anderen isolierten sal-ähnlichen Gene aus Vertebraten (Farrell und Munsterberg, 2000; Farrell et al., 2001; Hollemann et al., 1996; Köster et al., 1997) zeigen eine große Homologie zu einem der murinen sal-Gene und somit auch zu den humanen sal-Genen. sal-ähnliche Vertebratengene lassen sich daher in Gruppen einteilen und sollen im Folgenden kurz untereinander im Hinblick auf ihre Struktur und ihre Expression verglichen werden.

\subsubsection{Strukturvergleich}

Gene aus einem in der Evolution früh von der Entwicklungslinie der höheren Säugetiere abgetrennten Organismus wie Xenopus weisen eine erstaunliche Homologie zu den neueren Vertebratengenen auf. Tabelle 4.4 zeigt eine Aufstellung der mit Hilfe des Programms Complign der Software MacMolly ${ }^{\circledR}$ Tetra gewonnenen Homologiedaten. Die Werte sind auf die gesamte AS-Sequenz oder die präferierte Spleißvariante bezogen. Der deutlichste Unterschied zwischen der Gruppe der Sall1-ähnlichen und der Sall3-ähnlichen Gene besteht darin, dass hauptsächlich oder ausschließlich die Spleißvariante ohne den dritten DZF translatiert wird (Farrell et al., 2001; Hollemann et al., 1996; Köster et al., 1997; Kohlhase et al., 1999a; Ott et al., 1996). Dieser Gruppe gehören die meisten der bisher isolierten sal-ähnlichen Vertebratengene an. Csal2 und Medaka-sal (Olsal) wurden daher mit dieser Spleißvariante des Sall3-Gens verglichen. Die Aminosäuresequenzen wurden aus der NCBI Genbank (zugänglich über http://www.ncbi.nlm.nih.gov/) ermittelt. Die Zugangsnummern sind im Anhang dargestellt (s. Tab. A.1).

Ein weiteres aus Xenopus isoliertes Gen, das Xsal-3-Gen (Onuma et al., 1999), ist wahrscheinlich einer vierten Gruppe zuzuordnen, da die ungewöhnliche Prozessierung keinem anderen sal-ähnlichen Vertebratengen ähnelt. Es wurde bisher kein weiteres Gen isoliert, das in die Gruppe von Sall2 und SALL2 einzuordnen ist. Ein phylogenetischer Vergleich, in ähnlicher Form von Farrell et al. (2001) vorgeschlagen, ist in Abbildung 4.8 gezeigt. Das Modell basiert auf der 


\begin{tabular}{llllll}
\hline \multicolumn{2}{c}{ Sall1-Gruppe } & \multicolumn{2}{c}{ Sall2-Gruppe } & \multicolumn{2}{c}{ Sall3-Gruppe } \\
AS- & Homo- & AS- & Homo- & AS- & Homo- \\
Sequenzen & logie & Sequenzen & logie & Sequenzen & logie \\
\hline Sall1 / SALL1 & $90 \%$ & Sall2 / SALL2 & $88 \%$ & Sall3 / SALL3 & $78 \%$ \\
Sall1 / Csal1 & $82 \%$ & & & Sall3 / Csal2 & $70 \%$ \\
& & & & Sall3 / Xsal-1 & $67 \%$ \\
& & & & Sall3 / Olsal & $46 \%$
\end{tabular}

Tabelle 4.4: Homologievergleich zwischen den einer Gruppe zugerechneten Vertebratenproteinen. Es wurden die aus der NCBI Genbank erhältlichen Aminosäuresequenzen zugrunde gelegt.

Annahme, dass zunächst durch eine Duplikation zwei Linien entstanden, die sich unterschiedlich weiterentwickelten. Aus einer entstand die Gruppe der SALL2Gene, die das vermutlich vorher durch intragenische Duplikation o.ä. erworbene vierte DZF-Motiv wieder verloren haben (Kohlhase, 1996). Die andere Linie veränderte sich weiter und brachte drei verschiedene Gruppen hervor, die alle für vier DZF-Domänen kodieren und dennoch charakteristische Unterschiede aufweisen.

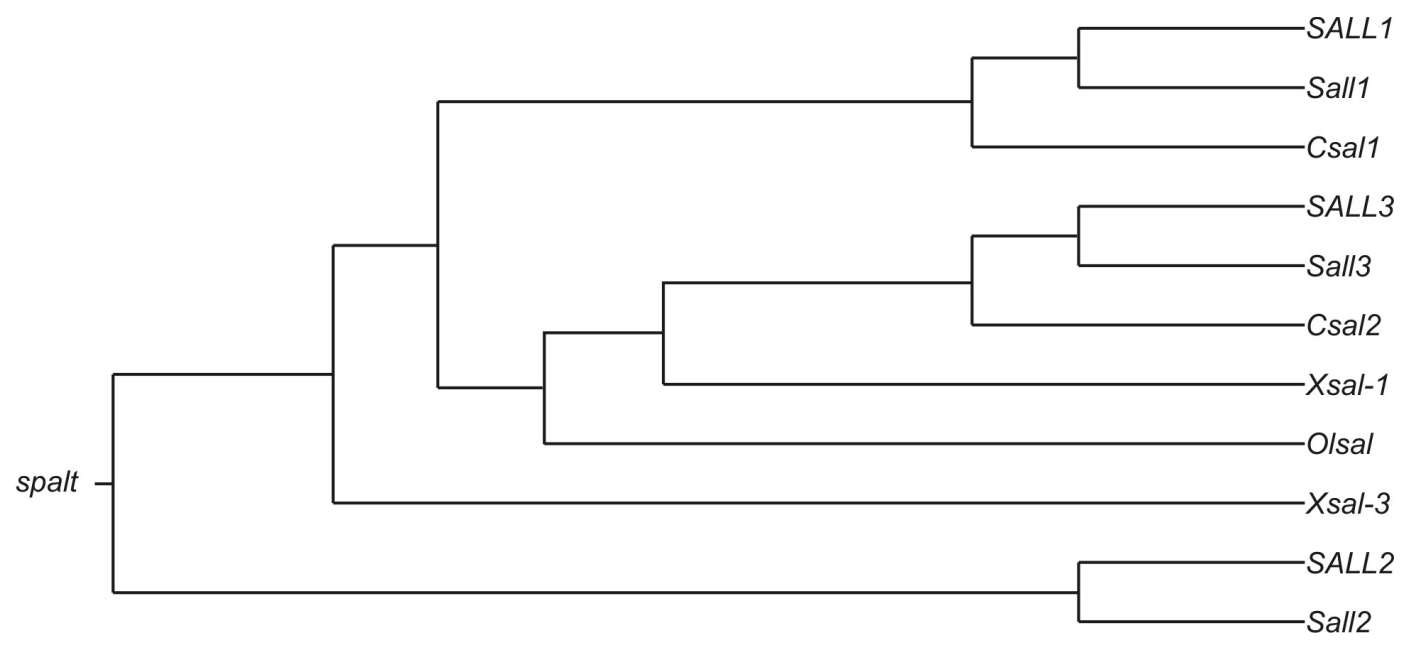

Abbildung 4.8: Phylogenetischer Vergleich aller sal-ähnlicher Vertebratengene. Die Gene können aufgrund ihrer Homologie Gruppen zugeordnet werden. 


\subsubsection{Vergleich der embryonalen Expression}

Der Embryo vom Huhn ist ein wichtiges Untersuchungsobjekt für die GliedmaBenentwicklung bei Vertebraten, da er während der Embryonalentwicklung in vivo manipuliert werden kann, z. B. durch Transplantationsexperimente oder Applikation synthetischer Signalmoleküle (Gillbert, 1997). Die Expression von Csal1 in den Gliedmaßenknospen des Huhns (Farrell und Munsterberg, 2000) ähnelt sehr dem für Sall1 festgestellten Expressionsmuster. Ein erheblicher Unterschied besteht jedoch darin, dass die Transkriptmenge ab dem Hamburger-Hamilton- $(\mathrm{HH}$; (Hamburger und Hamilton, 1951)) Stadium 24/25 im Mesenchym von Flügel- und Beinknospen herunterreguliert wird und die Expression in der ERL im HH 26 endet. Das Huhn zeigt also nicht die bei der Maus festgestellte hohe Transkriptmenge in den Finger- und Zehenspitzen. Daraus lässt sich die Vermutung ableiten, dass die beiden homologen Gene trotz der großen Überlappung der Expressionsdomänen in späteren Stadien der Embryonalentwicklung unterschiedlichen Regulationsmechanismen bzw. unterschiedlichen Regulatorgenen unterworfen sind. Das frühe Expressionsmuster ist jedoch sehr ähnlich, so dass einige Beobachtungen aus dem Huhn auf die Maus abgeleitet werden können. Farrell und Munsterberg (2000) stellten für das Huhn fest, dass Sonic hedgehog (Shh) die Csal1-Expression nur zusammen mit weitere Faktoren aus der epithelialen Randleiste (ERL) erhöhen kann. Zudem vermuten die Autoren eine Kooperation von Wnt3a und Wnt7a mit Fgf-Signalen zur Induktion und Aufrechterhaltung der Csal1-Expression. Die Sall1-Expression könnte also unter der Kontrolle verschiedener Signalmoleküle stehen. Die mögliche Regulation von Sall1 durch shh wird in 4.6 ausführlicher diskutiert. Die embryonale Expression des SALL1-Gens wurde an Schnitten aus fetalem Gehirngewebe untersucht (Kohlhase et al., 1996), dazu liegen keine vergleichbaren Daten von anderen Genen dieser Gruppe vor. Zumindest lässt sich feststellen, dass alle bisher bekannten Gene der Gruppe Sall1-ähnlicher Gene während der Embryonalentwicklung in Gehirnstrukturen exprimiert werden.

Die embryonale Expression des humanen SALL2-Gens wurde ebenfalls an fetalen Gehirnschnitten untersucht (Kohlhase et al., 1996), zu denen keine vergleichbaren Daten bei der Maus vorliegen. Weitere Gene, die zur Gruppe Sall2ähnlicher Gene gehören, wurden bisher nicht isoliert.

Wie in Tabelle 4.4 gezeigt, gehören die meisten bisher isolierten sal-ähnlichen Vertebratengene der Gruppe der Sall3-ähnlichen Gene an. Die Homologie dieser Gene spiegelt sich auch in ihren embryonalen Expressionsmustern wider. So wer- 
den Sall3, SALL3, Csal2, Xsal-1 und Medaka-sal im sich entwickelnden ZNS des Embryos exprimiert (Farrell et al., 2001; Hollemann et al., 1996; Köster et al., 1997; Kohlhase et al., 1999a; Ott et al., 1996). Wiederum wurden die Daten des humanen Sall3-Gens an fetalen Gehirnschnitten gewonnen (Kohlhase et al., 1999a), die nicht mit den Daten aus whole mount-in situ-Hybridisierungen vergleichbar sind. Im Huhn beginnt die Expression des Csal2-Gens wie bei Sall3 in den frühen Stadien der Neuralplatte, in Xenopus in parallelen Streifen der Neuralplatte. Wie Sall3 werden auch Csal2 und Medaka-sal in der MRG exprimiert, nicht jedoch das Xsal-1-Gen. Auch im weiteren Verlauf der ZNS-Entwicklung entsprechen sich die Expressionsdomänen der homologen Gene aus verschiedenen Spezies partiell.

Die Expression des Csal2-Gens in den Gliedmaßenknospen des Huhns ist wie bei dem Sall3-Gen nur vorübergehend und beginnt im posterioren Bereich (Farrell et al., 2001), jedoch ist die Expressionsdomäne stets auch auf diesen Bereich der sich entwickelnden Gliedmaßenknospen begrenzt. Bei Xenopus wird Xsal1 in einer der PZ entsprechenden Region exprimiert (Hollemann et al., 1996). Ein identisches Expressionsmuster beschreiben Köster et al. (1997) bei Medaka. Farrell et al. (2001) berichten von einer Expression des Csal2-Gens im Genitalhöcker des Huhns, wie sie auch bei Sall3 festzustellen ist. In Medaka liegen Medaka-sal-Transkripte im exkretorischen System vor (Köster et al., 1997). Csal2 wird im Augenbecherstiel exprimiert, Medaka-sal im Augenbecherstiel und im optischen Vesikel. Sall3 wird dagegen nicht während der Augenentwicklung exprimiert. Medaka-sal wird im Pronephros exprimiert, Xsal-1 im Opistonephros und Csal2 sowie Sall3 im Mesonephros.

Die mit dem Sall3-Gen verglichenen sal-homologen Gene aus Vertebraten, die aufgrund ihrer Homologie in einer Gruppe zusammengefasst wurden, zeigen in vielen Bereichen der sich entwickelnden Organismen ein übereinstimmendes Expressionsmuster. Somit scheint die Bedeutung, die diese Gene bei der Steuerung von Entwicklungsprozessen einnehmen, über die weite evolutionäre Spanne von Fisch zu Mensch bemerkenswert gleich geblieben zu sein.

\subsection{Zur Regulation des murinen sal-ähnlichen Gene durch Sonic hedgehog}

In einem multizellulären Organismus ist die Ausbildung der Strukturen von Positionierungsinformationen abhängig, die durch vorübergehende Gradienten sekre- 
tierter Signalmoleküle generiert werden (Lawrence und Struhl, 1996). Diese abgestufte Aktivität wird durch die differenzielle Expression von Zielgenen dauerhaft etabliert. In Drosophila wird eines dieser Signalmoleküle zur Positionierung und Musterbildung von dem Segment-Polaritätsgen hedgehog ( $h h$ ) kodiert. Es vermittelt die Musterbildung während der Segmentierung (Lee et al., 1992) und während der Determinierung der Imaginalscheiben (Tabata und Kornberg, 1994). Das diffundierende Hh-Protein vermittelt die Musterbildung im Embryo sowohl über kurze als auch über lange Distanzen (Chuang und Kornberg, 2000; Johnson et al., 1996; McMahon, 2000).

In Säugetieren konnten bisher drei $h h$-homologe Gene isoliert werden: desert hedgehog (dhh), indian hedgehog (ihh) und sonic hedgehog shh, alle Echelard et al. (1993)). Es exisitert also eine hedgehog-Genfamilie von sekretierten Signalmolekülen (Zardoya et al., 1996). Aus dieser Familie ist sonic hedgehog (shh) am besten charakterisiert. Zunächst wird shh im Embryonalknoten exprimiert, ist dann während der Achsenformierung in der ventralen Mittellinie lokalisiert und nachfolgend im Notochord, in der Bodenplatte und im anterioren Bereich im prächordalen Mesoderm angesiedelt. Später findet sich shh-Expression in der ZPA der sich entwickelnden Gliedmaßenknospen und im exkretorischen System (Hammerschmidt et al., 1997).

Die Strukturierung des Vertebratenauges wird durch Shh, das vom darunterliegenden prächordalen Mesoderm der embryonalen Mittellinie sezerniert wird, vermittelt. shh-defiziente Mäuse zeigen Zyklopie (Chiang et al., 1996), was die Vermutung nahelegt, dass Mittelliniensignale von Shh für die richtige Separation der anterioren Augendomäne benötigt werden. Shh spielt eine wichtige Rolle bei der Musterbildung des Zentralen Nervensystems (Goodrich und Scott, 1998; Hammerschmidt et al., 1997; McMahon, 2000), da es für die Differenzierung verschiedener Zelltypen im ventralen Rückenmark benötigt wird. Zudem kontrolliert die laterale Diffusion von Shh aus den Mittellinienstrukturen die Strukturierung des paraxialen Mesoderms (Fan und Tessier-Lavigne, 1994; Fan et al., 1995; Johnson et al., 1994). Im exkretorischen System bewirkt Shh zahlreiche Musterbildungsprozesse und Induktionsereignisse (Chiang et al., 1996). Während der GliedmaBenentwicklung wird Shh in der ZPA generiert und ist an der Organisation der anterior-posterioren Polarität der Gliedmaßen beteiligt (Kraus et al., 2001; Wang et al., 2000; Yang et al., 1997).

Alle Mitglieder der Hh-Familie agieren vermutlich über das Transmembranprotein Patched (ptc), das als Hh-Rezeptor dient. In der Abwesenheit eines Hh- 
Liganden inaktiviert Ptc das Transmembranprotein Smoothened (Smo; (Alcedo und Noll, 1997; Chen und Struhl, 1998; Marigo et al., 1996; Murone et al., 1999; Stone et al., 1996)). Die Inhibierung von Smo wird durch die Bindung von $\mathrm{Hh}$ an Ptc aufgehoben und Smo kann das Hh-Signal transduzieren. Dieser Vorgang resultiert in der Produktion einer aktiven Form des Transkriptionsfaktors Cubitus interruptus $(\mathrm{Ci})$ oder dessen homologen Vertebraten-Faktoren, kodiert von Mitgliedern der Gli-Genfamilie (Aza-Blanc et al., 1997; Chen et al., 1999; Methot und Basler, 1999; Ohlmeyer und Kalderon, 1998; Sasaki et al., 1999; Wang et al., 2000).

Es besteht eine große Ähnlichkeit zwischen den embryonalen Expressionsdomänen muriner sal-ähnlicher Gene und denjenigen des shh-Gens. Sall1 und Sall3 werden wie shh in der Mittel-Rautenhirn-Grenze (MRG), dem Neuralrohr, den Gliedmaßenknospen sowie in Bereichen des exkretorischen Systems (Mesonephros, Metanephros) exprimiert. In Drosophila wird sal in der FlügelImaginalscheibe durch hh aktiviert (Sturtevant et al., 1997). Im Fisch Medaka wird sal durch ektopische Shh-Signale aktiviert, und die Reduktion der hh-Signale durch den Antagonisten Proteinkinase A resultiert in verminderter sal-Expression (Köster et al., 1997).

Um die Abhängigkeit der Expression sal-ähnlicher Gene in der Maus vom ShhSignal zu prüfen, wurden $s h h^{-/-}$-Embryonen mit Sonden für Sall1, Sall2 und Sall3 hybridisiert (s. Abb. 3.32). Dabei zeigt sich zunächst ein recht ähnliches Expressionsmuster zwischen den Deletionsmutanten und den Wildtyp-Embryonen, bei einer genaueren Analyse lassen sich dann jedoch signifikante Unterschiede in bestimmten Domänen feststellen. Das trifft besonders für den Kopfbereich zu, wo bei allen drei Genen mehrere Expressionsdomänen kleiner und/oder diffuser erscheinen als bei den Wildtyp-Embryonen. So ist die Transkription von Sall1 in der MRG der shh ${ }^{-/-}$-Embryonen schon an $10.5 \mathrm{dpc}$ nicht mehr detektierbar, und die aneinander angrenzenden und überlappenden Expressionsdomänen der drei Gene im Mittelhirn sind in den Deletionsmutanten stark eingeschränkt. Hier könnte man also eine Abhängigkeit der Sall1-Expression vom Shh-Signal vermuten. Im Neuralrohr ist die Expression nicht reduziert, sondern scheint, eventuell aufgrund des fehlenden Shh-Signals, diffuser zu sein. In dem Fall würde die Rolle von shh nicht darin liegen, die Transkription von Sall1 zu induzieren, sondern auf bestimmte Gewebe zu lokalisieren. Die Expression in den Gliedmaßenknospen ist ebenfalls in den $s h h^{-1-}$-Embryonen beeinträchtigt. Sall1-Transkripte sind nur in den distalen Bereichen festzustellen, und das vornehmlich im mittleren Bereich 
exprimierte Sall3 lässt eine wesentlich reduzierte Transkription erkennen. Eventuell werden also Sall1 und Sall3 in den mittleren Regionen der Gliedmaßenknospen durch Shh reguliert. Weitere Expressionsdomänen wie der Genitalhöcker, die Branchialbögen und die Schwanzspitze scheinen in den knock out-Mäusen unbeeinflusst zu sein.

Die Auswertung dieser Ergebnisse unterliegt der Problematik, dass sich das äußere Erscheinungsbild der shh ${ }^{-1-}$-Embryonen stark von dem der WildtypEmbryonen unterscheidet (Chiang et al., 1996). Es muss daher die Möglichkeit in Betracht gezogen werden, dass die Unterschiede in der Expression der drei Gene nicht oder nicht allein daraus resultieren, dass durch das fehlende Shh-Signal ihre Expression vermindert aktiviert wird. Die Expression eines Gens ist meist auch von Umgebungsfaktoren wie dem entsprechenden Gewebe abhängig. Ist also die entsprechende Region wie z. B. ein Mittelhirn-Bereich nicht oder nur rudimentär vorhanden, bleibt auch die Expression der für diese Region spezifischen Gene aus oder ist auf den verkleinerten Bereich beschränkt. Weitere Untersuchungen können diese Problematik beheben, indem für bestimmte Gewebsbereiche bekannte Markergene zur Hybridisierung von shh ${ }^{-/-}$-Embryonen verwendet werden und so festgestellt werden kann, ob die Umgebungsfaktoren zur Expression der murinen sal-Gene gegeben sind oder nicht.

\subsection{Weiterführende Arbeiten}

Die Ergebnisse der vorliegenden Arbeit eröffnen vielfältige Möglichkeiten für weitere Forschungsarbeiten. Ein bedeutender Schritt wird dabei die Analyse der Sall1knock out-Mäuse sein. Hieraus können Rückschlüsse auf die Funktion des Gens bei der Maus und beim Menschen gezogen werden. Dabei könnten genaue Untersuchungen der beim TBS betroffenen Organe Erkenntnisse über die Entstehung der Fehlbildungen liefern. Bei einem Phänotyp, der auf eine ähnliche funktionelle Bedeutung des Sall1- und SALL1-Gens bei der Maus und beim Menschen schließen lässt, würde durch die Herstellung einer knock in-Maus, in welche ein Konstrukt mit einer TBS-typischen Mutation eingebracht wird, ein idealer Modellorganismus für das TBS geschaffen werden. Über die gegen das murine Sall1und das humane SALL1-Protein erzeugten Antikörper könnte sich klären lassen, ob durch die zum TBS führenden Mutationen ein trunkiertes SALL1-Protein, das über den Dominant-Negativen Effekt eine Haploinsuffizienz bewirkt, entsteht, oder das verkürzte Protein durch Proteolyse wieder abgebaut wird. Auch wird es dann 
möglich sein, die Lokalisation des Proteins im Gewebe zu bestimmen.

Für die Sall2-knock out-Linie sind in nächster Zeit weitere Ergebnisse zu erwarten. Sollte sich die Vermutung, mit Sall2 ein wichtiges Signal zur Gehirnentwicklung identifiziert zu haben, bestätigen, würden weitere Untersuchungen z. B. die Hybridisierung der Embryonen mit bekannten Markergenen für die Gehirnentwicklung einschließen. Sollte damit die Einordnung des Gens in die Signalkaskade gelingen, wäre ein wichtiger Schritt zur Aufklärung der Bedeutung des Gens in den Säugetieren getan. Eine Kreuzung der Sall1- und Sall2-knock out-Linien könnte neue Anhaltspunkte für eine partielle Redundanz der biologischen Funktionen der beiden Gene liefern. Langfristig sollte auch eine Sall3-knock out-Maus hergestellt werden, um die Erkenntnisse über die Bedeutung der sal-ähnlichen Gene in Säugetieren zu komplettieren. 


\section{Zusammenfassung}

Das zu dem humanen SALL1-Gen homologe Sall1-Gen der Maus wurde durch die mittelstringente Hybridisierung einer murinen Cosmid-Bibliothek mit einer SALL1Sonde isoliert. Die genaue Charakterisierung erfolgte über die Herstellung einer Restriktionskarte, Klonierungen und Sequenzierungen. Anhand einer NorthernBlot-Analyse konnte gezeigt werden, dass das Sall1-Gen am stärksten in Nierenund Gehirngeweben der Maus exprimiert wird. Mittels whole mount-in situHybridisierungen von Embryonen und Paraffinschnitten von Embryonen wurde gezeigt, dass das Gen im zentralen Nervensystem, im Mesonephros, in den Gliedmaßen und in weiteren Strukturen der Embryonen verschiedener Entwicklungsstadien exprimiert wird. Mit Hilfe des pTKneo-Vektors wurde ein Konstrukt zur Generierung einer Sall1-knock out-Maus hergestellt. Durch homologe Rekombination in embryonalen Stammzellen wurde das vollständige Exon 2 und ein Teil des Exon 3 auf einem Allel der positiven ES-Zellen durch das Neomycin-Resistenzgen ersetzt. Aus den ES-Zellen hergestellte Chimären werden zur Zeit mit WildtypMäusen gekreuzt. Ein Antiserum aus Kaninchen, das gegen ein humanes SALL1Peptid hergestellt worden war, wurde durch das Binden des Peptids an eine Säule aufgereinigt. Anhand des aufgereinigten Antikörpers konnte das homologe Sall1Protein der Maus in Kernproteinextrakten nachgewiesen werden.

Mittels whole mount-in situ-Hybridisierungen konnte gezeigt werden, dass das Sall2-Gen im zentralen Nervensystem im Mesonephros sowie im optischen und otischen Vesikel exprimiert wird. Zu dem bereits isolierten und größtenteils charakterisierten murinen Sall2-Gen wurden weitere Daten durch die Isolierung eines weiteren Cosmidklons, Klonierungen und Sequenzierungen gewonnen. Mit Hilfe dieser Daten wurde ein Sall2-knock out-Konstrukt hergestellt und zur Deletion des Exon 1a und Exon 2 in embryonalen Stammzellen eingesetzt. Positive ES-Zellen wurden in Blastocysten injiziert und die daraus enstandenen Chimären mit Wildtyp-Mäusen verpaart. Mittels Genotypisierung über PCR identifizierte he- 
terozygote Sall2 ${ }^{+/-}$-Mäuse der F1-Generation wurden weiter verpaart und die in der F2-Generation auftretenden für die Deletion homozgygoten Mäuse auf einen Phänotyp hin untersucht. Die adulten Mäuse zeigten keine Auffälligkeiten, die durchschnittliche Anzahl an Nachkommen bei Verpaarungen von homozygoten Sall2 $2^{-1-}$-Mäusen war jedoch geringer als normal. Durch die Präparation von Embryonen konnte gezeigt werden, dass mehrere Embryonen Defekte in der SchlieBung des Neuralrohrs aufwiesen, die wahrscheinlich zum pränatalen Absterben der Tiere führen. Ein Bereich aus Exon 2 wurde für die Herstellung eines Streptag-Fusionsproteins zur Produktion eines Antiserums ausgewählt. Anhand des Strep-tag-spezifischen StrepTactin-Moleküls wurde die Überexpression des Fusionsproteins in Bakterienkulturen nachgewiesen und nach einer Aufreinigung des Proteins mit der Immunisierung von Kaninchen begonnen.

Anhand der in der Genbank veröffentlichten Nukleotidsequenz des Sall3-Gens wurden Primer hergestellt und ein Fragment aus genomischer Maus-DNA amplifiziert. Das DIG-markierte Fragment wurde zur whole mount-in situ-Hybridisierung von Embryonen eingesetzt. Alle drei isolierten sal-ähnlichen Gene der Maus wurden anhand ihrer Expressionsdaten verglichen. Durch die whole mount-in situHybridisierung von shh $^{-/}$-Embryonen mit den drei Sonden für Sall1, Sall2 und Sall3 konnte gezeigt werden, dass die für andere Vertebraten gezeigte Abhängigkeit der sal-Expression von Sonic hedgehog für die Maus nur in bestimmten Organen zutrifft. Es wurde gezeigt, dass die murinen sal-Gene für ihre Expression nicht generell auf das Shh-Signal angewiesen sind. 


\section{Literaturverzeichnis}

Adham I.M., Nayernia K. und Engel W. (1997). Spermatozoa lacking acrosin protein show delayed fertilization, Mol Reprod Dev 46: 370-376.

Alcedo J. und Noll M. (1997). Hedgehog and its patched-smoothened receptor complex: a novel signalling mechanism at the cell surface, Biol Chem 378: 583590.

Alles A.J. und Sulik K.K. (1989). Retinoic-acid-induced limb-reduction defects: perturbation of zones of programmed cell death as a pathogenetic mechanism, Teratology 40: 163-171.

Altmann M.E. (1998). Mündliche Mitteilung.

Altschul S.F., Koonin E.V., Madden T.L., Schaffer A.A., Zhang J., Zhang Z., Miller W., Lipman D.J., Gish W. und Myers E.W. (1998). Iterated profile searches with PSI-BLAST-a tool for discovery in protein databases Gapped BLAST and PSI-BLAST: a new generation of protein database search programs Basic local alignment search tool, Trends Biochem Sci 23: 444-447.

Archangelo L. (1999). Mündliche Mitteilung.

Ausubel F.M., Brent R., Kingston R.E., Moore D.D., Seidman J.G., Smith J.A. und Struhl K. (1994). Current Protocols in Molecular Biology, John Wiley \& Sons Inc., USA.

Aza-Blanc P., Ramirez-Weber F.A., Laget M.P., Schwartz C. und Kornberg T.B. (1997). Proteolysis that is inhibited by hedgehog targets Cubitus interruptus protein to the nucleus and converts it to a repressor, Cell 89: 1043-1053.

Baker C.V. und Bronner-Fraser M. (2001). Vertebrate cranial placodes I. Embryonic induction, Dev Biol 232: 1-61.

Birnboim H.C. und Doly J. (1979). A rapid alkaline extraction procedure for screening recombinant plasmid DNA, Nucleic Acids Res 7: 1513-1523.

Blanck C. (2000). Mündliche Mitteilung.

Bonyadi M., Rusholme S.A., Cousins F.M., Su H.C., Biron C.A., Farrall M. und Akhurst R.J. (1997). Mapping of a major genetic modifier of embryonic lethality in TGF beta 1 knockout mice, Nat Genet 15: 207-211. 
Bouchard M., Pfeffer P. und Busslinger M. (2000). Functional equivalence of the transcription factors Pax2 and Pax5 in mouse development, Development 127: 3703-3713.

Bradford M.M. (1976). A rapid and sensitive method for the quantitation of microgram quantities of protein utilizing the principle of protein-dye binding, Anal Biochem 72: 248-254.

Breathnach R. und Chambon P. (1981). Organization and expression of eucaryotic split genes coding for proteins, Annu Rev Biochem 50: 349-383.

Buck A., Archangelo L., Dixkens C. und Kohlhase J. (2000). Molecular cloning, chromosomal localization, and expression of the murine SALL1 ortholog Sall1, Cytogenet Cell Genet 89: 150-153.

Buck A., Kispert A. und Kohlhase J. (2001). Embryonic expression of the murine homologue of SALL1, the gene mutated in Townes-Brocks syndrome, Mech Dev 104: 143-146.

Buck L.B. (2000). The molecular architecture of odor and pheromone sensing in mammals, Cell 100: 611-618.

Bullock W.O., Fernandez J.M. und Short J.M. (1987). XL1-blue: A high efficiency plasmid transforming recA Escherichia coli strain with beta-galactosidase selection, Biotechniques 5: 376-378.

Burfeind P. und Hoyer-Fender S. (1991). Sequence and developmental expression of a mRNA encoding a putative protein of rat sperm outer dense fibers, Dev Biol 148: 195-204.

Burrow C.R. (2000). Regulatory molecules in kidney development, Pediatr Nephrol 14: 240-253.

Cameron T.H., Lachiewicz A.M. und Aylsworth A.S. (1991). Townes-Brocks syndrome in two mentally retarded youngsters, Am J Med Genet 41: 1-4.

Capecchi M.R. (1989). Altering the genome by homologous recombination, Science 244: 1288-1292.

de Celis J.F., Barrio R. und Kafatos F.C. (1996). A gene complex acting downstream of dpp in Drosophila wing morphogenesis, Nature 381: 421-424.

de Celis J.F., Barrio R. und Kafatos F.C. (1999). Regulation of the spalt/spaltrelated gene complex and its function during sensory organ development in the Drosophila thorax, Development 126: 2653-2662.

Celis J.F.d., Barrio R. und Kafatos F.C. (1996). A gene complex acting downstream of dpp in Drosophila wing morphogenesis, Nature 381: 421-424. 
Chen C.H., von Kessler D.P., Park W., Wang B., Ma Y. und Beachy P.A. (1999). Nuclear trafficking of Cubitus interruptus in the transcriptional regulation of Hedgehog target gene expression, Cell 98: 305-316.

Chen C.K., Kühnlein R.P., Eulenberg K.G., Vincent S., Affolter M. und Schuh R. (1998). The transcription factors KNIRPS and KNIRPS RELATED control cell migration and branch morphogenesis during Drosophila tracheal development., Development 125: 4959-4968.

Chen H. und Johnson R.L. (1999). Dorsoventral patterning of the vertebrate limb: a process governed by multiple events, Cell Tissue Res 296: 67-73.

Chen Y. und Struhl G. (1998). In vivo evidence that Patched and Smoothened constitute distinct binding and transducing components of a Hedgehog receptor complex, Development 125: 4943-4948.

Chiang C., Litingtung Y., Lee E., Young K.E., Corden J.L., Westphal H. und Beachy P.A. (1996). Cyclopia and defective axial patterning in mice lacking Sonic hedgehog gene function, Nature 383: 407-413.

Chien A., Edgar D.B. und Trela J.M. (1976). Deoxyribonucleic acid polymerase from the extreme thermophile Thermus aquaticus, J Bacteriol 127: 1550-1557.

Chu P.H., Bardwell W.M., Gu Y., Ross J. J. und Chen J. (2000). FHL2 (SLIM3) is not essential for cardiac development and function, Mol Cell Biol 20: 7460-7462.

Chuang P.T. und Kornberg T.B. (2000). On the range of hedgehog signaling, Curr Opin Genet Dev 10: 515-522.

Clark J.M. (1988). Novel non-templated nucleotide addition reactions catalyzed by procaryotic and eucaryotic DNA polymerases, Nucleic Acids Res 16: 9677-9686.

Clark K.L., Halay E.D., Lai E. und Burley S.K. (1993). Co-crystal structure of the HNF-3/fork head DNA-recognition motif resembles histone H5, Nature 364: 412420.

Cohn M.J. und Bright P.E. (1999). Molecular control of vertebrate limb development, evolution and congenital malformations, Cell Tissue Res 296: 3-17.

Copp A.J., Brook F.A., Estibeiro J.P., Shum A.S. und Cockroft D.L. (1990). The embryonic development of mammalian neural tube defects, Prog Neurobiol 35: 363-403.

Costa G.L. und Weiner M.P. (1994). Polishing with T4 or Pfu polymerase increases the efficiency of cloning of PCR fragments, Nucleic Acids Res 22: 2423.

Courey A.J. und Tjian R. (1988). Analysis of Sp1 in vivo reveals multiple transcriptional domains including a novel glutamine-rich activation motif, Cell 55: 887-898. 
Dagert M. und Ehrlich S.D. (1979). Prolonged incubation in calcium chloride improves the competence of Escherichia coli cells, Gene 6: 23-28.

Dealy C.N., Roth A., Ferrari D., Brown A.M. und Kosher R.A. (1993). Wnt-5a and Wnt-7a are expressed in the developing chick limb bud in a manner suggesting roles in pattern formation along the proximodistal and dorsoventral axes, Mech Dev 43: 175-186.

Demski L.S. (1993). Terminal nerve complex, Acta Anat 148: 81-95.

Denhardt D.T. (1966). A membrane-filter technique for the detection of complementary DNA, Biochem Biophys Res Commun 23: 641-646.

Dolle P., Izpisua-Belmonte J.C., Brown J.M., Tickle C. und Duboule D. (1991). HOX-4 genes and the morphogenesis of mammalian genitalia, Genes Dev 5: 1767-1767.

Dolle P., Ruberte E., Kastner P., Petkovich M., Stoner C.M., Gudas L.J. und Chambon P. (1989). Differential expression of genes encoding alpha, beta and gamma retinoic acid receptors and CRABP in the developing limbs of the mouse, Nature 342: 702-705.

Dolle P., Ruberte E., Leroy P., Morriss-Kay G. und Chambon P. (1990). Retinoic acid receptors and cellular retinoid binding proteins. I. A systematic study of their differential pattern of transcription during mouse organogenesis, Development 110: 1133-1151.

Echelard Y., Epstein D., St-Jacques B., Shen L., Mohler J., McMahon J. und McMahon A. (1993). Sonic Hedgehog, a Member of a Family of Putative Signaling Molecules, Is Implicated in the Regulation of CNS Polarity, Cell 75: 1417-1430.

El-Baradi T. und Pieler T. (1991). Zinc finger proteins: what we know and what we would like to know, Mech Dev 35: 155-169.

Elstob P.R., Brodu V. und Gould A.P. (2001). spalt-dependent switching between two cell fates that are induced by the Drosophila EGF receptor, Development 128: 723-732.

Fan C.M., Porter J.A., Chiang C., Chang D.T., Beachy P.A. und Tessier-Lavigne M. (1995). Long-range sclerotome induction by sonic hedgehog: direct role of the amino-terminal cleavage product and modulation by the cyclic AMP signaling pathway, Cell 81: 457-465.

Fan C.M. und Tessier-Lavigne M. (1994). Patterning of mammalian somites by surface ectoderm and notochord: evidence for sclerotome induction by a hedgehog homolog, Cell 79: 1175-1186. 
Farbman A.I. (1994). Developmental biology of olfactory sensory neurons, Semin Cell Biol 5: 3-10.

Farrell E.R. und Munsterberg A.E. (2000). csal1 is controlled by a combination of FGF and Wnt signals in developing limb buds, Dev Biol 225: 447-458.

Farrell E.R., Tosh G., Church E. und Munsterberg A.E. (2001). Cloning and expression of CSAL2, a new member of the spalt gene family in chick, Mech Dev 102: 227-230.

Favor J., Sandulache R., Neuhauser-Klaus A., Pretsch W., Chatterjee B., Senft E., Wurst W., Blanquet V., Grimes P., Sporle R. und Schughart K. (1996). The mouse Pax2 (1Neu) mutation is identical to a human PAX2 mutation in a family with renalcoloboma syndrome and results in developmental defects of the brain, ear, eye, and kidney, Proc Natl Acad Sci U S A 93: 13870-13875.

Fekete D.M. (1996). Cell fate specification in the inner ear, Curr Opin Neurobiol 6: 533-541.

Fekete D.M. (1999). Development of the vertebrate ear: insights from knockouts and mutants, Trends Neurosci 22: 263-269.

Finkenzeller D., Fischer B., McLaughlin J., Schrewe H., Ledermann B. und Zimmermann W. (2000). Trophoblast cell-specific carcinoembryonic antigen cell adhesion molecule 9 is not required for placental development or a positive outcome of allotypic pregnancies, Mol Cell Biol 20: 7140-7145.

Fritzsch B., Barald K.F. und Lomax M.I. (1997). Early embryology of the vertebrate ear., Development of the Auditory System (Hrsg. Rubel E.W., Popper A.N. und Fay R.R.), Springer Verlag, New York.

Gashler A.L., Swaminathan S. und Sukhatme V.P. (1993). A novel repression module, an extensive activation domain, and a bipartite nuclear localization signal defined in the immediate-early transcription factor Egr-1, Mol Cell Biol 13: 45564571.

Gelehrter T., Collins F. und Ginsburg D. (1998). Principles of Medical Genetics, 2nd Edn., Williams \& Wilkins, Baltimore, Maryland, USA.

Gerwin N., Rosée A.L., Sauer F., Halbritter H.P., Neumann M., Jäckle H. und Nauber U. (1994). Functional and conserved domains of the Drosophila transcription factor encoded by the segmentation gene knirps, Mol Cell Biol 14: 7899-7908.

Gilbert S.F. (1997). Developmental Biology, 5th edition Edn., Sinauer Associates, Inc., Sunderland, Massachusetts.

Goodrich L.V. und Scott M.P. (1998). Hedgehog and patched in neural development and disease, Neuron 21: 1243-1257. 
Grainger R.M. (1992). Embryonic lens induction: shedding light on vertebrate tissue determination, Trends Genet 8: 349-355.

Graw J. (1996). Genetic aspects of embryonic eye development in vertebrates, Dev Genet 18: 181-197.

Greer J.M., Puetz J., Thomas K.R. und Capecchi M.R. (2000). Maintenance of functional equivalence during paralogous Hox gene evolution, Nature 403: 661665.

Gruss P. und Walther C. (1992). PAX in development, Cell 69: 719-722.

Hamburger V. und Hamilton H.L. (1951). A series of normal stages in the development of the chick embryo., J Morphol 88.

Hammerschmidt M., Brook A. und McMahon A.P. (1997). The world according to hedgehog, Trends Genet 13: 14-21.

Han K. und Manley J.L. (1993). Transcriptional repression by the Drosophila evenskipped protein: definition of a minimal repression domain, Genes Dev 7: 491503.

Hanahan D. (1985). Techniques for transformation of Escherichia coli, DNA cloning. A practical approach., IRL Press, Oxford.

Hanks M., Wurst W., Anson-Cartwright L., Auerbach A.B. und Joyner A.L. (1995). Rescue of the En-1 mutant phenotype by replacement of En-1 with En-2, Science 269: 679-682.

Haraguchi R., Suzuki K., Murakami R., Sakai M., Kamikawa M., Kengaku M., Sekine K., Kawano H., Kato S., Ueno N. und Yamada G. (2000). Molecular analysis of external genitalia formation: the role of fibroblast growth factor (Fgf) genes during genital tubercle formation, Development 127: 2471-2479.

Harroch S., Palmeri M., Rosenbluth J., Custer A., Okigaki M., Shrager P., Blum M., Buxbaum J.D. und Schlessinger J. (2000). No obvious abnormality in mice deficient in receptor protein tyrosine phosphatase beta, Mol Cell Biol 20: 77067715 .

Hentze M.W. und Kulozik A.E. (1999). A perfect message: RNA surveillance and nonsense-mediated decay, Cell 96: 307-310.

Hinrichsen K.V. (1990). Gesichtsentwicklung, Humanembryologie (Hrsg. Hinrichsen K.V.), Springer-Verlag, Berlin, 650-692.

Hodge R. (1994). Preparation of RNA gel blots, Methods Mol Biol 28: 49-54. 
Hollemann T., Schuh R., Pieler T. und Stick R. (1996). Xenopus Xsal-1, a vertebrate homolog of the region specific homeotic gene spalt of Drosophila, Mech Dev 55: 19-32.

Hu G. (1993). DNA polymerase-catalyzed addition of nontemplated extra nucleotides to the 3' end of a DNA fragment, DNA Cell Biol 12: 763-770.

Ishikiriyama S., Kudoh F., Shimojo N., Iwai J. und Inoue T. (1996). Townes-Brocks syndrome associated with mental retardation, Am J Med Genet 61: 191-192.

Jean D., Ewan K. und Gruss P. (1998). Molecular regulators involved in vertebrate eye development, Mech Dev 76: 3-18.

Johnson G.D. und Nogueira Araujo G.M. (1981). A simple method of reducing the fading of immunofluorescence during microscopy, J Immunol Methods 43: 349350.

Johnson J.P., Poskanzer L.S. und Sherman S. (1996). Three-generation family with resemblance to Townes-Brocks syndrome and Goldenhar/ oculoauriculovertebral spectrum, Am J Med Genet 61: 134-139.

Johnson R., Laufer E., Riddle R. und Tabin C. (1994). Ectopic expression of Sonic Hedgehog alters dorsal-ventral patterning of somites, Cell 79: 1165-1173.

Johnson R.L. und Tabin C.J. (1997). Molecular models for vertebrate limb development, Cell 90: 979-990.

Jorde L., Carey J. und White R. (1995). Medical Genetics, Mosby-Year Book Inc., St. Louis, Missouri, USA.

Joyner A.L. (2000). Gene Targeting, 2nd Edn., A Practical Approach, Oxford University Press, New York.

Jürgens G. (1988). Head and tail development of the Drosophila embryo involves spalt, a novel homeotic gene, EMBO J 7: 189-196.

Jürgens G. und Weigel D. (1988). Terminal versus segmental development in the Drosophila embryo: the role of the homeotic gene fork head, Roux's Archives of Developmental Biology 197: 345-354.

Kaufman M.H. (1992). The Atlas of Mouse Development, Academic Press, London.

Kaufman T.C., Lewis R. und Wakimoto B. (1980). Cytogenetic analysis of chromosome 3 in Drosophila melanogaster: the homeotic gene complex in polytene chromosome interval 84A, B, Genetics 94: 115-133.

Kessel M. und Gruss P. (1990). Murine developmental control genes, Science 249: 374-379. 
Koehler M.R., Bosserhoff A., von Beust G., Bauer A., Blesch A., Buettner R., Schlegel J., Bogdahn U. und Schmid M. (1996). Assignment of the human melanoma inhibitory activity gene (MIA) to 19q13.32-q13.33 by fluorescence in situ hybridization (FISH), Genomics 35: 265-267.

Kohlhase J. (1996). Isolierung und Charakterisierung einer humanen Genfamilie mit Ähnlichkeit zu spalt, einem regionsspezifischen homöotischen Gen von Drosophila melanogaster, Med. diss., Universität Göttingen.

Kohlhase J. (2000a). Mündliche Mitteilung.

Kohlhase J. (2000b). SALL1 mutations in townes-brocks syndrome and related disorders, Hum Mut 16: 460-466.

Kohlhase J., Altmann M., Archangelo L., Dixkens C. und Engel W. (2000). Genomic cloning, chromosomal mapping, and expression analysis of msal-2, Mamm Genome 11: 64-68.

Kohlhase J., Hausmann S., Stojmenovic G., Dixkens C., Bink K., Schulz-Schaeffer W., Altmann M. und Engel W. (1999a). SALL3, a new member of the human spaltlike gene family, maps to 18q23, Genomics 62: 216-222.

Kohlhase J., Köhler A., Jäckle H., Engel W. und Stick R. (1999b). Molecular cloning of a SALL1-related pseudogene and mapping to chromosome Xp11.2, Cytogenet Cell Genet 84: 31-34.

Kohlhase J., Schuh R., Dowe G., Kühnlein R.P., Jäckle H., Schroeder B., SchulzSchaeffer W., Kretzschmar H.A., Köhler A., Müller U., Raab-Vetter M., Burkhardt E., Engel W. und Stick R. (1996). Isolation, characterization, and organ-specific expression of two novel human zinc finger genes related to the Drosophila gene spalt, Genomics 38: 291-298.

Kohlhase J., Taschner P.E.M., Burfeind P., Pasche B., Newman B., Blanck C., Breuning M.H., Kate L.P.t., Maaswinkel-Mooy P., Mitulla B., Seidel J., Kirkpatrick S.J., Pauli R.M., Wargowski D.S., Devriendt K., Proesmans W., Gabrielli O., Coppa G.V., Wesby-vanSwaay E., Trembath R.C., Schinzel A.A., Reardon W., Seemanova E. und Engel W. (1999c). Molecular analysis of SALL1 mutations in Townes-Brocks syndrome, Am J Hum Genet 64: 435-445.

Kohlhase J., Wischermann A., Reichenbach H., Froster U. und Engel W. (1998). Mutations in the SALL1 putative transcription factor gene cause Townes-Brocks syndrome, Nat Genet 18: 81-83.

Köster R., Stick R., Loosli F. und Wittbrodt J. (1997). Medaka spalt acts as a target gene of hedgehog signaling, Development 124: 3147-3156.

Kraus P., Fraidenraich D. und Loomis C.A. (2001). Some distal limb structures develop in mice lacking Sonic hedgehog signaling, Mech Dev 100: 45-58. 
Kühnlein R.P., Frommer G., Friedrich M., Gonzalez-Gaitan M., Weber A., WagnerBernholz J.F., Gehring W., Jäckle H. und Schuh R. (1994). spalt encodes an evolutionary conserved zinc finger protein of novel structure which provides homeotic gene function in the head and tail region of the Drosophila embryo, EMBO J 13: 168-179.

Laemmli U.K. (1970). Cleavage of structural proteins during the assembly of the head of the bacteriophage T4, Nature 227: 680-685.

Lai E., Prezioso V.R., Smith E., Litvin O., Costa R.H. und Darnell J. E. J. (1990). HNF-3A, a hepatocyte-enriched transcription factor of novel structure is regulated transcriptionally, Genes Dev 4: 1427-1436.

Lai E., Prezioso V.R., Tao W.F., Chen W.S. und Darnell J. E. J. (1991). Hepatocyte nuclear factor 3 alpha belongs to a gene family in mammals that is homologous to the Drosophila homeotic gene fork head, Genes Dev 5: 416-427.

Laird P.W., Zijderveld A., Linders K., Rudnicki M.A., Jaenisch R. und Berns A. (1991). Simplified mammalian DNA isolation procedure, Nucleic Acids Res 19: 4293.

Lawrence P.A. und Struhl G. (1996). Morphogens, compartments, and pattern: lessons from drosophila?, Cell 85: 951-961.

LeCouter J.E., Kablar B., Whyte P.F., Ying C. und Rudnicki M.A. (1998). Straindependent embryonic lethality in mice lacking the retinoblastoma- related p130 gene, Development 125: 4669-4679.

Lee J.J., von Kessler D.P., Parks S. und Beachy P.A. (1992). Secretion and localized transcription suggest a role in positional signaling for products of the segmentation gene hedgehog, Cell 71: 33-50.

Lewin B. (1997). Genes, vi Edn., Oxford University Press Inc., New York.

Lewis E.B. (1978). A gene complex controlling segmentation in Drosophila, Nature 276: 565-570.

Licht J.D., Grossel M.J., Figge J. und Hansen U.M. (1990). Krüppel is a transcriptional repressor, Nature 346: 76-79.

Lichter P., Cremer T., Borden J., Manuelidis L. und Ward D.C. (1988). Delineation of individual human chromosomes in metaphase and interphase cells by in situ suppression hybridization using recombinant DNA libraries., Hum Genet 80: 224234.

Lin M.S., Comings D.E. und Alfi O.S. (1977). Optical Studies of the interaction of 4'-6'-diamidino-2-phenylindole with DNA and metaphase chromosomes, Chromosoma 60: 15-25. 
Lipschutz J.H. (1998). Molecular development of the kidney: a review of the results of gene disruption studies, Am J Kidney Dis 31: 383-397.

Liu J.P., Baker J., Perkins A.S., Robertson E.J. und Efstratiadis A. (1993). Mice carrying null mutations of the genes encoding insulin-like growth factor I (Igf-1) and type 1 IGF receptor (Igf1r), Cell 75: 59-72.

Manak J.R. und Scott M.P. (1994). A class act: conservation of homeodomain protein functions, Dev Suppl : 61-71.

Mansouri A., Hallonet M. und Gruss P. (1996). Pax genes and their roles in cell differentiation and development., Curr Opin Cell Biol 8: 851-857.

Marigo V., Davey R.A., Zuo Y., Cunningham J.M. und Tabin C.J. (1996). Biochemical evidence that patched is the Hedgehog receptor, Nature 384: 176-179.

Marlin S., Blanchard S., Slim R., Lacombe D., Denoyelle F., Alessandri J.L., Calzolari E., Drouin-Garraud V., Ferraz F.G., Fourmaintraux A., Philip N., Toublanc J.E. und Petit C. (1999). Townes-Brocks syndrome: detection of a SALL1 mutation hot spot and evidence for a position effect in one patient, Hum Mutat 14: 377-386.

Masuya H., Sagai T., Moriwaki K. und Shiroishi T. (1997). Multigenic control of the localization of the zone of polarizing activity in limb morphogenesis in the mouse, Dev Biol 182: 42-51.

McMahon A.P. (2000). More surprises in the Hedgehog signaling pathway, Cell 100: $185-188$.

Mendelsohn C., Ruberte E. und Chambon P. (1992). Retinoid receptors in vertebrate limb development, Dev Biol 152: 50-61.

Mendelsohn C., Ruberte E., LeMeur M., Morriss-Kay G. und Chambon P. (1991). Developmental analysis of the retinoic acid-inducible RAR-beta 2 promoter in transgenic animals, Development 113: 723-734.

Methot N. und Basler K. (1999). Hedgehog controls limb development by regulating the activities of distinct transcriptional activator and repressor forms of Cubitus interruptus, Cell 96: 819-831.

Miller J., McLachlan A.D. und Klug A. (1985). Repetitive zinc-binding domains in the protein transcription factor TFIIIA from Xenopus oocytes, EMBO J 4: 16091614.

Moore K.L. (1996). Grundlagen der medizinischen Embryologie, 2nd Edn., Ferdinand Enke Verlag, Stuttgart.

Murakami R. (1986). Development of the os penis in genital tubercles cultured beneath the renal capsule of adult rats, J Anat 149: 11-20. 
Murone M., Rosenthal A. und de Sauvage F.J. (1999). Sonic hedgehog signaling by the patched-smoothened receptor complex, Curr Biol 9: 76-84.

Nagy A., Rossant J., Nagy R., Abramow-Newerly W. und Roder J.C. (1993). Derivation of completely cell culture-derived mice from early-passage embryonic stem cells, Proc Natl Acad Sci U S A 90: 8424-8428.

Nellen D., Burke R., Struhl G. und Basler K. (1996). Direct and long-range action of a DPP morphogen gradient, Cell 85: 357-368.

Newman W.G., Brunet M.D. und Donnai D. (1997). Townes-Brocks syndrome presenting as end stage renal failure, Clin Dysmorphol 6: 57-60.

Nisani R., Chemke J., Cohen-Ankori H. und Nissim F. (1981). Neural tube defects in trisomy 18, Prenat Diagn 1: 227-231.

Niswander L., Tickle C., Vogel A., Booth I. und Martin G.R. (1993). FGF-4 replaces the apical ectodermal ridge and directs outgrowth and patterning of the limb, Cell 75: 579-587.

Niswander L., Tickle C., Vogel A. und Martin G. (1994). Function of FGF-4 in limb development, Mol Reprod Dev 39: 83-88; discussion 88-89.

Norman M., Mc Gillivray B., Kalousek D., Hill A. und Poskitt K. (1995). Congenital Malformations of the Brain - Pathological, Embryological, Clinical and Genetic Aspects, Oxford University Press, New York, USA.

Nüsslein-Volhard C., Wieschaus E. und Kluding H. (1984). Mutations affecting the pattern of the larval cuticle in Drosophila melanogaster. - I. Zygotic loci on the second chromosome, Roux's Arch. Dev. Biol. 193: 267-282.

O'Callaghan M. und Young I.D. (1990). The Townes-Brocks syndrome, J Med Genet 27: 457-461.

Ohlmeyer J.T. und Kalderon D. (1998). Hedgehog stimulates maturation of Cubitus interruptus into a labile transcriptional activator, Nature 396: 749-753.

Onuma Y., Nishinakamura R., Takahashi S., Yokota T. und Asashima M. (1999). Molecular cloning of a novel Xenopus spalt gene (Xsal-3), Biochem Biophys Res Commun 264: 151-156.

Ott T. (1995). Isolierung und Charakterisierung eines zum Drosophila spalt-Gen homologen Gens der Maus, Naturwiss.-math. diss., Heidelberg.

Ott T., Kaestner K.H., Monaghan A.P. und Schütz G. (1996). The mouse homolog of the region specific homeotic gene spalt of Drosophila is expressed in the developing nervous system and in mesoderm-derived structures, Mech Dev 56: 117-128. 
Ott T., Parrish M., Bond K., Schwaeger-Nickolenko A. und Monaghan A.P. (2001). A new member of the spalt like zinc finger protein family, Msal-3, is expressed in the CNS and sites of epithelial/mesenchymal interaction, Mech Dev 101: 203207.

Pieler T. und Theunissen O. (1993). TFIIIA: nine fingers-three hands?, Trends Biochem Sci 18: 226-230.

Pinkel D., Straume T. und Gray J.W. (1986). Cytogenetic analysis using quantitative, high-sensitivity, fluorescence hybridization, Proc Natl Acad Sci U S A 83: 2934-2938.

Piscione T.D. und Rosenblum N.D. (1999). The malformed kidney: disruption of glomerular and tubular development, Clin Genet 56: 341-356.

Powell C.M. und Michaelis R.C. (1999). Townes-Brocks syndrome, J Med Genet 36: 89-93.

Rapp G., Klaudiny J., Hagendorff G., Luck M.R. und Scheit K.H. (1989). Complete sequence of the coding region of human elongation factor 2 (EF-2) by enzymatic amplification of cDNA from human ovarian granulosa cells., Biol Chem Hoppe Seyler 370: 1071-1075.

Riddle R.D., Johnson R.L., Laufer E. und Tabin C. (1993). Sonic hedgehog mediates the polarizing activity of the ZPA, Cell 75: 1401-1416.

Rieger L. (2001). Mündliche Mitteilung.

Rigby P.W., Dieckmann M., Rhodes C. und Berg P. (1977). Labeling deoxyribonucleic acid to high specific activity in vitro by nick translation with DNA polymerase I, J Mol Biol 113: 237-251.

Roessler E., Belloni E., Gaudenz K., Jay P., Berta P., Scherer S., Tsui L. und Muenke M. (1996). Mutations in the human Sonic Hedgehog gene cause holoprosencephaly, Nat Genet 14: 357-360.

Rojo S., Stebbins C.C., Peterson M.E., Dombrowicz D., Wagtmann N. und Long E.O. (2000). Natural killer cells and mast cells from gp49B null mutant mice are functional, Mol Cell Biol 20: 7178-7182.

Rossmiller D.R. und Pasic T.R. (1994). Hearing loss in Townes-Brocks syndrome, Otolaryngol Head Neck Surg 111: 175-180.

Rudelli R. (1987). Anencephalic phenotype in the 13q-syndrome, Arch Pahol Lab Med 111: 896-897. 
Rusten T.E., Cantera R., Urban J., Technau G., Kafatos F.C. und Barrio R. (2001). Spalt modifies EGFR-mediated induction of chordotonal precursors in the embryonic PNS of Drosophila promoting the development of oenocytes, Development 128: $711-722$.

Said K., Jaqart T., Montgelard C., Sonjaya H., Helal A.N. und Britton-Davidian J. (1986). Robertsonian house mouse population in Tunisia: a karyological and biochemical study, Genetica 68: 151-156.

Saiki R.K., Gelfand D.H., Stoffel S., Scharf S.J., Higuchi R., Horn G.T., Mullis K.B. und Erlich H.A. (1988). Primer directed enzymatic amplification of DNA with a thermostable DNA polymerase, Science 239: 487-491.

Salinovich O. und Montelaro R.C. (1986). Reversible staining and peptide mapping of proteins transferred to nitrocellulose after separation by sodium dodecylsulfatepolyacrylamide gel electrophoresis, Anal Biochem 156: 341-347.

Sambrook J., Fritsch E.F. und Maniatis T. (1989). Molecular cloning: a laboratory manual, 2nd Edn., Cold Spring Harbor Laboratory Press, Cold Spring Harbor, NY.

Sanger F., Nicklen S. und Coulson A.R. (1977). DNA sequencing with the chain terminating inhibitors, Proc Natl Acad Sci U S A 74: 5463-5467.

Sanyanusin P., McNoe L.A., Sullivan M.J., Weaver R.G. und Eccles M.R. (1995). Mutation of PAX2 in two siblings with renal-coloboma syndrome, Hum Mol Genet 4: $2183-2184$.

Sasaki H., Nishizaki Y., Hui C., Nakafuku M. und Kondoh H. (1999). Regulation of Gli2 and Gli3 activities by an amino-terminal repression domain: implication of Gli2 and Gli3 as primary mediators of Shh signaling, Development 126: 3915-3924.

Saunders J.W. und Fallon F. (1966). Cell death in morphogenesis, Major problems in developmental biology. (Hrsg. Locke M.), Academic Press, New York, 298-314.

Saunders J.W. und Gasseling M.T. (1968). Ectodermal-mesodermal interactions in the origin of limb symmetry., Epithelial-Mesenchymal Interactions. (Hrsg. R. F. und R.E. B.), Williams \& Wilkins, Baltimore, 78-97.

Schmidt T.G. und Skerra A. (1993). The random peptide library-assisted engineering of a $\mathrm{C}$-terminal affinity peptide, useful for the detection and purification of a functional Ig Fv fragment, Protein Eng 6: 109-122.

Schoenwolf G.C. (1991). Cell movements driving neurulation in avian embryos, Development Suppl: 157-168.

Schoenwolf G.C. und Smith J.L. (1990). Mechanisms of neurulation: traditional viewpoint and recent advances, Development 109: 243-270. 
Schuh R., Aicher W., Gaul U., Côté S., Preiss A., Maier D., Seifert E., Nauber U., Schröder C., Kremler R. und Jäckle H. (1986). A conserved family of nuclear proteins containing structural elements of the finger protein encoded by Krüppel, a Drosophila segmentation gene, Cell 47: 1025-1032.

Schwabe J.W., Rodriguez-Esteban C. und Izpisua Belmonte J.C. (1998). Limbs are moving: where are they going?, Trends Genet 14: 229-235.

Scotting P.J. und Rex M. (1996). Transcription factors in early development of the central nervous system, Neuropathol Appl Neurobiol 22: 469-481.

Simeone A. (2000). Positioning the isthmic organizer where Otx2 and Gbx2 meet, Trends Genet 16: 237-240.

Singer N., Gersen S. und Warburton D. (1987). The value of chromosome analysis in cases of neural tube defects: A case of anencephaly associated with fetal dup (2) (p24-pter), Prenat Diagn 7: 567-571.

Smith J.L. und Schoenwolf G.C. (1991). Further evidence of extrinsic forces in bending of the neural plate, J Comp Neurol 307: 225-236.

Southern E.M. (1975). Detection of specific sequences among DNA fragments separated by gel electrophoresis, J Mol Biol 98: 503-517.

Stone D.M., Hynes M., Armanini M., Swanson T.A., Gu Q., Johnson R.L., Scott M.P., Pennica D., Goddard A., Phillips H., Noll M., Hooper J.E., de Sauvage F. und Rosenthal A. (1996). The tumour-suppressor gene patched encodes a candidate receptor for Sonic hedgehog, Nature 384: 129-134.

van Straaten H.W., Hekking J.W., Consten C. und Copp A.J. (1993). Intrinsic and extrinsic factors in the mechanism of neurulation: effect of curvature of the body axis on closure of the posterior neuropore, Development 117: 1163-1172.

Strachan T. und Read A.P. (1994). PAX Genes, Curr Opin Genet Dev 4: 427-438.

Strachan T. und Read A.P. (1996). Molekulare Humangenetik, Spektrum Akademischer Verlag Gmbh, Heidelberg.

Sturtevant M.A., Biehs B., Marin E. und Bier E. (1997). The spalt gene links the A/P compartment boundary to a linear adult structure in the Drosophila wing, Development 124: 21-32.

Suda Y., Nakabayashi J., Matsuo I. und Aizawa S. (1999). Functional equivalency between Otx2 and Otx1 in development of the rostral head, Development 126: 743-757.

Summerbell D. (1979). The zone of polarizing activity: evidence for a role in normal chick limb morphogenesis, J Embryol Exp Morphol 50: 217-233. 
Summerbell D., Lewis J.H. und Wolpert L. (1973). Positional information in chick limb morphogenesis, Nature 244: 492-496.

Tabata T. und Kornberg T.B. (1994). Hedgehog is a signaling protein with a key role in patterning Drosophila imaginal discs, Cell 76: 89-102.

Theunissen O., Rudt F., Guddat U., Mentzel H. und Pieler T. (1993). RNA and DNA binding zinc fingers in Xenopus TFIIIA, Cell 71: 679-690.

Tickle C. (1995). Vertebrate limb development, Curr Opin Genet Dev 5: 478-484.

Tickle C. (1996). Genetics and limb development, Dev Genet 19: 1-8.

Tickle C., Summerbell D. und Wolpert L. (1975). Positional signalling and specification of digits in chick limb morphogenesis, Nature 254: 199-202.

Torres M. und Giraldez F. (1998). The development of the vertebrate inner ear, Mech Dev 71: 5-21.

Torres M., Gomez-Pardo E., Dressler G.R. und Gruss P. (1995). Pax-2 controls multiple steps of urogenital development, Development 121: 4057-4065.

Townes P.L. und Brocks E.R. (1972). Hereditary syndrome of imperforate anus with hand, foot and ear anomalies, J Pediatr 8: 321-326.

Vainio S. und Muller U. (1997). Inductive tissue interactions, cell signaling, and the control of kidney organogenesis, Cell 90: 975-978.

Van Allen M.I., Kalousek D.K., Chernoff G.F., Juriloff D., Harris M., McGillivray B.C., Yong S.L., Langlois S., MacLeod P.M., Chitayat D. und et al. (1993). Evidence for multi-site closure of the neural tube in humans, Am J Med Genet 47: 723-743.

Vogelstein B. und Gillespie D. (1979). Preparative and analytical purification of DNA from agarose, Proc Natl Acad Sci U S A 76: 615-619.

Wang B., Fallon J.F. und Beachy P.A. (2000). Hedgehog-regulated processing of Gli3 produces an anterior/posterior repressor gradient in the developing vertebrate limb, Cell 100: 423-434.

Wassef M. und Joyner A.L. (1997). Early mesencephalon/metencephalon patterning and development of the cerebellum, Perspect Dev Neurobiol 5: 3-16.

Wischermann A. und Holschneider A.M. (1997). Townes-Brocks-Syndrom, Monatsschr Kinderheilkd 145: 382-386.

Yamaguchi T.P., Bradley A., McMahon A.P. und Jones S. (1999). A Wnt5a pathway underlies outgrowth of multiple structures in the vertebrate embryo, Development 126: 1211-1223. 
Yang Y., Drossopoulou G., Chuang P.T., Duprez D., Marti E., Bumcrot D., Vargesson N., Clarke J., Niswander L., McMahon A. und Tickle C. (1997). Relationship between dose, distance and time in Sonic Hedgehog-mediated regulation of anteroposterior polarity in the chick limb, Development 124: 4393-4404.

Zardoya R., Abouheif E. und Meyer A. (1996). Evolutionary analyses of hedgehog and Hoxd-10 genes in fish species closely related to the zebrafish, Proc Natl Acad Sci U S A 93: 13036-13041.

Zörnig M., Klett C., Loav H., Hameister H., Winking H., Adolph S. und Möroy T. (1995). Establishment of permanent wild-mouse cell lines with readily identifiable marker chromosomes., Cytogenet Cell Genet 71: 37-40.

Zumel R., Darnaude M., Delicado A., Diaz de Bustamante A., de Torres M. und Lopez Pajares I. (1989). Trisomy 20p from maternal translocation and anencephaly. Case report and genetic review, Ann Génét 32: 247-249. 


\section{Anhang}

\begin{tabular}{lc}
\hline Gen & Genbank-Zugangsnummer \\
\hline Sall1 & NM021390 \\
Sall2 & AJ007396 \\
Sall3 & X97581 \\
SALL1 & NM002968 \\
SALL2 & X98834 \\
SALL3 & AJ007421 \\
Csal1 & AF288697 \\
Csal2 & AF304358 \\
Xsal-1 & L46583 \\
Xsal-3 & AB030827 \\
Medaka-sal & U77376 \\
\hline
\end{tabular}

Tabelle A.1: Genbank-Zugangsnummern der verglichenen sal-ähnlichen Gene von Vertebraten. Diese Nummern werden von der genebank-Datenbank als accession numbers vergeben. Die Datenbank ist über die entsprechenden www Server (z. B. NCBI Blast Notebook, http://www.ncbi.nlm.nih/) zugänglich. 
1 tagtaattt ttattctgce ccagctgatg tttgagcCAG CATGTCGCGG AGGAAGCAAG

61 CGAAGCCTCA ACATTTCCAA TCCGACCCCG AAGTGGCCTC GCTCCCCCGG CGAGATGgt 121 agtgctocgg ogcogcggac acacagacac gcactcacac gcacactogg accoacgcac

181 acgcggeggg cccogcgcoc accgccgett tcgcettctg cactcogcgc gtctgattt

241 attcatgct tcctcgatt aattgccgg gccaggctcc cctgtcccgg gagagccagc

301 ctatcccggc tggagctttc cggagttccg tgtcctcgac tgggcggagt agggtcgact

361 ggccggctcg ctcotcogcc cagagggtcg gaggagcogc goccacgacc atgccgcccc

421 gagoggogat ctotcggoca gaggcoatct goagctgcoc acgogagoto totcocgcto

481 cccgcgcgcc acccgggtcc ccgggctggg cctctgtcgc ctgggcctca ccgcccagce

541 ctgcggccaa cgttaagaa gtttacttcg tccgggtggc tgaacgccga gcgcatgggg

601 aactctccgt acccaccccc ccaaactctc gttcccactt ggctagcggg cgaaatatgg

661 taccttggg ggttccgagc cgtgagaact gggggttggg gtggaggagc gacatcctgg

721 ggtcgcggce gagtgctgce ggtcgctetg gagactgget tagggacagg gaagtgtcgc

781 ttggtccggc ttcccaagtt tgttctcctg tcgtttcttt ccacacttgc acccataacc

841 cgtcaaagtc gggcttggat gtgtgcaccc cacgtattat ggagtcccat cettcgggac

901 ccgttctggt aagggtcatt agacactttc ttgggtcccg ggtattagco cgccagacco

961 ctggagccag ccgagcaatg aaggcagggt tccgaagga ctgaatgagt agggaaagt

1021 ttgtgtgcgg gaactgtggc ctagaatggg agagacccgc gcagggaact ggggtcactg

1081 agggaagacc cccetccgac cccagcttga cctgaactgt tctagggcag agtttccgag

1141 ctccoaggco agaggctacg ctcggttocg gggtcaccgg actttgtgoc tgactctcog

1201 ctgcgtaggt tggagagtga ccagaccoga ggctoggcgg coccggctgc cottogggaa

1261 tccctcgatc ccgggcgtgg aggaaggagc tgcaccccag cagagctcgg aagcgtgacc

1321 tgagatccgc acctctggcc actacgctct gegggegctg gagccccaca tctgcaggct

1381 ccgtccccag aggcctggct ctgagcggct ctgggtgcgg gtacgcgcag gcagagccag

1441 agcgacaagg gatcgacagc ttacttcctc ctcgctgttg ggagagggca atcotggcgt

1501 gagacacctg gacattttt caggcgatct gagagccatt aaggcactgt tttgcccagc

1561 acctttgaaa gctgaagcct caccagtgtg attctctgag tcctctggaa ggatcccttg

1621 aaacacaccc agtttcccac cccaaagaa ccggtttgag ggtaaacca gatgaatta

1681 gccaaggceg cagcaaccac tcggactatt tttgtggggt ttctcagcta gtttcttagg

1741 ctttctgccg cccccacaac aatctttcct aaggtgaggc ctttgcaccg ggatgctgtt

1801 aaacttaac aatttgcata cgggggtggg ggtgggagaa aacaacctg gggaa aaga

1861 ggtgtttttt ggtttttgtt ttttaaattt atactggttg tttgtatttt ccacgcaaag

1921 aatttcaaaa ctaacaacca ccacctcgag cttcggaaga aagaccctt gctagttctt

1981 cgcttgagt ctagagctgg aattttaat agttaaggct totcataag cgatagcatt

2041 aaggagttc actgcctct actattatta tttattagta catttttt ttagtttatt

2101 tgagcttga ggtaagttaa ttagggact gaatcaagtt tccttcttt ctttccttc

2161 ttttttca cttaattct cotttttct tcctaaagc tggttcattg tcgacaago

2221 agtgattatc ccgaacaccc taggaacac ccctcccagg ccagctcct actccctcct

2281 tttcttcagt agtaatagt ttagottatg actotttta catgoctgaa caataagtt

2341 gggagaagtt gcctagaggg caggtttgt aatagggtta caggatttag tgtgctgtaa

2401 tagtactcta cacaagcagc cctccccagc agctgacagt caggagggcc cgccataccc

2461 cgaatcttt catttgggaa tagttgtgag agacatacag aggaaagtgc atgacacagc

2521 tcacgtttge ttttaaag tcgactcttc tgcaacgagt ccagccatct ccatccatt

2581 ccctacccag aacagaacat gtgcctgagg agccgctgct gttgggcgtt tggtgggtt

2641 tttgtttttg tttttgtttt tttttacttt ggagggcaac cccttactca gatgccagct

2701 ttacactttc tcttgtctca agagggtctt actacacaca gcatatgaa tatcaggcat

2761 taccaaagta gatcttgtt agacccttcc cctcccttg ttgtccccca gactgtctga

2821 cttctacaca gaggaaacc ttagaaagt tttcagagcc acagtggcoc tgaagcagco

2881 tctctaattc tatgttctgt ggccccatcc tgtagtatgt gtcgtgtttg agttttacaa

2941 agaagotac gccttgctaa gcaccagtcc caacacctcc attcaattt taaaaaaat

3001 gattatttag ttgatcttag aagttaatct tagaaccttg atagtttatt ctactgagt

3061 attcctataa ggtattttc tgttccttat gaaactggg attgtggtga gtagggttca

3121 tctcttaaa gatattcaac aagtctccag ttacttgtag agagataagt agccttggaa

3181 gaattattta ccatgatgga taatcctgg aaagggat gtgcaaatct aatgattta

3241 tttgtggtta cttttctt gagtttggat ttccaggtgc gtgcetgtgt gtgtgtgtgt

3301 gtgtgtctgt gtgtctgtgt gtgtgtgtgt gtgtgtgtgt gtgtgtgtgt ctgtgtgtgt

3361 gtgtgtgtat ctgtgtgtgt gtgtctgtgt gtgtgtctgt gtgtgtgttg ggtttttgg

3421 tgggttggtt cactccatt ggtggtgatg gttcaagat tcctgcagct tctgacaggc

3481 cccattccga ctccattcgt ttaacaatt tgctgctcag ettttaaag gaaggataa

3541 tgttggaaga aacttagaac atcgggatt acagagaag cattgactct cotalggat

60

120

180

240

300

360

420

480

540

600

660

720

780

840

900

960

1020

1080

1140

1200

1260

1320

1380

1440

1500

1560

1620

1680

1740

1800

1860

1920

1980

2040

2100

2160

2220

2280

2340

2400

2460

2520

2580

2640

2700

2760

2820

2880

2940

3000

3060

3120

3180

3240

3300

3360

3420

3480

3540

3600 
3601 acctgaaac cccttcttac tcatattaat aagaaattc tattatttac caagtaatt 3661 tactcattgt aagcagctta atggccacac attgatttct gggcccaaaa ggttagagaa

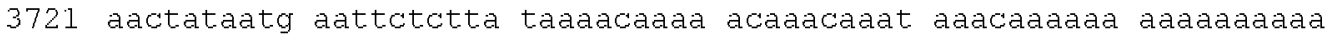
3781 a acaagaaa gaaccotgac acctgcaaga taaggcagtt ggaagaatt catgtttcat 3841 caagcccatt tttaagtttg gcataataga agattctaga tgagaaatg tgaactgttt 3901 tttggtcttg ttttgttttg ttgcgatttg cttcaggctg caatacttt ctaaatgtta 3961 aaaacaagc acccgggaa gcctgctgag gcaggagata aactgggaag gtagctttc 4021 ggcattgagc aattgttggt gtatttaca tccagtttct gcaatggctc agggcacaag 4081 taccaaatta tagggtgctg tttgggaaac cgtttcttt ctctaaggtt ggagacttct 4141 agttgtcttt ttaccaacaa tatccttcag aaggcaaag cccacatttt tctggtagcg 4201 aatctggagg gcgatgggag gagggaattc aggcaggttc cgggtttcaa aacttagcca 4261 agctcactca gtgtgaagta accagaaaa aatcgaatt ettctgcagc ttaatgtgt 4321 ttttttccaa cacagtccct agtgcagaa acctgtgttc taaatattc tttgaggaga 4381 gaagagaat attaacctga ggcttgacac tcctccccca agaaggaaaa aaagttggtg

4441 tgccaggctt tagaaacct ggacgtgtag agctgtttta acctttgcca gcctcctccc

4501 atgcagaggt gacaaggtcc agatcataat gtgtccttca gtgtcttccc ggtgaccccc

4561 aattgagtc ttgctagtca cttagcagga acttggtagt ttatttagt ttctcctat

4621 cagcttggct tetttecta accttattcc cccgccaccc cccagatgcc agacccccaa

4681 aggggaagat tgacaggtag ttcccacggc tcagcttcac cctccaacaa cagggattta

4741 gtttcttgtg acttgccaa tgtttgtgta gtcagtgtt agatctcgcc ttaaggagto

4801 totctttac gogtcactgg aataggaag ccacagagta gtttgtgaac aaccottgo

4861 tgttggatcc ccatctagtg ttcactttaa ttctccatag ggaagacatt ttcccctca

4921 ttgtgagccg gaggtgggtc tggaccagaa ctttaaatgg agtatcttgt ccatgttatt

4981 tttttccag agggtttct tgtctcctc cacacaatca gggctggcac tgtaaactg

5041 aaggggacca gttcatttgt catttggttg tatgctgcat aaaggaact tcagacatta

5101 cagaaatat gcgcagcata tgttgtattt acagctttt ttttttctgg aaccttaagt

5161 tggacattcg gatcctgctt ttaaaaata aacataaa agataaagca cactcaatca

5221 aatatgttca tgatcgcctc tgcaagcagg cotgtgggaa ggaacagcet gttaaatta

5281 ggggcccca gtccactatt gtttgagttc tattaagaa tgctaatgta gtcttaaggt

5341 actggcaagt agtgttaagt gtctttctga ggcgctccca aagagaaaac taaatctggt

5401 agagcctggt ggttggtttc tactttttg ttttgttttg ettrgetttg ttttctgtt

5461 tgttttgtt ttcccctcet cttctctcet ggctggctga acctttctgt gegaggcata

5521 gttttatat ttttgcttc tgagtagaga ggctgcaacg cttcgttttc ctgcttccaa

5581 attctgctgt gtttggttaa gaggataaa agtgacaat ttgaattggg tacctagata

5641 gttcagccag agcttaaca totggaatt aagtgacaat ttggtaatga ttcaacatct

5701 ccttcaaaa aagaacagaa attctaagca tctttgggg gggttgctga ggggaaaaa

5761 gggctcttgc tttgtaalg ttcctatctg gctggaatta cgagatttgt gtgaatgcaa

5821 aatccataga aagaatctg gaatgtgatt tcactacaa taggaggaac aagggaactg

5881 tagttactaa aaggagotca ccagttgoca tcctotgtaa cagattatt aagagatac

5941 aagaacacag ggctctgtgt gtgtgtgtgt gtgtgtgtgt gtgtgtgtgt gttctgcct

6001 gctcgttatc taattgtaac ttttagtcat tcctttagt aactgggcta aagatccatg

6061 ctggtttccc tggaattctg ttcaccatgc agaatggttt aagttaggc actgtagagt

6121 gtagcaacac ctgettctga gocgaatcaa aatagatgcc aggatttggg agggagcaga

6181 ttgttcataa acatcaggaa attaattag otgatggtac agtgcgatca aatgtcagct

6241 tgctaaattg tgaaatcga agctcaata tggccaactt ttataaaggg tctctctctc

6301 tctctctctc tctctctctc tctctctctc tctctcaaaa gcaagcaggc atttattct

6361 aagcgtett atttccatc taattagcat aatcctaat ataaaatgt tcaggtagaa

6421 aacttaaa attctctca gtgagtcttg aagcggcacg a atgcaaac cocagtgcag

6481 ggaagtagaa atcagtgtaa ccttcgaag taacctagct tttattttt ttctatatat

6541 tatgagaata tcagatgttt gcaagttata aagaattaaa atgcccttta accgtgagca

6601 cagatgtgct aaatattga agcaaccaca ttgtaatgtg tacaattgat gaagtcagtt

6661 ttctgatttc cottgctggt tattagtto tgatctgtc attatttgtc taagccoagc

6721 tgaccaagca aaactgtgtt ttaagtggc tttatgttt gataaatgtg agctggttga

6781 aaggtattt ccactgaatg cagagcttaa tagaacatgc tgacataata gttttaatgc

6841 atttgttga aatgtgtga acaacagaa tagctttgt toctcataa ttggctgtaa

6901 aagtagatgg aacatagcc attacatatg gaatgtgca agagaaga aataacatt

6961 ctgttgaata tattaggaat tgcatttcct agtttaaat aggcatctga aatgggggat

7021 catttaaat cagttgtcaa aatacgaagc tttacactga atttttgtca catcatttt

7081 ttttgtcce gcgtgaggca ggataactt agcaatttc atttaatatt ttgtttgtag

7141 tatttcaagt caggagaaga gacagaagt gcttaaaaca gcaccttcag cgagcatggg

3660

3720

3780

3840

3900

3960

4020

4080

4140

4200

4260

4320

4380

4440

4500

4560

4620

4680

4740

4800

4860

4920

4980

5040

5100

5160

5220

5280

5340

5400

5460

5520

5580

5640

5700

5760

5820

5880

5940

6000

6060

6120

6180

6240

6300

6360

6420

6480

6540

6600

6660

6720

6780

6840

6900

6960

7020

7080

7140

7200 
7201 aatctggtgc caattaggat gattaaacat taattaaa ctggatcatt attggtattt

7261 tctgctacaa ctgcgatttg tttggtgttg ttaatgcatg ttgcactata accccgtgta

7321 gatttaaga tggggattag gaa getggc ttattaa ata taactcagcc actaaacta

7381 tgccagtgag gagagtgcac gcgtcccctc tctcctctgg ccagcagact ttaccagggg

7441 ccctatcaa ctcctcatc actccaggca gatagagtta aggaattca cagtgacta

7501 tttaggtgtt aattgtattt tctgaaatgc aaactcttc cgagctttt agatgcttaa

7561 tccaaagga taacctctgg ctcttctgaa tgtgctctgg gttgactggg attcotgggg

7621 taggcagcat tttgatttc catgtattca tatctgcaat tactttttt ttccctcctg

7681 caagtttct agagattca atttggagt catggaact acctattatc tgattcagct

7741 ctgtagaaaa gcatgcgggg aggcaatcct tgaattaaac agtttttttt ttttcacagc

7801 ctttggagat gaccacacac accattcgta caacaggagc tggtgttccc catgctgagc

7861 aaacaagggg acgccattct gtcttgat aggatgttag ettggagttg gagatttgat

7921 gtttaattta caatggatc ttagtgagaa gacatctgag caaccagtaa agccaacaa

7981 tcaagggata tgaataggga gatggatgga tggatggatg gatggatgga tggatggatg

8041 gatgtgtgtg tgtgggtgtg tgtgggtgtg tgtgtgatgt atatgtatat gtatatgtat

8101 atgcaatgta ttcaggacaa tctgttagac aatcgataac accaaaggc aagtattt

8161 taaggcatt cagacaaga tttccaact ctcccctggg tgggcatgat ttcttaagga

8221 agggaggace tctcagcacc ttcttcttca gctagcattt agcagaactg tagatgccac

8281 gccaatttt agagacagaa agaccactt tgaggattat ttagaaccta gccacgtgga

8341 gcatggtggc atatattct tacotaggag aatgtagcag cagagctcaa toctgatt

8401 gaaaattca cgtotggggg gggggtgata cataggtacc agacaggcot gtgagggata

8461 accatcctgc attctttca tttgcctgt gagggtgttg ctttctggtt tgaagtcgaa

8521 acgggtctgt tactgattgg actgaactgt gtttgtcacc actgggcccc caagctcagg

8581 atccaggcag ggacttgagg tgattctgaa gtcatcagtc cccagctggg tgatatgcat

8641 tttcccccct tgtcaacaac tgattggaac ctgaacgact acaaattagt ttagtgacag

8701 aacagactgt cacagatatc tttgcatcag ttgaaatga ataaggttga cagaactca

8761 agagcctaat aagtcctcag tgtgctggag ggaccctctc ccggcaagta gacaatcggt

8821 gtataaata ttggaatca atatttgct atggaatttc attatgtacc aatgtccaco

8881 cttcatggta ttttatatt tgatgaatta tctaaggcc ttaactatcc aaataccag

8941 ctagtcagga gttcctcggc atcccaggaa atacagcctg gctttggggg ggtcacattt

9001 ggagtttage agatagaag catttatgge cettctatc aatttcalgt cattactgac

9061 agtetgtect cgettcact ttaaccetge acctttgat gtttgtagGG GACACAGAGA

9121 AGGGTCAACC AAGTCGCCCC ACTAAGAGCA AGGATGCCCA TGTCTGTGGC CGGTGCTGCG

9181 CTGAATTCTT TGAATTATCA GACCTTCTGC TCCATAAAAA GAGCTGCACT AAAAATCAAT

9241 TAGTTTTGAT TGTCAATGAA AGTCCAGCCT CCCCAGCAAA AACCTTCCCT CCTGGCCCGT

9301 CTCTCAATGA TCCCGATGAC CAAATGAAAG ACGCGGCGAA TAAAGCAGAC CAAGAAGACT

9361 GCAGCGACCT TTCAGAACCC AAGGGGCTTG ACAGGGAAGA GTCCATGGAG GTGGAGGTCC

9421 CAGTTGCCAC CACCACCACC ACCACCACTG GCGGCAGCGG CGGGAGTGGT GGCAGCACTC

9481 TGAGCGGTGT CACCAACATC ACCACCCCGA GCTGCCACAG CGGCTGTTCC TCGGGTACCT

9541 CAGCGATCAC AACCTCTCTA CCTCAACTGG GGGACCTGAC GACACTGGGC AACTTCTCGG

9601 TGATCAACAG CAACGTCATC ATTGAGAATC TCCAGAGCAC CAAGGTAGCG GTGGCCCAGT

9661 TCTCCCAGGA GGCGAGGTGT GGGGGGGCCT CCGGAGGCAA GCTGCTCATC TCAACCCTCA

9721 TGGAACAACT CCTGGCTCTG CAGCAGCAGC AGATTCACCA GCTGCAGCTC ATAGAGCARA

9781 TACGTCACCA AATACTGCTG CTGGCCTCTC AGAGCGCAGA CCTGCCGGCA GCACCCTCTA

9841 TCCCGTCTCA AGGTACTCTG CGAACATCTG CCAACCCCTT GACCACACTG AGCTCCCATC

9901 TGTCTCAACA GCTGGCGGTG GCAGCTGGAT TAGCACAGAG CCTTGCTAGC CAATCTGCCA

9961 ACATCAGCGG TGTGAAGCAG CTTCCCCACG TCCAGCTACC TCAGAGCAGC TCCGGCACCT

10021 CCATCGTCCC GCCCAGTGGT GGCACTTCTC CCAACATGAG CATAGTGACG GCTGCAGTGC

10081 CCACCCCGTC CTCAGAAAAA GTGGCTTCCA ATGCTGGTGC CTCCCATGTC AGCTCCCCGG

10141 CCGTCTCAGC ATCGTCCTCA CCAGCATTCG CAATAAGCAG TCTGTTGAGT CCTGAATCTA

10201 ACCCACTTCT ACCTCAGCCG ACCCCAGCTA ACGCTGTTTT CCCTACCCCT TTGCCTAACA

10261 TTGCAACAAC CGCAGAAGAT TTGAACTCCC TGTCTGCCTT GGCCCAGCAA AGAAAAAGCA

10321 AGCCACCAAA TGTCACTGCC TTTGAAGCGA AAAGTACTTC AGACGAGGCG TTCTTTAAAC

10381 ACAAGTGCAG GTTCTGTGCG AAGGTCTTCG GGAGCGACAG TGCCTTGCAG ATCCACTTGC

10441 GCTCCCATAC TGGAGAGAGG CCGTTCAAGT GCAACATCTG TGGGAACAGG TTCTCTACTA

10501 AGGGCAATCT GAAAGTCCAC TTTCAGCGCC ACAAAGAGAA GTACCCCCAC ATCCAGATGA

10561 ACCCCTACCC TGTACCGGAG CACTTGGACA ATGTCCCCAC GAGCACCGGC ATTCCCTACG

10621 GCATGTCCAT CCCTTCAGAG AAGCCAGTTA CCAGCTGTCT AGACACCAAG CCAGTCCTGC

10681 CCACTCTGAC CACTTCCGTC GGCCTACCAT TGCCTCCAAC TCTCCCAAGC CTCACGCCCT

10741 TCATCAAGAC GGAAGAGCCA GCCCCCATCC CTATTAGCCA TTCTGCTGCC AGTCCCCAAG

7260

7320

7380

7440

7500

7560

7620

7680

7740

7800

7860

7920

7980

8040

8100

8160

8220

8280

8340

8400

8460

8520

8580

8640

8700

8760

8820

8880

8940

9000

9060

9120

9180

9240

9300

9360

9420

9480

9540

9600

9660

9720

9780

9840

9900

9960

10020

10080

10140

10200

10260

10320

10380

10440

10500

10560

10620

10680

10740

10800 
10801 GCTCAGTCAA AAGTGACTCT GGGGCCCCTG ATTTGGCCAC AAGAAACCCA AGCGGCGTCC 10861 CCGAGGAAGT GGAAGGGTCT GCTGTGCCAC CCTTTGGTGG CAAGGGTGAA GAGAGTAACA 10921 TGGCAAGCTC CGCCGTCCCG ACAGCGGGCA ACAGTACTCT GAACTCCCCA GTGGCTGACG 10981 GTGGTCCAGG AGGGACCACC TTCACCAACC CTCTGTTGCC CCTCATGTCT GAGCAGTTCA 11041 AGGCCAAGTT TCCTTTTGGG GGACTCTTAG ATTCTGCCCA GGCCTCAGAG ACATCCAAGC 11101 TGCAGCAACT GGTAGAAAAC ATTGACAAGA AGGCCACGGA TCCCAATGAG TGTATCATCT 11161 GCCACCGGGT TCTCAGCTGC CAGAGCGCCT TGAAAATGCA CTACCGGACA CACACTGGGG 11221 AGAGGCCCTT CAAGTGTAAG ATCTGCGGCC GGGCTTTCAC CACGAAAGGG AACCTCAAGA 11281 CCCATTACAG CGTCCATCGG GCTATGCCTC CACTCAGAGT CCAGCATTCC TGCCCCATCT 11341 GTCAGAAGAA GTTCACAAAC GCAGTGGTCC TCCAGCAGCA TATTCGTATG CACATGGGAG 11401 GCCAGATCCC CAACACCCCA GTCCCTGACA ACTACCCTGA GTCCATGGAG TCTGACACAG 11461 GCTCCTTTGA TGAGAAДAAT TTCGACGACT TAGACAACTT CTCAGATGAG AATATGGAAG 11521 AGTGTCCTGA GGGCAGCATC CCAGACACAC CCAAGTCAGC GGACGCTTCC CAAGATAGCC

11581 TGTCATCTTC GCCTCTGCCC CTCGAGATGT CGAGCATCGC TGCTCTGGAA AATCAGATGA

11641 AGATGATCAA TGCTGGCCTG GCGGAGCAGC TGCAGGCCAG CCTGAAGTCT GTGGAGAACG

11701 GATCCATGGA AGGGGATGTG CTGACCAACG ACTCTTCCTC AGTGGGTGGC GACATGGAGA

11761 GCCAGAGTGC AGGCAGCCCA GCCATCTCAG AGTCTACCTC TTCCATGCAG GCTCTGTCCC

11821 CGTCCAACAG CACCCAAGAA TTTCACAAGT CACCCGGCAT GGAGGAAAAG CCACAGCGAG

11881 TGGGGCCAGG CGAGTTCGCC AATGGTCTAT CTCCCACCCC AGTGAACGGA GGTGCTTTGG

11941 ACTTGACTTC TAGTCATGCA GAGAAAATCA TCAAAGAAGA TTCTCTGGGA ATCCTCTTTC

12001 CTTTCAGAGA CCGGGGTAAA TTTAAAAACA CTGCTTGCGA CATTTGTGGC AAGACCTTTG

12061 CTTGTCAGAG TGCCTTGGAC ATTCACTACA GAAGTCATAC CAAAGAGAGA CCGTTCATTT

12121 GCACAGTTTG CAATCGTGGC TTTTCCACAA AGGGTAATTT GAAGCAGCAC ATGTTGACAC

12181 ATCAGATGCG AGATCTGCCA TCGCAGCTCT TTGAGCCCAG TTCCAACCTC GGCCCCAATC

12241 AGAACTCTGC AGTGATTCCC GCCAACTCGC TGTCATCTCT CATCAAAACA GAGGTCAACG

12301 GCTTTGTACA CGTTTCTCCT CAGGACAGTA AGGACGCCCC CACTAGTCAT GTCCCTCAGG

12361 GGCCTCTGTC GTCCTCTGCG ACATCCCCAG TTCTGCTCCC AGCTCTGCCC CGGAGAACTC

12421 CCAAACAGCA CTATTGTAAC ACGTGTGGTA AAACCTTCTC TTCTTCGAGT GCCCTGCAGA

12481 TCCACGAGAG AACTCACACT GGAGAGAAGC CCTTTGCTTG CACTATCTGT GGAAGAGCAT

12541 TCACAACAAA AGGCAATCTG AAGgtaccaa atttattcaa ggcgttggga caggcagcaa

12601 gctacagget gccettgtcc ctgccatgat cotgacctca caaggctcet ccatgtctco

12661 ccacctcage tacgtggagc aggtcccett tccagaacct tctccctggc tacgcagctg

12721 agggctccag gaccatgtgc aatcatcaac caagggcatg gggaagggct gaggggcggt

12781 agggtgcggg cagagcgggt acctaagcga agcagcaggc ctcttctgc tgtctagct

12841 aagtgcatca aatgaattgc tttacctacc aatcagaca gcctggcgtt gccatggggt

12901 attgattaa gacctccgtg tggcctgcac actgcccata tcacttaata attacagctc

12961 tctacggctc tctcoggcgt atgcagctat ttttcataac cccagtctag catggtttat

13021 tttctagca acagtaacgt cactcctcac ctaatgggta ttatgataat tgattacacg

13081 acatttccta ctgatatgtg ttggaaatat agccaatat gcacggtcta gagcaacagt

13141 tgagcactct cgctgtgtac attttctgt tgacagagta ttcctcggga ggttgctgcc

13201 agtaatgtgg gatgaataat tactttctgg gtttttctct ctgcgcaagg ccctccaatg

13261 ggcaatcagt gagggttact ttcttcccat ctgaaagga catctacagg gtaaagagtg

13321 tcagatacaa tacttaccac tgcaatgaga gtggacataa cattctaac cetgcgagga

13381 getatctatg actgcetgge ttgcttgagg ccattataag ctaaatacag gtaataaaa

13441 cagagtaagt aaggcgagtt agccaggaag aagagagcca acccagcact gcagagagca

13501 aacacgttat tactagacca tgggagtgga tggttcctgg tgtcttttcc cctgtctgtc

13561 ctgtaataag aatagacatt cgggtcact gettgtcga gtgttgggat atgaagttga

13621 gacagaatc ggctattaag ctccctggct ctctcttgtt tetctctct cocccaacco

13681 acattacagG TCCACATGGG CACCCATATG TGGAACAGCA CCCCTGCACG CCGGGGCCGG

13741 CGGCTCTCAG TGGATGGCCC CATGACATTT CTAGGAGGCA ATCCTGTCAA GTTCCCAGAA

13801 ATGTTCCAGA AGGATCTAGC GGCGAGGTCA GGAAGCGGGG ATCCGTCCAG CTTTTGGAAC

13861 CAGTATACAG CAGCACTGTC CAACGGGCTG GCCATGAAGG CCAACGAGAT CTCTGTCATT

13921 CAGAACGGCG GCATCCCTCC AATTCCTGGA AGCCTGGGCA GTGGGAGCTC ACCTATCAGT

13981 GGGCTGACTG GGAACGTGGA AAAACTGGGC AATTCGGAAC CCAGTGCTCC TCTGGCTGGC

14041 CTGGAGAAAA TGGCGAGCAG CGAGAACGGA ACCAACTTCC GTTTCACCCG CTTCGTGGAG

14101 GACAGCAAAG AGATCGTCAC AAGCTAAAGC TGCCAGAGTG CTTCCTCTCA GAATGTCGCC

14161 CCGAGGTTGG CCTCCTGCCC CTCCCCCCGC CCTTTACCTT CTGGCCCCTG GGACTATGAA

14221 CTACACTATG AAGACATTCT TTTGTATGTT GTTCAACCTC TAGAGTTCTA AGAAAGCTTA

14281 TTTATTAGTG CTATAACCTT GCTTTGCAAA CAGAGTGCAG GCATTAACTT TGGTCTTCTG

14341 TATTTTGGAC TAAATACTAA TGGACTAGAG TGCTCCTAGC TTGCTGTAAC ATTTATGGCA

10860

10920

10980

11040

11100

11160

11220

11280

11340

11400

11460

11520

11580

11640

11700

11760

11820

11880

11940

12000

12060

12120

12180

12240

12300

12360

12420

12480

12540

12600

12660

12720

12780

12840

12900

12960

13020

13080

13140

13200

13260

13320

13380

13440

13500

13560

13620

13680

13740

13800

13860

13920

13980

14040

14100

14160

14220

14280

14340

14400 
14401 ATCGCAAGTT GCCCTGCTAG GCGGTCTTAA TCCGGCATTA ACTTATTTTC TATATCCAGT $14460^{\circ}$

14461 TTAATATGAA TCTGGTGTTT GATGCAATGC CTCCCGTGAT ACGTTAGATC TCTAATAAAG 14520

14521 TTGTATATAA ATGTACACTT TGATCCTGCT GGAAAATTTT ATCAGCGAAC ACATTGTCTA 14580

14581 ATCTTTCCAA ACAGATTTAA GGGAAGGACT TTAAGTACAG GCTGAACATT TGGAAGGCTT 14640

14641 AGGGTTTGTT GTTGTTGTTG TTTGTTTGTT TGTTTGTTTG TTTTGGTTTT GGTTTCATTT 14700

14701 TGATTCTAAA CTTCAACCTG CTTTTTTTTT TTTGGTTTTG TTTTAGAGAG TTAACCATTT 14760

14761 CCGTTTTGAA CTATTTGTAT TGTGCTTTTT ACTTGAGTCG TCTTCAATGT TAATACGTTT 14820

14821 TCTGTACAGT AATAAGCACG CAGAATTCTT TAGCAGGAAA AAAAAAACCA CAAGTGTTGT 14880

14881 TTTGGTAGTT GAAACTGAGA CGTAGCATTT TGGCCTTGTA GGGTATATTC ACAGTAGAAA 14940

14941 ACGTGTGCTG GAATTTCACA ATGCTGCTAA CGATAGCATC TTGAACGACC TTCAGTGGAG 15000

15001 AАATGTAGAT GCTCTTCTAT АTACAATAAG AAATATCACT TTCATTAAAA TGTACATATG 15060

15061 TTCCTTACAA GAGCAAATGC CTCTTGATCA AGAGCAGGTA TAGTGTTGGT TTATTTTGTA 15120

15121 TTAGGTATGG AAGGAAAAAA ATGGACTGTT ACATGCACTT TCTTGGAAAG TTGAAGGGGG 15180

15181 GGTTCCAATT TCTTTAACAT TTAATACTTA CTAACAACAG AGATACTGTA ATTTTACTCA 15240

15241 AGTAATCAAA TACAttttt ttgccacaga taacagagtg cttcctctca gaatgtcgcc 15300

15301 ccgaggttge etcctgccec tccccccgcc etttaccttc tggcecctgg gactatgaac 15360

15361 tacactatga agacattctt ttgtatgttg ttcaacctct agagttctaa gaagcttat 15420

15421 ttattagtgc tataaccttg ctttgcaaac agagtgcagg cattaacttt ggtcttctgt 15480

15481 attttggact aatactaat ggactagagt gctcctagct tgctgtaaca tttatggcaa 15540

15541 togcaagttg coctgctagg cggtcttaat coggcattaa cttattttct atatccagtt 15600

15601 taatatgaat ctggtgttga tgcaatgcet cogtgatacg ttagatctct aataagtct 15660

15661 gtatataat gtacactttg atcctgctgg aaaatttat cagcgaacac attgtctaat 15720

15721 cttccaaac agatttaagg gaaggactt aagtacaggc tgaacatttg gaaggcttag 15780

15781 ggtttgttgt tgttgttgtt tgttgttg ttgttgtt ttggtttgg tttcattttg 15840

15841 attctaact tcaacctgct ttttttttt tggtttgtt ttagagagtt aaccattcco 15900

15901 gtttgaact atttgtattg tgcttttac ttgagtcgtc ttcaatgtta atacgtttct 15960

15961 gtacagtaat aagcacgcag aattctttag caggaaaaa aaaccacaa gtgttgtttt 16020

16021 ggtagttgaa actgagacgt agcatttgg cotgtaggg tatattcaca gtagaaacg 16080

16081 tgtgctggaa ttcacaatg ctgctaacga tagcatcttg aacgaccttc agtggagaa 16140

16141 tgtagatgct cttctatata caataagaaa tatcactttc attaaaatgt acatatgttc 16200

16201 cttacaagag caatgcctc ttgatcaaga gcaggtatag tgttggttta ttttgtatta 16260

16261 ggtatggaag gaaaaatg gactgttaca tgcactttet tggaaagttg aagggggggt 16320

16321 tccaattct ttaacatte atacttacta acaacagaga tactgtaatt ttactcaagt 16380

16381 atcaatac atttttttg ccacagataa

16410

Abbildung A.1: Genomische Nukleotidsequenz des Sall1-Gens. Dargestellt ist der in der vorliegenden Arbeit sequenzierte Bereich des Sall1-Gens ohne regulatorische Regionen und Exon 1a. Die DNA-Sequenz des kodierenden Stranges der cDNA ist in Großbuchstaben angeführt, die intronische Sequenz in Kleinbuchstaben. Das Translationsstart- und Stoppkodon sowie die Exon/Intron-Übergänge sind durch Fettdruck hervorgehoben. Die Nummerierungen für die Nukleotidsequenz ist auf beiden Seiten angegeben. 
I aagctttata cacaatgag ggaactggct tatgctcaag cagtctgact tgggggaact

61 agcgacctta acaatactat aadccagtgc tagaactcat tagaccgata gacaataagg

121 aa accoaac tggaatgct gataatatt agaaatatc gtatagaatc tcaaactac

181 cagcttctca tctagaatat ccctcaacc tcaggctgcc aggaggatca aatagtgcca

241 gaggtggaaa aagtctcatt ttcctattgt gtatcattc cagtgccct gagtacctct

301 tcagggtctt ggaactaag tccttagtta catttccaa gaattagatc acagattgaa

361 ggagaagat tgctacactc atgtttect gtcacaggto tottccttt ttccatttot

421 atctctcot toattctto totcotgtco tttotttcot totccotoco tottcoccot

481 tcccctcccc tctccacttc accacacaca gaaatccctt ttgaagggg cttttttcc

541 aactcagtga agtaaagtct ttgccccttt gtggggaagg ctcattaaca ttccctcagc

601 agcatctct caaggattct acttttgtaa ttccgaaggg aggtcaagag gccacaatgg

661 agaggtaaa aagagaaaa aaatgtggt aadgaggagg aggtggaaga atggagagga

721 ggggaaagag accttcett cataataagg ccggcaaaa gagggaaat aggaaaagat

781 gaagatggce gagactcaaa aaaaagaca aatacgggtc cccaagtatg cccttttaga

841 tgtcacacag atgtctgaga aaagcagaat gctgtgtgtg tgctcttctt tttcttcctc

901 acgaagggaa taacggtgc aacaacagg aagagggtaa caggacacag tccattccet

961 tgaaagcta gaatcttcc tgcctcacct acaatgttcc actaaatat gtgttaaat

1021 gtgaggagcg ggacttcgaa aaacagagag tgaggcagcc gctcaggacc tgaaactaaa

1081 catctggtaa aatagcagag attctgggaa ctccacaaac ggggagcaat gagttgccaa

1141 acatctccac aagtggcatc ttcotcctco tcatgctag catcgcttot agcaccagct

1201 gcottcttc totttttag tattgtcac actagccogg acttgtcgag acaacagago

1261 tttgcatcat caacataaa ggaaaaata atgctttct aattggtgtt tcaaatgttg

1321 tcctgcctga gccagaagag aaaatgtata cacagttaa caagggaatt cggatactat

1381 gactagagga tagggcatga ctgggatatt ctagacccaa tactactcgc ccggggaaga

1441 cgccataatt agaagttaa gaacaaagco gggcgtgatg gctcacacct ttagtcccag

1501 cactcaggag gcagaggcag gcagatttct gagtctgagg ccagcctgga ctacaagtg

1561 agttccagga cagccagggc tacacagaga aaccctgtct tgaaaacaa aaagaagaa

1621 gaagaagaag gagaagaaga agaagaagaa gaagaagaag aagaagaaga agaagaagaa

1681 gaagaagaag aagaagaaga agaagaagaa gaagaagaag aagaaggggt atggctgagg

1741 ctgagttaat tttttaaat tagtgggtgg tggtttatgc tgataaatac tgtgctctaa

1801 tggtcaaggc aggaggactg ctgtgagtto caggccagt tagattgcag agtgattco

1861 aagttagcct gggctacgga gtaaagtcc tatctcaaaa caacaacaac aacaacaacc

1921 tgttattgtt tttctgacta agcatctata cgtgtagctg gtgctaacct taatttagg

1981 agctcotaa ttcttgggta ttaagaatgc agatacaca cagtgtgcod agctgggtga

2041 attcottct tttgttttc cottatggtg atggggatta aactaaagcc attcactgcg

2101 ctaggcaat gctctgctgg taaactgcag cacagcctac ctgccagatt atttaaagg

2161 tctaattga cacccacaag cagtccttc cacagaaccc ttgactgtta tttcctacct

2221 gtgaagacgt taagaggat ccacggattc agcacagcct cctctcagac tttattctga

2281 agcocagaag gaatcatct gctctcctot cttctcacaa gcatcotttc cactgaaaga

2341 cctggacagg accaggagag acagctgtco acagcagagc attcttataa aaccotgctg

2401 tggatgttgt atgtggtgac acacacacct gtaaattcta gcgcttgaga ggcagaggca

2461 ggcaggtcta tgtgaatttg aggccaacct gtctatacag tgagttccag gccagccaga

2521 gctacaaat gtgtgtgtgt gtgtgtgtgt gtgtgtgtgt gttgtgtatg gggggagggg

2581 cgctgctgtg ggetggcaca aattgtctca gccettgctg atcaagtctg acaactgag

2641 ttggattccc aaaactggga tccagatgta aggagaaaac caactcccca caagttgtc

2701 ttttgatttc cacgttcgtt cattcatgtc ggatcaggaa tgctcattca cacatgaatc

2761 atgcacacat acacagtaat aacttttca ttaaaatt taaagctgc tgagctaatt

2821 tcaagaatt tagtactaa atacatcata gaagtggaga totgtataa ttattaagc

2881 tatatctaca tgattattat aatgtctatg tgtactcagt ctaccaatct ttacatattc

2941 cattttcatc tggcaatagc tgacttcttg gcctgaaaa aatcaatata tatgagaaag

3001 tttgtgttga agtttctaac ccagaagctg agcttogtca aggcacaatt atggaaaat

3061 caaaggoto cgaaggaag atattgggag aagAGTTAGA ACAGCAAGCC TTGGGCAGTC

3121 CCAGAGAGGC CGGCAGAGTC CTGGCAGGGA GGAGAGGGTT AAATCCCTTC CTCTGCAGTA

3181 CAAAAGAAAA GAGTGTGCGG AAAGATTAGG ATTTTTGCTT TTACAATAGG AGCTGCAGGA

3241 GCGTTGGGAA GAAGCTGAAG GGAAAAAAAG GGGGCGTCTC TCCTTTAAAG ACTTGGGAGA

3301 TTGAGAGAGA AAGGGAGTCG GGAAAGAGTC ACACTAGTCA GTCCGGCTCT GGGACGGGAG

3361 AATTCCTCTG CTCCTCAGTG GTTTGCACTG GGGTACCGAT ACCCGTTGGC CTCAGGCTAG

3421 ACAGGGTGAT CGGACCAGGT CACCCCATTA AAACTCAGTG CGCGGTGAGG TGCCCTCCCT

3481 CTCTTACCGC TCACTACTCG GGAATGTCTC GGCGAAAGCA ACGGAGACCC CAACAGTTAA

3541 TCTCGGACTG TGAAGGTCCC AGCGCATCTG AGAACGgtgg gtgctggggg caggaggtag

60

120

180

240

300

360

420

480

540

600

660

720

780

840

900

960

1020

1080

1140

1200

1260

1320

1380

1440

1500

1560

1620

1680

1740

1800

1860

1920

1980

2040

2100

2160

2220

2280

2340

2400

2460

2520

2580

2640

2700

2760

2820

2880

2940

3000

3060

3120

3180

3240

3300

3360

3420

3480

3540

3600 
3601 cggggattcg gggggtgggg gggggggagg tgtaggattc aaagcctgca tggttcaggc 3661 cagggcaatg gagggcacct cggccaagag ccaaacctga gcaggacttg gtcactgggg 3721 atgtgaagga ctctagact gaggatgagg agagggctog tgcaaaggag atacccccoc 3781 ttggctgttg togggattca ttctgtttgt gttttccttg ctttcctcog gatgaatgt 3841 agtttcaaa ctggctctgt ctctctaccc aagagtttc tctccaagtc cttcttgct 3901 cgctggtctt tgtgccgttg ctaagtaacg tcctcagacc tgaagaccgt ctcttangga 3691 tgggattcc ccctcttct tctggagaga gttgggttgc a agagatga attggataa 4021 cgtgaaggtt cccctgaggg gggaagagaa taagtttct cattgttgcg ctgggctgag 4081 agcagaactc ccagaggaag aaagctaatg tcggtcagaa tgcaggctag cttgggggtg 4141 tgctcctcct tatccgaagg gaaactgaaa gacagccctg taaagggact caggtttgtg 4201 ttttaaggga ggcaaagatg gtatttaacg tgcgagttaa cataactgtt catatacgct 4261 atcactgtat aaggatcttg ctatttatt attttttag tttctgggac gatctgctta 4321 tgttgcccag actagctcta tagtcactat acagccetgg ttggcetgga acttttggca 4381 attctcctgt ctcagacatc tgaacaatg tgcaccatca tgctaagttg ctgtattttt 4441 tttttttta atcaacaat ttcctttggg agaagagaac aggctatatg gagctgtagc 4501 caagctggce ttaactggt aatcctccag ccctctacc ttctgtgtgc tgtgattaca 4561 gccatgcact ggcacagcag aatgcaaag tctgtgcagt cttagacaac tccagcaggt 4621 gaaaggccgt gagaggaaga ggaggacatt aggaactgat tgttcaacgc ctccgagata 4681 accgaagacg tggtcagcgg gaaaaaatt atgtatctgg atgcttatat ccctaaggct 4741 ggtgatactc actgtctgag gctgagccag gataggtat ctatgtctag atgagtctga 4801 gactcaagac agtttgggat taagtagtat agctacatgt gtgcctacaa catggaagto 4861 agaaghtca accctggggc cagtcttttg cttagcaaac acatggtatg cctcaaata 4921 tataaataa ggttatgcat aagggttctg aagtcatatt tttaggattg gtttttttt 4981 ggacaaaccc agttccccct ctatgctagc tatacaagct tggtttgct totctgtgcc 5041 tcagtttct catctgttag acagagatgg ataagtacaa tagttacct attaacctgg

5101 gtaagctctt tggggaaatg gccagcataa atggcatttc ttagagacat acttaccata

5161 agtacttagt gagaaggaat attgcagtta tcacatgtga gggcagtgac cactcaggga 5221 cctcagtatg ccttrataag acacgcaggg ctctggggga ctgtatttgt ggcagctaga 5281 actaattatg aactgaact gttccactc tacaaaatg actttcggtc gagtcagtgc 5341 agcatgcaca atgaaacct aacaaacaag ttaagtttgg ggtaggacca tcttcccaag 5401 ceattgettg getgagatce cactgtgec atattagag gttctatggt gatggcatco 5461 ttcccccctg agacacatta agccttctta atgctgctat aggccggatg tttcttcctg 5521 gagctctata ggagatttcc cctagagcct gagagttgcc tctcagtcct gcttccctgc 5581 tggtcaattg tggaactgtg ctgaacgcca cccccaaccc coagaggca tgttctccto 5641 gccttcttcc catctgctca cccattccco acaccgtggc tgagggaaag ttttctgcac 5701 aagtcagagg gtgtccagca gctggattct caagccttt agggtacagt ttcactagga 5760 gggctctgga tacctggaag tgtagtgacg ctgctgtaga tccattccta tagaaaccgg 5820 aaggcttac accctatgaa gcaagaaat ttaggtagat aaacttgca ttggtaggag 5881 aggccaaggg taacataggg atctgcctta agcagaagga a agtgctgac cagctctctg 5941 tccgtggcag tggtcctcag ccttcctaat gctgcaaccc tttaacacag ttcctcatga 6001 tgtggtggcc ccaaccataa catttgtgtt gctactgcat aactttaatt ttgctactgt 6061 tatgaatcat catgtaagta tctgttttct gatggtctta ggcgacccct gtgcaagggt 6121 catttggtct ctaagaggtc ggtccaaaca cacaggttga gaacagttg gtccatggca 6181 tatgcacacg cacataata ctactactco tacaataata ataatcata aacaatctt 6241 ttttttttga gatggggttt ctctgtgtag ttttggctgt cctagaactt gaatctgtaa 6301 actcgcctag ccttgattgt tgttggatt ttttgcttgt ttgtttgttt gcttgttta 6361 agatttgct ctaaggcata agagcacaga ttgctttatc agaggaccca atttagattc 6421 acagtaccaa catggcagct cacacccatc tgtaattcta gtgccagggt acccattgcc 6481 ctcttctggc ttccatgggt accaggtcca aagtggtgt gtatacatag atgcatgcaa 6541 gacactcata gctataaat aaaataal acattttaa gaaatatt atttatttta 6601 totatatgag tacactgtag ctgtctoa acacaccaga goagagtatc agatcocatt 6661 acagaaggtt gtgagccgcc atgtggttgc tgggaattga actcgggacc totggaagag 6721 cagtcagtgc tcttaagcce ctgagccacc tatacagccc aataaataaa tttttttaa 6781 aatctacct taagaactcc taaagttctg ggcatggtgg tactctaatc ccagtgctga 6841 ggagacagag acaggtcgat ctctgtgaga ccaagaccat caagaaaag agaaagacg

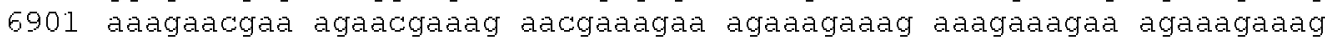
6941 aaaggaagga aggaaggaag gaaggaagga aggaaagaag gaaggaagga acggagggag 7021 ggaagggagg gagggagcag aaagaactcc taagggttt tatatcagaa ctccttggag 7081 attttcttat ctagtctcct ttcatgacct gaatagagge ctgttggttc tetcetgcaa

7141 ttgacatgge tatctaaac tctctcett cttataagca tgtaacatat aattctcat 
7201 tctctcctct tcataggggt gtctctaaa ggattgggct atagtagaaa getaaagaga

7261 ttgcctggca ttcatgggga gccetgcctt atcatttaca cagatccac taatacccat

7321 gccatcatta tgtttctaac cttgccttco accccagagc atggcocaga gttagacagg

7381 aaggattogg gatgtaactc agggaaagag cgtgtgtgag gocettggtt ttatctacac

7441 acaagcaat gattacacta aataagacct gcctgccgtc catccttgc ttatctgtaa

7501 acttagagtg catttctatt gtgccttaa gaaacagccc cgagaaacct attttcccac

7561 tttcttcttg cacagctccc tgatgagaac atcaaacct a acagaatac ttcccacaca

7621 taagtgatga gcaggaaga ggctacttac tcaaaactc gggagaaga agaagagtct

7681 ctcccccaca gagtctagat atcagaatta gagggcataa gggacatcac cggaggaat

7741 gttaactggt acatctgggg aatgatcaga agcccagata tttagtgagg agaaaccagg

7801 acaacagcca cgcagacctg gagggagaga agggagctgg caaacagcaa gaatagcaga

7861 ggcaaggaag gcaaaaata gggcacctta cacatgaaag agagggctca totctcaggo

7921 ttctgaacce acagagact cagttttagg tacetgetgc agtggccgtc agaaagata

7981 tatctctaag tagacagaaa gtaattcagg agtctgtgtt gtgcgtgaag caggatgatc

8041 atgagttcaa ggccagtctg agcaactcta gactgtcaag aaaggatggg agacagggag

8101 agagactgac tgacttagcc ttggctagaa ettgggataa ggaacagaa aacccacctt

8161 ttcttttct ttettect tgttttgtt cgttcgtttg tttgtttgtc cttgagacag

8221 gttttctctg tttgttttgc tatcactctg tagaccaggg tagcetcaag ctcaaagaga

8281 tctgcttgtc tctgcctcct aaatgctggg attaaaggca tgcagcacac tgccettcgc

8341 cottcttgg agtaaatgg gtttcaat taagggagc tgggcagtgg tgcatgctt

8401 taatcccagc acttgggagg cagaggcagg tggatttctg atttcgaggc cagcctggtc

8461 tacagagtga gttccaggac agctagggct acacagagaa accctgtccc agaaaaaaa

8521 aaaaattaaa ctagtctggc gctcaaggat atatgatatg accttttaac cctgaacaaa

8581 ttctttttc ccaagtttc aaggaaggga aacccaccca ccccccactc ctcattttgt

8641 tttgtgttt ggttgtttgg tttgtttgg tgatggcatc actgtagctc agactggetc

8701 tctgtgaatc cctgatcctt ctgcttcagc ctccccagcc ctgggatcag aagcctatgc

8761 caatattcat acccatgtgg atctcaggtg tgggctgcca gaccatagtg ctcaccaggg

8821 acacatgcag tggetgtgct ccgetgttct gttettgcac ttccttcatt ttattccttc

8881 ccactcctcc atcatcagct gccetacal aacttgtttg tttgtttgtt gtttattctg

8941 agacagggte tcactaagta gccetagctg gccttgaact cacaagagat ctgtctgcct

9001 cagtcacctg aatgctgaga ttaaggcat gtgctaccac atctagctgt ettcatttca

9061 ttatttttat tttagcgtct ttattttatt ttatgtgtat gggtgtttta cctgcatata

9121 tgccagtgtt ctacatgtgt gcttggtgct tgtagaggcc agaagagggg gtcagagggg

9181 gtcagatcot gtagaactgg ggttacagtc agttgtgatg tgggtgctgg gaaccaaco

9241 tgggtcotct gcalaacag caatgcatc cattgatcc aaacttgga gocagaggga

9301 ggcagatctc tgagtttgag gccaacctag gtccacagag ccagtttcag gacagccaag

9361 gctactcagt aaccttgtct taaaaaaa aaaaaagg aaagaaaa aaaaaagaa

9421 taagaatag aagataagg catggtggca cacaattaca cagttttaat ctttgcactc

9481 agaagaaaa gataatgga tctctgtgag ttccaggtag cotggtatac agaatgagtt

9541 tcaagccatc cagggctaca gagagaccct gttcragat gaagaaaga aaggaagaga

9601 gacagacaga cagagagaca gagtcagaga ttctcctcaa gttgaaaaga gaaaaaacc

9661 ctttaattga ctatttgtgc tcagtgaagg gtcagatctc taaatacct ttgagcttca

9721 agacagtgct tgcattctac acaatgtot toctcacttg gtatctggta totgagtcat

9781 cttgcetctc atctactgcg tggaacagge catgggtgca tetgcaggtt tcagtatagc

9841 agtttggttt gacaajgac gacgtgtatg agtttagtaa agaagactga gaaagagac

9901 agtggaacag tctctaaaa gtgatcttgg caacatttac aagtctattt ctatttaccg

9961 aggctgcoga tgagcagcga tttaattcag gtagcacttg tgaggaacag gggaaggtt

10021 gaagagcata gtccttgaag ctctattatt ggagtacttg cetcttcttg tgtgctgtgg

10081 gatgggattg tgtgtgtgct ggacacggaa cccaaggcct gtggactgat aatactttgc

10141 cactggacag cagcagcagc agaccatagt ttcaacacgt cattgatatc tgtaatatat

10201 atcagggtot tactctatgt agctcagaa ttaatagtg gcacagccag acactggagt

10261 gacaggcact catgcccact ctgtgtgtgt gtgtgtgtgt gtgtgtgtgt gtgtgtgtgt

10321 gtgtgtgtat acatgcatgg ttcacttagg attaactca gagcctcaat ttgtattagg

10381 taagtgctct tccactgaaa ggtccttcc agccttcagc agtacaatgg aataagtgag

10441 gagcttcata aaacactaat gcttaggctg gagagatggc tcagcggtta agagcactga

10501 ctgctcttco agaggtcotg agttcaatc ccagcaacca catggtgget cacaaccatc

10561 tgtaatggga tcctgccett agggcctttg aatgtattt agccttgaga tgggttttt

10621 tgtttgtttg gtttggggtg tgtgtgtgtg tgtgtgtgtg tgtgtgtgtg tgtgttttgt

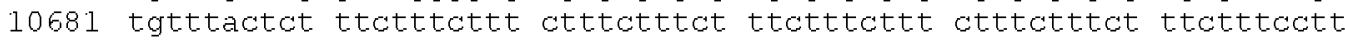

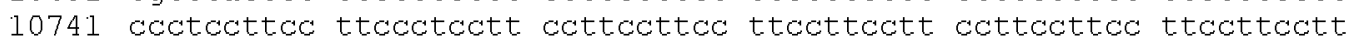

7260

7320

7380

7440

7500

7560

7620

7680

7740

7800

7860

7920

7980

8040

8100

8160

8220

8280

8340

8400

8460

8520

8580

8640

8700

8760

8820

8880

8940

9000

9060

9120

9180

9240

9300

9360

9420

9480

9540

9600

9660

9720

9780

9840

9900

9960

10020

10080

10140

10200

10260

10320

10380

10440

10500

10560

10620

10680

10740

10800 
10801 cctccetcce tccetccetc ccttccttct tctgtttgtg attgaactca gggactcctt 10861 ttgagttata gtcccagccc aagacatcag aatgtcctaa aagctctaa ggcagtccta 10921 atgacagta aggctgagag ccactgttta gatacaccac totgctgcoc aggccotatg 10981 tggtttgac tgtgttcttc ctaaccattc tctcccaagc ctgaagcagc ttatcggggt 11041 accaggttt ttgcttatt ctcagatagt gtcttatata gttcaggcta gccactaact 11101 tatgttgaag tcataagga tacccttgac cttctgattc agctgcctcc gactccaaag 11161 tgctggggtt aaggtgtgtg tgcctggtt atgttgggga ttgaaccca ggggtttgtg 11221 cttgtgccag actetctgcc tactgaacta gacccctagc ttctggatac caggcctaga

11281 agagaagcta cttggcttt tttgtttgtt tatttatt tatttatt tatttttca

11341 gctcttcgta aatttgaaca accatgtgca ggtccacatc catcacagac cccctttctg

11401 ctacctaggt gtcacctgct tagcatgtcc ctgtgttcta tgactttagc cctgtctgca

11461 cgagaatcte gotctcttt tcaggatogg cactgagtga aaggggtgc caaggagtgg

11521 gtggttccte ttacagtgge tgetgataca tcaccttca coagggacta aacttacct

11581 aaagggtgta gatcaatga cacatcagaa agcacatttc attacaaagc aagaaagggg

11641 acactgtttc ccaggagaag aagaaagaa aaggatttct tttcttgtcc aaggacttga

11701 cagaacagca actggatatc aatgttogg tgctaatta cgactgctog gtagaagto

11761 tccatctgat tccctctctc tgacttgagg gcagggagga gccacacagg ctccttctc

11821 cagctttagg atacgcatgg gaaactggac aggagccaga gtggtgactg ctgctccatt

11881 gaattactct gtggacttga aaaggtcgct taacctctgt gagcttcagt ttccttatct

11941 gtaacactaa agcttagctg tgtotcaaac aactgaaac cotgaactco atctcogtt

12001 gcaggggtca ggtottaga aaacagagtt agctcatcca tttcagtgct ctgattcatg

12061 aggcttataa ggctaaatct tttcttgtct ttttttttt tttaagatt attttatgta

12121 aatgagtgct ctatctatat atacaactgc atgccagaag agggcatcag atcccaggga

12181 tagatggttg tgtgccccca tgtggttgct gggaattga ctcaggacct ctggatgctc

12241 ttaaccactg agccatctt cagccctggg attattccaa ggtt aaaac ataagatggg

12301 tattattatt aattatttga ccagagtggt ctcaaactca gagagtcatt cacttgcctc

12361 tgcttgtatt gctgggatta aagacatgcg ccacaactgc ccggctattt tcagttata

12421 aatacagtag ctgtttactc ttttttttt tttttttt tttttttta agacagggt

12481 ctcactatat aacccaagat ggtctggagc tctctatgta gaccaggetg gettgaact

12541 aattgcetce tgagtgctgg ggtcaaaggt atgtgccacc actctcaagt atgtactgaa

12601 atttgatta gattggggca catactccc ttcctaaggc tettracet agacataggo

12661 cagtgatacc actcagaat taacaaggtt ggggagctga aggacgaggc tggcgctcag

12721 gaggagagct cttgctctag catttgtggg atcctaggtt caatccccac aatgttggga

12781 tgcagtggac atggtgatc aggtttataa taatctgagt coatgggtag taggagcagg

12841 aagaggctag ccagtctgtg ctatgtagta agtttgaggc cagcctggtc tacagagtga

12901 gttccaggac agccaggggc tacacagaga aaccctgtct cgaagaaaa aaaaaaaga

12961 caaccaacaa gcaaaagat attattttag ttgtatgtgt attttaggtt ctcttattaa

13021 aatataat tectaatcc ataatatta aggatcttca aattaaaa agttcctaat

13081 ttatattcto tttggaggg gaaaagtco cacatatgtt aatactttgc ttcaagcatt

13141 ccctagtctg ggcatacagc tcggtggtgg gtcacttggt acaagttcc attgcoagca

13201 ccacaaaac aaacggtttg caatttgtct gctttcaaaa tattttttct gatagtgtat

13261 gtaaatatt gtctcttat aaaaggggg atggggcatt ttccgtgcaa ctggctccag

13321 cttatcagce aggcaaaac agaagtggga agactgtgat tgtagaatt gaggaagget

13381 gtgagettac cactagactc aggtacaarg accatgtttc aaatcaaac agaacogagg

13441 aagccatagt tggagcceta gcatttggga agctgaggca ggaaggttgc tgattcaaag

13501 tcaacttggg ttacaccgaa catttcaaa agaaaagaa aagaaaaga caaaagaaa

13561 aagaaggaa caatatgagt ttatttattg ctaccacca a acacaatc cargactga

13621 gatcacttt ttttccatg taaaatacg ggatttgggg ctggtgagat ggctcagtgg

13681 gtaagaatac ctgactgctc ttccaaaggt ccagtgttca agtcccagca accacatggt

13741 ggctcacaac catccgtaac aagatctgac gccctcttct ggtgtgtctg aagacagcta

13801 cagtgtact acatataata aataatct acaaaaca aaacaaaa acgggattt

13861 gccgggcagt ggtggcgcac gcctttagtt ccagcaattg ggaggcagag gcagacggat

13921 ttctgagttc gaggtcagcc tggtctacaa agtgagttcc aggacagcca gggccataca

13981 gagaaacct gtcttgaaga aaaaataa taaacaaagg atttaggaa gtaggggacc

14041 ctttaaatct cagttcaagg aagaaaaga atgcagaata cotggtctgc ggtacttact

14101 ccctctgaat aaaggcagg gcccgatgga ggtgagcagg tgtcagtct gtttaggaat

14161 tgaatccgc ttggggcccg ttaggagctt tggatcctga gctgcagaca gtgaaagccc

14221 attccgcatc ttccccattg tttcagaagg agctcccctc cccccagggt tggagctggg

14281 tggacctcct taggccttg taagctaata tcttatttaa ttgtccacat tagggacggg

14341 gtgggttgga aagagggtac cgaaccggaa agaagggett ttttaaagt aggaactctg

10860

10920

10980

11040

11100

11160

11220

11280

11340

11400

11460

11520

11580

11640

11700

11760

11820

11880

11940

12000

12060

12120

12180

12240

12300

12360

12420

12480

12540

12600

12660

12720

12780

12840

12900

12960

13020

13080

13140

13200

13260

13320

13380

13440

13500

13560

13620

13680

13740

13800

13860

13920

13980

14040

14100

14160

14220

14280

14340

14400 
14401 catttggtat atggccggtg gcctgtggac tagcttgtgt tgaactctgg gggaagggct 14461 tggtgttcct caagaagggg ccctcaatg actcccttgg gaattctatc ttgcaatcca 14521 cccccctcce caarctctt ttgtgaaarg agatgagggt aagatgggag taggggtgaa 14581 gacaaaact gagatcattc tgcggtgtgc gagctggtaa ggggtgggtg tttgaggctg 14641 ctcctccat tettgtcctc cgacctctga ggcgagctga gcaccetttg gaatccacgt 14701 tttccgagct cagcagatcc tttatccaa gaaaattac tgaagcctat cgcctaatc 14761 tattgagcgg gcatgttc ccactgtggg cttgaggctg acccagtgga agcagctagg 14821 ataagacat ctggggtggg gagctggcag aggatagggc acagtgggco cotaaggtgo 14881 ctcactgaca cCTGACCCAG AGCCGGAGTA AAGCTTCCTA GACTTGCCCC CTCCCCGCTC 14941 CCCCCTCCCC CCCTCCCCCC CGCACTCTCC GCTCTCGCCT CCTCCAGCTT TCGTCTCCCT 15001 CCCTGGAGCT TCTCCCCACA AACTCTCCTC CCCCATCTCC CCACTACCAG CTTTCGCCGC 15061 TCCAGCTCCT CCCCTCCTCC GCGCCTTCTC GCTTCCCTCC CCCCTCCGCC GCTGCTCCCT

15121 GCCCCCGCCA CCGCCGTTCT CCTCCGCAGT CTGGGTCGCT GGGTGCAAAG ACTGCCGCAG

15181 CGCCGGCGGC CTCCCCAGAC CGGATACCCA TTGTGTCTTA ACCCATCCCG CCTTCCAATT

15241 CCCACGGCCA TGGCGCAGGA AACCGGGAGC AGCTCTCGAC TCGGGGGACC CTGCGGGGAG

15301 CCTGCGGAGC GCGGAGgtgc ggtagggcca ggcttgggca gagatggggg cctagggaac 15361 actcgtgtgt aaggactta agtgggcgga taaatgtgt gattctgcac ataggcccca 15421 ggtctcgcat ccattctcac ccttcctggg ccagaggagg gggaggggta acggaggagg 15481 ctgggagagt gcgcgcecta tcccccaacc cccgttttgc tggctgtcca ggaaccacga

15541 gagtoggato tggtctgaga gotagcttoc tgcagggtct gactgtaagc ttaaattcog

15601 accotaacog gaggttoctg ggcogccogt tottagago ctocgttato caacactgtg

15661 gcattaccca cactttetc cttgtcttct ccccagGTGA TGCTAGCGAG GAACACCACC

15721 CCCAAGTCTG TGCCAAATGC TGCGCACAAT TCTCTGACCC GACCGAATTC CTCGCTCACC

15781 AGAACTCATG TTGCACTGAC CCACCGGTAA TGGTGATAAT TGGAGGCCAG GAGAATCCCA

15841 GCAACTCTTC AGCCTCCTCT GCGCCCCGAC CAGAGGGCCA CAGTAGGTCC CAGGTCATGG

15901 ATACAGAGCA CAGCAATCCC CCAGATTCTG GGTCCTCTGG GCCCCCGGAT CCCACTTGGG

15961 GGCCAGAGCG GAGGGGAGAG GAATCTTCTG GGCAATTCCT GGTCGCTGCC ACAGGTACAG

16021 CGGCTGGGGG AGGTGGGGGC CTTATCTTGG CCAGTCCCAA GCTGGGAGCA ACCCCATTAC

16081 CTCCAGAATC CACTCCTGCA CCCCCTCCTC CCCCACCTCC CCCTCCCCCT CCAGGTGTAG

16141 GCAGTGGCCA CTTGAACATT CCTCTGATCT TGGAAGAGTT GCGGGTGCTG CAGCAGCGCC

16201 AGATTCACCA GATGCAGATG ACTGAACAAA TCTGCCGCCA GGTGCTGCTA CTTGGCTCCT

16261 TGGGGCAGAC CGTGGGTGCC CCTGCCAGTC CCTCAAAGCT ACCTGGGACA GGGGCTGCCT

16321 CTTCCACCAA GCCCCTACTG CCTCTCTTCA GTCCCATCAA GCCAGCGCAA ACTGGCAAGA

16381 CACTGGCATC TTCCTCTTCG TCATCCTCCT CCTCTGGAGC TGAACCGCCT AAGCAGGCTT

16441 TCTTCCACCT TTACCATCCA CTGGGATCAC AGCATCCCTT CTCTGTAGGA GGGGTTGGGC

16501 GGAGCCACAA ACCCACCCCT GCCCCTTCCC CTGCGCTGCC AGGCAGTACG GATCAGCTGA

16561 TTGCTTCACC TCATCTGGCA TTCCCAGGCA CCACTGGACT CCTGGCAGCT CAGTGTCTTG

16621 GGGCAGCAAG GGGCCTTGAG GCTGCTGCCT CCCCAGGGCT CCTGAAGCCA AAGAACGGAA

16681 GTGGTGAACT GGGCTATGGG GAAGTGATCA GTTCCTTGGA GAAACCCGGT GGAAGGCACA

16741 AATGCCGCTT TTGTGCAAAA GTATTCGGCA GTGACAGCGC CCTGCAGATC CACCTTCGTT

16801 CCCACACTGG TGAGAGGCCC TATAAGTGCA ACGTCTGTGG TAACCGTTTC ACAACTCGGG

16861 GCAACCTCAA AGTACATTTT CACCGGCATC GTGAGAAGTA CCCACATGTG CAAATGAATC

16921 CACATCCAGT ACCTGAGCAC CTAGACTACG TCATCACCAG CAGTGGGCTG CCTTACGGAA

16981 TGTCTGTGCC ACCAGAGAAA GCAGAAGAGG AGGCAGGCAC ACCAGGCGGA GGTGTTGAAC

17041 GCAAACCCCT AGTGGCCTCC ACCACAGCAC TCAGTGCCAC AGAGAGCCTG ACACTGCTCT

17101 CCACTGGCAC AAGCACAGCA GTGGCTCCTG GGCTCCCTAC TTTCAACAAG TTTGTGCTCA

17161 TGAAGGCAGT GGAACCCAAG AGTAAAGCGG ATGAGAACAC GCCCCCAGGG AGTGAGGGCT

17221 CCGCCATCGC TGGAGTAGCA GACAGTGGCT CAGCAACCCG AATGCAGCTA AGTAAGCTGG

17281 TGACGTCACT ACCGAGTTGG GCACTGCTTA CTAATCACTT GAAGTCAACT GGAAGTTTCC

17341 CCTTCCCTTA TGTGCTAGAA CCCTTGGGGG CTTCGCCTTC TGAGACCTCA AAGCTGCAGC

17401 AGCTAGTAGA AAAGATTGAC CGCCAAGGAG CTGTGGCGGT GGCATCTACT GCCTCGGGAG

17461 CTCCCACCAC TTCTGCCCCT GCACCTTCCT CCTCCGCTTC TGGACCTAAC CAGTGTGTGA

17521 TCTGTCTTCG GGTCCTGAGC TGCCCTCGGG CTCTACGCCT GCATTATGGC CAACATGGAG

17581 GTGAGCGGCC CTTCAAGTGT AAAGTGTGTG GCCGAGCTTT CTCCACAAGG GGCAATTTGC

17641 GCGCACATTT CGTGGGTCAC AAGACCAGTC CAGCTGCCCG GGCTCAGAAC TCCTGCCCCA

17701 TTTGTCAGAA GAAGTTCACT AATGCTGTCA CTCTGCAGCA ACATGTTCGG ATGCACCTGG

17761 GGGGCCAGAT CCCCAATGGG GGTTCCGCAC TTTCTGAAGG TGGGGGAGCT GCCCAGGAAA

17821 ACAGCTCTGA GCAGTCTACA GCCTCTGGAC CAGGGAGTTT CCCCCAGCCG CAGTCCCAGC

17881 AGCCATCTCC AGAAGAGGAG ATGTCTGAGG AAGAGGAAGA GGATGAGGAA GAGGAGGAAG

17941 ACGTGACAGA TGAAGATTCC CTAGCAGGAA GAGGCTCTGA GAGTGGGGGA GAGAAGGCCA

14460 14520

14580

14640

14700

14760

14820

14880

14940

15000

15060

15120

15180

15240

15300

15360

15420

15480

15540

15600

15660

15720

15780

15840

15900

15960

16020

16080

16140

16200

16260

16320

16380

16440

16500

16560

16620

16680

16740

16800

16860

16920

16980

17040

17100

17160

17220

17280

17340

17400

17460

17520

17580

17640

17700

17760

17820

17880

17940

18000 
18001 TATCAGTACG AGGTGACTCA GAAGAGGTAT CTGGGGCAGA GGAAGAAGTG GCAACATCAG 18060

18061 TAGCAGCACC CACCACTGTG AAGGAGATGG ACAGTAATGA GAAAGCCCCT CAACACACTC 18120

18121 TGCCGCCACC TCCGCCACCA CCCGACAACC TGGATCATCC CCAACCCATG GAGCAGGGAA 18180

18181 CCAGTGATGT TTCCGGAGCC ATGGAGGAAG AAGCCAAACT GGAGGGAATC TCAAGCCCGA 18240

18241 TGGCAGCCCT CACCCAAGAA GGGGAGGGCA CCAGCACCCC TTTGGTGGAA GAGCTGAACT 18300

18301 TACCGGAAGC CATGAAGAAG GATCCAGGAG AGAGCAGCGG CAGGAAGGCC TGTGAAGTAT 18360

18361 GTGGCCAGAG CTTTCCTACC CAGACAGCTC TGGAGGAGCA TCAGAAGACC CATCCCAAGG 18420

18421 ATGGGCCACT CTTCACTTGT GTCTTCTGCA GGCAGGGCTT CCTTGACCGT GCTACCCTCA 18440

18441 AGAAGCACAT GCTGTTGGCT CACCACCAGG TACCGCCCTT TGCACCCCAT GGCCCTCAGA 18500

18501 ATATTGCTAC TCTTTCCTTG GTCCCTGGCT GTTCCTCCTC CATCCCTTCT CCAGGGCTCT 18560

18561 CCCCATTCCC TCGAAAAGAT GACCCCACCA TGCCATGAGC CTGCTTTCTG TACCTGGTCC 18620

18621 TCTATGACCC AGAGAGCAGA AACCTGAGAG CTTCATAGAG GAACCTCCAA GATTTACTCA 18680

18681 CCCTCCTCTT GTCCTTTCTC AAGTCCTGAC ATGATGTTTC TAGTGGCTTC TTCTCTAGTC 18740

18741 CCTGAGCTTG ACAATTGCCT TTGAAAGAGA ATGTCCCCTT AAGAAATTTT TATCACCTTT 18800

18801 TTGTTCTGTG TAACTAAGGG AAACAAATTC CCTATAGCTT TTACATTCTC AAGGGGGAGC 18860

18861 TCTCTCTTCT TCTCCCTTTC CCTTTGGCAG GTATACTAGA ACCCCCATCC TTGGAGTGGC 18920

18921 AGCCTTGGTC CAAGGGGCTG GCAACTGTAC CATGGAAGGC CCAGCGTTAC TCCTTGGTGA 18980

18981 TCTTGACCAC CCTGCAAGAC TTTCTAGGGC CGGGACCTTC TTGAGAAGCT TGTAAGGGGT 19040

19041 GGTAGGTTTC TTTCTGCAAC CACTACCCAG TTTTCCACTG AGCCCTGGAG TTCTGGACCT 19100

19101 ACCTGCATTG CCACTCGGGC CCTAGTACCA TCATTGCTGT GAAAGCCCAG GAACTGTGTT 19160

19161 TCACAAGGTG ACTCCAGTGA CATGATCCAG AGAGGCAAAG AACATAGCCT CCGGAAGTTG 19220

19221 AGGCTGTGCC CAACAAGCAC ACCGGAAGAA AGAAGAAACT ATAACTTCTT TCTCCTTCCC 19280

19281 CCCTGCTCCA GAGAGTGCTG GCAATAAAGA TATTCTAGCA ATTGGTGACT CACCCTAGAA 19340

19341 GGTAGGGACA AGTGAAGGAC TGGGATCCTT TTTGCAGTAT GTTCCTTGAC TCGCCACATT 19400

19401 GAGGCAAAGA TAGTGGCTGG TCAAGATGCC AGGACTACTC CAGCTTCCCA TCATGTCCTC 19460

19461 TCAACCAACA AGCAGGTTTC CTACCAAGAG GTCTCTCGTG TGATAGTTTA GGGAGTATGA 19520

19521 AGTTTCTAAC TCTAAAGAAT CCTGTTGGTG AGGATGATTA TTTAAGCAAT GATGGGGAGT 19580

19581 TGAGGGTTGT TGCTAAAACA GGCATTGCTG GGAATCTATT TGATGAAGAA CAGGACTTGA 19640

19641 TGTAAGGGGA CTCGATGTTC AGCTCTTGTG AGTATGAACG TTTTCTTTGA GCTAATGGTG 19700

19701 ATGTGGTATG CAGAGGTACC AGGGGCCATG GGGGTGTGTG TGCTTCCTGT CACTAGAATG 19760

19761 TTTTTAGTTT TAGATGACTC CCTATTTTAT TCCCTCACCC CTTGTATTTC CCTTGCTGTC 19820

19821 TTCTCAAAAC CCCTTTCCTC CCCCAGTTTT GCCTGACCAT GGGCCAGAGC TTATGTCTTA 19880

19881 TTTTTTTTCT AGAAGTTGAG AGACAGAGCT TCAAGTGGTT TCCCCCCGTC TCTGTCTTGT 19940

19941 AGTGAGATGT AGTATTTACT CTTAACATAG GATCCTGTGG AACAGGTGTT CTGAGAAGAC 20000

20001 TGAATTTTGC TGTTAGCTGT TGTCAATGAT GATTCTCTAA AGTAGTGGGC TCCAGAGCTC 20060

20061 CCTAACACAG TGAAATGTGT AAGAGCCGAG AGGGGAGATA CTAGAATTTT TTCCTTCATC 20120

20121 ATTAAAGGTG TTTTGGCCAA GTTTTTTTTG TGTGTTTCTC CTTATTTTAT GACTAAATAG 20180

20181 CCAGATGGGG TGTGATGTTG GCATTCCCGA ATTCAGAGAT TCTCTTCCCA CCCTTTTCTC 20240

20241 CTGCCAAAGC TGAACATATG GTGTAAAAAT ACTTAACTTC CTCAGTCAGC CTCATTCCCA 20300

20301 AACAACCTCC AATGGATGTC ATTTCACTGG GG 20332

Abbildung A.2: Genomische Nukleotidsequenz des Sall2-Gens. Dargestellt ist der kodierende Bereich des Sall2-Gens und die in der vorliegenden Arbeit gewonnenen Sequenzdaten aus Intron 1. Der Beginn der 5'-UTR und das Ende der 3-UTR sind nicht enthalten. Die DNA-Sequenz des kodierenden Stranges der cDNA ist in Großbuchstaben angeführt, die intronische Sequenz in Kleinbuchstaben. Die beiden alternativen Translationsstartpunkte, das Stoppkodon sowie die Exon/Intron-Übergänge sind durch Fettdruck hervorgehoben. Die Nummerierungen für die Nukleotidsequenz ist auf beiden Seiten angegeben. 


\section{Publikationen}

Buck A., Archangelo L., Dixkens C. und Kohlhase J. (2000). Molecular cloning, chromosomal localization, and expression of the murine SALL1 ortholog Sall1, Cytogenet Cell Genet 89: 150-153.

Buck A., Kispert A. und Kohlhase J. (2001). Embryonic expression of the murine homologue of SALL1, the gene mutated in Townes-Brocks syndrome, Mech Dev 104: 143-146. 


\section{Danksagung}

Herrn Professor Dr. W. Engel danke ich für die Bereitschaft, diese Arbeit zu betreuen. Seine stetige Diskussionsbereitschaft und die zügigen Korrekturen haben wesentlich zu ihrem Gelingen beigetragen.

Bei Frau Professor Dr. S. Hoyer-Fender bedanke ich mich für die Übernahme des Korreferats.

Mein Dank gilt auch Dr. Jürgen Kohlhase für die Überlassung des Themas, die Möglichkeit, weitgehend unabhängig zu arbeiten und die Unterstützung besonders in der Endphase der Arbeit. Des Weiteren möchte ich mich für die großzügige finanzielle Unterstützung beim Besuch von Tagungen bedanken.

Prof. Dr. Andreas Kispert danke ich für die Möglichkeit, in seinem Labor die Technik der in situ-Hybridisierung erlernen zu können, sowie für die Unterstützung beim Publizieren, Dr. Walter Schulz-Schaeffer für die histologischen Untersuchungen und Dr. Christa Dixkens für die Anleitung bei der FISH-Hybridisierung. Dank auch an Sonja Bingemann und Manuela Liebers für die gewissenhafte Assistenz und Einsatzbereitschaft bei der Durchführung der Arbeit, sowie an René Heise und Karl Rücker für die zuverlässige Sequenzierarbeit.

Einen herzlichen Dank an Dr. Peter Burfeind, der stets mit Rat und Tat beiseite stand und dessen Korrekturen sehr hilfreich waren, sowie an meinen Bruder Thomas, der mich mit der Einführung in die ${ }^{4} \mathrm{~T} E \mathrm{E}$-Welt vor einer Menge ComputerTerror bewahrte und immer Zeit hatte, wenn's mal wieder brannte.

Ich danke allen Kolleginnen und Kollegen in der Abteilung für ihre Unterstützung und das gute Arbeitsklima. Besonders hervorgehoben sei hier die 105er-PartyCrew Goran, Leticia, Meike und Saskia, die von Laborkollegen zu Freunden wurden.

Vielen Dank meinen (weit mehr als) Mitbewohnerinnen Susanne und Sandra, den Grellis und allen Freundinnen und Freunden für Anlehnung, Aufmunterung, Abwechslung und vieles mehr.

Mein ganz besonderer Dank gilt meinen Eltern, die durch ihre uneingeschränkte Unterstützung und ihr unerschütterliches Vertrauen den Grundstein für diese Arbeit legten. 


\section{Lebenslauf}

\section{Persönliche Daten}

Name:

Anja Buck

Geburtsdatum:

02. 03.1972

Geburtsort:

Kiel

Staatsangehörigkeit:

deutsch

Familienstand:

ledig

\section{Schulausbildung}

1978-1979

Grundschule: „Fröbelschule“ in Kiel

1979-1982

Grundschule: „Theodor Möller Schule“ in Kiel

1982-1992

Gymnasium: „Gymnasium im Schulzentrum Elmschenhagen" in Kiel

Mai 1992

Abitur

\section{Studium}

Oktober 1992

Aufnahme des Studiums der Biologie an der Christian-Albrecht-Universität zu Kiel

November 1994

Diplomvorprüfung in den Fächern Botanik,

September 1995 Zoologie, Chemie und Mathematik Aufnahme des Studiums der Biologie an der Georg-August-Universität zu Göttingen

Februar 1997 Diplomhauptprüfung in den Fächern Organische Chemie, Biochemie und Botanik

Februar 1997-Juni 1998 Experimentelle Arbeiten zur Diplomarbeit am Albrecht-von-Haller-Institut für Pflanzenwissenschaften der Georg-August-Universität Göttingen unter der Leitung von Herrn Prof. Dr.

R. Tischner über das Thema „Veränderungen im Phosphorylierungsgrad der Nitratreduktase in Wurzeln von Gerstenkeimlingen (Hordeum vulgare L.)"

Juni 1998 Abschluss des Studiums der Biologie mit dem Diplom ab Juli 1998 Beginn der experimentellen Arbeit zur vorliegenden Dissertation 